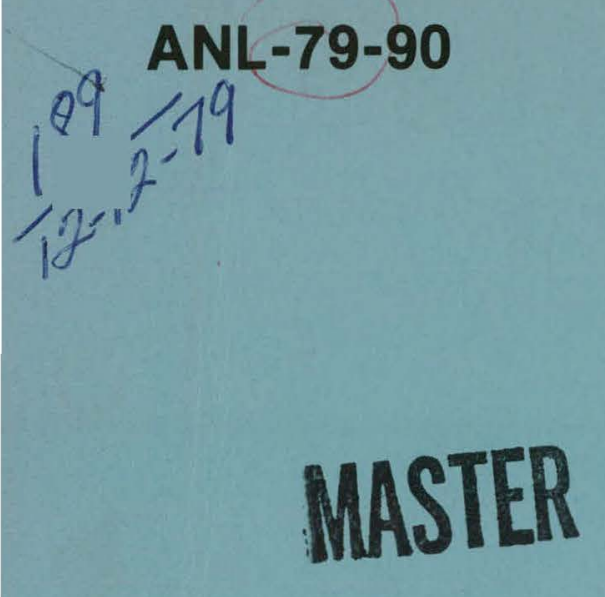

4h. $401 \mathrm{~V}$

ANL-79-90

\title{
DIVISION OF BIOLOGICAL AND MEDICAL RESEARCH
}

\section{Annual Report}

1978

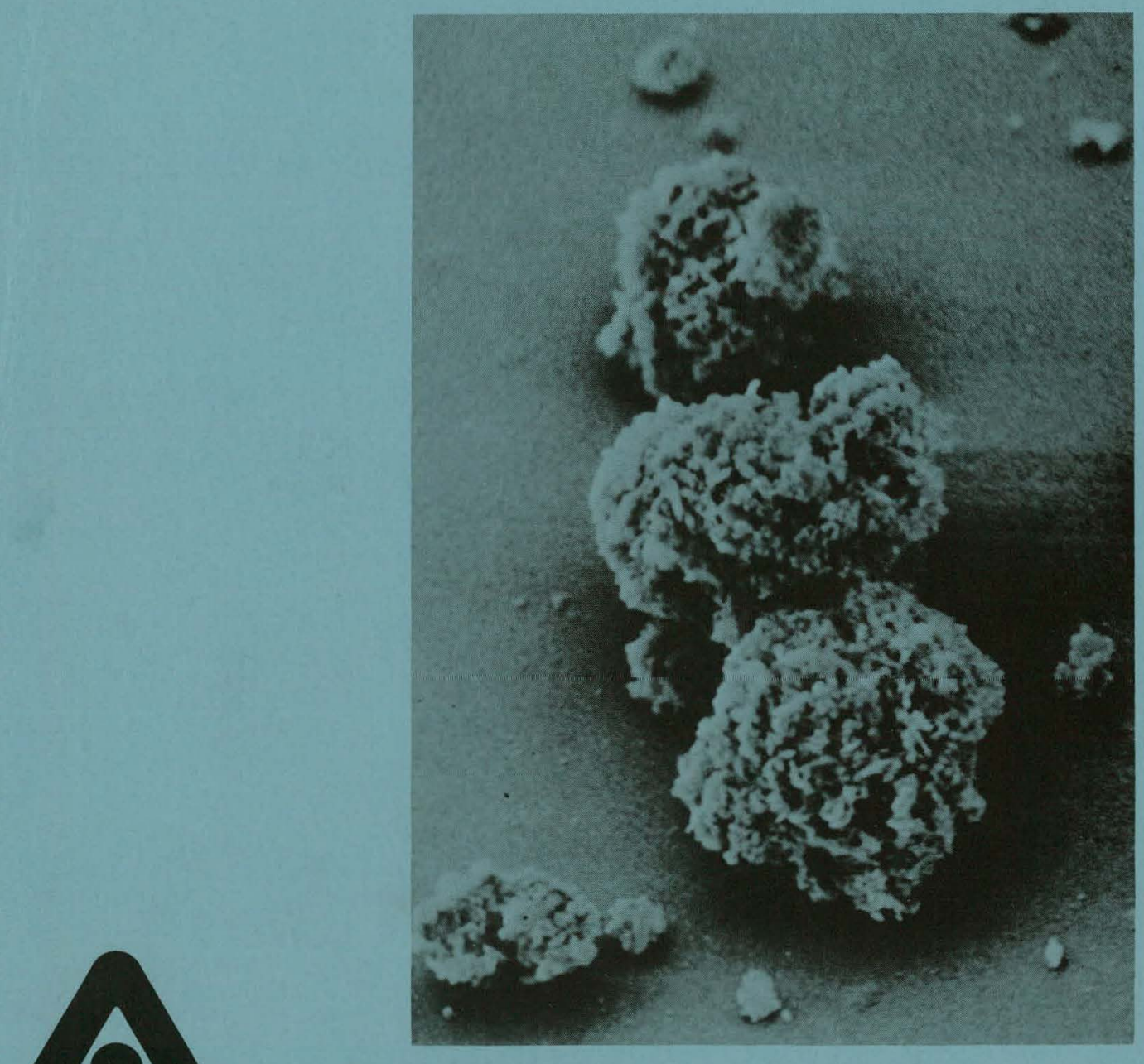

ARGONNE NATIONAL LABORATORY, ARGONNE, ILLINOIS

Prepared for the U. S. DEPARTMENT OF ENERGY under Contract W-31-109-Eng-38 


\section{DISCLAIMER}

This report was prepared as an account of work sponsored by an agency of the United States Government. Neither the United States Government nor any agency Thereof, nor any of their employees, makes any warranty, express or implied, or assumes any legal liability or responsibility for the accuracy, completeness, or usefulness of any information, apparatus, product, or process disclosed, or represents that its use would not infringe privately owned rights. Reference herein to any specific commercial product, process, or service by trade name, trademark, manufacturer, or otherwise does not necessarily constitute or imply its endorsement, recommendation, or favoring by the United States Government or any agency thereof. The views and opinions of authors expressed herein do not necessarily state or reflect those of the United States Government or any agency thereof. 


\section{DISCLAIMER}

Portions of this document may be illegible in electronic image products. Images are produced from the best available original document. 
The facilities of Argonne National Laboratory are owned by the United States Government. Under the terms of a contract (W-31-109-Eng-38) among the U.S. Department of Energy, Argonne Universities Association and The University of Chicago, the University employs the staff and operates the Laboratory in accordance with policies and programs formulated, approved and reviewed by the Association.

\section{MEMBERS OF ARGONNE UNIVERSITIES ASSOCIATION}

The University of Arizona

Carnegie-Mellon University

Case Western Reserve University

The University of Chicago

University of Cincinnati

Illinois Institute of Technology

University of Illinois

Indiana University

The University of lowa

Iowa State University
The University of Kansas

Kansas State University

Loyola University of Chicago

Marquette University

The University of Michigan

Michigan State University

University of Minnesota

University of Missouri

Northwestern University

University of Notre Dame
The Ohio State University

Ohio University

The Pennsylvania State University

Purdue University

Saint Louis University

Southern Illinois University

The University of Texas at Austin

Washington University

Wayne State University

The University of Wisconsin-Madison

This report was prepared as an account of work sponsored by an agency of the United States Government. Neither the United States nor any agency thereof, nor any of their employees, makes any warranty, expressed or implied, or assumes any legal liability or responsibility for any third party's use or the results of such use of any information, apparatus, product or process disclosed in this report, or represents that its use by such third party would not infringe privately owned rights. Mention of commercial products, their manufacturers, or their suppliers in this publication does not imply or connote approval or disapproval of the product by Argonne National Laboratory or the United States Government.

Printed in the United States of America

Available from

National Technical Information Service

U. S. Department of Commerce

5285 Port Royal Road

Springfield, VA 22161

NTIS price codes

Printed copy: A11

Microfiche copy: A01 
Distribution Category:

Biology and Medicine

(UC-48)

ANL-79-90

ARGONNE NATIONAL LABORATORY

9700 South Cass Avenue

Argonne, Illinois 60439

DIVISION OF BIOLOGICAL

AND MEDICAL RESEARCH

ANNUAL REPORT

1978

Douglas Grahn, Director

Steven S. Danyluk, Associate Director

John F. Thomson, Associate Director

Marcia W. Rosentha1, F.ditor

This book was prepared as an account of work sponsored by an agency of the United States Government. Neither the United States Government nor any agency thereof, nor any of their employees, makes any warranty, express or implied, or assumes any legal liablity or responsibility for the accuracy, completeness, or usefulness of any information, apparatus, product, or process disclosed, or represents that its use would not infringe privately owned rights. Reterence herein to any specific commercial product, process, or service by trade name, trademank, manufocturer, or otherwise, does States Government or any agen thereot. The vieus and opinions of anthers expresed herein do not

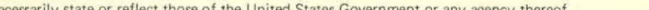

Preceding Report

ANL-78-90 


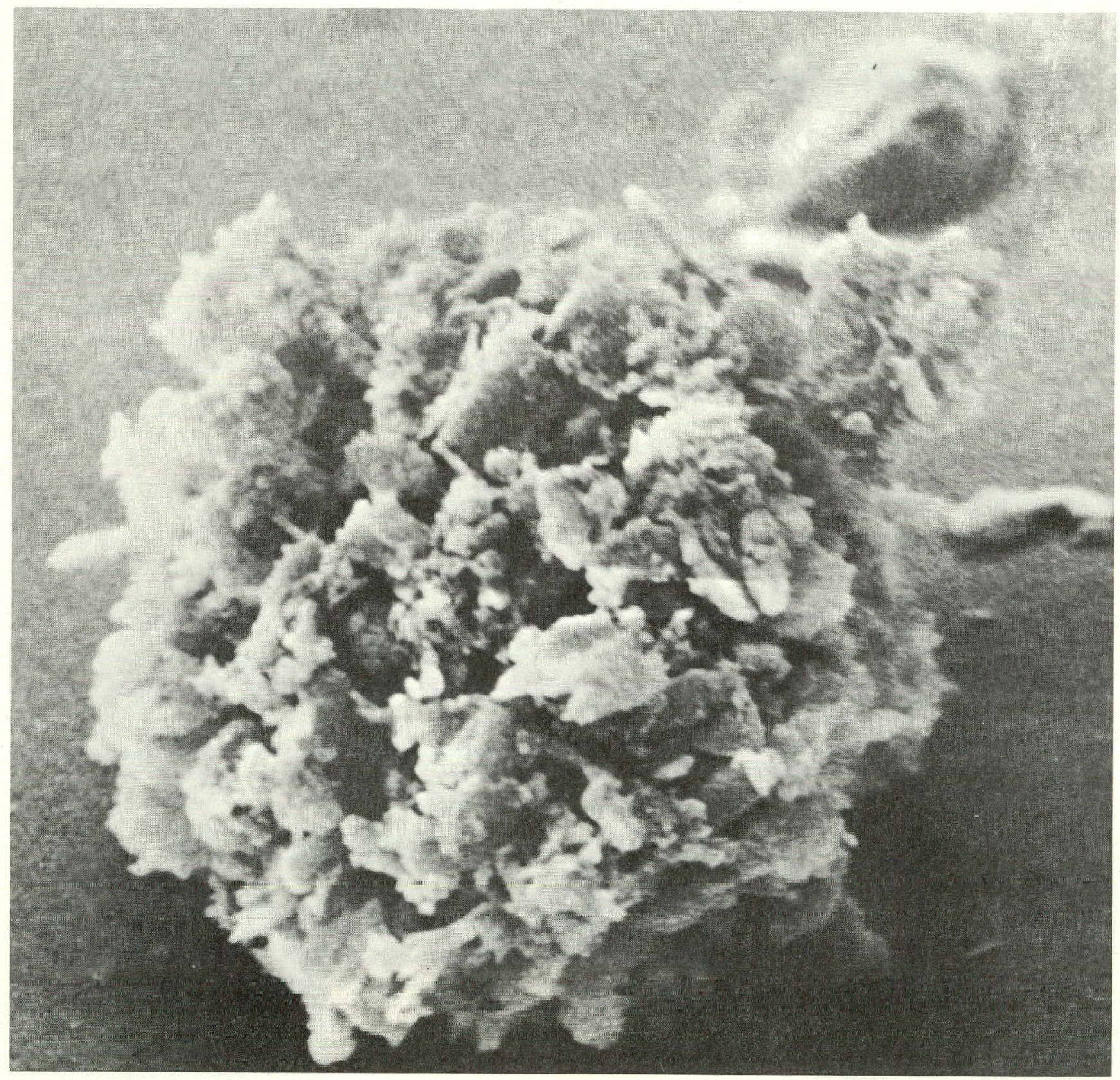

COVER

FLY ASH PARTICLES FROM FLUIDIZED BED COMBUSTION OF COAL, REAEROSOLIZED FOR CONTROLLED EXPOSURES TO EXPERIMENTAL ANIMALS (SEE PAGE 41). THE REPRESENTATIVE PARTICLE ABOVE HAS A DIAMETER OF $13.5 \mu \mathrm{m}$. SCANNING ELECTRON MICROGRAPHS TAKEN BY F. R. KIRCHNER. 
ABSTRACT

The research during 1978 in the Division of Biological and Medical Research, Argonne National Laboratory, is summarized. Studies related to nuclear energy Include responses of beagles to continuous low-1eve 160 Co gamma radiation, and development of leukemic indicators; comparison of lifetime effects in mice of low-level neutron and ${ }^{60}$ Co gamma radiation; genetic effects of high LET radiations; and metabolic and therapeutic studies of heavy metals. Studies of nonnuclear energy sources deal with characterization and toxicological evaluation of effluents of fluidized bed combustion and coal gasification; electrical storage systems; electric fields associated with energy transmission; and development of population projection models and assessment of human risk. Basic research studies include fundamental structural and biophysical investigations; circadian rhythms; mutagenesis in bacteria and mammalian cells; cell killing, damage, and repair in mammalian cells; carcinogenesis and cocarcinogenesis; the use of 1iposomes as biological carriers; and studies of environmental influences on life-span, physiological performance, and circadian cycles. In the area of medical development, proteins in urine and tissues of normal and diseased humans are analyzed, and advanced analytical procedures for use of stable isotopes in clinical research and diagnosis are developed and applied. The final sections of the report cover support facilities, educational activities, the seminar program, staff talks, and staff publications. 
THIS PAGE

\section{WAS INTENTIONALLY}

LEFT BLANK 


\section{DIVISION DIRECTOR'S INTRODUCTION}

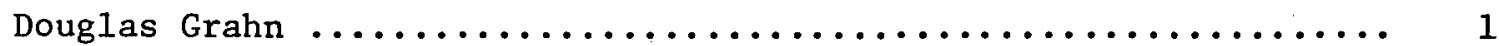

2. RADIATION TOXICITY IN DOGS

INTRODUCTION

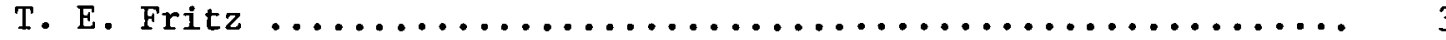

RESPONSES OF YOUNG ADULT BEAGLES TO CONTINUOUS EXPOSURE TO ${ }^{60}$ Co GAMMA RAYS

T. F. Fritz, T. M. Seed, C. M. Pnole, L. S, Lnmbard,

D. V. Tolle, W. G. Keenan, J. M. Angerman, S. M. Cullen,

D. E. Doyle, L. V. Kaspar, N. D. Kretz, P. H. Polk, and

M. Sanderson

INFLUENCE OF DOSE RATE AND TOTAL DOSE ON LATE EFFECTS OF TERMINATED EXPOSURES GIVEN YOUNG ADULT BEAGLES

T. E. Fritz, T. M. Seed, C. M. Poole, L. S. Lombard,

D. V. Tolle, W. G. Keenan, J. M. Angerman, S. M. Cullen,

D. E. Doyle, L. V. Kaspar, N. D. Kretz, P. H. Polk, and

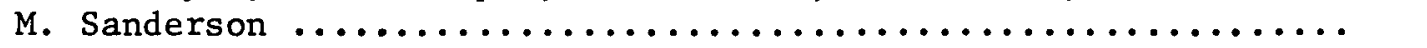

EFFECT OF RADIATION AND RADIATION DOSE RATE ON BEAGLES IRRADIATED DURING FETAL LIFE

T. E. Fritz, T. M. Seed, L. S. Lombard, C. M. Poole, D. V. Tolle, W. G. Keenan, D. E. Doyle, P. H. Polk, and $M$. Sanderson

\section{CELLULAR INDICATORS}

INTRODUCTION

T. M. Seed

PRECLINICAL AND CLINICAL PHASES OF LEUKEMIA INDUCTION DY RADIATION

T. M. Seed, T. E. Fritz, D. V. Tolle, L. V. Kaspar,

C. M. Poole, D. M. Buchholz, S. M. Cullen, D. E. Doyle,

P. H. Polk, J. M. Angerman, W. G. Keenan, M. Sanderson,

and P. C. Brennan 
CHEMICAL LEUKEMOGENESIS, BENZENE INTOXICATION

T. E. Fritz, T. M. Seed, S. Bourne, A. Jirka,

N. D. Kretz, D. V. Tolle, M. A. Gabriel, and

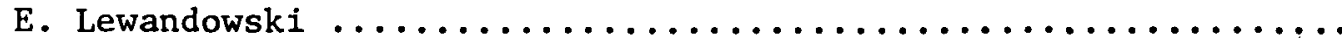

DEVELOPMENT AND APPLICATION OF HEMOPOIETIC CELL

CLONING METHODS AS GENERAL TOXICOLOGICAL ASSAYS

T. M. Seed, G. T. Chubb, L. V. Kaspar, B. J. Wright,

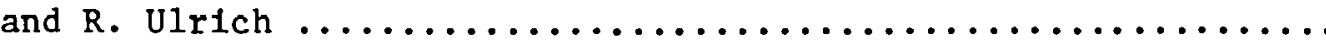

ATTEMPTS AT IMMUNOGICAL IDENTIFICATION OF CANINE

PLURIPOTENTIAL HEMOPOIETIC STEM CELLS

D. M. Buchholz and T. M. Seed ..................... 14

SPECTRAL ANALYSIS OF LUMINESCENCE FROM BIOLOGICAL

STAINS USING THE SCANNING ELECTRON MICROSCOPE

D. G. Oldfield, G. T. Chubb, and T. M. Seed

4. NEUTRON AND GAMMA-RAY TOXICITY STUDIES

INTRODUCTION

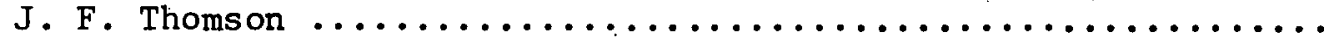

STUDIES OF LIFE SHORTENING

J. F. Thomson, F. S. Williamson, L. S. Lombard,

K. H. Allen, J. L. Hulesch, V. A. Ludeman,

A. R. Sallese, and E. F. Staffeldt

ACUTE RADIATION TOXICITY

J. F, Thomson, F. S. Williamson, J. L. Hulesch,

G. I. Holmblad, E. G, Johnson, Jr. . and J, E. Trier ...........

CARDIOVASCULAR EFFECTS OF EXTERNAL RADIATIONS

S. P. Stearner, E. J. B. Christian, R. L. Devine,

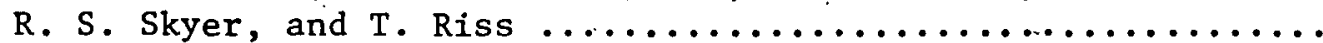

5. GENETIC EFFECTS OF HIGH LET RADIATIONS

INTRODUCTION

D. Grahn

DOMINANT LETHAL MUTATIONS AND CHROMOSQME ABERRATIONS

INDUCED IN MALE MICE BY INCORPORATED ${ }^{239} \mathrm{Pu}$ AND EXTERNAL

FISSION NEUTRON AND GAMMA IRRADIATION

D. Grahn, B. H. Frystak, C. H. Lee, J. J. Russe11,

and $A$. Tindenhaum 
GENETIC EFFECTS OF LOW SINGLE DOSES OF NEUTRONS AND GAMMA RAYS

D. Grahn, B. H. Frystak, and C. H. Lee ............... 26

GENETIC EFFECTS OF AMERICIUM-241

D. Grahn, B. H. Frystak, J. J. Russell, C. H. Lee,

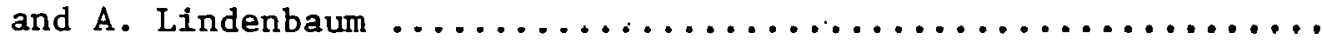

6. THERAPY OF POISONING BY RADIOACTIVE AND NONRADIOACTIVE METALS

INTRODUCTION

M. H. Bhattacharyya $\ldots \ldots \ldots \ldots \ldots \ldots \ldots \ldots \ldots \ldots \ldots \ldots \ldots \ldots \ldots \ldots$

DEVELOPMENT OF AN OPTIMAL DTPA THERAPY PROTOCOL FOR DECORPORATION OF ACTINIDES

A. Lindenbaum, E. S. Moretti, and J. J. Russell ........... 33

WOUND EXPOSURE TO PLUTONIUM IN THE MOUSE

M. H. Bhattacharyya and D. P. Peterson ................ 33

TESTICULAR PLUTONIUM AND AMERICIUM: RETENTION AND THERAPEUTIC REMOVAL

J. J. Russell, A. Lindenbaum, and D. Grahn ............. 34

GASTROINTESTINAL ABSORPTION OF PLUTONIUM

M. H. Bhattacharyya, A. Lindenbaum, R. P. Larsen,

R. D. Oldham, and E. S. Moretti .................... 34

METABOLISM AND DECORPORATION OF LEAD IN THE YOUNG RODENT

E. M. Sorensen, E. S. Moretti, E. Saltz,

M. H. Bhattacharyya, and A. Lindenbaum $\ldots \ldots \ldots \ldots \ldots \ldots \ldots \ldots . \ldots \ldots$

DTPA-INDUCED EXCRETION OF PLUTONIUM INTO DOG BILE

M. H. Bhattacharyya and D. P. Peterson ............... 35

7. TOXICOLOGICAL EVALUATIONS OF PROCESSES FOR UTILIZATION OF COAL

INTRODUCTION

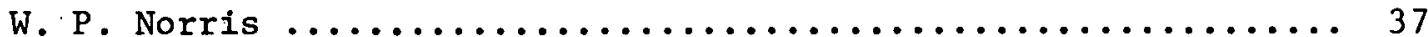

CHARACTERIZATION AND FRACTIONATION OF COMPLEX ORGANIC MIXTURES FROM FLUIDIZED BED COMBUSTION AND GASIFICATION OF COAL

S. Bourne, A. Jirka, and P. T. Cunningham ............. 40 
CHEMICAL AND PHYSICAL CHARACTERIZATION OF PARTICULATE

EFFLUENTS FROM THE ATMOSPHERIC FLUIDIZED BED COMBUSTION

OF COAL

F. R. Kirchner, E. T. Kucera, W. P. Norris,

J. O. Hutchens, P. T. Cunningham, S. S. Danyluk,

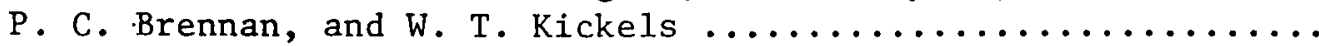

A SYSTEM FOR REAEROSOLIZING FLUIDIZED BED COMBUSTOR

FLY ASH FOR ANIMAL EXPOSURES

F. R. Kirchner, J. O. Hutchens, W. P. Norris,

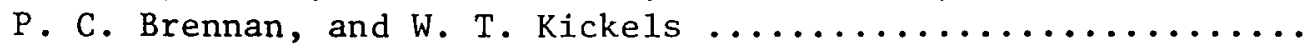

THE FLUIDIZED BED .COMBUSTION TOTAL EFFLUENT TOXICOLOGY SYSTEM

R. Kumar, J. O. Hutchens, W. P. Norris, F. R. K1rchner,

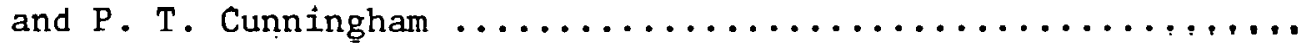

MUTAGENICITY OF COAL FLY ASH RECOVERED FROM ELECTRIC POWER PLANT PRECIPITATORS

H. E. Kubitschek and L. Venta ................... 45

MUTAGENICITY AND CHEMICAL CHARACTERIZATION OF EFFLUENTS FROM FLUIDIZED BED COMBUSTORS

H. E. Kubitschek, D. A. Haugen, S. Bourne, D. M. Williams,

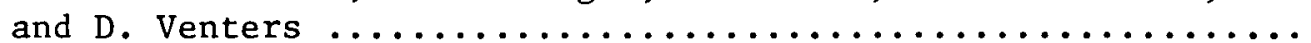

MUTAGENICITY OF OIL PROCESS STREAMS IN THE HYGAS COAL GASIFICATION PLANT

B. S. Hass, S. S. Dornfeld, S. Bourne, and D. M. Smith ...... 50

COMPARISON OF MUTAGENICITY AND GROWTH INHIBITION OF WATER QUENCH PROCESS STREAMS FROM THE HYGAS GASIFICATION PLANT

B. Hass, S. S. Dornfeld, and T. Matsushita ............ 52

CYTOTOXIC EFFECTS OF THE EFFLUENTS FROM FLUIDIZED BED COAL COMBUSTION

G. R. Lankas, M. M. Elkind, and E. M. Buess ........... 54

TOXICOLOGICAL RESPONSES OF MICE EXPOSED TO REAEROSOLIZED

FLY ASH FROM ATMOSPHERIC PRESSURE FLUIDIZED BED COMBUSTION

P. C. Brennan, W. P. Norris, F. R. Kirchner, T. M. Seed,

S. P. Stearner, D. M. Buchholz, W. T. Kickels, and

S. S. Dornfeld .............................. 5

BIPHENYL AS A MODEL SUBSTRATE IN THE CHARACTERIZATION OF CYTOCHROME P-450-DEPENDENT MONOOXYGENASES

D. A. Haugen, K. M. Suhrbier, W. C. Bauman, and

J. R. Milstead 
8. HUMAN HEALTH EFFECTS AND RISK ASSESSMENTS

INTRODUCTION

D. Grahn

PREDICTIVE MODELS FOR HEALTH IMPACTS FROM ENERGY

RELATED ENVIRONMENTAL POLIUTION: THE DEMPAK MODEL

R. T. Lundy and M. E. Ginevan ...................... 61

STATISTICAL QUESTIONS IN ASSESSMENT OF HUMAN HEALTH

IMPACTS OF ENERGY RELATED EFFLUENTS

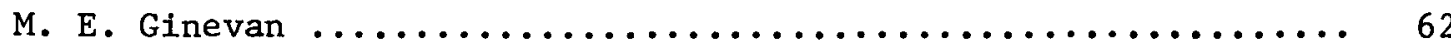

INTERACTIONS OF SOCIOECONOMIC VARIABLES AND HUMAN MORTALITY PATTERNS

D. K. Dixon-Davis, D. Grahn, J. J. Collins,

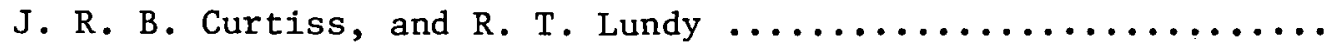

COMPARATIVE EVALUATIONS OF THE HUMAN HEALTH IMPACTS

OF DIVERSE ENERGY TECHNOLOGIES

C. D. Brown and J. R. B. Curtiss ................... 64

9. BIOMEDICAL AND ENVIRONMENTAL EFFECTS OF ELECTRICAL STORAGE SYSTEMS

INTRODUCTION

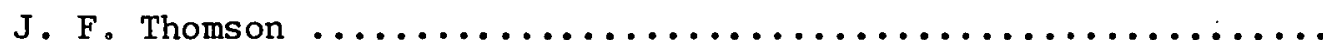

10. BIOMEDICAL EFFECTS OF ENERGY TRANSMISSION

INTRODUCTION

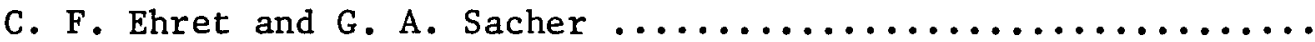

DESIGN AND CONSTRUCTION OF BASIC FIELD GENERATORS FOR EXTREMELY LOW FREQUENCY ELECTRICAL FIELD STUDIES WITH SMALL RODENTS

C. F. Ehret, G. A. Sacher, A. Langsdorf, and

R. N. Lewis $\ldots$

DESIGN AND CONSTRUCTION OF CAGE FACILITIES FOR CIRCADIAN

STUDIES OF EXTREMELY LOW FREQUENCY ELECTRIC FIELD EFFECTS

IN THE RAT

C. F. Ehret, K. R. Groh, J. C. Meinert, and G. Svihla ...........

EFFECTS OF HIGH-VOLTAGE FIELDS IN ENERGY METABOLISM AND BEHAVIOR OF MICE

G. A. Sacher, P. H. Duffy, and J. J. Russell ............. 74

EFFECTS OF HIGH-VOLTAGE FIELDS ON BEHAVIOR IN THE MOUSE

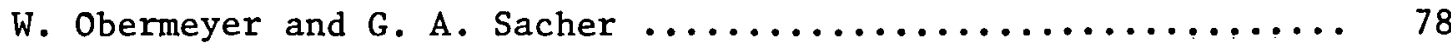




\section{MOLECULAR BIOPHYSICS}

INTRODUCTION

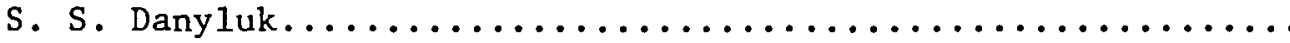

ALKYLATION EFFECTS ON NUCLEIC ACID CONFORMATIONS

S. S. Danyluk, C. F. Ainsworth, and M. MacCoss

HIGH-RESOLUTION MAGNETIC RESONANCE SPECTROSCOPY

OF INTACT BIOLOGICAL MATERIALS

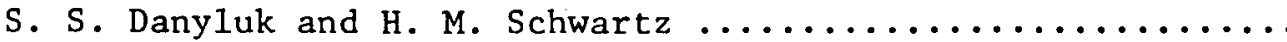

NEW SYNTHETIC USES FOR ADENOSINE $\mathrm{N}^{1}$-OXIDE DERIVATIVES

M. MacCoss, E. K. Ryu, R. S. White, and R. L. Last .........

SYNTHESIS OF P.OTENTIAL ANTIMETABOLITES AND MOLECUT.AR DEET'I' DKUGS

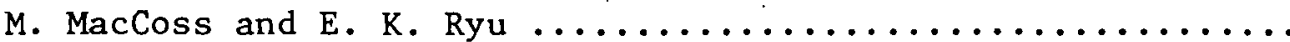

CRYSTALLOGRAPHIC REFINEMENT OF THE Mcg $\lambda$-TYPE BENCE-JONES DIMER

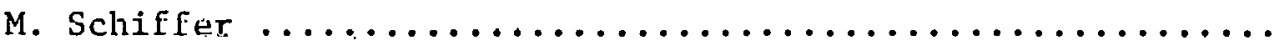

STRUCTURE DETERMINATION OF THE $K_{\text {II }}$-TYPE BENCE-JONES PROTEIN FIN

M. Schiffer, N. Panagiotopoulos, F. A. Westholm,

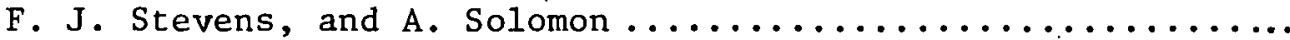

SELF-ASSOCTATION OF KI-IMMUNOGLOBULIN LIGHT CHALNS

F. J. Stevens, F. A. Westholin, A. Solomon, and

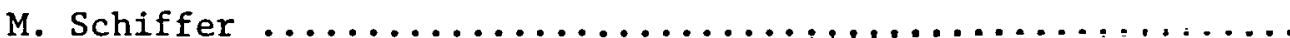

DE'SICN AND DEVELOPMENT OF A SMALL-ANGLE DIFFRACTOMETER

FUR A PULSED NEUTRON SOURCE

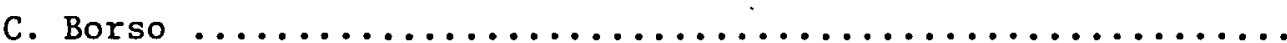

CIRCADIAN PHYSIOLOGICAL MANIFESTATIONS OF BARBITURATE ADDICTION AND WITHDRAWAL IN THE RAT

C. F. Ehret, C. Peraino, J. C. Meinert, and K. R. Groh ......

CIRCADIAN REGULATION ALONG THE NEUROENDOCRINE AXIS

C. F. Ehret, A. L. Cahill, N. D. Horseman, K. R. Groh,

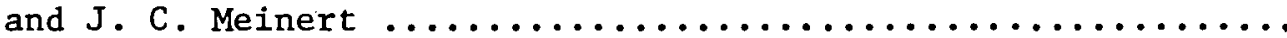

12. MUTAGENESIS: MOLECULAR AND GENETIC MECHANISMS OF ENVIRONMENTAL MUTAGENS

INTRODUECTION

H. E. Kubitschek .............................

MUTATIONAL SYNERGISM

H. E. Kubitschek and D. Venters .................... 99 
REPRODUCIBILITY OF THE AMES SALMONELLA MICROSOMAL ASSAY

H. E. Kubitschek and D. M. Williams ................ 99

DELAYED REPLICATION OF DIFFERENTIALLY STAINED

CHROMOSOMES IN MOUSE MYELOMA CELLS

T. Matsushita, A. Simms, and .G. Matsushita ............. 101

CELL GROWTH AND PYRIMIDINE DIMER REMOVAL IN

MOUSE MYELOMA CELLS

T. Matsushita and A. M. Shotola ..................... 101

ELECTRICAL DETERMINATION OF VIABILITY IN MOUSE

MYELOMA CELLS

T. Matsushita, A. M. Brendzel, and A. M. Shotola ......... 102

MOUSE MYELOMA SUSPENSION CULTURES AS A SYSTEM FOR

CYTOTOXIC AND CYTOGENETIC TESTS FOR ENVIRONMENTAL POLLUTANTS

T. Matsushita and G. Matsushita ................... 102

NEAR-ULTRAVIOLET MUTAGENESIS: THE ROLE OF recA ${ }^{+}$

IeXA+ REPAIR IN MUTAGENESIS BY MONOCHROMATIC

365-nm AND BROAD SPECTRUM RADIATION

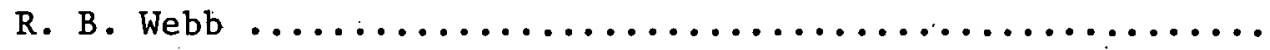

SYNERGISTIC AND ANTAGONISTIC RELATIONSHIPS BETWEEN

BROAD SPECTRUM NEAR-UV AND FAR-UV RADIATION IN

STRAINS OF ESCHERICHIA COLI WITH DIFFERING REPAIR

CAPABILITIES

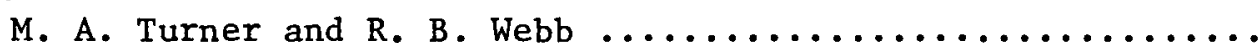

NEAR-ULTRAVIOLET . LETHALITY : NONRECIPROCAL SYNERGISTIC INTERACTION BETWEEN A NEAR-ULTRAVIOLET $(365 \mathrm{~nm})$ AND A VISIBLE (405 nm) WAVELENGTH IN ESCHERTCHIA COLI

M. S. Brown and R. B, Wehh

THE BS-1 CHEMOSTAT IN THE ABSENCE OF EXOGENOUS ACTIVATION AS A SENSITIVE INDICATOR OF MUTAGENICITY OF BENZO(A)PYRENE AND COMPLEX MIXTURES FROM HIGH-BTU GASIFICATION PLANT PROCESS STREAMS

B. S. Hass, R. B. Webb, and T. Gambill ..............

SYNERGISTIC, ADDITIVE, AND ANTAGONISTIC MUTAGENIC EFFECTS OF TWO COMPONENT MIXTURES OF POLYCYCLIC AROMATIC HYDROCARBONS

B. S. Hass, E. Brooks, K. Schumann, and

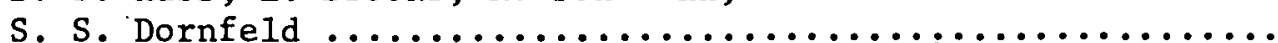


13. MAMMALIAN CELL BIOLOGY

INTRODUCTION

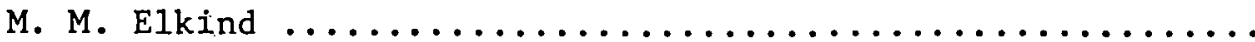

REPAIR OF POTENTIALLY LETHAL DAMAGE AND "SINGLE-HIT" KILLING

H. Utsumi, P. Ross-Riveros, C. M. Liu, and

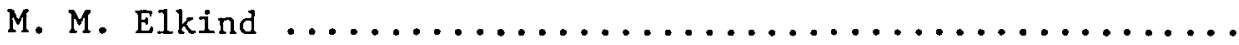

CHANGE IN REPAIR COMPETENCY AFTER 5-BROMODEOXYURIDINE

PULSE LABELING AND NEAR-ULTRAVIOLET LIGHT

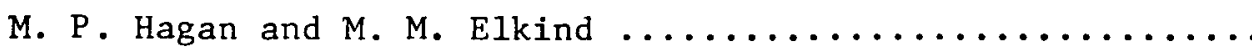

DAMAGE-REPAIR STUDIES OF THE NEOPLASTIC TRANSFORMATION OF MOUSE C3H/1OTI/2 CELLS USING FRACTIONATED DOSES OF $X$-RAYS AND FISSION-SPECTRUM NEUTRONS

A. Han, C. Hill, J. L. Dainko, E. M. Buess, and

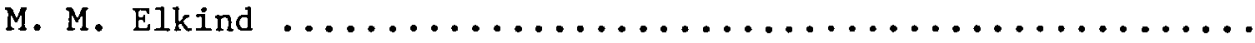

THE INTERACTION OF DAMAGE DUE TO "SUNLIGHT" AND X-RAYS

A. Han, J. L. Dainko, C. M. Liu, and M. M. Elkind ........

PHOTODYNAMIC CYTOTOXICITY IN MAMMALIAN CELLS EXPOSED TO SUNLIGHT-SIMULATING NEAR-ULTRAVIOLET LIGHT IN THE

PRESENCE OF THE CARCINOGEN 7,12-DIMETHYLBENZ (A) ANTHRACENE

H. Utsumi, G. R. Lankas, J. L. Dainko, and M. M. Elkind ....

14. CARCINOGENESIS

IÑTRODUCTION

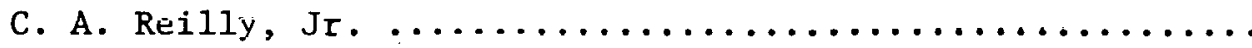

CIRCADIAN REGULATION OF ORNITHINE AMINOTRANSFERASE AND SERINE DEHYDRATASE SYNTHESIS IN RAT LIVER

K. B. Ekelman, C. Peraino, A. M. Prapuolenis, and

D. P. Peterson .............................

DIETARY PHENOBARBITAL EFFECTS ON FOOD UTILIZATION EFFICIENCY AND CIRCADIAN CYCLING OF FOOD INTAKE AND DEEP-BODY TEMPERATURE IN RATS

C. Peraino, C. F. Ehret, K. R. Groh, J. C. Meinert,

G. D'Arcy-Gomez, and A. M. Prapuolenis ..............

EFFECTS OF VARYING THE DIETARY CONCENTRATION OF PHENOBARBITAL ON ENHANCEMENT OF 2-ACETYLAMINOFLUORINEINDUCED HEPATIC TUMORIGENESIS

C. Peraino, E. F. Staffeldt, V. A. Ludeman,

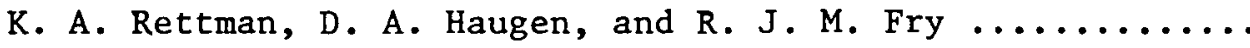


EFFECTS OF BUTYLATED HYDROXYTOLUENE ON HEPATIC

MICROSOMAL CYTOCHROME P-450

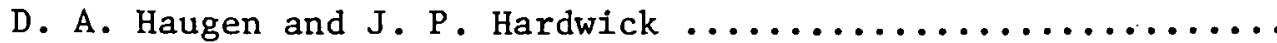

TWO-DIMENSIONAL ELECTROPHORETIC ANALYSIS OF RAT

LIVER AND NOVIKOFF HEPATOMA PROTEINS

K. E. Willard, T. E. O'Connor, and N. G. Anderson .........

PHOTOCHEMICAL INDUCTION OF SKIN TUMORS

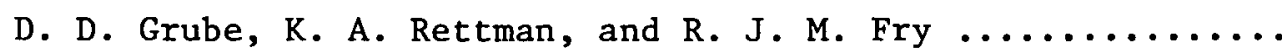

BIOCHEMICAL AND BIOPHYSICAL CHARACTERIZATION OF

FBJ AND FBR MURINE OSTEOSARCOMA VIRUSES

E. W. Chan, P. J. Dale, I. L. Greco, C. K. Lee,

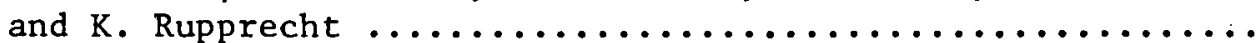

IMMUNOLOGICAL CHARACTERIZATION OF MURINE OSTEOSARCOMA VIRUSES FBJ AND FBR

L. Bodoni, J. R. Mitchen, B. Amsler, E. W. Chan,

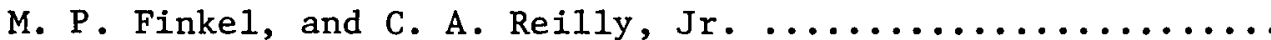

IN VITRO PROPERTIES OF A BENIGN MURINE BUNE'

TUMOR VIRUS

C. K. Lee, E. W. Chan, G. Rockus, V. A. Pahnke,

R. Updegrove, M. P. Finkel, and C. A. Reilly, Jr. ........

ISOLATION AND CHARACTERIZATION OF RETROVIRUSES FROM ${ }^{90} \mathrm{Sr}$-INDUCED OSTEOSARCOMAS

M. P. Finkel, C. K. Lee, E. W. Chan, L. S. Lombard,

G. Rockus, V. A. Pahnke, I. L. Greco, P. J. Dale,

M. F. Williams!, and C. A. Reilly, Jr. ..............

ENHANCEMENT OF REVERSE TRANSCRIPTASE AND OTHER POLYMERASE ACTIVITIES BY POLYETHYLENE GLYCOL

E. W. Chan, P. J. Dale, I. L. Greco, J. G. Rose,

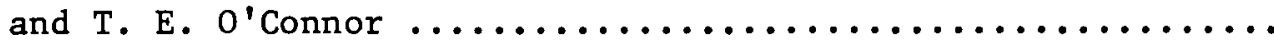

ANTIVIRAL PROPERTIES OF POLY (1-METHYL-6-THIOINOSINIC

ACID)

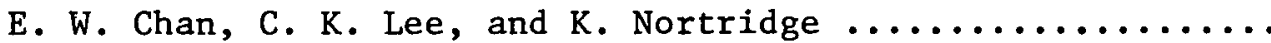

ALVEOLAR MACROPHAGES: ROLE IN LUNG DAMAGE INDUCED BY PARTICULATE AND NONPARTICULATE TOXICANTS

Y. E. Rahman, C. Peraino, A. M. Prapuolenis,

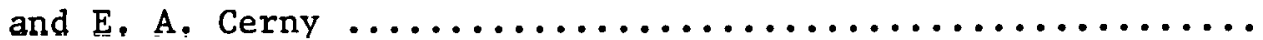

RAT TRACHEAL RING CULTURES USED FOR THE EVALUATION OF ONCOGENIC ACTIVITY OF POLYCYCLIC AROMATIC HYDROCARBONS

N. N. Beales and C. A. Reilly, Jr. 
USE OF LIVER FOR THE RAPID SCREENING OF ENVIRONMENTAL POLLUTANTS FOR TUMOR INITIATING OR PROMOTING ACTIVITY

C. Peraino, E. F. Staffeldt, V. A. Ludeman,

A. R. Sallese, K. A. Rettman, and R. N. Feinstein .........

B IOCHEMICAL AND IMMUNOLOGICAL MARKERS OF

DIFFERENTIATION AND NEOPLASIA

T. E. O'Connor, B. A. Sedita, K. A. Rettman,

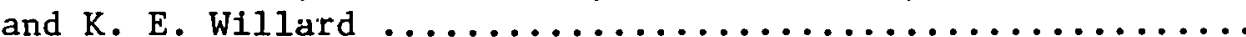

15. LIPOSOMES AS BIOLOGICAL CARRIERS

INTRODUCTION

Y. E. Rahman.

LIPOSOMES IN CANCER CHEMOTHERAPY

Y. E. Rahman, K. R. Patel, M. M. Jonah, and

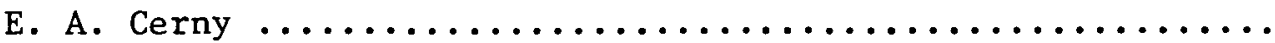

LIPOSOMES IN METAL CHELATION THERAPY

Y. E. Rahman, E. H. Lau, B. J. Wright, and

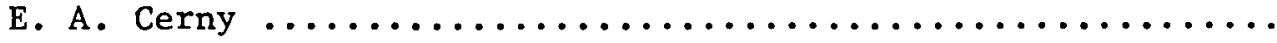

16. ENVIRONMENTAL PHYSIOLOGY

INTRODUCTION

G. A. Sacher ............................... 143

ENVIRONMENTAL INFLUENCES ON LIFE-SPAN, LIFETIME

PERFORMANCE, AND DISEASE MORBIDITY

G. A. Sacher, P. H. Duffy, J. J. Russell,

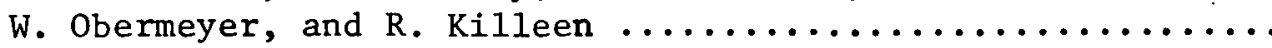

DIEL PATTERNS OF MOTOR ACTIVITY, ENERGY METABOLISM, AND BODY TEMPERATURE

G. A. Sacher, P. H. Duffy, and J. J. Russell ...........

THE EFFECTS OF A COLD ENVIRONMENT ON THE LIFE-SPAN

AND TUMOR INCIDENCE OF LABORATORY MICE

J. J. Russell and G. A. Sacher

17. MOLECULAR ANATOMY PROGRAM

INTRODUCTION

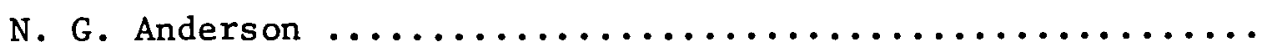

DEVELOPMENT OF TECHNIQUES FOR HIGH RESOLUTION PROTEIN MAPPING

N. L. Anderson and B. J. Hickman 
VERY HIGH SENSITIVITY PROTEIN STAINING

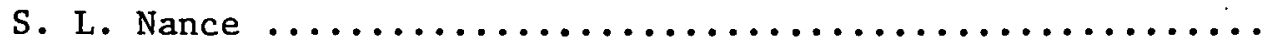

TWO-DIMENSIONAL ELECTROPHORETIC MAPPING OF BASIC

PROTEINS: THE BASO-DALT SYSTEM

K. E. Willard and N. G. Anderson ................. 150

TWO-DIMENSIONAL ELECTROPHORETIC ANALYSIS OF HUMAN URINARY PROTEINS

N. G. Anderson, S. L. Tollaksen, and

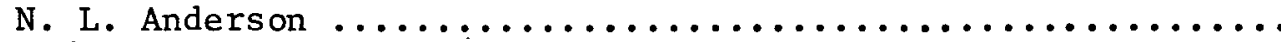

TWO-DIMENSIONAL ELECTROPHORETIC MAPPING OF MUSCLE PROTEINS

C. Smith, N. L. Anderson, and N. G. Anderson

RED CELL PROTEINS: TWO-DIMENSIONAL MAPPING OF HUMAN ERYTHROCYTE PROTEINS

J. J. Edwards, N. G. Anderson, S. L. Nance,

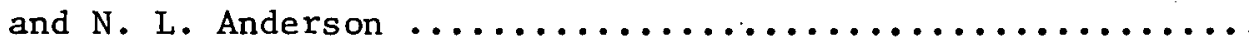

COMPUTERIZED REDUCTION OF TWO-DIMENSIONAL GEL DATA

N. L. Anderson, John Taylor, Jr., B. S. Coulter,

A. Scandora, and M. Kempf ........................ 158

18. THE ARGONNE BIOANALYTICAL CENTER FOR THE STUDY OF STABLE ISOTOPE APPLICATIONS IN HUMAN HEALTH AND DISEASE

INTRODUCTION

P. D. Klein 159

INSTRUMENTATION

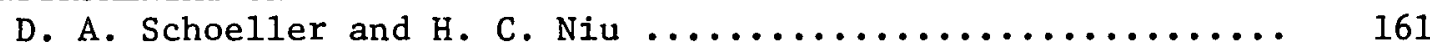

ORGANIC SYNTHESES

D. L. Hachey and K. Y. Tserng .................... 161

STUDIES WITH STABLE ISOTOPES OF METALS

D. L. Hachey and J. C. Blais ...................... 162

METHADONE PHARMACOKINETICS

D. L. Hachey and K. Nakamura ...................... 163

ANTIEPILEPTIC DRUGS

B. R. DeMark ................................ 163

TAURINE KINETIC MEASUREMENTS

C. S. Irving ................................. 164

PYRIDOXINE REQUIREMENTS

B. R. DeMark and J. C. Blais ...................... 164 
CARBOHYDRATE MALABSORPTION

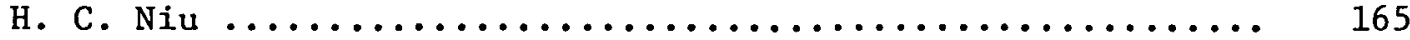

FALLSTONE FORMATION

P. A. Szczepanik-Van Leeuwen and B. R. DeMark ........... 166

STUDIES OF BILE ACIDS IN LIVER DISEASE

P. A. Szczepanik-Van Leeuwen and F. Stellaard ........... 166

SYNTHETIC DIETS

P. A. Szczepanik-Van Leeuwen and C. S. Irving .......... 167

METHADONE STUDIES

D. L. Hachey and K. Nakamura ..................... 167

BREATH TESTS AND FECAL COMBUSTION STUDIES

P. D. Klein and D. A. Schoeller ................. 168

INFORMATION DISSEMINATION AND TRAINING

P. D. Klein, E. R. Klein, D. A. Schoeller, and

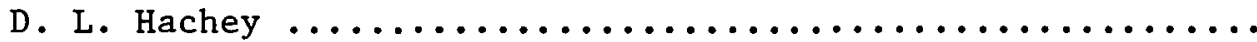

\section{SUPPORT FACILITIES}

ANIMAL FACILITIES

J. G. Linsley, T. E. Fritz, P. C. Brennan,

W. G. Keenan, C. M. Poole, R. C. Simkins, and

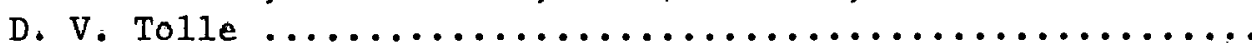

COMPUTER SUPPORT FACILITIES

F. S. Williamson, J. A. Blomquist, and C. A. Fox ....... 173

ELECTRON MICROSCOPE CENTER

T. M. Seed and G. T. Chubb ...................... 173

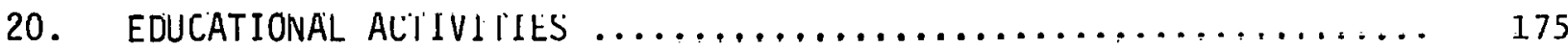

21. DIVISIONAL SEMINARS DLRING $1978 \ldots \ldots \ldots \ldots \ldots \ldots \ldots \ldots \ldots \ldots \ldots$

22. OUTSIDE TALKS BY DIVISIONAL STAFF DURING $1978 \ldots \ldots \ldots \ldots \ldots \ldots \ldots$

23. PUBLICATIONS APPEARING IN CALENDAR YEAR $1978 \ldots \ldots \ldots \ldots \ldots \ldots$

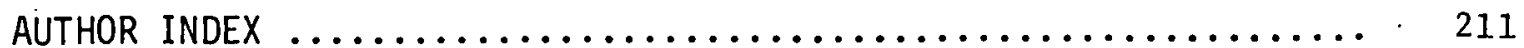




\section{DIVISION DIRECTOR'S INTRODUCTION}

This report is concerned with the progress of research in the Division of Biological and Medical Sciences in the calendar year 1978. The individual sections are organized into the four major activities of the Division. These activities are concerned with studies of the biological effects of nuclear energy technology; biological aspects of alternate energy sources, primarily coal; basic biomedical science; and development of medical technologies. The first seventeen sections present the activities of each of the research groups within the Division (Figure 1.1); in two cases, the work of a group is presented in two sections. Collaborations among groups are frequent, as indicated by cross references in the text and by the authorship of the individual research reports. Collectively, the introductions to the research sections provide an overview of the goals and accomplishments of the Divisional programs.

Finally, the last five sections of this report indicate the range of other activities in the Division. They present the major support facilities, the varied graduate and undergraduate level educational activities, the formal and informal seminars series in the Division, staff seminars and presentations at scientific meetings, and a list of staff publications appearing during the calendar year 1978 .

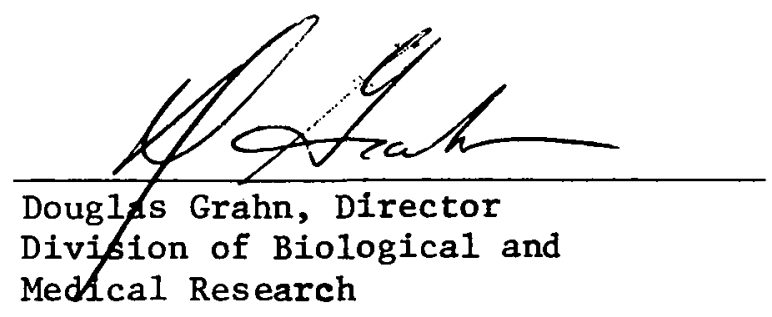




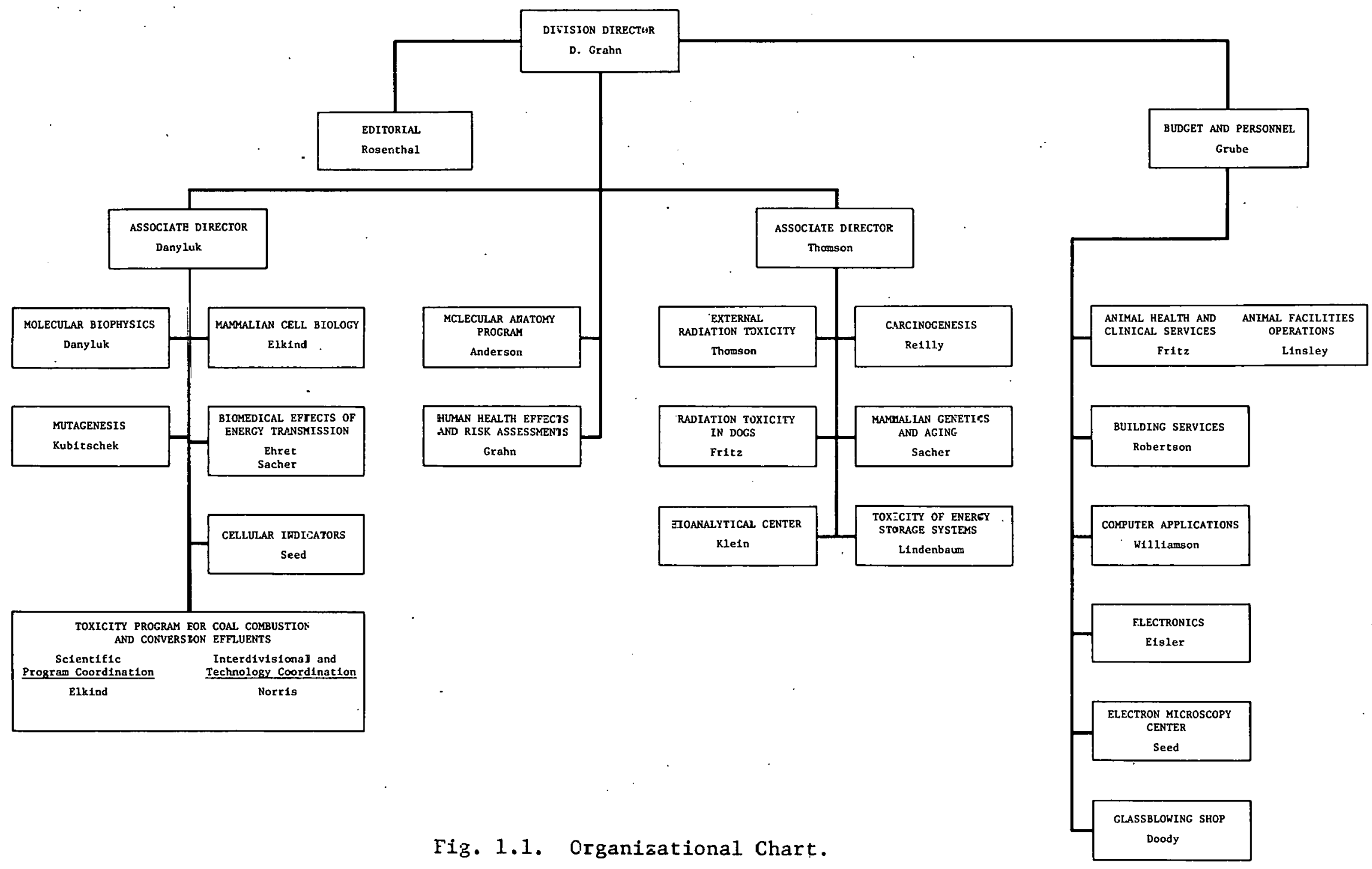


2. RADIATION TOXICITY IN DOGS

\section{INTRODUCTION}

Thomas E. Fritz

The basic objective of this study is the generation of data that will be useful for extrapolation to man on the late effects of low doses of lonizing radiation in a large, long-lived experimental animal. Lacking controlled data from exposed humans, particularly data on effects of low exposures after long time periods, it is necessary to use selected animal species and to search for biologically significant end points. Where interspecies differences are found, it is important to seek an explanation that can be expressed as a single unifying concept of predictive value for man. It is essential to measure the effects in a larger, long-lived animal because of the need for measuring longitudinal, sequential clinical responses.

The specific goals and areas of investigation within this broad objective can be summarized as follows:

1) To determine the influence of three major factors of exposure--(a) the daily irradiation exposure rate, (b) the accumulated exposure to irradiation, and (c) the influence of age at the time irradiation is initiated.

2) To provide data for estimates of radiation-specific excess mortality in the dog in order to allow interspecies comparisons to existing rodent data and to provide for extrapolation to man.

3) To provide base-line data and specimens to define the pathogenesis of leukemia and to study the mechanisms of radiation leukemogenesis.

Continuous or duration of life exposures, unlike single-dose or fractionated exposures, result in 11 fe shortening that is highly reproducible and has been found to take the mathematical form of an increase in the Gompertz slope relation. In laboratory rodents where adequate data are obtainable, the function has a well-defined slope, and at exposures between 25 and $125 \mathrm{R} /$ day the Gompertz slope varles as the square of the daily exposure rate whereas at daily exposures below $25 \mathrm{R} /$ day the trend of the slope rhanges to one that varies as the first power of daily exposure rate as determined by total dose.

The rate-squared slope (exposures of 25-125 $\mathrm{R} /$ day in mice) has been demonstrated only for rats and mice and has not been tested in longer lived species. This situation was a major consideration in the design of our study of continuous Irradiation in beagles. 
This research is being approached through a series of experiments that utilize protracted whole-body irradiation (22 hours/day, 7 days/week) from ${ }^{60} \mathrm{Co}$ gamma ray sources in three specially built exposure rooms. These experiments are characterizing the biological responses of beagles exposed at various exposure rates (1) until they die (beginning as young adults), (2) until they accumulate predetermined total doses of irradiation, and (3) during various stages of development and growth including fetal life.

Whole-body irradiation from ${ }^{60}$ Co gamma rays was selected in order to simulate the effects of protracted irradiation from either (1) radionuclides deposited internally as a result of accidents with nuclear technologies or from weapon testing, or (2) external irradiation from increased ambient background from similar episodes. The dosimetry of such 60 Co exposures is relatively uncomplicated compared to that from deposited radionuclides and provides nearly uniform exposure to the whole body. The exposure rate and total dose, therefore, can be precisely. controlled and varied and there is no excretion of radioactive materials.

In preliminary reports (e.g., Norris, W. P., and T. E. Fritz, in Radiobiology of Plutonium, Eds. B. J. Stover and W. S. S. Jee, Univ. of Utah Press, Salt Lake City, 1972 , pp. 243-260; Fritz, T. E., et al. Late Biological Effects of Ionizing Radiation, Vol. II. IAEA International Symposium on the Late Biological Effects of Ionizing Radiation, Vienna, March 13-17, 1978, International Atomic Energy Agency, Vienna, 1978, pp. 71-82), the interactions of dose rate and total dose in determining tissue reactions to continuous exposure of the dog to whole body irradiation were discussed. The data demonstrated that over the range of exposure rates of $5 \mathrm{R} /$ day to more than $100 \mathrm{R} / \mathrm{day}$, the target organ is the hematopoietic system and the causes of death are related to the square of the dose rate. From the data then available it was decided to initiate a study at lower exposure rates designed to establish whether the change to unit slope would hold true in dogs, which have a mean life-span $\sim 7$ times that of laboratory mice, and are $\sim 3.5$ times more sensitive to acutely lethal exposures of ${ }^{60} \mathrm{Co} \gamma$-irradiation. On the basis of a detailed analysis of the existing dog data at exposures of $\overline{>} \mathrm{R} /$ day it was shown that significant mortality data could be obtained with groups of 80 , 40 , and 40 dogs at exposure rates of $0.4,1.0$, and $2.5 \mathrm{R} /$ day, respectively, and these studies have been initiated.

The need to compare the effect of protracted irradiation given at various exposure rates to that given to death is also an important objective that developed early in these studies. This objective is being approached by exposing dogs in the gamma field until the exposure reaches either 600 or $1400 \mathrm{R}$ at exposure rates of $35,17,10$, or $5 \mathrm{R} /$ day, $200 \mathrm{R}$ at 17,10 , or $5 \mathrm{R} / \mathrm{day}$, or $4000 \mathrm{R}$ at $10 \mathrm{R} /$ day.

As a result of the earlier studies at dose rates of $5 \mathrm{R} /$ day and above, where leukemia was the most significant end point, an expanded collaborative study on the mechanisms of leukemogenesis was initiated (see Section 3). 


\section{REGULAR STAFF}

Doyle, Donald E. (Scientific Assistant)

Fritz, Thomas E. (Veterinary Pathologist)

Kaspar, Lillian V. (Scientific Assistant)

Keenan, William G. (Scientific Associate)

Kretz, Norbert D: (Scientific Assistant)

Lombard, Louise S. (Veterinary Pathologist)

Polk, Patrick H. (Scientific Assistant)

Poole, Calvin M. (Veterinarian)

Sanderson, Margaret M. (Scientific Associate)

Seed, Thomas M. (Assistant Biologist)

Tolle, David V. (Scientific Associate) 
RESPONSES OF YOUNG ADULT BEAGLES TO CONTINUOUS EXPOSURE TO 60 Co GAMMA RAYS

T. E. Fritz, T. M. Seed, C. M. Poole, L. S. Lombard, D. V. Tolle,

W. G. Keenan, J. M. Angerman, S. M. Cullen, D. E. Doyle, L. V. Kaspar,

N. D. Kretz, P.H. Polk, and M. Sanderson

During the past year we have completed the entry of dogs into the lower exposure rate study. A total of 230 dogs includes 92 irradiated at $0.4 \mathrm{R} /$ day and $46 \mathrm{each}$ at $1.0 \mathrm{R} / \mathrm{day}, 2.5 \mathrm{R} / \mathrm{day}$, and unirradiated controls. Only one dog has died but the death is not experimentally significant because it was caused by a parvovirus infection also seen in controls. To this time, those dogs irradiated for $\sim 1000$ days are showing a dose rate dependent depression of mean circulating platelet and total leukocyte numbers, while erythrocytes are largely unaffected. At $2.5 \mathrm{R} / \mathrm{d}$ ay the depression is obvious, while at $1.0 \mathrm{R} /$ day it is of questionable significance when compared to controls. The values in dogs irradiated at $0.4 \mathrm{R} /$ day are not different from control values. These results demonstrate that significant hematopoietic damage is occurring at $2.5 \mathrm{R} /$ day and suggest the bone marrow aplasia or myeloproliferative disorders may result at higher exposure rates.

Six males at each exposure rate and six controls selected for sequential evaluation of the effects on spermatogenesis have. now been followed for $\sim 400$ days. The dogs being irradiated at all three exposure rates are showing significant reductions in sperm counts. Those irradiated at 2.5 and $1.0 \mathrm{R} /$ day have become essentially aspermic. Dogs irradiated at $0.4 \mathrm{R} /$ day have sperm counts $\sim 10 \%$ of preirradiation values and there are associated increases in abnormal morphology and reductions in live-dead ratio and motility. Thus we have already determined that reproduction cannot occur in the presently available gamma field dose rates because of the sensitivity of the male gonad.

INFLUENCE OF DOSE RATE AND TOTAL DOSE ON LATE EFFECTS OF TERMINATED EXPOSURES GIVEN YOUNG ADULT BEAGLES

T. E. Fritz, T. M. Seed, C. M. Poole, L. S. Lombard, D. V. Tolle,

W. G. Keenan, J. M. Angerman, S. M. Cullen, D. E. Doyle, L. V. Kaspar,

N. D. Kretz, P. H. Polk, and M. Sanderson

These studies continue to focus on the late effects occurring in dogs given total exposures between 600 and $2000 \mathrm{R}$ at rates between 5 and $35 \mathrm{R} /$ day as described earlier in this and in previous reports. Of the 357 dogs given terminated exposures, 193 lived more than 100 days following termination of irradiation and are being followed as chronic survivors and observed for late effects. A total of 52 of the chronic survivors have died to this time. Because of the schedule by whtch dogs were staged into the gamma field, survival time to date varies considerably. Some dogs have been observed as long as 3500 days after exposure while others have been out of the gamma field only 500 days. In addition to 9 hematopoietic tumors (leukemias and lymphosarcomas), there have been a variety of other malignancies including 8 mammary carcinomas. 
From these interim data it is difficult to speculate on dose or dose rate effects except to say that:4 of the leukemias have occurred in the group given $4000 \mathrm{R}$ at $10 \mathrm{R} / \mathrm{day}$ which is the highest total dose given to a group.

The minimum terminated exposure to produce.myelogenous disorders still remains $1700 \mathrm{R}$, and the mean induction time is $\sim 400$ days. The incidence of myelogenous leukemia appears to decrease rapidly in dogs that survive beyond this time and, as in dogs irradiated until death, appears related to the recovery of the bone marrow--in this case, after termination of irradiation.

The large number of mammary malignancies, 8 among 21 female decedents, is significantly greater than in the colony control population where there have been 3 among 35 female decedents. A total of 6 nonmalignant mammary tumors in the dogs given terminated exposures is not appreciably different from the 11 in the control population. These data suggest that there is a higher frequency of total mammary tumors in these irradiated dogs and that the increase results from the malignant forms. It will be interesting and important to see whether these interim conclusions will be substantiated as the remaining dogs age and die. Subsequent to the early wave of myelogenous leukemias described above and the other soft tissue tumors, there were no other deaths that can be related to the irradiation.

EFFECT OF RADIATION AND RADIATION DOSE RATE ON BEAGLES IRRADIATED DURING FETAL LIFE

T. E. Fritz, T. M. Seed, L. S. Lombard, C. M. Poole, D. V. Tolle, W. G. Keenan, D. E. Doyle, P. H. Polk, and 'M. Sanderson

As discussed in our previous reports, continuous irradiation given during fetal life producesdiscrete affects that are dose rate dependent and uniquely different (except for aspermia) from effects on adults. The most obvious is the failure of the adult gonads to produce gametes, thus resulting in sterility in both sexes. There are distinct differences in the sensitivities of the two sexes that are dependent on the dose rate given the fetus; oogenesis fails in the adult female given $5 \mathrm{R} /$ day during fetal life, while spermatogenesis proceeds in the adult male at $5 \mathrm{R} /$ day but not $10 \mathrm{R} /$ day. Although normal in most other respects, both sexes also attain a size significantly less than normal in adult life. The lack of anomalies or birth defects has also been a significant finding in dogs given continuous irradiation during gestation.

A total of 62 adult dogs irradiated during fetal life is now surviving and being observed for late effects at ages between 500 and 2900 days of age. There have been eleven deaths in dogs surviving the neonatal periods. Two of these decedents, both irradiated at $10 \mathrm{R} /$ day, died of renal disease at 918 and 1168 days of age. Another, irradiated at $5 \mathrm{R} /$ day, died of a malignant lymphoma (1ymphosarcoma) at 2561 days of age. These are the only deaths that appear related to the radiation exposure during fetal life. The remaining dogs appear normal except for the reproductive effects described above and their smaller than normal size. 


\section{THIS PAGE \\ WAS INTENTIONALLY \\ LEFT BLANK}

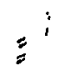

$\because \vdots$ 


\section{CELLULAR INDICATORS}

\section{INTRODUCTION}

Thomas M. Seed

This new program, formed as an outgrowth of the Radiation Toxicity in Dogs Project, has three major research goals: (1) characterization of pathological progression in leukemia induced in dogs by ${ }^{60}$ Co or benzene; (2) development of sensitive preclinical cellular predictors of impending disease; and (3) development and use in vitro of hemopoletic cell cloning methods for the clarification of the mechanisms of the hemotoxic responses and for the practical and rapid in vitro assessments of hemotoxic potential of radiation, benzene, and other potentially troublesome industrial or environmental po1lutants.

Relative to the in vivo studies, the experimental approach has been to assess serially phase-related changes within the hemopoletic system of exposed animals. Work during the past year continues to support and to strengthen the concept that preleukemia is characterized by a progressive aberrant expansion of the granulocyte reserves and the committed stem cell compartments of the marrow. These early preclinical changes occur without the full complement of cytological cellular abnormalities that characterize overt leukemia. Further work in this area promises to Identify specific cellular events in the pathological progression of induced leukemia.

The studies, as outlined, are based on the premise that leukemia induction is a progressive process with identiflable preclinical stages and that the process involves the selection and proliferation of aberrant hemopoietic clones. The developmental work on the in vitro cloning methods assumes that the pluripotent stem cell and its early commitment phases of differentiation are the basis of toxicant-induced hemopoietic dysfunction. Our efforts to identify, by immunological techniques, pluripotential hemopoietic stem cells should prove useful in assessing change in numbers and function of these key regulating cells during preclinical phases (see the report by Buchholz and Seed). The eventual application of the high resolution fluorescent labeling techniques to scanning electron microscopy (see the report by 01dfield et al.) will support our efforts to study stem cell function.

Several investigations by outside collaborators continue to assist the efforts to elucidate pathological mechanisms. These studies include: correlative studies of histocompatibility type (DLA) and proneness to radiationinduced marrow aplasia or leukemla (Drs. F. Wilson and K. Stitzel, University of California, Davis); sequential examination of serum profiles of suspectpreleukemic dogs ( $\mathrm{Dr}$. F. Quimby, Tufts University); and continued attempts to 
detect oncornavirus by molecular probe methods designed to complement our direct electron microscopic searches ( $\mathrm{Dr}$. $G$. Todaro, National Cancer Institute).

We were pleased to have had Dr. Theodore Fliedner of the University of Ulm, (West Germany) for several days in our laboratory. In addition, Dr. D. Oldfield (Biology Department, DePaul University, Chicago) and Dr. J. R. Seed (Texas A \& M University) were Faculty Research Participants in our laboratory. Dr. Oldfield is developing scanning electron microscopic luminescence techniques and $\mathrm{Dr}$. Seed is studying tumor progression-regression as modulated by microbial infections.

REGULAR STAFF

Kaspar, Lillian V. (Scientific Assistant)

Seed, Thomas M. (Assistant Biologist)

TEMPORARY STAFF DURING 1978

Buchholz, Donna M. (Postdoctoral Appointee) 
PRECLINICAL AND CLINICAL PHASES OF LEUKEMIA INDUCTION BY RADIATION

.T. M. Seed, T. E. Fritz, ${ }^{1}$ D. V. Tolle, ${ }^{1}$ L. V. Kaspar, C. M. Poole, ${ }^{1}$

D. M. Buchholz, S. M. Cullen, 1 D. E. Doyle, 1 P. H. Polk, J. M. Angerman, 1

W. G. Keenan, 1 M. Sanderson, 1 and P. C. Brennan ${ }^{2}$

Previous studies have shown that under the condition of continuous, wholebody gamma $\left({ }^{60} \mathrm{Co}\right)$ irradiation at the dose rate of $10 \mathrm{R} /$ day the incidences of aplastic anemia and myelogenous leukemia in beagles both approached $50 \%$. A longitudinal study of the irradiated beagle's hemopoietic system is being carried out with the intent to localize structural and functional lesions and clonal aberrancies. The identification of specific hemopoietic lesions during preclinical phases should aid us in our prognostication of impending leukemia in irradiated dogs and perhaps in man.

To date, 30 dogs ( 4 replicate groups of 6 experimental animals, plus 6 controls) have been assigned to the current longitudinal leukemogenic studies and as of January 1979 are from 220 to 1027 days into the experiment after accumulated total gamma radiation doses of from 2200 to $10,270 . R$ (at $10 \mathrm{R} / \mathrm{day}$ ). of 24 irradiated dogs, a total of 14 deaths have occurred resulting from aplastic anemia and two dogs have died (mean time of 455 days) with myeloproliferative syndromes characterized histopathologically as myelomonocytic leukemia and myelofibrosis. Six of the eight animals still alive are in suspected preleukemic states.

We presently recognize four distinct preclinical phases in leukemia development: (I) progressive development of severe leukopenia and thrombocytopenia, (II) partial hemopoietic recovery after $2000 \mathrm{R}$ of accumulated exposure, (III) an equilibration of subnormal hemopoletic function, and (IV) a classical preleukemic phase. Overt leukemia is the fifth and last phase of the sequence which ends in terminal leukemla. Survivors of the hemopoietic crisis period (the terminal part of phase I), which predictably occurs between 200 to 300 days in the gamma field, show a broadly based recovery: in hemopoietic function and have a high probability of developing myeloproliferative disease. The committed stem cell pool, following its inftial (phase I) contraction to $10 \%$ of its pre-exposure size, slowly expands (phase II) from $30 \%$ to $40 \%$ of 1 ts original size and subsequently remains relatively stable (phase III) over several hundred days. Entry into phase IV appears to be characterizèd by a second, more rapild expansion of the granulopoietic stem cell compartment, for in several of our long-lived animals ( $i . e .,>800$ days in the gamma field) the compartment has expanded beyond its pre-exposure size, but st111 remains smaller than in patently leukemic animals.

The sequential monitoring of the granulocyte reserves by the endotoxin stress assay has indicated corresponding time-dependent phase shifts, i.e., an initial contraction in phase I, followed by a small expansion in phase II to a subnormal level of approximately $25 \%$ of control value, and further expansion in late phase III and early phase IV.

$1_{\text {Radiation Toxicity in Dogs Group. }}$

2 Toxicity Program for Coal Combustion and Conversion Effluents. 
Correlated with the quantitative change in granulopoietic stem cells with time and accumulated dose of irradiation, are the qualitative, phase-related, changes in clonal growth properties. During the late part of phase I and early into the recovery phase (i.e., II), the developing colonies are atypical,i.e., small and loosely compacted. Growth in phase III is generally stronger; colonies are larger, more luxurious, and size/shape aberrancies are commonly noted. The latter growth patterns of phase III more closely resemble those of chronic leukemia, rather than the acute, blastic leukemia whose growth pattern is characterized by a "lawn-like" development of small clusters and single cells but with the formation of few or no colonies. Results of our cloning experiments also suggest that the absolute rate of spontaneous colony formation in the absence of specific canine serum factors (i.e., colony stimulating activity, CSA) increases during phases II and III.

The sequential change in CSA that regulates the proliferative and differentiative cycles of. committed stem cells continues to be evaluated with time-of-irradiation and stage of pathological progression using normal, unirradiated marrow stem cells as serum-responsive targets in the cloning assay. The serum CSA levels of dogs destined to radioaccommodate are initially highest early in phase I when the number of committed stem cells within marrow are at their nadir. There is a progressive decline in CSA activity which occurs concomitantly with the previously noted expansion of the stem cell pool. CSA activity during phase III is subnormal and remains so for several hundred days.

\section{CHEMICAL LEUKEMOGENESIS, BENZENE INTOXICATION}

T. E. Fritz, ${ }^{1}$ T. M. Seed, S. Bourne, ${ }^{2}$ A. Jirka, ${ }^{2}$ N. D. Kretz, ${ }^{1}$

D. V. Tolle, 1 M. A. Gabriel, 3 and E. Lewandowski 4

Benzene, a radiomimetic-like chemical, of ten produces upon prolonged exposure a marked suppression of bone marrow function and the occasional case of granulocytic leukemia; as the terminal pathological sequelae. Benzene is suspected to be leukemogenic in man based on cpidcmiological data; however, in contrast to the leukemogenic effects of lonizing radiation, the leukemogenic effect of benzene has not been conclusively documented in laboratory animals--hence the need for further toxictty testing.

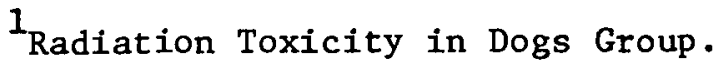

2 Analytical Chemistry Laboratory of the Chemical Engineering Division.

${ }^{3}$ Spring 1978 participant in the Undergraduate Honors Research Participation Program and particlpant in the 1978 Summer Research Institute in Biology, University of Dallas.

${ }^{4}$ Summer 1978 participant in the Undergraduate Honors Research Participation Program, University of Chicago. 
During the past year an inhalation chamber designed to deliver an atmosphere containing 100-200 ppm of benzene and to handle approximately 50 mice was designed and bullt. Analytic procedures were developed for sampling and analyzing blood, by gas chromatography, for concentrations of benzene as low as $0.1 \mathrm{ppm}$. The latter is an important advancement, for it allows us to associate the variables of the route of exposure, the tolerated dosages, and blood and tissue concentrations relative to the extent of hemopoietic suppression.

The direct myelotoxic effect of benzene on cultured hemopoletic cells has been initially evaluated in vitro. We demonstrated a dose-dependent inhibition of stem cell (committed granulocytic-monocytic progenitors) cloning. At the concentration of $5000 \mathrm{ppm}$ there was approximately $80 \%$ inhibition. The absolute viability of benzene-exposed cells, as assayed by trypan blue dye exclusion, appeared unchanged. Interestingly, the degree of inhibition was much more pronounced in the presence of autologous canine serum than in fetal calf serum; this would suggest a serum-spectfic sensitization.

DEVELOPMENT AND APPLICATION OF HEMOPOIETIC CELL CLONING METHODS AS GENERAL TOXICOLOGICAL ASSAYS

T. M. Seed, G. T. Chubb, ${ }^{1}$ L. V. Kaspar, B. J. Wright, ${ }^{2}$ and R. Ulrich ${ }^{3}$

This part of the Cellular Indicators program presently deals with an in vitro culture method in soft agar in which the proliferating and differentiating growth patterns of stem cells can be directly assessed following in vitro or in vivo exposure to the toxicant. With appropriate research and development, these in vitro assays might provide a rapid and sensitive assessment of hemotoxic potential. In essence, the key regulator cell of the hemopoietic system, i.e., the stem cell, would be used as an in vitro biological dosimeter to assess directly the hemotoxic (perhaps mutagenic) effects of ionizing radiation, benzene, and fluldized bed coal combustion effluents and thereby to reduce the need for extensive animal testing for hematological end points.

Time-dependent features of granulopolesis in soft agar cultures have been studied over the past year. A degree of synchrony is displayed by cloned granulocytic cells in the terminal stages of colony development, and an incomplete maturation of granulopoletic cells is observed. In addition, we have successfully developed new ultrastructural methods that will enable topographical and spatial, as well as cytological, analyses of in vitro cloned cells.

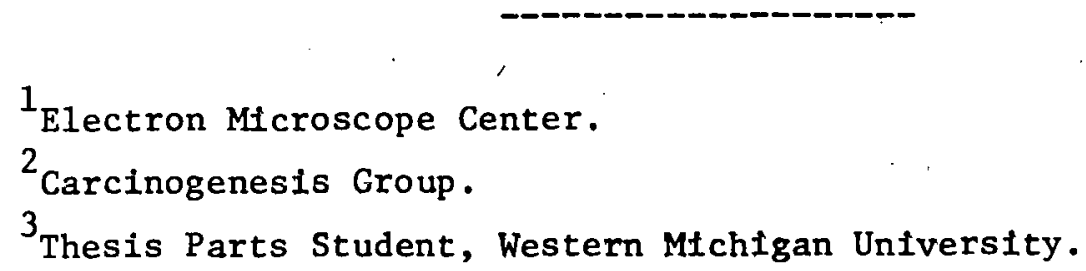


Preliminary work to automate the colony counting part of the cloning assay using a modified image particle analyzer equipped with a TV camera and low power, wide angle lens to image and count colonies suggests that the system will enable us to evaluate, collate, and effectively store data concerning hemopoietic colony size, shape, and distribution.

ATTEMPTS AT IMMUNOGICAL IDENTIFICATION OF CANINE PLURIPOTENTIAL HEMOPOIETIC STEM CELLS

D. M. Buchholz and T. M. Seed

The intent of this study is to assess the functional change in pluripotential hemopoietic stem cells of dogs as a consequence of exposure to hemotoxic physicochemical agents, and to relate causally the induced cellular dysfunction to subsequent hemopathologies, e.g., aplastic anemia and leukemia.

An immunological approach is employed in attempting to identify both murine and canine pluripotential stem cells. It has previously been demonstrated in rodents that antisera directed to brain tissue identify stem cells (CFU-s) as measured in the Till and McCulloch spleen colony assay. Specificity of the antisera for the plurtpotential stem cells has been verified by the inability to inhibit in vitro soft agar colony formation by the conmitted stem cells (CFU-C). We used the Till and McCulloch assay together with the in vitro soft agar assay. to differentiate between the pluripotential (CFU-S) and the committed (CFU-C) stem cells. Antisera were prepared to both murine and canine brain tissue. Bone marrow cells removed from mouse femurs were treated in vitro as indicated in Table 3.1 and then injected into irradiated recipient mice for assay of spleen colony formation. Table 3.1 demonstrates the inability of the antisera-treated murine marrow cells to form splenic colonies. This inability demonstrates that the pluripotential stem cells (CFU-s) have been inhibited, and thus identified, by the antisera.

Table 3.1: Effect of Anti-Brain Sera on Mouse Spleen Colony Formation

Treatment of Marrow Cel1s ${ }^{a} \quad$ CFU $/ 10^{5}$ N.C.

Hanks' balanced salt solution $\quad 41.67$

Normal rabbit serum $+C^{\prime} \quad 36.02$

Rabbit anti-mouse brain serum $+C^{\prime} \quad 4.57$

Rabbit anti-dog brain serum $+C^{\prime} \quad 6.57$

a Treatment consisted of a 45 minute incubation at $0^{\circ} \mathrm{C}$ with the designated serum followed by a 30 minute incubation with guinea pig complement $\left(C^{\prime}\right)$ at room temperature.

${ }^{\mathrm{b}}$ Colony forming units per $10^{5}$ nucleated cells. 
Treatment of mouse bone marrow cells with efther rabbit anti-mouse brain or rabbit anti-dog brain antiserum significantly decreased spleen colony formation (Table 3.1), either by suppressing proliferation of the stem cells or by inactivating the stem cells by cytolysis. By indirect immunofluorescence the fully absorbed antisera (1.e.,against liver, spleen, thymus, and peripheral blood) spectifically label a small lymphocyte-like subpopulation of both dog and mouse bune marrow cells. Our preliminary in vitro evidence using the soft agar assay indicates that the antisera specifically identify only pluripotential, not committed, stem cells. Further morphological identification of these immunologically identified cells will be carried out by electron microscopy employing ferritin-labeled antibody.

SPECTRAL ANALYSIS OF LUMINESCENCE FROM BIOLOGICAL STAINS USING THE SCANNING ELECTRON MICROSCOPE

D. G. Oldfield, ${ }^{1}$ G. T. Chubb, and T. M. Seed

The purpose of this study is to develop apparatus and techniques for obtaining luminescence of several biological stains (dyes) at high magnification using the scanning electron microscope (SEM). A microanalytical method of this type would be a distinct improvement over existing methods since it would give simultaneously both the high spatial resolution afforded by the SEM and the high chemical resolution obtainable from luminescence spectra of known dye molecules. When the dye molecule used is such that it (or its conjugate) binds preferentially to one particular cell component (e.g., membrane glycoprotein, cytoplasmic carrier protein, chromosomal nucleoprotein, etc.), the method would be expected to provide a more accurate and more sensitive in vitro localization and quantitation of cell components than is feasible using conventional techniques. Thus, subtle cellular effects of toxicologic, mutagenic, or tumorigenic agents might be detected earlier and/or more sensitively than by methods currently in use.

The apparatus used has been described previously (0ldfield; D. G., et al., ANL-75-30, 1974, p. 98). For initial checks on the system, two types of size-graded fine sulfide particles (one exhibiting red fluorescence, the other exhibiting green fluorescence under optical excitation) were used. Also used in the initial work were the fluors anthracene, dimethylphenyloxazolyl benzene, and divinylbenzene-impregnated polystyrene spheres and nine different biological stains.

Luminescence spectra have been obtained. from the above luminors in two different ways: (1) by setting the interference filter to several different wavelengths while the specimen field is being scanned, holding each wavelength setting for 20 seconds; and (2) by holding a single, constant wavelength setting. while the entire specimen field is scanned. The first method is more rapid and can be particularly useful at high magnification when inhomogeneities

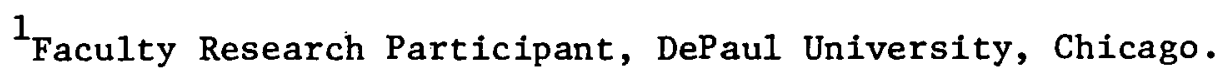


in specimen detail are expected to be negligible. The second method is more useful when only a few wavelengths are to be examined or when it is desirable to obtain color prints of the luminescence.

Our results to date indicate that appreciable differences in luminescence intensity exist between different luminors (judged on the basis of weight of luminor used). For example, the acridine orange specimen emitted relatively weakly while the fluorescein specimen emitted relatively strongly. The spectra obtained were in reasonable agreement with expectations from optically induced fluorescence as judged by simple qualitative evaluations of the optical densities obtained. The next problem to be addressed is that of detection sensitivity for dyes bound in cells. 
4. NEUTRON AND GAMMA-RAY TOXICITY STUDIES

\section{INTRODUCTION}

John F. Thomson

The Neutron and Gamma-Ray Toxicity Program, which has as its objective the study of the late effects of low levels of ionizing radiation in experimental animals, consists of two subtasks, one concerned with observation of animals for their entire life-span and subsequent establishment of the causes of death, the other focusing on specific pathophysiologic effects of ionizing radiation on the structure and function of the cardiovascular system.

Both subtasks employ the same radiation sources $\left({ }^{60}\right.$ Co gamma rays and fission neutrons from the JANUS reactor), the same species of animals (Mus musculus, the B6CF hybrid of the C57BL6 and BALB/c strains of the 1aboratory mouse; and Peromyscus leucopus, the white-footed mouse, descended from wild animals trapped on the Argonne site), and the same logistic support for dosimetry, dața processing, and animal maintenance.

The radiation facilities also support numerous other programs in the Division; special mention should be made of $\mathrm{Dr}$. Douglas Grahn's studies on Genetic Effects of High-LET Radiation (reported in Section 5, following), which seek to establish dose-response curves for several genetic end points over the same dose ranges for which we are measuring somatic effects.

At the present time, exposures of Mus musculus have been completed to provide dose-response curves, for all causes of death and for specific causes, under the following conditions:

1) Single neutron exposures 5 to $240 \mathrm{rads}$.

2). Single gamma-ray exposures, 90 to $788 \mathrm{rads}$.

3) Fractionated neutron exposures ( 24 fractions given at weekly intervals), 10 to $320 \mathrm{rads}$.

4) Fractionated gamma exposures, 206 to $5110 \mathrm{rads}$.

5) Weekly neutron exposures for duration of 1 ife, $0.67,1.67$, and 2.67 rads per fraction.

6) Weekly duration of 1 ife gamma exposures, 7, 17.4, and 31.9 rads per fraction . 
We have also completed exposures of Peromyscus leucopus to single doses

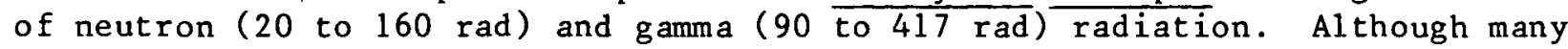
Mus and Peromyscus are still alive, a number of conclusions can be drawn, which are not likely to change qualitatively, concerning the comparative effects of neutron and gamma radiation on 1 ife shortening; the se are discussed in the first report.

The second report in the series deals with the acute toxicity of neutron and gamma radiation to Mus and Peromyscus. The latter is more resistant than Mus to gamma rays, but more sensitive to neutrons.

Then follows a status report on the effects of neutrons and gamma rays on the cardiovascular system. Previous studies of radiation effects on coronary arteries have been supplemented by electron-microscopic examination of renal arteries, which show a similar spectrum of degenerative changes.

\section{REGULAR STAFF}

Allen, Katherine A. (Scientific Associate)

Christian, Emily J. B. (Scientific Associate)

Devine, Rosemarie L. (Scientific Associate)

Holmblad, Gordon L. (Scientific Associate)

Hulesch, Jane L. (Scientific Assistant)

Johnson, Emil G., Jr. (Eng ineering Assistant)

Jordan, Donn L. (Scientific Associate)

Lombard, Louise S. (Veterinary Pathologist)

Ludeman, V. Ann (Scientific Assistant)

Miller, Marietta (Scientific Assoçiate)

Sallese, Anthony R. (Scientific Assistant)

Staffeldt, Everett F. (Scientific Associate)

Stearner, S. Phyllio (Biologist)

Themson, John F. (Geniü Biulug1se)

Trier, Joseph E. (Engineering Assistant)

Williamson, Frank S. (Physicist)

$1_{\text {Terminated during } 1978 .}$ 


\section{STUDIES OF LIFE SHORTENING}

J. F. Thomson, F. S. Williamson, L. S. Lombard, K. H. Allen,

J. L. Hulesch, V. A. Ludeman, A. R. Sallese, and E. F. Staffeldt

Since the previous report (ANL-78-90), emphasis has been directed toward completion of various exposure series then under way; no new major experiments have been initiated.

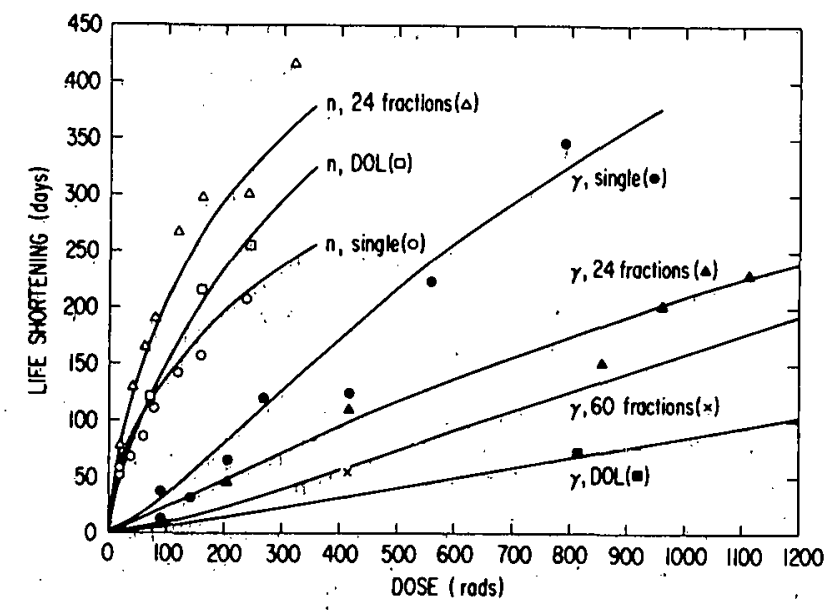

Fig. 4.1. Dose-response curves for male mice given single, fractionated, or duration-of-life (DOL) exposures of neutron or gamma radiation. Animals were 110 days old when irradiation was begun.

Figure 4.1 shows the life. shortening produced in male $\mathrm{B} 6 \mathrm{CF}$ mice by neutrons and gama radiation in various exposure modes ( ing fewer data points, are available for female mice). The graph does not show the data for 1 ife shortening produced by exposure to fractionated gamma radiation at total doses greater than 1110 rads.

From these data a number of conclusions can be drawn, despite the fact that appreciable numbers of mice are still alive at the lowest dose levels: 
1) Fractionation of gamma radiation results in a longer mean survival time than that observed when the same total dose is given in a single exposure; and the more extensively the dose is fractionated, the less effective is the total dose.

2) Fractionation of neutron radiation, on the other hand, produces an augmentation of life shortening that is statistically significant at high doses ( $>100 \mathrm{rads}$ ); at lower doses, although the evidence for augmentation may not be convincing, there is at least full additivity.

3) Females are more sensitive than males to neutron but not to gamma radiation (data not shown).

4) Less life shortening is observed in animals exposed to single doses of neutron or gamma radiaton at 194 and 278 days of age than at 110 days, the age at which the animals were exposed in most of the experiments (data nnt shown).

5) The single-dose RBE for JANUS fission neutrons relative to gamma rays varies inversely with the square root of the neutron dose over a range of 20 to 240 rads; projections from the present data suggest that at 1 rad the RBE will be about 40 .

\section{ACUTE RADIATION TOXICITY}

J. F. Thomson, F. S. Williamson, J. L. Hulesch, G. L. Holmblad,

E. G. Johnson, Jr.; and J. E. Trier

Since the first exposures of mice in the JANUS program were begun 8 years ago, we have observed a slight but perceptible increase in the life-spans of control animals, both males and females. We thought it desirable to remeasure the acute radiation toxicity of the $\mathrm{B} 6 \mathrm{CF}$ mice, not only for comparison with the 1971 determination (Ainsworth, E. J., et al., ANL-7770, 1970, p. 32), but also for anticipated comparison with mice to be used in future experiments involving rederivation of the breeder strains and maintenance of the mice in isolators. In addition, we have measured the 30 -day $L_{50}$ 's for Poromyseus leucopus.

The data are shown in Table 4.1. The values calculated for the 30-day $\mathrm{LD}_{50}$ 's in the present experiment do not differ significantly from those reported by Ainsworth et al. (367 and 905 rads for neutron and gamma radiation, respectively) when the Ainsworth et al. values are corrected in 1 ight of dosimetric refinements. For $P$. leucopus we have confirmed their somewhat greater resistance than Mus to gamma rays, so that the RBE for acute toxicity is about $35 \%$ higher.

Nore also that the slopes of both probit-dose lines for $P$. leucopus are on 1 y $40 \%$ as steep as the corresponding slopes for Mus. This observation reflects the considerably greater heterogeneity of the Peromyscus. 
Table 4.1. Acute Toxicity of Neutrons and Gamma Rays

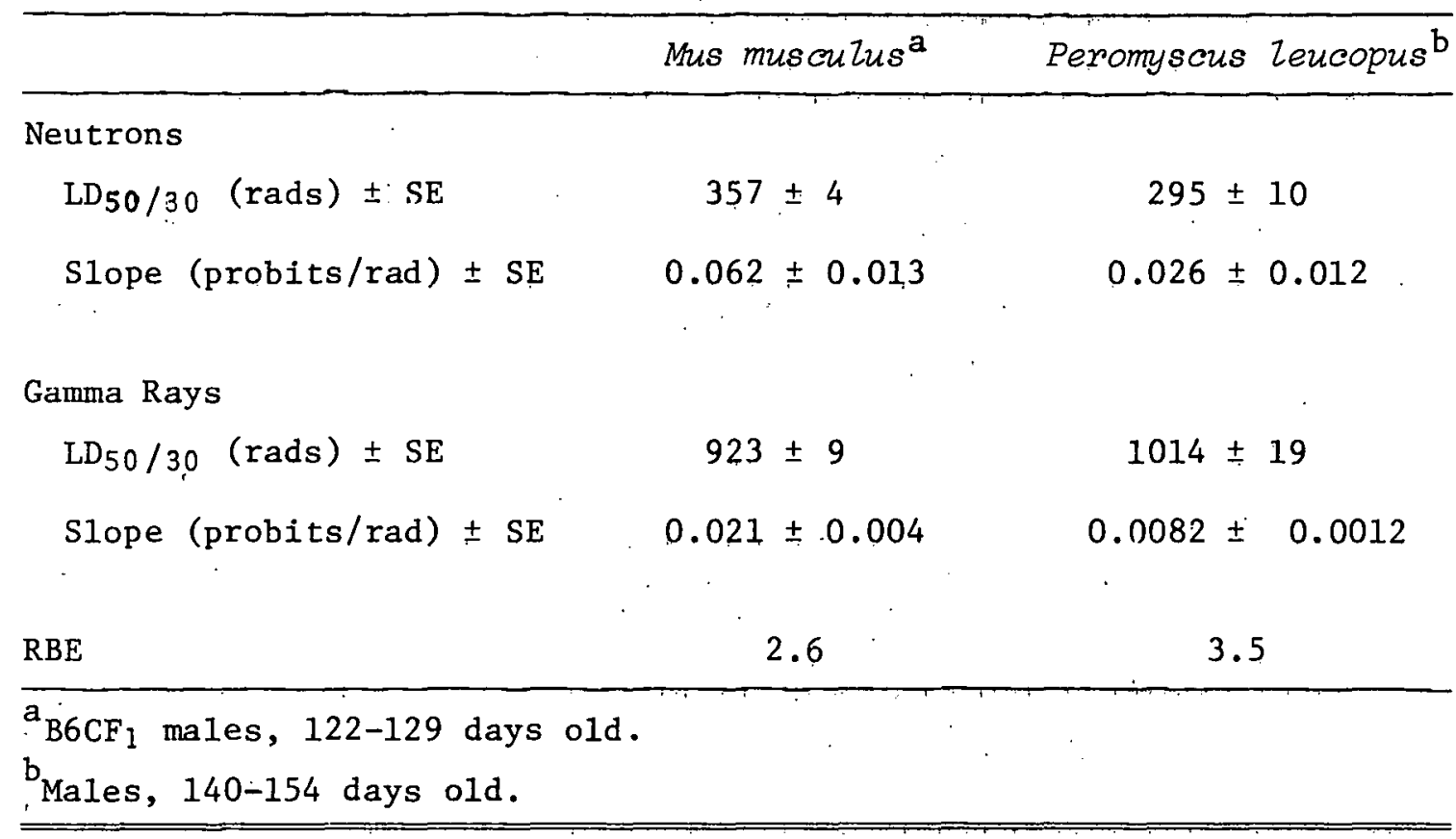

CARDIOVASCULAR EFFECTS OF EXTERNAL RADIATIONS

S. P. Sţearner, E. J. B.' Christian, R. L. Devine, R. S. Skyer, ${ }^{1}$ and T. Riss ${ }^{2}$

Long-term cardiovascular changes were studied in the irradiated $\mathrm{B} 6 \mathrm{CF}$ mouse. Total-body radiation treatment included a single dose of 788 gamma rads or 80 or 240 neutron rads, or a fractionated dose ( 24 weekly fractions) of 823 or 2690 gamma rads or 20,80 , or 240 neutron rads. Comparisons of structural and functional changes continue to be emphasized. U1trastructural observations (transmission electron microscopy) through 24 months revealed degenerative changes in the myocardium as well as in coronary arteries, aorta, and blood vessels of other tissues. Degeneration was generally more extensive after fractionated neutron irradiation than after comparable single doses. In

${ }^{1}$ Summer 1978 participant in the Undergraduate Honors Research Participation Program, Rochester Institute of Technology.

${ }^{2}$ Participant in the 1978 Summer Research Institute in Biology, Illinois State University. 
contrast, fractionation of the gamma dose reduced the resultant damage.

Damage to myofibers and capillaries of the heart was most severe at 30 to 90 days after a single exposure, but persisted above control levels throughout the 24-month observation period... Matrix accumulations (proteoglycans) and fibrosis were more prominent in neutron- than in gamma-treated animals; these conditions correspond to similar reactions following neutron doses in the therapy range reported in the clinical literature.

Degenerative changes in coronary arteries became prominent only after 6 to 12 months; at 18 and 24 months there was persistent and increased damage, especially after fractionated neutron treatment. Most severe damage was to medial smooth muscle, whereas endothelium appeared largely intact at later times. Evaluation of degenerative changes in renal arteries, as yet incomplete, indicates they are similar to those in coronary arteries, but are somewhat less severe in relation to radiaton treatment. Noteworthy are clusters of abnormal smooth muscle cells that may represent abortive attempts at regeneration or remnants of medial cells displaced to the adventitia. The augmented effect of fractionated neutron exposures has relevance to the clinical use of fractionated high-LET radiations in the radiotherapy of tumors in humans.

Evaluations of 1 ate changes in blood pressure are of interest in view of our observations of late degenerative changes in arterial smooth muscle and elastica. Blood pressure measurements made to date with a pressure cuff developed (in collaboration with G. Svih1a) for use on the mouse hind limb revealed no consistent change in mean systolic pressure in relation to age or radiation treatment. After irradiation, however, animals had higher values, and a fall in blood pressure was correlated with the near-terminal condition.

In conclusion, studies of structural damage in irradiated mouse arteries revealed unexpected sensitivity, especially to fractionated doses of fission neutrons. The greater the degree of coronary artery degeneration the greater was the extent of myocardial damage. Fractionation of the exposure augmented neutron dose effectiveness, whereas gamma-ray fractionations reduced the resultant damage. 
5. GENETIC EFFECTS OF HIGH LET RADIATIONS

\section{INTRODUCTION}

Douglas Grahn

This series of studies was motivated by the observation that there were no experimental data upon which to make judgments about the potential genetic hazards of gonadal burdens of plutonium or the other transuranic elements. Genetic studies have been performed at two levels of ${ }^{239} \mathrm{Pu}$, injected as single doses intravenously as the citrate into male mice. Dominant lethal mutation rate, chromosome translocation rate in spermatogonial cells, and the frequency of abnormal sperm hàve been measured in a comparative analysis of the effects of internally deposited plutonium alpha particles, and external radiation from fission neutrons and Co gamma rays. These experiments are near completion and the results indicate that neutrons and alpha particles have approximately the same mutagenicity. They both have a greater mutagenicity than gamma rays, but the ratio of effectiveness depends upon germ cell stage, dose rate, total dose, and pattern of exposure. The minimum ratio of neutrons or alpha particles over gamma rays is about 5 , for lethals induced in mature germ cells.by single exposures, and the maximum effectiveness ratio is about 40 , for the induction of reciprocal chromosome translocations following protracted low intensity exposures.

This effort led to a detailed study of these same genetic end points following extremely low single doses of neutrons ( 1 to $10 \mathrm{rads}$ ) as it became apparent that reliable dose-response data were not available for the conventional external radiation sources at low doses. For some end points significant responses are seen at doses as low as 1 to 5 rads. The low dose issue also arose as a result of two additional sets of observations: the reexamination of selected human data on low dose neutron leukemogenesis and the recurring experimental observations on mice that low neutron doses might have an unexpectedly high potential for inducing biological damage.

In the past year, we have also performed an initial study with ${ }^{241} \mathrm{Am}$ to determine whether this element would show the same pattern of gonadal uptake and distribution as ${ }^{239} \mathrm{Pu}$, and whether deposition of americium would be associated with the same level of genetic damage per unit of injected dose. 
REGULAR STAFF

Frystak, Barbara H. (Scientific Assistant)

Grahn, Douglas (Senior Biologist)

TEMPORARY STAFF DURING 1978

Lee, Chung Hee (Research Associate) 
DOMINANT LETHAL MUTATIONS AND CHROMOSOME ABERRATIONS INDUCED IN MALE MICE BY INCORPORATED ${ }^{239} \mathrm{PU}$ AND EXTERNAL FISSION NEUTRON AND GAMMA IRRADIATION

D. Grahn, B. H. Frystak, C. H. Lee, J. J. Russe11, 1 and A. Lindenbaum ${ }^{2}$

The genetic effects of gonadal burdens of ${ }^{239} \mathrm{Pu}$ following intravenous injection of plutonium citrate at levels of either 5 or $10 \mu \mathrm{Ci} / \mathrm{kg}$ have been compared over the reproductive $\frac{1}{6} \mathrm{f}$ fetime of male $\mathrm{B} 6 \mathrm{CF}$ mice with the effects of external whole-body ${ }^{6}$ Co gamma ray or fission neutron irradiation. Gamma irradiations were given as single, weekly, or continuous (22 hours/day) exposures and peutron irradiations were given as single or weekly exposures. Testicular ${ }^{239} \mathrm{Pu}$ burdens remain unchanged at 0.05 percent of the injected dose for over 400 days and localize in the interstitial tissue and along the basement membrane of the spermatogenic tubules.

The dominant lethal mutaton rate with alpha particle irradiation is $0.0064 \pm 0.0011$ mutations/gamete/rad. The average rate for postmeiotic germ cells is similar to this following single and weekly doses of neutrons. These rates are 5-fold greater than those following single or weekly gamma irradiation and more than 10-fold greater than the rate following continuous irradiation.

For the induction of reciprocal chromosome translocations, weekly neutron exposures are more effective than the same dose given as a single exposure, above $\sim 20 \mathrm{rads}$, and the dose response is 1 inear, compared to the nonlinear response after a single dose of neutrons. The translocation rate following continuous gamma irradiation is $0.175 \pm 0.017\left(x 10^{-4}\right) / \mathrm{rad}$, which is about $1 / 10$ th the effect of single gamma irradiation and $1 / 40$ th the effect of weekly neutron exposures. The translocation yield shows no response to accumulating dose from plutonium alpha particles. The responses were above that seen following continuous gamma irradiation and below the response to neutrons. However, the average frequency of translocations is related to the measured gonadal burden. This finding that plutonium-induced genetic damage to the stem cell population does not follow a linear, cumulative dose-response function may be due to spermatogonial cell killing, to relocation of the plutonium away from the basement membrane, to the possible establishment of spermatogonial clones in radiation-free regions of the tubule, or to some combination of these factors.

There are dose and dose-rate dependent relationships for effects related to damage induced in spermatogonia just prior to meiosis and in all meiotic and postmeiotic cell stages; however, total dose accumulations are 1 imited to the 4 to 6 week period of gamete development and maturation. The evidence supports the position that the majority of the dominant lethal mutations transmitted by males carrying plutonium burdens are induced in the meiotic and postmeiotic cell stages, not in the stem cell population. This is an important discrimination with regard to considerations of the potential genetic

1 Biomedical Effects of Energy Transmission Group.

2 Toxicity of Energy Storage Systems Group. 
risks that might be associated with long-term body burdens of plutonium and the other transuranic elements, since it establishes that the mutagenicity of plutonium is about equal to that of high LET fission neutrons.

\section{GENETIC EFFECTS OF LOW SINGLE DOSES OF NEUTRONS AND GAMMA RAYS}

D. Grahn, B. H. Frystak, and C. H. Lee

This single dose experiment compares neutron dose levels of $1,2.5,5$, 10,20 , and 40 rads with a 1 imited gamma ray series of $22.5,45$, and 145 rads in 100-day-old B6CF, male mice. Sampling statistics were established on the expectation of detecting significant $(P \sim 0.05)$ changes at 2.5 to 5 rads and above so that the response to $1 \mathrm{rad}$ could be judged for its conformance to predictions based upon the data at the higher doses.

There is evidence for a slight, and sometimes significant, excess of response to the neutron doses of 1 to 5 rads when compared to the expectations linearly projected from the higher doses. This excess response is seen for the average number of live fetuses per pregnant female, the incidence of preimplantation lethality, and the incidence of postimplantation loss. It is suggested in the data for numbers of chromosome translocations, but it is not seen in the data for abnormal sperm. At most, the excess effect over expectation is by a factor of two. These data are summarized in Table 5.1 and Figures 5.1 and 5.2 .

\begin{tabular}{|c|c|c|c|c|c|c|}
\hline $\begin{array}{l}\text { Dose Leve1 } \\
\text { (rade) }\end{array}$ & $\begin{array}{l}\text { Live Fctugco } \\
\text { Per Pregaant } \\
\text { Female }\end{array}$ & $\frac{\text { Dom. Lethal }}{\text { Pre1mp. }}$ & $\frac{\text { Race/Gamete }}{\text { Postimp. }}$ & 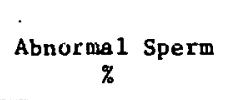 & Cells & $\begin{array}{l}\text { with Translocation } \\
\%\end{array}$ \\
\hline Control & $7.59 \pm 0.15(141)$ & $.077 \pm .008$ & $.047 \pm .006$ & $2.37 \pm .18$ & & $0.021 \pm .021$ \\
\hline \multicolumn{7}{|l|}{ Neutrons } \\
\hline 1 & $7.45(242)$ & $.071(.60)^{c}$ & $.063(.09)^{c}$ & $2.69(.29)^{c}$ & & $0.068(.35)^{r}$ \\
\hline 2.5 & $7.22(172)$ & . $.099^{\star}$ & $.069^{\star}$ & $3.32^{\star \star}$ & & $0.265^{\star \star}$ \\
\hline 5 & $7.11(133)$ & $.104^{*}$ & $.073^{\star}$ & $4.46^{\star \star}$ & .. & $0.373^{\star \star}$ \\
\hline 10 & $7.26(66)$ & $.089(.40)^{c}$ & $.092^{\star \star}$ & $7.17^{\star \star}$ & & $1.06^{\star \star}$ \\
\hline 20 & $6.64(66)^{\star}$ & $.132^{\star \star}$ & $.152^{\star \star}$ & $12.56^{\star \star}$ & & $0.60^{\star \star}$ \\
\hline 40 & $5.43(58)^{\star \star}$ & $.171^{\star \star}$ & $.259^{\star \star}$ & $2,4.92^{\star \star}$ & & $1.90^{\star \star}$ \\
\hline$\gamma$-Rays & & & & & & \\
\hline 22.5 & $7.29(136)$ & $.095(.14)^{c}$ & $.068^{\star}$ & $3.71^{\star \star}$ & & $0.216^{\star *}$ \\
\hline 45 & $7.35(66)$ & $.104(.08)^{\mathrm{c}}$ & $.074^{\star}$ & $6.88^{\star \star}$ & & $0.429^{\star \star}$ \\
\hline 145 & $6.44(59)^{\star}$ & $.106(.07)^{c}$ & $.202^{\star \star}$ & $16.82^{\star \star}$ & & $1.38^{* \star}$ \\
\hline
\end{tabular}

Mnle B6CF 1 mice subjected to whole body exposure at 100-120 days of age. Dominant lethal mutations (preimplantation and postimplantation) and related data from the first five weeks of mating after exposure; abnormal sperm measured at weeks 5 and 6 ; translocations scored at weeks 5 to 7 .

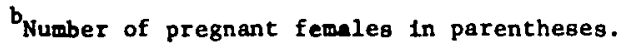

${ }^{c}$ Estimated $P$ value from $x^{2}$ test; one degree of freedom for control vs. dose. ${ }^{*} P \leq .05$. ${ }^{\star *} P \leq .01$. 

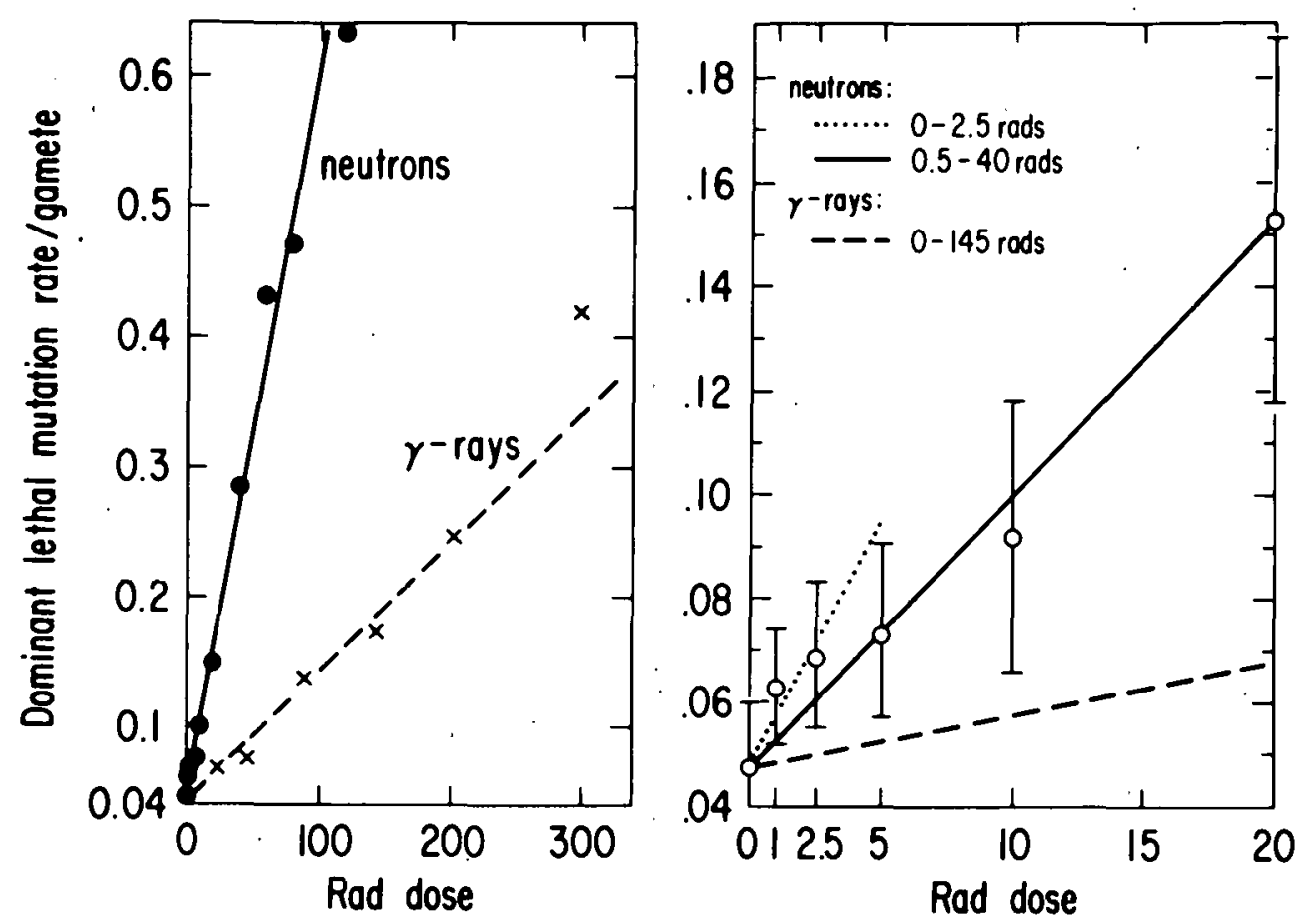

Fig. 5.1. Postimplantation dominant lethal mutation rate summed over the first 5 weeks after single exposure. Rates are based upon fetal survival and expressed as :

$-\ln \left(\frac{\text { live fetuses }}{\text { total implants }}\right)$.

On the right-hand panel, mutation rate estimates for the identified portions of the data were $0.0096 \pm 0.0023$

(neutrons, 0-2.5 rads, three dose levels); $0.0052 \pm$

0.0001 (neutrons, $0.5-40 \mathrm{rads}$, five dose levels); $0.0010 \pm$

0.0001 (gamma rays, 0-145 rads, four dose levels).

The overall data from this and past experiments indicate that the postimplantation dominant lethal mutation rate rises linearly for both radiation qualities, but a detailed look at the lowest neutron dose levels shows the provocative nonlinear component (Figure 5.1, right). The increased respuise at 1 and 2.5 rads is about 2-fold above a simple linear fit but neither increase over linear expectation was signficant. This nonlinearity is also evident in gamma ray data at 22.5 and 45 rads (data not shown). Complementary findings are also seen in the translocation data, in which the low doses of neutrons (up to $10 \mathrm{rads}$ ) appear to show an excess response.

The low dose data on abnormal sperm morphology (Figure 5.2) show interesting differences in response related to time of measurement. The pooled data for weeks 5 and 6 ( 35 and 42 days postexposure, respectively) display a generally good linear fit, and significant effects at all doses except $1 \mathrm{rad}$. However, this linear curve is composed of two extremely nonlinear components with the greater low dose effect at 5 weeks, and high dose effect at 6 weeks. 


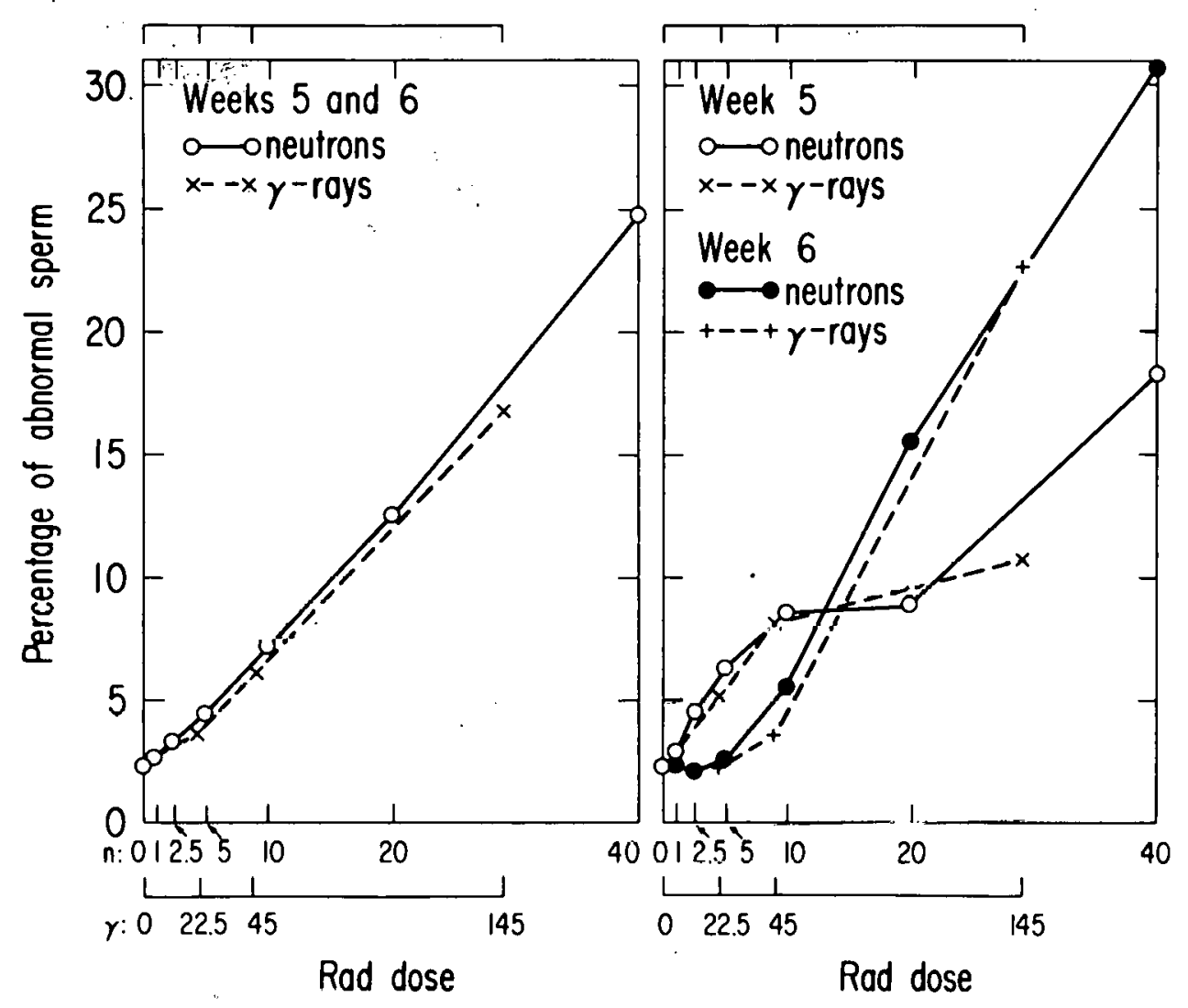

Fig. 5.2. Percentage nf abnormal opcrm saüpled from preparations made from both epididymides. The left panel pools the data from the fifth and sixth weeks (measured on the 35 th and 42 nd days postexposure) and the right panel presents the two weeks separately. Estimates are based upon 1800 to 3600 sperm per sampling period (600/male).

Interpretation of the $1 \mathrm{ag}$ in response at the higher doses is difficult because the cell stage at risk is not entirely clear.

Finally, the data for dominant lethal mutations were studied on a dose by week basis with the hope that the low dose excess response might be attributed to a specific germ cell maturation stage interacting with dose. However, at ,the $1,2.5$, and 5 rad doses, the difference between irradiated and control was apparently distributed randomly across all 5 weeks, although statistically significant differences did occur for weeks 1, 3, and 5 (mature sperm, early spermatids, and primary spermatocytes). The possibility exists that there is significantly less germ cell killing at these extremely low doses, thus permitting more induced and spontaneous lethals or lethal equivalents to become involved in conception and development to the blastocyst stage. 
GENETIC EFFECTS OF AMERICIUM-241

D. Grahn, B. H. Frystak, J. J. Russell, ${ }^{1}$ C. H. Lee, and

A. Lindenbaum ${ }^{2}$

Americium may have a slightly different metabolic hehavior than the other transuranic elements (ICRP Publication 19, 1972). To determine whether this difference is correlated with different genetic response in the testis, we injtiated a preliminary test using a single injected dose of $10 \mu \mathrm{Ci} / \mathrm{kg}$ of $24 \mathrm{Am}$ given intravenously to 100 -day-old $\mathrm{B}^{2} \mathrm{CF}{ }_{1}$ mice. Thy level of gonadal retention was on 1 y $50 \%$ to $60 \%$ of that seen for ${ }^{2} 39 \mathrm{Pu}$. Retention through the first 100 days after injection remained unchanged, as for plutonium, and preliminary autoradiography indicates that the microdistribution is similar to that seen for plutonium. The estimated whole gonad dose for the measured burden of about 350 picocuries per gram of gonadal tissue...was 0.092 $\mathrm{rad} /$ day, slightly above the dose delivered by the ${ }^{239} \mathrm{Pu}$ dose of $5 \mu \mathrm{Ci} / \mathrm{kg}$. The genetic responses were below those expected. Frequencies of abnormal sperm between 50 and 100 days after injection were $2.56 \%$ for the control and $2.69 \%$ for irradiated mice, compared to a value of about $4.3 \%$ expected on the basis of the plutonium data. The observed mutation rate during a 10-week dominant lethal series performed between 125 and 195 days after injection was 0.0097 lethals/gamete compared to the 0.0165 anticipated. In fact, the dominant lethal response to americium was not statistically significant $(P=0.3)$. Translocation frequency at 60 days was no more than about $0.2 \%$, when $0.3 \%$ would be expected, although this difference is clearly not significant in a sample of only 1000 metaphase plates. Testis weight loss may be as expected, or even slightly in excess of expectation, but again sampling was limited. The remaining mice in this initial study were sacrificed at 230 days and the results of the various end points are conflicting. The frequency of abnormal sperm was now significatly higher in the americium group than in the controls ( $5.01 \%$ vs. $3.09 \%$ ), while the frequency of translocations had fallen to zero in a sample of 1000 scored metaphases.

Autoradiographic studies are still incomplete, and the possibility that americium might be more mobile than plutonium in the interstitial tissues will be further evaluated.

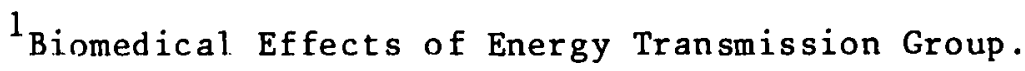

${ }^{2}$ Toxicity of Energy Storage Systems Group. 
THIS PAGE

WAS INTENTIONALLY

LEFT BLANK 
6. THERAPY OF POISONING BY RADIOACTIVE AND NONRADIOACTIVE METALS

\section{INTRODUCTION}

Maryka H. Bhattacharyya

The overall objective of this program is the development of methods for decorporation of toxic metals encountered as a result of developing energy technologies. Part of the research effort is directed toward the transuranic actinide plutonium because of its high radiotoxicity and the fact that plutonium, in many respects, is prototypical of other actinides and polyvalent heavy metals. In addition, we are investigating other toxic heavy metals of concern in energy programs. Present work includes: (1) investigation of the absorption, deposition, retention, and excretion of actinide compounds and the influence of alterations in their physicochemical properties on these end points; (2) metabolic and therapeutic studies with a nonradioactive toxic metal, lead, with particular emphasts on its retention and decorporation in the young; (3) selection and evaluation of potentially useful agents for therapeutic decorporation of toxic metals based on information derived from the above research. For economy and statistical validity, the mouse is the principal species for whole body studies. For extrapolation of results toward man, other species such as the dog are also being used.

Significant advances in our research program over the past year are described in the following sections. To summarize some of the highlights from recently obtained results:

1) We have completed a set of carefully planned experiments with beagles designed to aid in the development of an optlmal therapy protocol with diethylenetriaminepentaacetic acid (DTPA) for decorporation of plutonium (and probably americium) from man. It was found that (a) use of five daily injections at $0.18 \mathrm{mmole} / \mathrm{kg}$ instead of $0.036 \mathrm{mmole} / \mathrm{kg}$, the clinically accepted dose for man, initiated soon after exposure to plutonium, significantly improved removal of plutonfum; and (b) following these first five doses, daily treatment was not signiflcantly better than twice weekly treatment and it appears that intramuscular administration can replace intravenous administration.

2) A model for simulating wound exposure to plutonium has been established in the mouse. This model will enable us to carry out therapeutic removal studies using one of the two exposure modes relevant to the occupationally exposed population (the other mode being inhalation). 
3) A collaborative study with D. Grahn (reported in Section 5) of the genetic consequences of high IET irradiation of gonads was extended to include $241_{\text {Am. }}$.

4) In a collaborative study with R. P. Larsen (Radiological and Environmental Research Division), the gastrointestinal absorption of $\mathrm{Pu}(\mathrm{IV})$ in mice measured at the maximum permissible concentration (MPC) for plutonium in drinking water was found to be (a) the same as that for $\mathrm{Pu}$ (IV) and (b) 50 to 100 times the value used by the International Commission for Radiological Protection to set the MPC for plutonium in drinking water. These results bear the important implication that the MPC for plutonium in drinking water may need to be lowered.

REGULAR STAFF

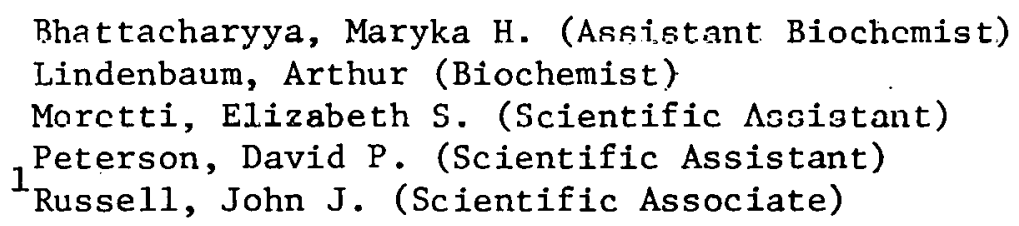

TEMPORARY STAFF DURING 1978

Sorensen, Elsie M. (Postdoctoral Appointee)

\footnotetext{
${ }^{1}$ Now in Environmental Physiology and Biomedical Effects of Energy Transmission Groups.
} 
DEVELOPMENT OF AN OPTIMAL DTPA THERAPY PROTOCOL FOR DECORPORATION OF. ACT INIDES

A. Lindenbaum, E. S. Moretti, and J. J. Russe11

Studies were continued to provide data needed for the development of an optimal protocol for DTPA treatment of human workers accidentally exposed to actinide radioelements such as plutonium. Beagles previously injected intravenously with monomeric ${ }^{239} \mathrm{Pu}$-citrate were treated with DTPA according to various regimens for 12 weeks in order to determine the effects of (1) initiating therapy using five daily intravenous DTPA injections at $0.18 \mathrm{mmole} / \mathrm{kg}$ (2) administering DTPA daily (6 days/week) vs. twice weekly, (3) starting treatment at 1 hour vs. 6 hours, and (4). using an intramuscular rather than intravenous mode of DTPA administration. Initiating daily treatment at a dose of $0.18 \mathrm{mmole} / \mathrm{kg}$ for 5 days before switching to $0.036 \mathrm{mmole} / \mathrm{kg}$ was clearly superior to the daily regimen using $0.036 \mathrm{mmole} / \mathrm{kg}$ (the currently accepted clinical dose) throughout. Skeletal plutonium levels were reduced to $32 \%$ of pretreatment levels using the higher dose at the start of therapy compared to $48 \%$ for the lower dose regimen. In addition, daily treatment with DTPA was somewhat more effective than twice weekly treatment, as was treatment starting at 1 hour rather than 6 hours. Daily injections via the intramuscular route $(0.036 \mathrm{mmole} / \mathrm{kg})$ appeared to be somewhat better in the removal of plutonium from bone than were daily intravenous injections (these two routes were initiated following five daily intravenous treatments with $0.18 \mathrm{mmole} / \mathrm{kg}$ and were continued to 12 weeks). The most effective regimen tested (five daily DTPA treatments at 0.18 mole/kg starting at 1 hour, followed by daily intramuscular DTPA injections at $0.036 \mathrm{mmole} / \mathrm{kg}$ ) achieved a fourfold reduction in skeletal plutonium levels compared to the level achieved using a standard regimen of twice weekly intravenous treatments at 0.036 moles $/ \mathrm{kg}$ starting at 6 hours.

WOUND EXPOSURE TO PLUTONIUM IN THE MOUSE

M. H. Bhattacharyya and D. P. Peterson

A model for simulating wound exposure to plutonium was established in the mouse utilizing an intramuscular injection into the gastrocnemius of ${ }^{239} \mathrm{Pu}$ in $2 \mathrm{~N} \mathrm{HNO}_{3}$. Analysis of the kinetics of plutonium translocation from the wound Indicated that (1) approximately $5 \%$ of the injected dose deposited in the skeleton and $3.2 \%$ in the liver by 24 hours, and (2) translocation of plutonium from the injection site was quite reproducible. The standard error of the mean for both skeletal and liver plutonium levels was about $8 \%$ of the mean at 24 hours. Analysis of the response to Intravenous DTPA administration indicated that translocation of plutonium from the wound site to liver and skeleton continued even after five daily intravenous injections of DTPA. Measurements of the fecal excretion of plutonium following intravenous DTPA administration thus did not give a good measure of skeletal plutonium levels in. the case of wound exposure. In order for our skeletal:fecal plutonium ratio method (Bhattacharyya, M. H., et al., Health Phys. $34,549,1978$ ) to be useful for the estimation of skeletal plutonium levels, the source of translocating plutonium must be removed prior to or at the start of chelation therapy. 
TESTICULAR PLUTONIUM AND AMERICIUM: RETENTION AND THERAPEUTIC REMOVAL

J. J. Russe11, A. Lindenbaum, and D. Grahn ${ }^{1}$

In order to evaluate further the potential genetic risk of testicular retention of alpha-emitting radionuclides, and the effect of removal therapy with DTPA, an experiment was initiated with $241_{\text {Am-citrate to parallel the }}$ $239 \mathrm{Pu}$-citrate work to date. The genetic data are summarized in Section 5 of this Report. Male $\mathrm{B}_{6 \mathrm{CF}}$ mice received $10 \mu \mathrm{Ci} / \mathrm{kg}$ of ${ }^{241} \mathrm{Am}$-citrate via intravenous injection. Treated animals were administered DTPA $(0.25 \mathrm{mmole} / \mathrm{kg})$ intraperitoneally starting 6 days after actinide injection and continuing twice weekly for a total of 12 weeks. Preliminary findings, through 100 days, of radiochemical analyses for americium and plutonium include: (1) a nearly constant testicular burden of $0.025 \%$ and $0.050 \%$ of the injected dose, respectively; (2) a testis weight loss of $8 \%$ and $18 \%$, respectively; (3) an average testis dose rate of 0.09 and 0.17 rad/day, respectively; and (4) a 4- to 5-fold reduction of testicular burden by DTPA therapy for both actinides. Autoradiographic and cytogenetic studies on the testes are in progress.

\section{GASTROINTESTINAL ABSORPTION OF PLUTONIUM}

M. H. Bhattacharyya, A. Lindenbaum, R. P. Larsen, ${ }^{2}$ R. D. O1dham, ${ }^{2}$ and E. S. Moretti

In studies on the gastrointestinal absorption of plutonium and the effect of oxidation state, plutonium solutions were administered by gavage or ad libitum to mice either in $0.01 \mathrm{M}$ bicarbonate, a concentration very similar to that in drinking water, or in $0.1 \mathrm{M}$ eitrate. The plutuinium cuncenladiun $\left(237 \mathrm{Pu}+{ }^{239} \mathrm{Pu}\right)$ was the same as the maximum permissible concentration (MPC) in drinking water $(5 \mathrm{pci} / \mathrm{ml}, 80 \mathrm{pg} / \mathrm{ml})$. Results obtained are in several ways contrary to those of other investigators: (1) there was no significant difference between the gastrointestinal absorption of $\mathrm{Pu}(\mathrm{VI})$, the form that would be present in drinking water, and that of $\mathrm{Pu}(\mathrm{IV})$, the form that was used almost exclusively in earlier experimental programs; (2) citrate did not markedly enhance the gastrointestinal absorption of plutonium; (3) the absorption factor measured for Pu(IV) $\left(2 \times 10^{-3}\right)$ was about two orders of magnitude higher than the gastrointestinal absorption factor used to set the MPC for soluble plutonfum in drinking water $\left(3 \times 10^{-5}\right)$, indicating that the MPC for plutonium in drinking water may need to be revised.

\footnotetext{
-ーーーーーーーーーーーーーーーーーー

${ }^{1}$ Human Health Effects and Risk Assessments Group.

2 Radiological and Environmental Research Division.
} 
METABOLISM AND DECORPORATION OF LEAD IN THE YOUNG RODENT

E. M. Sorensen, E. S. Moretti, E. Saltz,,$^{1}$. H. Bhattacharyya, and A. Lindenbaum

Groups of young hybrid mice were administered a single intravenous injection of lead citrate containing $10 \mathrm{mg} \mathrm{Pb} / \mathrm{kg}$ labeled with $15 \mu \mathrm{Cl}$ of $210_{\mathrm{Pb}} / \mathrm{kg}$. This was followed, three days later, by the first of fifteen $0.25 \mathrm{mM} / \mathrm{kg}$ intraperitoneal treatments, as follows: the calclum forms of ethylenediaminetetraacetate (EDTA), diethylenetriaminepentaacetate (DTPA), dibutyl ester of DTPA $\left(\mathrm{Bu}_{2} \mathrm{DTPA}\right)$, dihexyl ester of DTPA (Hex $\left.{ }_{2} \mathrm{DTPA}\right), \mathrm{Bu}_{2} \mathrm{DTPA}$ and DTPA, Hex 2 DTPA and DTPA, or an equal volume of saline $(0.15 \mathrm{ml})$. Treatment was repeated once daily! for 5 days, followed by 2 days of rest, for 3 weeks. Five days after the last treatment (26 days after the lead citrate injection) the mice were sacrificed for comparison of lead distribution within virious tissues, organs, and the entire carcass, as measured by the $0.047 \mathrm{MeV}$ gamma emission from $210 \mathrm{~Pb}$. Treatment of mice with either EDTA or DTPA alone was the most effective in reducing the level of lead in the brain; $49 \%$ and $43 \%$ reductions, respectively, were produced. The skeletal deposits, as measured in the femurs and clusely reflected in the whole body values in all groups, wcre mobilized to the greatest extent by DTPA alone and combined DTPA and Hex ${ }_{2}$ DTPA. These treatments reduced lead levels in the femurs and whole body by $31 \%$ to $33 \%$ of levels in control mice. The observed correspondence in lead decorporation between the femur and carcass suggests that most of the lead removed from the body was mobilized from skeletal deposits. In tissues other than brain and bone, most of the lead was lost without chemotherapy. Lead levels in kidneys, liver, spleen, and lung were reduced by 89 to $97 \%$ of pretreatment levels by Day 26 in saline-treated controls; the additional effect of therapy on lead removal from these organs was small. Chelation therapy thus had the greatest effect on lead levels in the two important organs, brain and skeleton, where the lead burden was stable with time. In addition, although esterification of DTPA did not enhance lead removal over that seen with DTPA alone, treatment with DTPA alone was somewhat more effective than EDTA alone for removal of lead from skeleton, blood, kidneys, liver, and spleen.

Preliminary experiments with neonatal rats (14 days of age) indicated that more lead was deposited in the brains of young rats than adults $(0.23 \%$ of the injected dose vs. $0.03 \%$, respectively). In addition, it was observed that, with time, lead left the brains of both groups of animals without treatment (25-30\% reduction in 2 weeks).

DTPA-INDUCED EXCRETION OF PLUTONIUM INTO DUG BLLE

M. H. Bhattacharyya and D. P. Peterson

Using bile duct-cannulated dogs, a study was completed on the measurement of DTPA-induced excretion of monomeric plutonium ( ${ }^{239} \mathrm{Pu}(\mathrm{IV})$ citrate) into the

${ }^{1}$ Participant in the 1978 Sumer Research Institute in Biology, University of Wisconsin, Whitewater. 
bile. A single, intravenous DTPA injection $(0.18 \mathrm{mmole} / \mathrm{kg})$ increased the concentration of plutonium in bile approximately 20-fold. The DTPA-induced excretion of plutonium into bile, however, could account for only about $40 \%$ of the plutonium lost from the liver foliowing DTPA administration. These data contrast to our results obtained earlier in the rat, where biliary excretion of plutonium following DTPA administration accounted we11 for the DTPA-induced loss of plutonium from the liver. Thus, there appears to be a species difference in the mechanism of DTPA removal of plutonium from the liver of rat and dog. The striking increase in biliary excretion of plutonium in the dog following DIPA treatment implies, however, that fecal excretion of plutonium following DTPA treatment can be used as a measure of tissue-deposited plutonium levels using the $S / F$ method (Bhattacharyya, et al., ibid) independent of whether man is more like rat or like dog in liver retention characteristics. 
7. TOXICOLOGICAL EVALUATIONS OF PROCESSES FOR UTILIZATION OF COAL

INTRODUCTION

William P. Norris

The Divisional program to identify and evaluate toxicological and environmental problems associated with combustion and/or conversion of coal has gained momentum during the past year. Two emerging technologies for coal utilization--fluidized-bed combustion (FBC) and high BTU coal gasification--are under active investigation. A proposal to begin the toxicological evaluation of a third technology, the magnetohydrodynamic process (MHD), was prepared and submitted to DOE. In addition, there have been limited studies of fly ash collected from the precipitators of conventional coal-burning electrical generating stations.

To date, the primary sources of materials for these toxicological studies have been the two 6-inch diameter, experimental fluidized bed combustors (one pressurized at 3-10 atmospheres, one at atmospheric pressure) operated by the Argonne National Laboratory Division of Chemical Engineering, and the HYGAS pilot plant for high BTU coal gasification operated by the Institute of Gas Technology for the Department of Energy. Corresponding studies of MHD will begin with a process development unit operated by the Argonne National Laboratory Engineering Division. The cooperation of engineering staff associated with these facilities is essential to the collection of samples and proper extrapolation of results of these biological studies to full-scale commercial systems. We gratefully acknowledge their many contributions.

More recently, we have been in contact with other laboratories having similar involvements with engineering developments and/or biological testing. The objectives are to obtain effluent samples from larger installations, some of which use different engineering designs, and to verify techniques for chemical analyses and biological assays.

Biological testing of materials collected from these processes is proceeding on two levels. Level One is represented by tests that use one of a variety of bacterial and in vitro mammalian cell systems to provide indications of toxicity and potential carcinogenicity within a few weeks. So far, the most useful of these have been the Ames Salmonella assay for mutagenicity and the V79 Chinese hamster cell assay for cytotoxicity and cellular transformations. However, a number of other potentially useful Level One assay procedures have been developed to the point of application.

Level Two testing involves the exposure of 1 aboratory rodents. Most of these exposures, so far, have been via inhalation of respirable fly ash collected from the final filters of a fluidized bed combustor. This has required 
development of exposure chambers and techniques for reaerosolization and size classification of such particulate material. A second approach is to expose rodents to the total, diluted effluent of fluidized bed combustion, and a facility for this purpose has been constructed adjacent to the atmospheric pressure combustor.

In Both Level One and Level Two testing, physical and chemical characterization of effluents and process streams is of primary importance. This is done collaboratively with Argonne's Analytical Chemistry Laboratory and Division of Energy and Environmental Systems. Data are being collected to characterize both the inorganic and organic content of fly ash from $F B C$ and the organic composition of HYGAS process streams and quench waters. Techniques have been developed for chemical class fractionations of organics from both these processes, with the result that the most toxicologically significant of the fractions have been tentatively identified in Level One testing.

The most significant accomplishments of the program during the past year result from the steadily increasing collaboration of staff in biological, chemical, and engineering disciplines. These interactions have produced a better. comprehension and interest in the solution of the problems to be faced in bringing emerging technologies to commercial status. More specifically, the Division now posseses a larger and improved battery of test procedures which provide a better capability for Level One assays. During this same period, facilities for pulmonary exposures of rodents have been put in place, and Level Two testing of FBC effluents has begun. The efforts of the Analytical Chemistry Laboratory in chemical class fractionation of FBC effluents and HYGAS process oils, combined with results of Level One testing, have shown that the most mutagenic components from both these sources reside with polar organic materials. Finally, a relationship between FBC operating conditions and the mutagenicity of the effluent stream is beginning to emerge. This 1 atter subject. will be explored in more detail during the coming ycar.

The eleven reports that follow describe results from componcnt efforts that, together, represent our current approach to an integrated assessment of the environmental and toxicological consequences resulting from emerging technologies for utilization of coal. In addition to the work described in these reports, mention should be made of the role of the Carcinogenesis Group in the development of rapid and reliable test systems for evaluating the neoplastic effects of coal combustion effluents, with the aim of complementing other ongoing test systems in the Division. Four systems are currently being examined: (1) in vitro culture of rat trachea in the presence of effluents, for detection of carcinogenic potential in the lung by identification of morphological and biochemical changes; (2) the quantitative measurement of hydrolytic lysosomal enzymes released from rat alveolar macrophages after in vitro exposure, as an indication of toxicity in the cell defense system and of cocarcinogenic activity in the lung; (3) the use of the early appearance of histochemically identifiable cellular changes in rat livers after in vivo exposure, as a predictor of subsequent tumor formation; and (4) biochemical or immunological detection of cellular chromosomal changes indicative of or correlated with neoplastic alterations. These four systems are described in Section 14, Carcinogenesis. 
Al1 four systems show potential usefulness, and testing with fluidized bed combustion effluents is under way with the first two models. Present data are still preliminary but suggest that samples from the effluents should be valuable for the verification and validation of each of the test systems.

\section{REGULAR STAFF}

Brennan, Patricia C. (Biologist)

Buess, Evelyn M. (Scientific Assistant)

Dainko, Julia L. (Scientific Assistant)

${ }^{1}$ Dornfeld, Suzanne S. (Scientific Assistant) Elkind, Mortimer M. (Senior Biophysicist)

Han, Antun (Biophysicist)

Hass, Bruce S. (Assistant Microbiologist)

Haugen, David A. (Assistant Biochemist)

Kickels, Wayne T. (Scientific Assistant)

Kubitschek, Herbert E. (Senior Biophysicist)

Matsushita, Tatsuo (Geneticist)

Norris, William P. (Biochemist)

Shotola, M. Anita (Scientific Assistant)

Suhrbier, Katherine M. (Scientific Assistant)

Venters, Dace (Scientific Assistant)

Williams, Donna M. (Scientific Assistant)

TEMPORARY STAFF DURING 1978

Griego, Viola M. (Postdoctoral Appointee)

Kirchner, Frederick R. (Postdoctoral Appointee)

Lankas, George R. (Postdoctoral Appointee)

${ }^{1}$ Now in Mutagenesis Group. 
CHARACTERIZATION AND FRACTIONATION OF COMPLEX ORGANIC MIXTURES FROM FLUIDIZED BED COMBUSTION AND GASIFICATION OF COAL

S. Bourne, ${ }^{1}$ A. Jirka, ${ }^{1}$ and P. T. Cunningham ${ }^{1}$

The Analytical Chemistry Laboratory supports the Divisional coal toxicology program by analyzing and preparing samples for biological testing. The preparation includes extraction of organic material from the original matrix (fly ash, coal dust, water, filters, etc.), fractionation of the organic material into chemically distinct cuts, with chemical characterization of each cut. The objectives of the work include (1) complete extraction of gram quantities of organics from the matrix; (2) quantitative separation of the complex mixtures of organic compounds into distinct chemical classes, with minimal chemical modification of the compounds; and (3) chemical characterization of the mixtures.

To date, the Analytical Chemistry Laboratory has prepared cuts for biological testing from HYGAS pretreater and quench waters and tars, HYGAS recirculation oils and char/oil slurries, fly ashes from both atmospheric and pressurized fluidized bed combustors, and filters from the combustor effluent lines. Extraction techniques have included sonic agitation or simple shaking followed by centrifuging, elution from columns, Soxhlet and separatory funnel extractions, and sublimation from particle surfaces. Separation techniques have included liquid-liquid and solid-liquid partitioning, distillation, and adsorption and gel permeation chromatography. A11 fractions have been fingerprinted by gas chromatography (GC) and infrared (IR) analysis.

The HYGAS samples show a wide range of polarity, starting with the nonpolar straight-chain hydrocarbons and aromatic hydrocarbons. The more polar cuts, especially from the quench waters, contain a predominance of phenols. The very polar cuts, which are gummy and insoluble in normal IR solvents, give. poor IR spectra showing smeared-out hydroxyl, carbonyl, and heteroatom bands. The fly ash fractions show minor amounts of hydrocarbon material; most of the material is polar and elutes from the gas chromatograph with difficulty. The oily material extracted from filters in the combustor effluent 1 ine appears to be mainly polynuclear aromatics.

Our continuing efforts involve development of a new, chemically very gentle technique of polarity separation from Teflon beads, sublimation of materials from fly ash surfaces, and development of sophisticated GC/mass spectrometry and GC/IR systems for chemical characterization.

${ }^{1}$ Analytical Chemistry Laboratory of the Chemical Engineering Division. 
CHEMICAL AND PHYSICAL CHARACTERIZATION OF PARTICULATE EFFLUENTS FROM THE ATMOSPHERIC FLUIDIZED BED COMBUSTION OF COAL

F. R. Kirchner, E. T. Kucera, 1 W. P. Norris, J. 0. Hutchens, ${ }^{2}$

P. T. Cunningham, 1 S. S. Danyluk, P. C. Brennan, and W. T. Kickels

Physical and chemical characterization of particulates derived from the fluidized bed combustion of coal was performed on material ("raw" fly ash) obtained from the final (woven wire mesh) filter of the bench scale atmospheric pressure fluidized bed combustor (AFBC) in the Chemical Engineering Division and on samples after reaerosolization with liquid nitrogen (see following report). Scanning electron microscopy showed that the fly ash has a very irregular, spongelike surface conformation, which was independent of particle size and the reaerosolization process. The surface area of the ash, measured by nitrogen adsorption, was $13 \mathrm{~m}^{2} \mathrm{~g}^{-1}$ for the raw material received from the final filter and $15 \mathrm{~m}^{2} \mathrm{~g}^{-1}$ for the reaerosolized materials, in which the particles were $<50 \mu \mathrm{m}$. Auger electron spectroscopy of the surface of the fly ash indicated that there were no significant differences following reaerosolization in the relative concentrations of $\mathrm{C}, \mathrm{Cl}, \mathrm{Ca}$, and $\mathrm{S}$ in the surface layers.

As a first step in the chemical characterization of the final filter material, a sample of fly ash both before and after reaerosolization with liquid nitrogen was analyzed by spark source emission spectroscopy (Table 7.1). Twenty-two elements were observed, with only one element (beryllium) showing an increase in concentration after reaerosolization. Seven of the elements were appreciably soluble in water (Table 7.1). In addition, mercury was measured by atomic absorption and found to be present at $5.29 \pm 0.26 \mathrm{ppm}$ in both $r$ aw and processed ash.

Particle counts made on reaerosolized fly ash with electrical mobility and optical size analyzers indicated that a large proportion of particles were in the respirable size range $(<5.0 \mu \mathrm{m})$.

\section{A SYSTEM FOR REAEROSOLIZING FLUIDIZED BED COMBUSTOR FLY ASH FOR ANIMAL} EXPOSURES

F. R. Kirchner, J. O. Hutchens, ${ }^{2}$ W. P. Norris, P. C. Brennan, and

W. T. Kickels

The purpose of this work was to develop a system for exposing small 1aboratory animals to reaerosolized fly ash under controlled conditions. A new technique using liquid nitrogen as a carrier for the purpose of reaerosolizing fly ash derived from the final filter of a fluidized bed combustor of coal has been developed. Initial attempts at reaerosolization were made by nebulizing an aqueous suspension of fly ash. However, because emission spectroscopy of

${ }^{1}$ Analytical Chemistry Laboratory of the Chemical Engineering Division.

Consultant, The University of Chicago. 
Table 7.1. Elemental Concentrations of "CT4" AFBC Fly Ash before and after Reaerosolization and in a 24-Hour Aqueous Extract of Fly Ash, Determined by Spark Source Emission Spectrosçopya

\begin{tabular}{|c|c|c|c|c|}
\hline Element & $\begin{array}{l}\text { Raw } \\
\text { Fly Ash }\end{array}$ & $\begin{array}{l}\text { Reaerosolized } \\
\text { Fly Ash }\end{array}$ & Water & $\begin{array}{l}\text { Extract of } 10 \mathrm{gm} \text { Raw Fly Ash } \\
\left(\mathrm{ppm} / 100 \mathrm{ml} \mathrm{H} \mathrm{H}_{2} \mathrm{O}\right)\end{array}$ \\
\hline $\mathrm{A} 1$ & $>10 \%$ & $>10 \%$ & & 400 \\
\hline B & 350 & 350 & & - \\
\hline $\mathrm{Ba}$ & 600 & 600 & & 390 \\
\hline $\mathrm{Be}$ & 30 & 50 & & - \\
\hline $\mathrm{Ca}$ & $3 \%$ & $3 \%$ & & 25,000 \\
\hline Co & 10 & 10 & & - \\
\hline $\mathrm{Cn}$ & 1,000 & 1,000 & & - \\
\hline $\mathrm{Cu}$ & 30 & 30 & & - \\
\hline $\mathrm{Fe}$ & $10 \%$ & $10 \%$ & & - \\
\hline $\mathrm{K}$ & $1.7 \%$ & $1.7 \%$ & & - \\
\hline $\mathrm{Li}$ & 60 & 60 & & 8 \\
\hline $\mathrm{Mg}$ & 500 & 500 & & 1,500 \\
\hline Mn & 300 & 300 & & 8 \\
\hline Mo & 20 & 20 & & 8 \\
\hline $\mathrm{Na}$ & $1.5 \%$ & $1.5 \%$ & & 760 \\
\hline $\mathrm{Ni}$ & 300 & 300 & & - \\
\hline $\mathrm{Pb}$ & 35 & 35 & & 2 \\
\hline $\mathrm{Rb}$ & 100 & 100 & & - \\
\hline $\mathrm{Si}$ & $>10 \%$ & $>10 \%$ & & 4 \\
\hline $\mathrm{Sr}$ & 1,000 & 1,000 & $\cdot$ & 500 \\
\hline $\mathrm{T} i$ & 8,000 & 8,000 & & - \\
\hline $\mathrm{V}$ & 75 & 75 & & 100 \\
\hline
\end{tabular}


the filtered aqueous suspension medium indicated that the water had dissolved some of the fly ash, liquid nitrogen (a very poor solvent under these conditions) was chosen to replace the water. Particulates in the respirable size range $(<5.0 \mu \mathrm{m})$ tend to form aggregates that require substantial energy for disaggregation. The aggregates were broken up by sonication in liquid nitrogen at the triple point. The suspension was dispersed from a liquid nitrogen Dewar under pressure while being maintained in suspension with a mechanical stirrer. The stream of 1 iquid nitrogen bearing the suspended particulates was directed to a-cylindrical 4-inch diameter Plexiglas evaporation chamber, where the nitrogen was mixed with dry, filtered air from four radially opposed air inlets. The liquid nitrogen rapidly evaporated, leaving the particulates suspended in the air stream. The air stream was warmed to room temperature and directed to an animal exposure chamber. The mass loading of particulate in the exposure chamber was $0.017 \mathrm{mg} / 1$ itre.

Physical and chemical characterization of the reaerosolized fly ash (see preceding report) indicated that the process did not alter the elemental composition, the surface area, or surface chemistry. Additionally; the biological activity as measured by H. E. Kubitschek using the Ames Salmonella test was not altered.

To date, only final filter fly ash material from the atmospheric pressure fludizied bed combustor in the Chemical Engineering Division has been used for reaerosolization. However, the technique may be applicable to other particulates, a possibility that is currently under investigation.

THE FLUIDIZED BED COMBUSTION TOTAL EFFLUENT TOXICOLOGY SYSTEM

R. Kumar, ${ }^{1}$ J. O. Hutchens, ${ }^{2}$ W. P. Norris, F. R. Kirchner, and P. T. Cunningham ${ }^{3}$

The objective of the total effluent toxicology system of the atmospheric pressure fluidized bed combustor is to provide a facility for the direct exposure of biological test systems to the entire effluent from a fluidized bed combustor (FBC), rather than to only portions of the effluent, such as. the fly ash. The system is composed of a delivery system and an exposure chamber. It provides for the dilution of the FBC effluent with filtered and conditioned air, aging of the effluent-air mixture in an illuminated atmospheric effects simulator (AES), and exposure of mice and other biological test systems to this mixture under controlled environmental conditions in a biological test chamber.

${ }_{1}^{1}$ Chemical Engineering Division.

${ }^{2}$ Consultant, The University of Chicago.

${ }^{3}$ Analytical Chemistry Laboratory of the Chemical Engineering Division. 


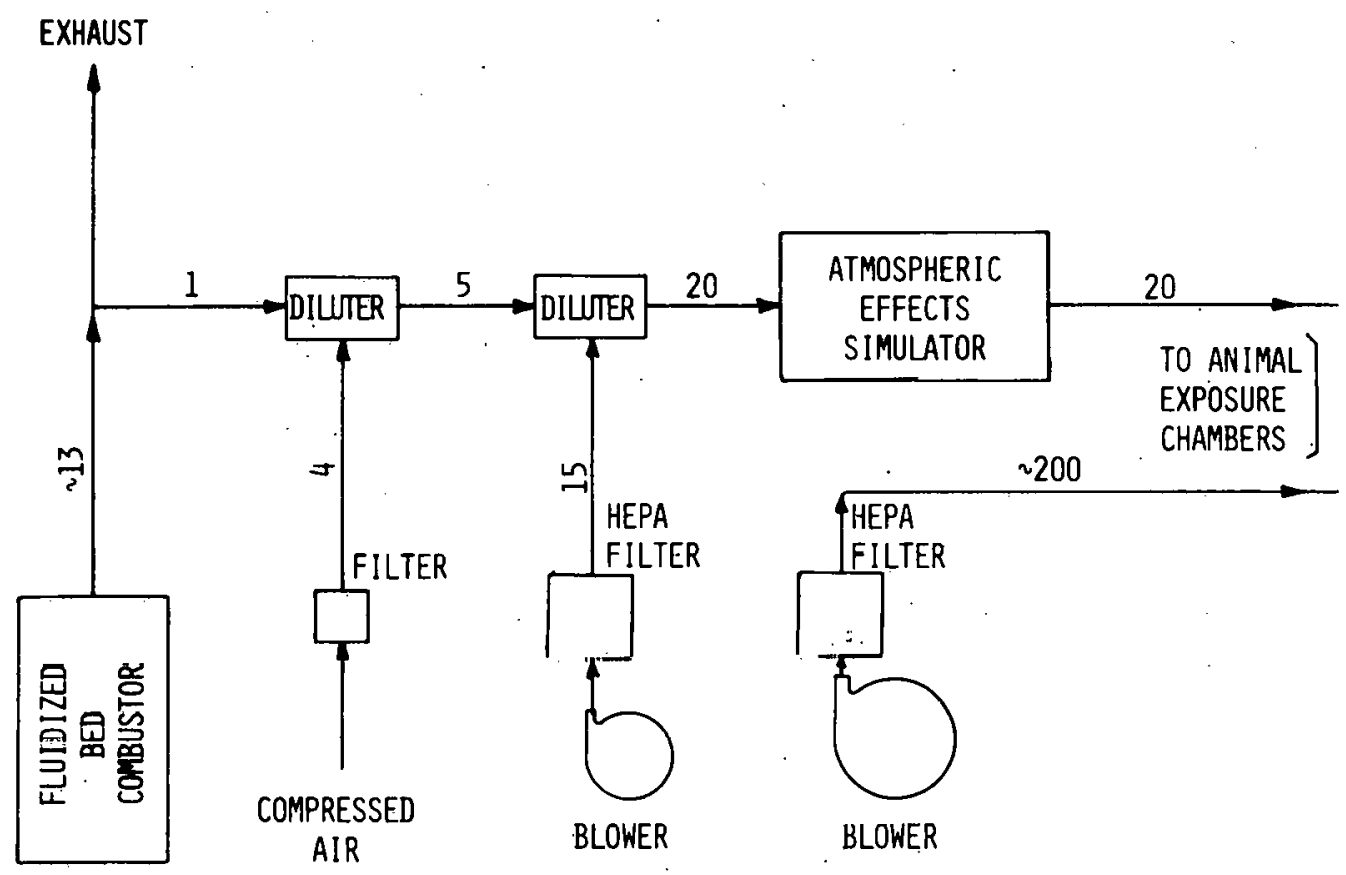

Fig. 7.1. FBC-effluent delivery system. The flow rates shown are in nominal cfm.

A schematic diagram of the delivery system is shown in Figure 7.1. The effluent source is an atmospheric pressure, 6-inch diameter, experimental fluidized bed combustor in the Chemical Engineering Division. The gas cleanup system on this combustor consists of a primary cyclone, a secondary cyclone, and a final filter. Approximately 1 standard cubic foot per minute ( $\mathrm{scfm}$ ) of the gaseous effluent from either before or after the final filter is diluted with $4 \mathrm{scfm}$ of filtered, dry air. Following a second dilution with $15 \mathrm{sc}$ fm of filtered air from a dedicated blower, the effluent enters the AES. The AES has Pyrex glass panels in the front and back, and is illuminated with a bank of Vita-Lite fluorescent lights. The AES provides for a gas residence time of aout 13 minutes. The aged effluent-air mixture from the AES, as well as 200 sc fm of clean, conditioned air from another dedicated blower, is delivered to the biological test chamber.

The biological test chamber is a room about $10 \times 4 \times 8$ feet made of sheet aluminum, Six animal exposure chambers, each about $30 \times 30 \times 8$ inches high, 
are mounted in two vertical stacks of three chambers each. The test mice are in gang cages placed inside these exposure chambers. Each of the se exposure chambers $c$ an be fed with adjustable proportions of the effluent from the AES and the clean air supply, so that in these chambers the overall FBC effluent dilution ratios may range from 20 to 1000 or higher. The biological test chamber, as well as the insides of the animal exposure chambers, is maintained at 68 to $70^{\circ} \mathrm{F}$ and $45 \%$ relative humidity. The animals to be used in the first series of experiments, are male $\mathrm{B} 6 \mathrm{CF}_{1}$ mice.

The detailed design of the various components of the FBC effluent toxicology system has been completed and the system will be operational during the summer of 1979 .

\section{CELLULAR ASSAY SYSTEMS}

The preceding four reports dealt primarily with the characterization of the effluents under study, and with methods for exposing biological test systems to these effluent delivery systems. The following five reports focus on the Level one tests. The first three use the Ames Salmonella assay; the fourth compares the response to the Ames test with growth inhibition in mammalian cells; the fifth uses two additional mammalian cell systems; and the sixth reports one approach to the development of a new enzymatic test.

MUTAGENICITY OF COAL FLY ASH RECOVERED FROM ELECTRIC POWER PLANT PRECIPITATORS

H. E. Kubitschek and L. Venta ${ }^{1}$

A major solid effluent produced by coal combustion for electric power generation is coal fly ash. In 1974 U.S. power plants burned an estimated total of 600 million tons of coal, producing some 50 million tons of fly ash, of which about $5 \%$ was released to the atmosphere. Using the Ames Salmonella reversion assay, Chrisp et al. measured the mutagenicity of the respirable fraction of fly ash collected from the smokestack breeching of a large power plant. burning low sulfur, high ash coal (Chrisp, C. E., et al., Science 199, $73,1978)$. Their dose response curve for fly ash mutagenicity in strain TA1538 gave approximately 30 revertants per plate per mg fly ash extracted with serum. They did not report measurements of mutagenicity of the great bulk of the ash, about $95 \%$, trapped in precipitators and hoppers.

\footnotetext{
${ }^{1}$ Summer 1978 participant in the Undergraduate Honors Research Parti-
} cipation Program, Northwestern University. 
We obtained six samples of fly ash from precipitators and hoppers of several midwestern electric power plants, all burning low sulfur, high ash coal, and measured mutagenicity with two Salmonella strains; TA98 and TA1538, in the Ames Salmonella system, with and without the microsomal activation system. Both serum and dimethyl sulfoxide were used as extractants, and serum extractions were carried out for as long as 4 weeks at $37^{\circ} \mathrm{C}$. Both benzo(a)pyrene and a dimethyl sulfoxide extract of fly ash from a fluidized bed combustor were used as positive controls. No mutagenicity ( $<0.3$ revertants/mg) was observed for any of the samples in some 30 tests involving the two strains and different conditions of extraction. (For example, see Figure 7.2.) To the extent that our samples are representative of fly ash from other U.S. electrical power plants, our results indicate that the great bulk of the fly ash from coal-fired generating plants is far less mutagenic than the ash actually discharged from the stacks.

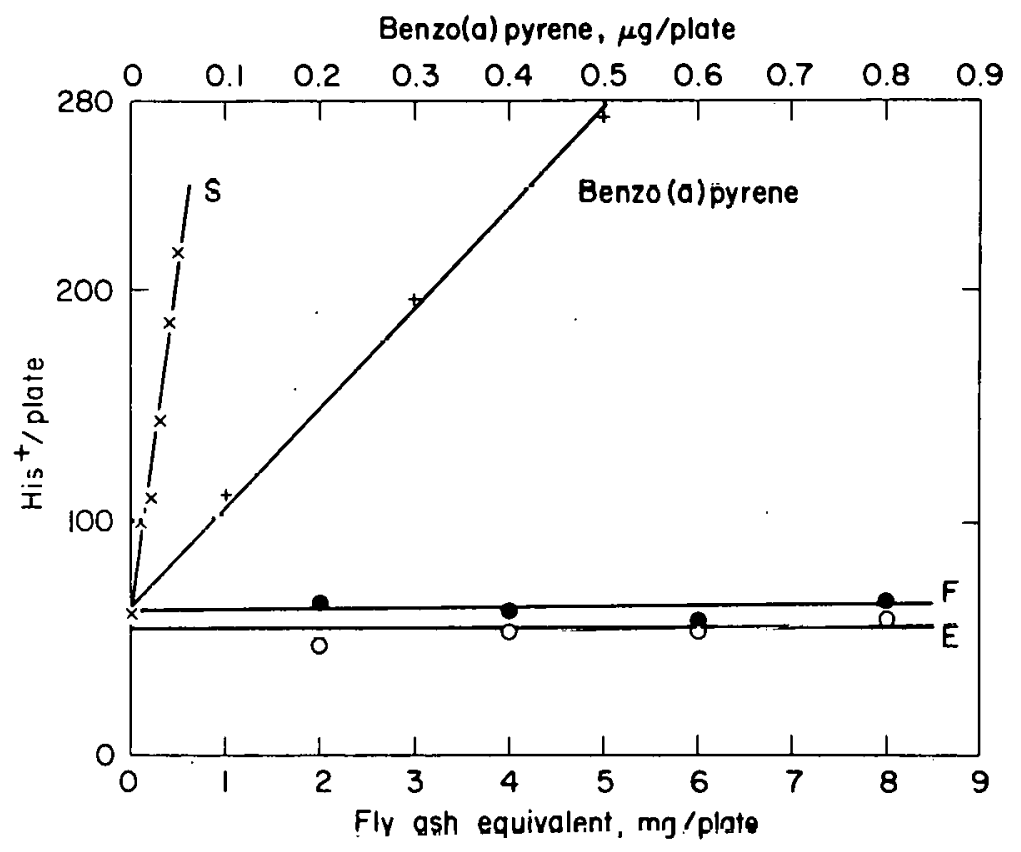

Fig. 7.2. Fly ash mutagenicity in the Ames Salmonella system with Strain TA98. Mutation responses.. (His ${ }^{+}$revertants) for precipitator tly ash samples, $E$ and $F$, are compared with those for two reference samples, benzo(a)pyrene and a standard mutagenic fly ash sample, $S$, from a fluidized bed combustor. Benzo(a)pyrene was metabolically activated (25 $\mathrm{\mu g}$ rat 1 iver microsome, fraction $\mathrm{S}-9$, per $\mathrm{ml}$ ); the other samples were not. Fly ash samples were extracted with dimethyl sulfoxide. 
MUTAGENICITY AND CHEMICAL CHARACTERIZATION OF EFFLUENTS FROM FLUIDIZED BED COMBUSTORS

H. E. Kubitschek, D. A. Haugen, S. Bourne, ${ }^{1}$ D. M. Williams, and

D. Venters:

Ames Salmonella assays were performed on particulate effluents from the two experimental bench scale fluidized bed combustors (FBC's) operated by the Chemical Engineering Division--an atmospheric (AFBC) and a pressurized (PFBC) combustor, both of which burned. bituminous, high sulfur (5.5\%) coal. For each, fly ash was collected on a porous metal filter downstream from the primary and secondary cyclones, at a temperature of about $70^{\circ} \mathrm{C}$ for the $\mathrm{AFBC}$ and about $170^{\circ} \mathrm{C}$ for the $\mathrm{PFBC}$. Our values for the mutagenicity of fly ash from these FBC's are shown in Table 7.2, where they are compared with those from another bench scale $\mathrm{FBC}$, and with values reported for fly ash from the

Table 7.2. Mutagenic Activities of Coal Combustion Effluents and Urban Air Particulates in Strain TA98

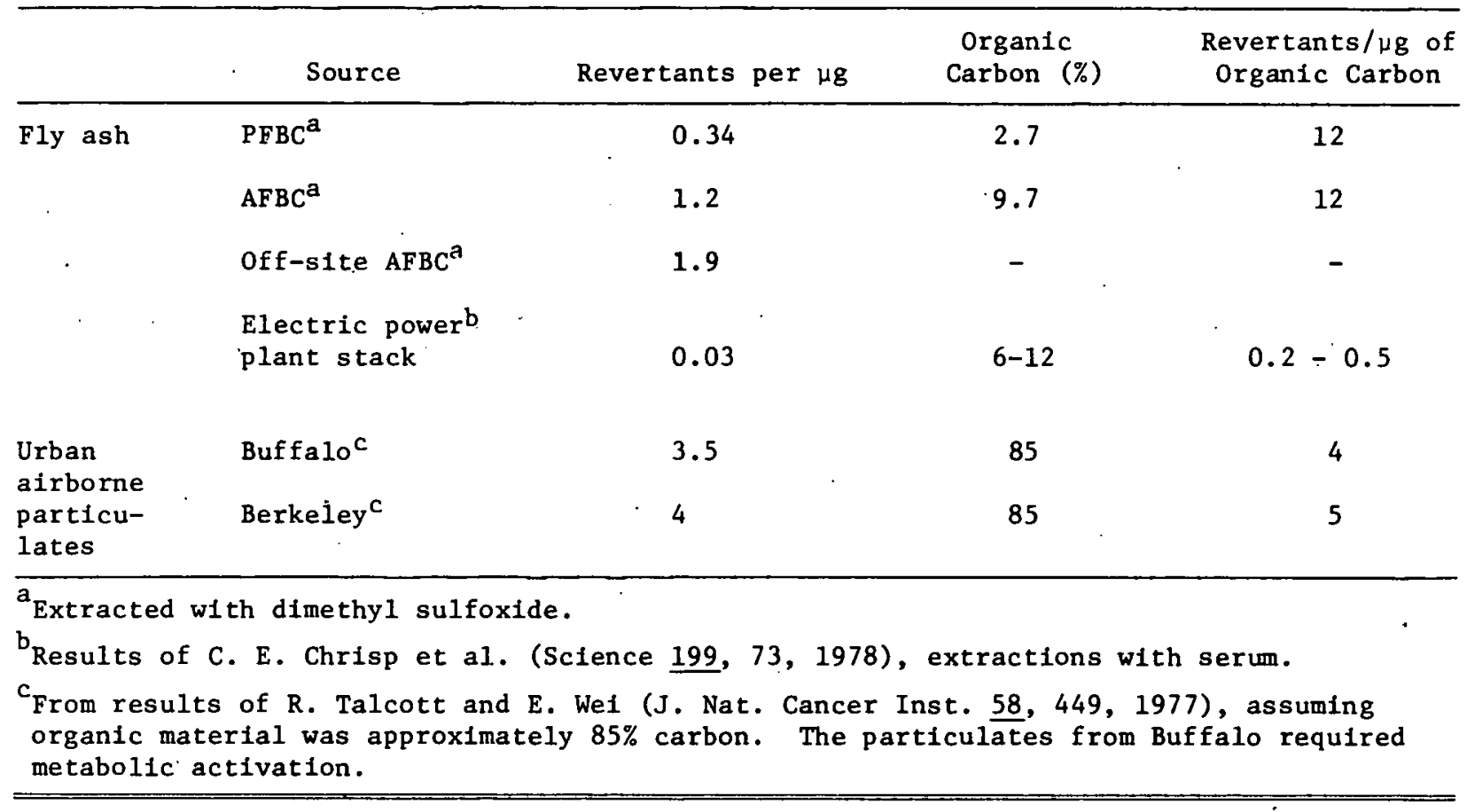

\footnotetext{
${ }^{1}$ Analytical Chemistry Laboratory of the Chemical Engineering Division.
} 
breeching of an electric generating plant, and also with some values reported for urban airborne particulates. All of these values were obtained with the same bacterial strain, Salmonella TA98. The specific mutagenicity of each of the FBC ashes were an order of magnitude larger than that observed for the electric power plant; but the FBC activities were less than that observed for urban airborne particulates in Buffalo and Berkeley. When values of specific mutagenicity are based on organic carbon content, both the fly ash from the FBC and the urban air particulates had values of about 1 to $2 \%$ of those for the carcinogen benzo(a) pyrene (300 to 400 revertants per $\mu g$ ).

In order to characterize further the organic components, fly ash was extracted with phosphate-buffered saline to yield an insoluble residue that was further extracted with a series of organic solvents. The extract was applied to a silica gel column and six fractions of increasing polarity were eluted. These fractions contained $90 \%$ of the activity applied to the column. Almost all of the mutagenic activity was distributed in the final four fractions (Table 7.3), representative of 4-6 ring aromatics, phenols and chemicals containing carbonyl and nitrile moieties, alcohols, and carboxylic acids and other strongly polar compounds; the activities of the first two low polarity chromatographic fractions and of the saline extract were negligible. The most polar fraction (eluted with methanol) contained the greatest mass and mutagenic activity. Fraction 4, however, had the greatest specific activity, and

Table 7.3. Mutagenlcity of PFBC Particulate Effluent Fractions

\begin{tabular}{|c|c|c|c|c|}
\hline Fraction & $\begin{array}{l}\text { Chemica } 1^{a} \\
\text { Constituents }\end{array}$ & mg/Fraction & Mutants/ug & Mutants/Fraction $\times 10^{-3}$ \\
\hline 1 & $\begin{array}{l}\text { Long cha1n aliphatics; } \\
\text { minor unsalurated } \\
\text { compounds. }\end{array}$ & 17.3 & 0 & 0 \\
\hline 2 & $\begin{array}{l}30 \% \text { aliphatic, } 70 \% \text { 11ght } \\
\text { aromat1cs }(2-3 \text { rings }) .\end{array}$ & 2.8 & 0 & 0 \\
\hline 3 & $\begin{array}{l}\text { Heavy aromatics ( } 4-6 \text { rings) } \\
5 \text { major components. }\end{array}$ & 9.9 & 61 & 604 \\
\hline 4 & $\begin{array}{l}\text { Mixture of phenols, } \\
\text { carbonyls, nitriles. }\end{array}$ & 3.4 & 250 & 850 \\
\hline 5 & $\begin{array}{l}\text { Phenols, carbonyls, } \\
\text { alcohols. }\end{array}$ & 36.6 & 18 & 660 \\
\hline 6 & $\begin{array}{l}\text { Carboxylic acids and } \\
\text { other very polar } \\
\text { compounds. }\end{array}$ & 276.2 & 4 & 1104 \\
\hline
\end{tabular}


was composed primarily of a mixture of phenols and of chemicals containing carbonyl and nitrile moieties. The specific mutagenic activity of this fraction was very high, approximately $50 \%$ that of benzo(a)pyrene; this fraction must therefore be considered potentially very hazardous.

Thus, our results with fly ash fractions clearly indicate the presence of many different kinds of mutagenic compounds. A broad spectrum of mutagenic compounds also has been observed for process stream mutagens produced in a high BTU gasification process and may well be representative of most kinds of coal combustion and conversion technologies.

A high-volume air sampler with a glass fiber filter was installed on an exhaust duct into which the PFBC effluent was vented downstream from the final fly ash filter. The temperature at this filter was $40-50^{\circ} \mathrm{C}$. Under typical operating conditions, 0.5 to 1 gram of effluent was collected on this filter, as a mixture of variable proportions of black particulate material and a condensed dense yellow-orange oil. The oil-like material is not believed to contain elemental sulfur, is insoluble in water, but is readily soluble in organic solvents such as hexane or dichloromethane. Gas chromatographic and mass spectrographic analysis revealed the presence of more than 30 aromatic compounds, and infrared analysis revealed the presence of carbonyl moieties.

In order to evaluate the biological activity of the condensate, filters containing either primarily the yellow oil or a mixture of oil and particulates were extracted with dichloromethane, the solvent was evaporated, and the residue was dissolved in dimethyl sulfoxide and evaluated by the Ames Salmonella as8ay. The condensate extracts from both the yellow oil and the more mixed sample were directly mutagenic and effective at $2-5 \mu \mathrm{g} / \mathrm{ml}$ or 20 revertants per $\mu \mathrm{g}$, indicating the presence of potent mutagens. The particulate effluents collected at higher temperatures from the porous metal filter were also directly. mutagenic, supporting the interpretation that the particulate effluent collected on the glass fiber filters represents effluent that passed the primary porous metal filter. In addition, the results suggest that the yellow condensate contains volatile mutagens that were not removed by deposition on ash collected by the porous metal filter and, therefore, that this condensate preferentially contains the most volatile of the mutagenic vapors produced during combustion. Thus these condensates, which contain high concentrations of organic materials, probably are the best source of material for initial identification and characterization of potent organic mutagens produced by fluidized bed combustion. 
MUTAGENICITY OF OIL PROCESS STREAMS IN THE HYGAS COAL GASIFICATION PLANT

B. S. Hass, S. S. Dornfeld, S. Bourne, ${ }^{1}$ and D. M. Smith ${ }^{2}$

Three different samples from oil process streams of the HYGAS plant have been examined for mutagenicity using the Ames Salmonella assay, with strain TA98 activated with S-9 rat microsomal enzymes. Two samples were from the oil recirculation loop--one collected when the plant was not in operation (Sample A) and the other collected during a test run (Sample B)--and the third sample was from the char-oil slurry stream.

Sample A and the char-oil slurry were fractionated on silica gel in exactly the same way. Both showed considerable specific mutagenicity (revertants/ $/ \mathrm{g}$ ) in Fractions 5 and 6 which are composed of polar compounds (Table 7.4). Fraction 3 of Sample A, containing 3-5 ring aroundicis, showed an unusually light specitıc mutagenicity, which might be related to the presence of

Table 7.4. Mutagen1c Response of SalmonelZa typhimurium Straln TA98 to ofl Reclrculat1on Loop Sample A, the Char-011 Slurry Sample, and Their Fractions

\begin{tabular}{|c|c|c|c|c|c|c|c|c|}
\hline \multirow[b]{2}{*}{ Sample } & \multirow[b]{2}{*}{$\begin{array}{l}\text { Sillca } \\
\text { Gel } \\
\text { Elutant }\end{array}$} & \multirow[b]{2}{*}{$\begin{array}{c}\text { Chemlcal } \\
\text { Classes } \\
\text { Identifled }\end{array}$} & \multicolumn{3}{|c|}{011 Recirculation Loop Sample A } & \multicolumn{3}{|c|}{ Char-011 slurry } \\
\hline & & & Revertant $8 / \mu \mathrm{B}$ & $\begin{array}{c}\text { Total } \\
\text { Sample } \\
(8)\end{array}$ & $\begin{array}{c}\text { Revertants/ } \\
\text { Sample } \\
\left(x 10^{-6}\right)\end{array}$ & Revertants/48 & $\begin{array}{l}\text { Total } \\
\text { Sample } \\
(g)\end{array}$ & $\begin{array}{c}\text { Revertants } \\
\text { Sample } \\
\left(x 10^{-6}\right)\end{array}$ \\
\hline Raw & & & 0.30 & 1000 & 300 & 36.01 & 475 & 171 \\
\hline $\begin{array}{l}\text { Total } \\
\text { nonvolat1le }\end{array}$ & & . & • & & & & & \\
\hline Fraction 1 & Hexane & $\begin{array}{l}\text { Long chain } \\
\text { aliphatics }\end{array}$ & 0 & 2.9 & 0 & 0 & 1.6 & 0 \\
\hline Fraction 2 & $\begin{array}{l}57 \text { hexane } \\
\text { 1ii hexane }\end{array}$ & $\begin{array}{l}30 \% \text { allphatic } \\
70 \% \text { aromatic }\end{array}$ & 0 & 3.5 & 0 & 0 & 2.8 & 0 \\
\hline Fraction 3 & $\begin{array}{l}50 \% \text { benzene } \\
\text { in hexane }\end{array}$ & $\begin{array}{l}3-5 \text { ring } \\
\text { aromat } 1 \mathrm{cs}\end{array}$ & 35.72 . & 1.3 & 46.6 & 2.40 & 0.6 & 1.4 \\
\hline Fraction 4 & Chloroform & $\begin{array}{l}\text { Phenols, } \\
\text { carbonyls, } \\
\text { nilcriles }\end{array}$ & 0 & 0.9 & 0 & 0 & 1.0 & 0 \\
\hline Fraction 5 & $\begin{array}{c}\text { Ethyl } \\
\text { acetate } \\
\qquad\end{array}$ & $\begin{array}{l}\text { Phenols, } \\
\text { alcohols, } \\
\text { carbonyls }\end{array}$ & 4.20 & 3.3 & 13.9 & 13.30 & 3.1 & 41.2 \\
\hline Fraction 6 & Methanol & $\begin{array}{l}\text { Carboxylic } \\
\text { acide and } \\
\text { other very } \\
\text { polar } \\
\text { compounds }\end{array}$ & 14.10 & 0.51 & 7.3 & 14.12 & 0.2 & 2.7 \\
\hline
\end{tabular}

${ }^{1}$ Analytical Chemistry Laboratory of the Chemical Engineering Divi-

Sponsored by the Argonne Affirmative Action Program. 
certain mutagenic chemical species that could accumulate with the changing combustion conditions of the shut-down process of the previous run, since lower temperatures are known to facilitate the synthesis of polycyclic aromatic hydrocarbons. The mutagenic balance (mutagenicity of a whole sample compared to that of the sum of its components) was excellent in the nonvolatile extract of the char-oil slurry ( $92 \%$, corrected for loss of mass in the fractions) and for Sample A, excluding Fraction 3, it was $87 \%$.

Sample B of the oil recirculation loop was assayed as collected ("raw") and as divided into volatile (b.p. $<200^{\circ} \mathrm{C}$ ) and nonvolatile portions (Table 7.5 ). Chemical recovery was $98 \%$ and the mutant recovery in the two portions was $109 \%$ of the mutagenicity of the undivided sample. Thus, if the low specific mutagenicities of the raw and volatile samples are statistically valid, it is possible to obtain reasonable mutant recoveries between the sample as collected and its components.

The fractionation procedure for the nonvolatile portion of Sample B was modified from that used for Sample A. Since polar material tended to adhere to the silica gel column, the very polar materials were first removed on a Teflon column before separation on the silica gel column. A comparison of the mutagenicities of the various fractions in Sample A (Table 7.4) with those in Sample B (Table 7.6) indicates that the mutagenic response was altered by the removal of the very polar fractions from Sample B. For example, mutagenicity appeared in the chloroform fraction which had earlier contained none.

One conclusion from the testing of the HYGAS oil streams is that the nonvolatile portions seem to produce lower mutagenic responses (revertants/ug) in the Ames Salmonella assay than organic samples from process and product streams of coal lique faction conversion technologies as reported by Epler, J. L., et a1. (Mutat. Res. 57, 265, 1978).

Table 7.5. Mutagenic Response of SalmoneZla typhimurium Strain TA98 to Oil Recirculation Loop Sample B

\begin{tabular}{|c|c|c|c|}
\hline & Revertants/ $\mu g$ & $\begin{array}{l}\text { Total } \\
\text { Sample } \\
\text { (g) }\end{array}$ & $\begin{array}{l}\text { Revertants/sample } \\
\quad\left(\times 10^{-6}\right)\end{array}$ \\
\hline Raw sample & 0.13 & 417.1 & 54.2 \\
\hline Volatile component & 0.13 & 404.0 & 52.5 \\
\hline Nonvolatile component & 1.90 & 3.5 & 6.7 \\
\hline
\end{tabular}


Table 7.6. Mutagenic Response of Salmonella typhimumium Strain TA98 to Fractions of the Nonvolatile Portions of Sample B

\begin{tabular}{|c|c|c|c|c|c|}
\hline Samp le & Column ${ }^{a}$ & Eluant & Revertants/ $/ \mathrm{g}$ & $\begin{array}{l}\text { Total } \\
\text { Sample } \\
\text { (g) }\end{array}$ & $\begin{array}{c}\text { Revertants/ } \\
\text { Sample } \\
\left(x 10^{-6}\right)\end{array}$ \\
\hline 3 & $\mathrm{~T}$ & $\begin{array}{l}\text { Methanol- } \\
\text { water }(2: 1)\end{array}$ & 1.40 & 4,60 & 6.4 \\
\hline 5 & SG & Hexane & 0.24 & 3.23 & 0.6 \\
\hline 5 & SG & $\begin{array}{l}5 \% \text { benzene } \\
\text { in hexane }\end{array}$ & 5.43 & 0.08 & 0.4 \\
\hline 7 & SG & $\begin{array}{l}50 \% \text { benzene } \\
\text { in hexane }\end{array}$ & 2.60 & 0.39 & 1.0 \\
\hline 8 & SG & Chloroform & 9.61 & 0.43 & 4.1 \\
\hline 9 & $\mathrm{SF}$ & Ethy 1 acetate & 1.24 & 0.27 & 0.3 \\
\hline 10 & $S G$ & Methanol & 1.22 & 0.05 & 0.06 \\
\hline 11 & SG & Water & 1.49 & 0.01 & 0.02 \\
\hline
\end{tabular}

COMPARISON OF MUTAGENICITY AND GROWTH INHIBITION OF WATER QUENCH PROCESS STREAMS FROM THE HYGAS GASIFICATION PLANT

B. Hass, S. S. Dornfeld, and T. Matsushita

A water quench process stream has been sampled and analyzed for mutagenic responses in the Ames Salmonella assay, using metabolically activated strain TA98, and for growth inhibition in mouse myeloma cells. This sample was collected from the gasifier pretreater quench stream. A second sample from the oil recirculation loop quench process stream, which collects recoverable oil evolved by the gasifier, was also anlayzed for mutagenicity.

The growth inhibition tests used mouse myeloma cells (MPC $11 ; 66.2$ subclone) grown in liquid suspension of Dulbecco's modified Eagle's medium containing $20 \%$ heat-inactivated horse serum. Culture growth was determined by a Coulter counter attached to a multichannel analyzer. This instrument enables the counting of viable cells according to size and distribution characteristics which are calibrated and correlated by vital staining techniques. Growth curves are plotted, and then the $\mathrm{ED}_{50}$ (effective dose to reduce the growth rate by $50 \%$ ) is determined graphically.

No bacterial mutagenicity was found in the pretreater quench stream sample, as collected, or in its aqueous component, and these were not examined 
for growth inhibition. The water of the quench stream contained a tarlike, insoluble material which was extracted repeatedly according to the scheme shown in Figure 7.3. Fractions $\mathrm{T}-3$ through $\mathrm{T}-7$ (see figure) were compared for mutagenicity and growth inhibition in mouse myeloma cells (Table 7.7). There is a poor correlation between mutagenicity and growth inhibition in Samples $\mathrm{T}-4, \mathrm{~T}-5$, and $\mathrm{T}-6$. In addition, the sample with the largest total mutagenicityvalue, $\mathrm{T}-7$, displayed a very low value for growth inhibition. The data al so indicate that the process of extraction altered the response of the components. For example, Fraction $\mathrm{T}-7$, one of three fractions derived from $\mathrm{T}-4$, displayed a higher total mutagenicity than the parent $\mathrm{T}-4$.

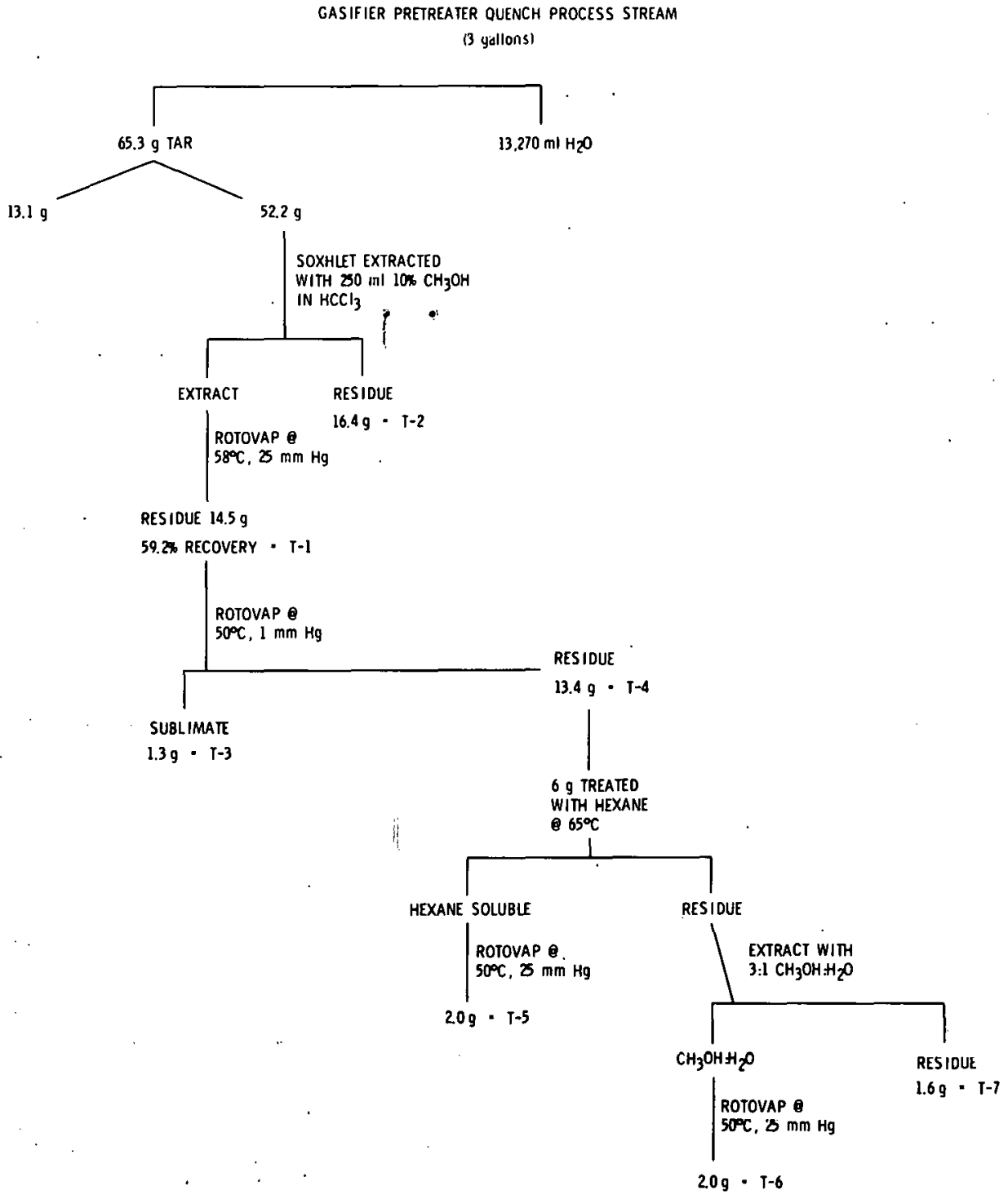

Fig. 7.3. Chemical separation scheme for a sample from the gasifier pretreater quench process stream. Chemical separation performed by $S$. Bourne and $A$. Jirca of the Analytical Chemistry Laboratory (see report by $S$. Bourne et al. in this Section). 


\begin{tabular}{|c|c|c|c|c|c|}
\hline \multirow[b]{2}{*}{ Fraction } & \multirow[b]{2}{*}{$\begin{array}{c}\text { Fraction } \\
\text { Identification }\end{array}$} & \multirow{2}{*}{$\begin{array}{l}\text { Total } \\
\text { Sample } \\
(g)\end{array}$} & \multicolumn{2}{|c|}{ Mutagenicity } & \multirow{2}{*}{$\begin{array}{c}\begin{array}{c}\text { Growth } \\
\text { Inhibition }\end{array} \\
\begin{array}{c}\left(E D_{50}\right. \\
\mu \mathrm{g} / \mathrm{ml})\end{array}\end{array}$} \\
\hline & & & $\begin{array}{c}\text { Spectflc } \\
\text { (revertants/ug) }\end{array}$ & $\begin{array}{c}\text { Total } \\
\text { (revertants/sample } \\
\left.\times 10^{-6}\right)\end{array}$ & \\
\hline$T-3$ & $\begin{array}{l}\text { Soxhlet sublimate } \\
\text { of extract }\end{array}$ & 1.3 & 0 & 0 & $>280$ \\
\hline$T-4$ & Parent ${ }^{a}$ & 13.4 & 0.24 & 3.22 & 112 \\
\hline$T-5$ & Nonpolar & 2.0 & 0.57 & 1.14 & 75 \\
\hline$T-6$ & Polar & 2.0 & 0.30 & 0.06 & 62 \\
\hline $\mathrm{T}-7$ & Very polar & 1.6 & 2.6 & 4.16 & $\therefore 120$ \\
\hline
\end{tabular}

The oil recirculation quench stream sample was fractionated on a silica gel column and eluted with solvents of increasing polarity. The significant mutagenic responses were from polar samples. The final four polar fractions produced the specific mutagenicities of $0.24,1.32,6.59$, and 1.03 revertants/ $\mu g$, respectively.

In conclusion, the comparison of the bacterial mutagenicity and growth inhibition in mammalian cells indicates that the two are poorly correlated, and suggests that a comprehensive evaluation of potential heal th hazards requires the use of more than one end point.

CYTOTOXIC EFFECTS OF THE EFFLUENTS FROM FLUIDIZED BED COAL COMBUSTION

G. R. Lankas, M. M. E1kind, and E. M. Buess

The effects of the effluents produced by the bench scale pressurized fluidized bed coal combustor have been studied in mammalian cells in culture. Small particulates up to about $10 \mu \mathrm{m}$ in diameter (fly ash), organic extracts of the fly ash particulates, and condensate material deposited on glass fiber filters located at the terminal end of the effluent stream were tested in $V 79$ Chinese hamster cells for cytotoxicity of the effluents alone and in combination with sunlight-simulating light, and for mutation induction at the 6-thioguanine-resistance locus. In addition, studies on the potential for induction of cell transformation in $\mathrm{C3H} / 10 \mathrm{~T} 1 / 2$ mouse cells, indicative of oncogenic activity, have been initiated using the effluent stream condensate material.

F1y ash was incubated at $37^{\circ} \mathrm{C}$ in cell culture medium containing $15 \%$ fetal calf serum at a concentration of. $2 \mathrm{mg} / \mathrm{ml}$. At various times the media were filtered and incubated directly with V79 cells for one week to measure colony forming ability. For periods up to 5 days of extraction, the resulting 
medium did not affect cell survival, but extraction for longer periods significantly reduced cell survival (maximum effect, $1 \%$ survival produced after 12 days of extraction). This 12-day extract did not photosensitize the cells to Westinghouse Sun Lamps (FS 20, 290-340 $\mathrm{nm}$ with a maximum intensity at $\sim 313$ $\mathrm{nm})$. However, when this same $f l y$ ash was extracted with a series of organic solvents, and the soluble material was eluted on a silica gel column with solvents of increasing polarity, it was found that the two most polar extracts, ethyl acetate and methanol, significantly enhanced the cell killing produced by the sunlight-simulating light.

The organic extract of the condensate was toxic to the cells exposed for 24 hours to concentrations over $10 \mu \mathrm{g} / \mathrm{ml}$. Interaction studies with the sunlight-simulating source indicated that pretreatment of the cells with the condensate material significantly increased the cell killing over that caused by the light alone. This effect was shown to be dependent upon both the length of pretreatment with the condensate and its concentration. Maximum photosensitization occurred when the cells were pretreated with $50 \mu \mathrm{g} / \mathrm{ml}$ of the condensate for 3 hours at $37^{\circ} \mathrm{C}$ followed immediately by the radiation (Figure 7.4). In addition, pretreatment of the cells with the condensate as above, followed by irradiation with General Electric Black Lights (F40 BL, emission maximum $365 \mathrm{~nm}$ ) over a dose range that is not cytotoxic, also results in significant photolethality.

To date, experiments on induction of mutations at the 6-thioguanine-resistance locus of V79 cells with the condensate material have yielded negative results. Additional studies are in progress employing a cell-mediated activation system to determine whether this material requires metabolic activation. for detection of mutagenic activity.

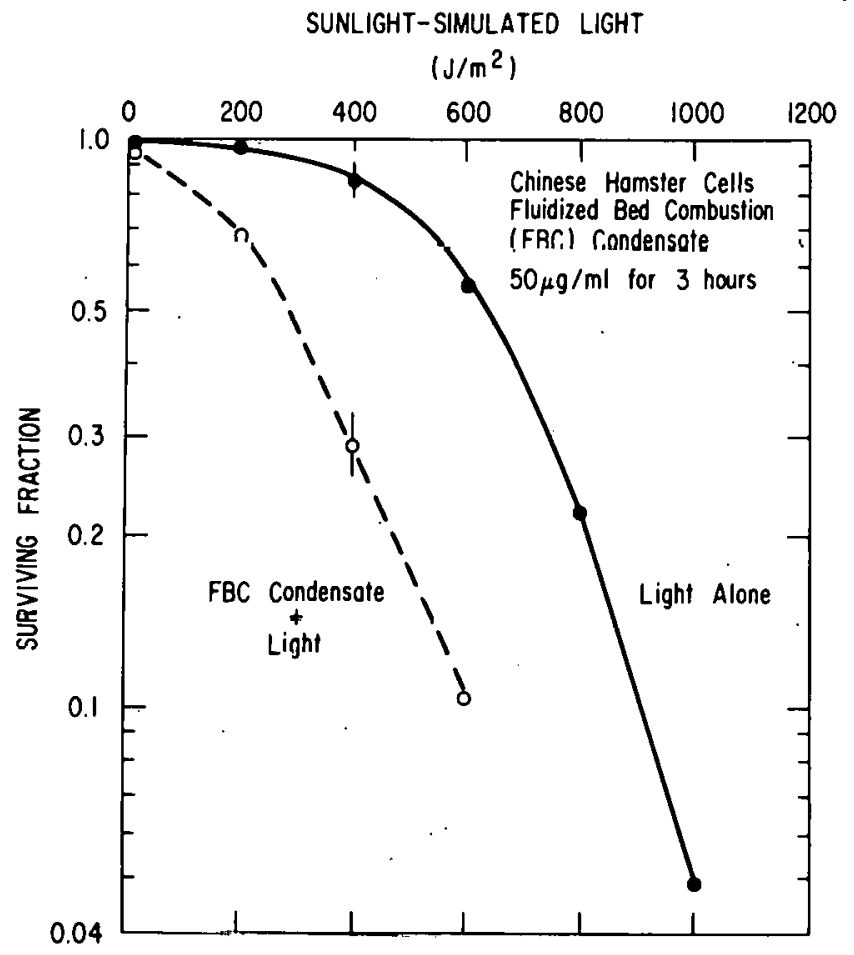

Fig. 7.4. Effect of fluidized bed combustion condensate on the sensitivity of Chinese hamster cells exposed to sunlight simulating light ( 290-340 $\mathrm{nm}$ ). The cells were treated with the condensate for 3 hours at a concentration. of $50 \mu \mathrm{g} / \mathrm{ml}$ just prior to the near-UV irradiation. Growth medium containing $0.5 \%$ acetone was used as the carrier soluciun. Uncertainties are standard errors. 


\section{MAMMALIAN TOXICOLOGY}

The final two reports deal with the exposure of mice to effluents from fluidized bed combustion and with the development of a new enzymatic test to detect mammalian tissue response to in vivo exposure of the animal to energy-related chemical pollutants.

TOXICOLOGICAL RESPONSES OF MICE EXPOSED TO REAEROSOLIZED FLY ASH FROM ATMOSPHERIC PRESSURE FLUIDIZED BED COMBUSTION

P. C. Brennan, W. P. Norris, F. R. Kirchner, T. M. Seed, ${ }^{1}$

S. P. Stearner, ${ }^{2}$ D. M. Buchholz, 1 W. T. Kickels, and S. S. Dornfeld

Male B6CF mice were exposed to reaerosolized fly ash in three separate experiments using the exposure system described by Kirchner et al. earlier in this section. The first two were of short duration, 30 hours ( 6 hours/day for 5 days), and were designed primarily to test the logistics of the exposure system, although preliminary evaluations of these mice were made. The fly ash used in these experiments, designated "Fly Ash A," was a composite of material from start-up and steady-state operation. The third experiment consisted of exposure of mice for 100 hours ( $\sim 6$ hours/day, 5 days a week) over a 4-week period, and was designed to detcrmine the organs and tissues at risk from fly ash in the respirable size range. The fly ash used was designated "CT4," and was obtained during steady-state operation only. As in Fly Ash $A$, the particles were predominantly $<5 \mu \mathrm{m}$. We learncd during the course of the 100-hour exposure that Fly Ash A is $\sim 10$ times more mutagenic itl tile Ames Salmonella test than is CT4 fly ash.

Because it was not known which tissues or systems would be primarily affected by fly ash, a number of biological responses were examined. However, special attention was given to lung alveolar macrophage function because we knew from preliminary studies that alveolar macrophages readily engulf fly ash particles. Mice exposed to Fly Ash A for one week showed a marked proliferation of alveolar macrophages and these macrophages were full of engulfed fly ash when examined by light microscopy. However, macrophages in culture from exposed mice were unable to kill a challenge dose of Staphylococcus aureus as effectively as those from control mice. This findring suggests an impaired function in the first line of defense against inhaled pathogens following short-term exposure to fly ash.

As with alveolar macrophages, other cell renewing systems showed an early proliferative response following short-term exposure to fly ash. Bone marrow stem cells, intestinal crypt. cells, and the proliferative response of spleen 1 ymphocytes were all increased following the short exposure to Fly Ash A. On the other hand, measurements of pulmonary compliance and histopathological studies did not show any appreciable change.

${ }^{1}$ Cellular Indicators Group.

2Extemal Radiation Toxicity Group. 
Only an early evaluation has been made on mice exposed to the less mutagenic CT4 fly ash for 100 hours. No effect was observed on any of the end points described above. Late effects of this exposure will be determined at 3-month intervals in the remaining mice.

BIPHENYL AS A MODEL SUBSTRATE IN THE CHARACTERIZATION OF CYTOCHROME P-450-DEPENDENT MONOOXYGENASES

D. A. Haugen, K. M. Suhrbier, W. C. Bauman, ${ }^{1}$ and J. R. Milstead ${ }^{2}$

Biphenyl is under evaluation as a model substrate for characterizing cytochrome $\mathrm{P}-450$-dependent monooxygenase systems because its metabolism is distinctly altered by in vivo exposure to polycyclic aromatic hydrocarbons, because several stable metabolites may be detected and quantitated, and because its metabolism is representative of that of polycyclic aromatic hydrocarbons. The relative and absolute amounts of three primary metabolites, 2-, 3-, and 4-hydroxybiphenyl, formed in the presence of different forms of partially purified rat liver microsomal cytochrome $P-450$, have been used to distinguish the substrate specificity of these different forms. The same approach has been used to detect alterations in the in vitro metabolism of biphenyl by liver microsomes isolated from rats treated with either phenobarbital or 3-methylcholanthrene. The former causes up to a 10-fold increase in the formation of 3-hydroxybiphenyl, and the latter causes up to a 30-fold increase in the formation of both 2-, and 3-hydroxybiphenyl, each having only a minor effect on the formation of 4-hydroxybiphenyl. Based on these observations, a procedure is under development whereby the metabolism of biphenyl is used to detect qualitative and quantitative changes in the monooxygenase systems of selected tissues in response to in vivo exposure to minimal levels of environmental chemicals, including products of coal combustion.

${ }^{1}$ Fall 1978 participant in the Undergraduate Honors Research Participation Program, Nebraska Wesleyan University.

${ }^{2}$ Summer 1978 participant in the Undergraduate Honors Research Participation Program, Southern Illinois University. 
THIS PAGE

\section{WAS INTENTIONALLY \\ LEFT BLANK}


8. HUMAN HEALTH EFFECTS AND RISK ASSESSMMENTS

\section{INTRODUCTION}

Douglas Grahn

This group's research is concerned with four general areas relevant to the quantification of the possible adverse health effects of energy technologies. These are as follows:

1) Analyses of existing data concerning the health effects of energy technologies to determine what adverse effects have occurred and to produce better estimates of what adverse effects might be expected from expansion of the same or similar technologies.

2) Construction of data bases and exploratory data analyses for the purpose of determining the degree to which the health impact of energy technologies may be modified by the socioeconomic composition of the exposed populations.

3) Development of age structured population projection models which will predict the health effects of a particular energy technology scenario with greater precision than conventional single coefficient models.

4) Development of new statistical methodologies and reevaluation of standard procedures used in the estimation of the health effects of energy technologies.

The ultimate goal of these diverse 1 ines of inquiry is to provide persons responsible for the assessment of health impacts with a unified body of fact and theory upon which they may base their analyses.

The major accomplishments of the past year include the following. Monte Carlo simulation routines for the basic DEMPAK model were developed. These routines can generate empirical error bounds for all DEMPAK projection estimates. Preliminary analyses of the Tri-state leukemia data were completed that indicate that low levels of diagnostic $X$-ray exposures may not be associated with an increased risk of adult nonlymphatic leukemias, as suggested by some earlier studies. Examination of the possible health consequences of the conversion by major users to coal from oil and natural gas resulting from the Powerplant and Industrial Fuel Use Act of 1978 identified a region of five states in the middle South as the most likely to experience the greatest relative impact. 
REGULAR STAFF

Brown, Charles D. (Scientific Assistant)

Curtiss, Jane R. B. (Scientific Assistant)

Dixon-Davis, Diana K. (Scientific Assistant)

Grahn, Douglas (Senior Biologist)

Lundy, Robert T. (Assistant Biologist)

TEMPORARY STAFF DURING 1978

Ginevan, Michael E. (Postdoctoral Appointee) 
PREDICTIVE MODELS FOR HEALTH IMPACTS FROM ENERGY RELATED ENVIRONMENTAL POLLUTION: THE DEMPAK MODEL

R. T. Lundy and M. E. Ginevan

This project is designed to generate a set of computer models which will, given any initial population, estimate the number of fatalities or illnesses that may result from exposure to a given health hazard. These models represent an advance over previous procedures in that they consider the effects of competing risks, time-varying base-line conditions, and age structured populations.

The basic model was defined and implemented earlier. During this year, several modifications and extensions have been incorporated.

Originally, the DEMPAK model produced an estimate of the population structure at any future time, and estimates of the births and deaths (allocated by age and cause) that occurred during the interval between the present and the specified time. In many circumstances, however, detailed analysis of the death rate structure is of greater interest than the actual numbers. Consequently, an option allowing the generation of multiple decrement 1 ife tables based on the projected rates was added.

Histories of individual age cohorts are also often of interest (e.g., persons less than 5 years of age in 1980). Because the original DEMPAK model lumped birth cohorts in its projections, a modification was made that generates summary projections of selected birth cohorts in isolation.

In other cases, only a "risk-estimator" is desired. This is a linear coefficient giving the relationship between a total person-dose and the resulting number of deaths or illnesses. This is strongly dependent on the population's dose history and its evolving age distribution. Thus, such a risk estimator must be specific to the initial population structure. It is valid only while the magnitude of the anticipated effects is small relative to the competing risks. DEMPAK has been modified to generate such estimators with each projection. The deviations from linearity in the estimator can be cherked by recomputing it for several dose levels.

Efforts were also initiated to specify confidence intervals for the projections. This work demonstrated that for analyses of single cohorts an approximation based on the Poisson distribution provides adequate error bounds for the projected numbers of deaths. When dealing with cross-sectional projections spanning a number of incomplete cohort histories, the situation is much more complex. Therefore a set of Monte Carlo simulation routines for DEMPAK have been developed. These programs can generate stochastic realizations of the population projection for any particular pollution scenario and population structure. By executing them a large number of times (100-500) for a given set of initial conditions, empirical error bounds for all DEMPAK projection estimates may be generated.

Present efforts involve incorporation of more realistic dose response functions, construction of improved submodels for the distribution of births 
by age of mother, and development of a set of routines to simulate a multiregional population with migration among the regions.

STATISTICAL QUESTIONS IN ASSESSMENT OF HUMAN HEALTH IMPACTS OF ENERGY RELATED EFFLUENTS

M. E. Ginevan

Epidemiological studies of the health effects of energy related effluents frequently arouse considerable controversy. More often than not the issues concern the appropriateness or potential biases of the statistical methodology employed. To date, my studies of these sorts of problems have involved two separate but related lines of research, real data analys is and development of new statistical methodology.

Data analyses have focused on a reevaluation of a possible link between diagnostic X-ray dosage and adult nonlymphatic leukemias. Some earlier studies have suggested that relatively small numbers of diagnostic X-ray exposures may be associated with significantly elevated risk of leukemia. Reanalysis demonstrates that the increases shown for low exposure persons (receiving less than 40 diagnostic $X$-rays in a 10 -year period) are due to the fact that they were lumped in a category with persons who had received very high X-ray exposure (greater than 60 in a 10-year period) who showed very high leukemia risk. The significance of the finding that persons with very high $\mathrm{X}$-ray exposure show very high leukemia risk is, however, problematic." Very high X-ray exposures may cause a precipitous rise in leukemia risk, but it is equally likely that undiagnosed leukemia manifests itself as a chronic disease state which results in X-ray exposures designed to determine the basis of ill health (Ginevan, M. E., Proceedings of the Second Workshop on Health Surveillance around Point Sources of Pollution, Albuquerque, NM, January 22-24, 1979, in press).

Further analyses of the relevant data will better determine the nature, if any, of the X-ray leukemia cause-effect relationship, and consider the validity of other claims (such as that $X$-rays cause heart disease) which have been made concerning deleterious effects of diagnostic $X$-rays.

Development of statistical methodology has been primarily concerned with expanding applications of the Poisson distribution to epidemiological studies, particularly those involving two population comparisons of cause of death data. This work has demonstrated that, under assumptions, the Poisson trials test using the binomial distribution is at least as good as more conventional chi-square procedures in terms of both sensitivity and power. Further, in terms of application it is both conceptually and computationally simpler (Ginevan, M. E., Health Phys., in press; Proceedings of the Biometric Society Meeting, Washington, DC, August 13-16, 1979, in press).

A more recent investigation concerns exploratory regression procedures used for hypothesis generation. In such analyses, "the best" $\mathrm{K}$ variable regression that $c$ an be produced from $N$ independent variables ( $K$ much less than 
$N$ ) is often judged in terms of the percentage variation explained $\left(R^{2}\right)$, but the resulting $R^{2}$ of the $K$ variable regression is an order statistic which has an expected value of much more than 0 . For the best ten-variable regression, taken from 50 independent variables, the expected $R^{2}$ is $\sim 0.20$ for a sample size of 200. Thus, we cannot test for significance using standard procedures. Work is being initiated to develop improved procedures for assessing the goodness of exploratory regressions.

INTERACTIONS OF SOCIOECONOMIC VARIABLES AND HUMAN MORTALITY PATTERNS

D. K. Dixon-Davis, D. Grahn, J. J. Collins, ${ }^{1}$ J. R. B. Curtiss, and R. T. Lundy

This study attempts to quantify the base-1ine relationship between human health, as measured by mortality, and various socioeconomic factors. In its initial phase, this study focused on 15 regions selected for their proximity to a variety of different types of energy producing facilities. Regions selected were sets of counties within 50 miles of these facilities. The selected regions sample the full spectrum of geographic, economic, and social variables in the U.S. and the full complement of current methods for generating electric power (gas, oil, coal, nuclear, and hydro).

The development of the primary data base for the 191 counties in the initial phase was completed in 1978. This data base includes mortality data for the period 1969-71 by age; sex, race, and for 28 causes as well as total mortality. Also included are data for selected socioeconomic variables derived from the U.S. Census, for air pollution (sulfur dioxide and total suspended particulates), climate (average annual maximum July and minimum January temperatures and total precipitation), for electric power production by type (nuclear, hydroelectric, fossil), and per capita consumption of beer and cigarettes (at the state level).

Regression analyses for all causes of death together in the primary data base suggest that socioeconomic factors are associated with nearly.half of the variation in the mortality. When individual causes of death were examined, it was found that the different causes vary in their association with socioeconomic factors in a consistent fashion.. Diseases that are thought to have a major genetic component (diabetes and congenital defects), and should therefore be relatively insensitive to socioeconomic factors, were not strongly associated. On the other hand, the proportion of explained variance in cardiovascular diseases and total cancer rates, which are thought to have a strong environmental component, was in excess of $35 \%$. In the coming year the predictive value of regression equations will be tested on a parallel data set consisting of all wainland U.S. countice.

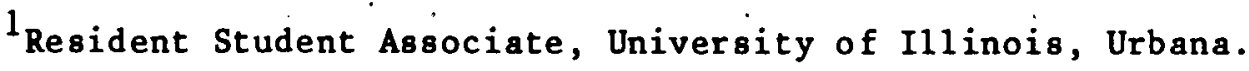


A major review (Curtiss, J. R. B., and D. Grahn, submitted for publication, 1979) was completed on the socioeconomic, demographic, cultural, and environmental factors influencing mortality. Fifteen variables are discussed and eight (education, occupation, industrial mix, urban residence, marital status, ethnic mix, and cigarette and alcohol consumption) are singled out as an initial set for further attention in the construction of models. The relationship of each to mortality is discussed. Unique to this review is the quantitative summary (presented as an appendix) of the variables influencing adult mortality. These numerical relationships, derived either directly or indirectly from published data, will support further modeling efforts.

COMPARATIVE EVALUATIONS OF THE HUMAN HEALTH IMPACTS OF DIVERSE ENERGY TECHNOLOGIES

C. D. Brown and J. R. B. Cuftiss

The energy strategy needed to meet predicted national power demand will include a mix of technologies, each carrying its own array of potential health hazards. The impact of such hazards must be considered before implementation of these new technologies so as to ensure a healthful environment, while meeting future energy demands.

Efforts over the past year have been devoted to developing procedures that enable quantitative assessment of nonuclear energy technology and application of these procedures to estimation of impacts from energy use scenarios. The primary emphasis of this work was on coal utilization. Other technologies considered for evaluation were the electric vehicle and the solar power satellite.

One major investigation concerned analysis of the coal fuel cycle. In this, accidental injury was considered as a major component of the overall health impact. Impact factors derived from current safety statistics, coal production, and railroad transportation statistics are shown in Table 8.1 . These factors are useful estimates of the contemporary impact of coal use since they are based on mid-1970's statistics. By referencing these to specific unit requirements of a coal use cycle, it is possible to assess a coal dependent energy system in terms of its impact, through accidential injury, upon an exposed occupational and general population.

Another part of our evaluations resulted in construction of a machine readable data set containing 1975 population weighted exposures to sulfur dioxide and total suspended particulates for all counties in the contiguous 48 states. This data set has recently been used in estimation of population health impacts, and will provide a valuable resource for future efforts.

A health effects assessment for the Powerplant and Industrial Fuel Use Act of 1978. (DOE/EIS-0038D) examined possible consequences of the conversion of major users to coal from oil and natural gas. Federal Region VI (Arkansas, Mississippi, New Mexico, Oklahoma; and Texas) was predicted to experience the greatest relative impact, largely as a result of occupational and public acci- 
Table 8.1. Accidental Injury Factors Associated with the Coal Use Cycle

\begin{tabular}{|c|c|c|c|}
\hline & Fatal Injuries & Nonfatal Injuries & Unit ${ }^{-1}$ \\
\hline \multicolumn{4}{|l|}{ Coal mining. } \\
\hline Surface & 0.06 & 3.37 & $10^{6} \mathrm{~T}$ mined $\operatorname{coal}^{\mathrm{a}}$ \\
\hline Underground & 0.35 & 30.93 & $10^{6} \mathrm{~T}$ mined coal \\
\hline Coal preparation & 0.03 & 0.13 & $10^{6} \mathrm{~T}$ mined coal \\
\hline \multicolumn{4}{|l|}{ Transportation } \\
\hline Railroad worker & 1.52 & 158 & $\begin{array}{l}10^{5} \text { loaded railcars } \\
(100 \mathrm{~T} / \mathrm{car})\end{array}$ \\
\hline Trespasser & 2.96 & 1.49 & $10^{5}$ loaded railcars \\
\hline Grade crossing & 3.48 & 7.08 & $\begin{array}{l}10^{6} \text { train-miles } \\
(100 \text { cars } / \text { train })\end{array}$ \\
\hline
\end{tabular}

$\mathrm{a}_{\mathrm{T}}=\mathrm{a}$ ton of 2,000 pounds.

dental injuries related to the transportation of coal to the area. On a national basis, increased coal use as a result of the Fuel Use Act is expected to result in 41 fatal and 1300 nonfatal injuries in 1985 with 78 fatal and 2500 nonfatal injuries in 1990.

In a health assessment of electric vehicle storage batteries, three batteries for near-term use (lead/acid, nickel/zinc, nickel/iron) were'extensively reviewed from the aspect of metal toxicity. As a part of this work, dose response functions for heavy metal exposure were examined. These studies demonstrated that, in the low dose range, an exponential function of the form

$$
y=a e^{b x},
$$

where $y$ is the response parameter and $x$ is the heavy metal dose, describes a number of different physiological responses and, on both practical and theoretical grounds, is preferable to other functions proposed.

Other impact assessment activities included the comparative assessment of industrial coal utilization processes (National Coal Utilization Assessment, ANL/IAPE/TM-DRAFT) and the identification of human health issues for a year 2000 scenario of a solar power satellite system. 
THIS PAGE

\section{WAS INTENTIONALLY LEFT BLANK}


9. BIOMEDICAL AND ENVIRONMENTAL EFFECTS OF ELECTRICAL STORAGE SYSTEMS

INTRODUCTION

John F. Thomson

As mentioned in the 1977 Annual Report (ANL-78-90, p. 1), a new program was begun in early 1978 that was concerned with the health and environmental effects associated with the manufacture and use of storage batteries, in anticipation of increased use in utility load leveling and in electric vehicles. The program is managed jointly by the Division of Biological and Medical Research (BIM) and the Envirommental Impact Statement Division (EIS). The initial emphasis was on the assessment of environmental and health effects of the complete cycle: mining and milling of raw materials, commerical production, use, recycling, and disposal of noncylable components. The project leader for the assessment phase is $\mathrm{Dr}$. R. K. Sharma (EIS), and both EIS and BIM personnel have been involved in the preparation of the assessments.

The original philosophy was that once areas where additional research was needed were identified as a result of the assessment; a program would be initiated in BIM to carry out such research. However, it became apparent that there were sizeable uncertainties in the technology development, which would control future development much more than toxicological considerations would.

Therefore, the decision was made 1 ate in 1978 to formulate a research program, with the objective of obtaining data on the toxicity of metals, particularly but not exclusively those of probable significance in energy-storage systems. The metals that appear to be of importance in battery development will generally receive first attention, but the approach will be essentially generic.

The program as presently formulated consists of seven projects, most of them outgrowths or extensions of current programs, ranging from molecular and cellular studies to sophisticated measurements of performance of whole animals :

1) Chemical and Molecular Interactions of Metals with Biological Molecules

2) Effects of Metals on the Cytochrome P-450-dependent Monooxygenase

3) Mouse Myeloma Cells as an in Vitro Testing System for Metal Toxicity

4.) The Effects of Metal Toxicants on Respiratory Carcinogenesis 
5) Analysis of Pregnant and Lactating Animals as a Potential "Population at Risk" from Exposure to Toxic Metals

6) Effects of Batterv-related Metals on Energy Metabolism, Activity, and Lifetime Performance, of Mice

7) Dyschronogenesis and the Circadian Toxicology of Heavy Metals in the Mammal

It may be noted that most of these systems are readily amenable to the study of mixtures of two or more metals, or mixtures of metals with other' pollutants, in order to study the possibilities of potentiation, additivity, antagonism, or synergism. These possibilities are important because the standards that have been established for toxic substances assume independence of action.

The major effort in thio program will not begin intil Ocluber 1979, and although some progress has been made in five of the seven projects during the. first few months of 1979, we feel that it would be premature to report these preliminary findings in detail.

\section{REGULAR STAFF}

Bhattacharyya, Maryka H. (Assistant Biochemist)

Danyluk, Steven S. ('Senior Chemist)

Ehret, Charles F. (Senior Biologist)

Haugen, David A. (Assistant Biochemist)

Lindenbaum, Arthur (Biachemist)

MacCoss, Malcolm (Assistant Biochemist)

Matsushita, Tatsuo (Geneticist)

Moretti, Elizabeth S. (Scientific Assistant)

Peraino, Car1 (Senior Biochemist)

Peterson, David P. (Scientific Assistant)

Rahman, Yueh-Erh (Biologist)

Sacher, George A. (Senior Biologist)

Thomson, John F. (Senior Biologist). 
10. BIOMEDICAL EFFECTS OF ENERGY TRANSMISSION

\section{INTRODUCTION}

Charles F. Ehret and George A. Sacher

This is a new program, on which work began in April of 1978. Its general aim is to ascertain whether or not sinusoidal electric fields of extremely low frequency $(10-240 \mathrm{~Hz})$ have any effect upon behavioral and neurophysiological functions, especially as indicated by perturbations of circadian oscillations in long time series, and of disturbances in ultradian episodes in the diel cycles of small rodents. This exploitation of the diagnostic significance of circadian and ultradian wave forms or "signatures" is based upon correlations between changes in signature with changes in performance, vigor, morbidity, and 1 ife expectancy (Ehret, C. F., K. R. Groh, and J. C. Meinert, Advances in Experimental Medicine and Biology, vol. 108, 185, 1978; Sacher, G. A., and P. H. Duffy, Advances in Experimental Medicine and Biology, vol. 108, 105, 1978; Sacher, G. A., and P. H. Duffy, Fed. Proc. $\overline{38}, \overline{184,1979) . ~ T h e ~ d i a g n o s t i c ~}$ use of circadian and ultradian signatures represents a highly sensitive, relevant, and unique approach to the problem of appraisal of potential environmental hazards.

The principal accomplishments of this year have been in the provision of controlled environment spaces for the experimental exposures, the design and construction of exposure facilities, behavioral and physiological monitoring systems, and dosimetric procedures for rats and mice (Ehret, C. F., et al., Proceedings of the 18th Annual Hanford Life Sciences Symposium on Biological Effects of Extremely-Low-Frequency Electromagnetic Fields, Richland, WA, October 16-18, 1978, in press). The initial designs described below are for 60-Hz electric fields at field strengths that can range from zero to $100 \mathrm{kV} / \mathrm{m}$. Field strengths in the two kinds of facilities were measured with a state-ofthe-art miniprobe provided by the National Bureau of Standards, with modifications developed at Argonne National Laboratory. 
REGULAR STAFF

Duffy, Peter H. (Scientific Assistant)

Ehret, Charles F. (Senior Biologist)

Groh, Kenneth R. (Scientific Assistant)

Meinert, John C. (Scientific Assistant)

Russe11, John J. (Scientific Associate)

Sacher, George A. (Senior Biologist)

Svihla, George S. (Biologist)

TEMPORARY STAFF DURING 1978

Cahil1, Anne L. (Postdoctoral Appointee)

Horseman, Nelson D. (Postdoctoral Appointee) 
DESIGN AND CONSTRUCTION OF BASIC FIELD GENERATORS FOR EXTREMELY LOW FREQUENCY ELECTRICAL FIELD STUDIES WITH SMALL RODENTS

C. F. Ehret, G. A. Sacher, A. Langsdorf, ${ }^{1}$ and R. N. Lewi ${ }^{2}$

The basic generator consists of toroidal end plate electrodes (inner diameter $=30.5 \mathrm{~cm}$ ) separated by lucite supporting elements at a constant distance of $30.5 \mathrm{~cm}$, and is equipped with three guard rings equally spaced between the end plates (Figure 10.1). The generator may be employed to deliver horizontal fields (in the rat experiments described below) or vertical fields (in the mouse experiments described below). The end plates are of polished aluminum and their tubular periphery is of $2.5-\mathrm{cm}$ diameter, 1 ike that of the guard rings. This diameter is sufficient to prevent corona discharge at applied voltages up to $30 \mathrm{kV}$ and field strengths up to $100 \mathrm{kV} / \mathrm{m}$. The available cylindrical space within the generator is just large enough to accommodate the animal cages described below; the small size of the generator permits the use of transformers of less than 100 watts to generate field strengths as high as $100 \mathrm{kV} / \mathrm{m}$. The guard rings enable the use of small parallel plate designs in which field distortions are minimized despite the small ratio (approximately 1:1) of end plate diameter to distance between end plates. The end plates are supplied voltages from the secondary of a high voltage transformer while the guard rings are supplied from a resistive divider across the transformer secondary or from taps on the secondary.

DESIGN AND CONSTRUCTION OF CAGE FACILITIES FOR CIRCADIAN STUDIES OF EXTREMELY LOW FREQUENCY ELECTRIC FIELD EFFECTS IN THE RAT

C. F. Ehret, K. R. Groh, J. C. Meinert, and G. Svih1a

The basic cage and data collection system for circadian studies in the rat is a modification of one that has been used successfully for several years in circadian studies (Ehret, C. F., et al., Science 188, 1212, 1975). The system consists of long-term housing for a single rat in the form of a glass cylinder, equipped with parts for ventilation, for water, and for food, and surrounded by an antenna for radiotelemetry reception of core temperature signals broadcast by a temperature transducer-transmitter implanted intraperitoneally. The radiotelemetry antenna is located within the central guard ring, which is held at ground potential in this configuration. Novel features in the electric field facility include a floor fabricated of a $2.5 \times 2.5 \mathrm{~cm}$ mesh glass gridwork, which is suspended by nylon strands from a force transducer (Figure 10.2). Ultradian activity episodes are recorded as displacement forres each time the rat moves within the cage; transducer values recorded during quiescent phases reflect weight and weight changes. Behavioral responses are measured by means of programmed tapping and bar-press devices that are a part of each cage. In operant conditioning response paradigms, rats can

${ }^{1}$ Physics Division.

2Electronics Division. 


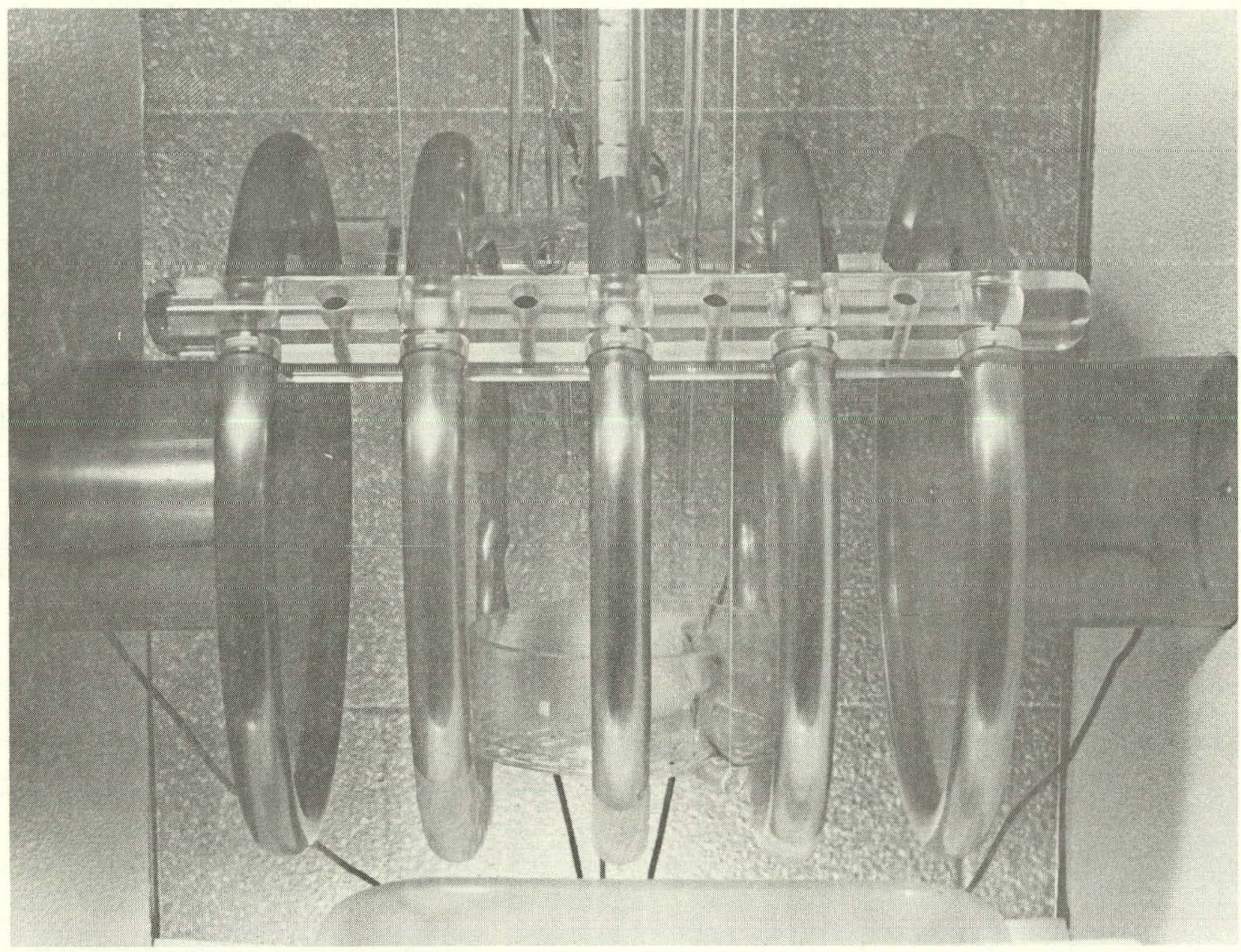

Fig. 10.1. Closeup view of horizontal field generator. The glass grid upon which the rat is seated is suspended by nylon cord. Glass food hoppers with pelleted food enter the cage top through the feeding guides. Note also the bar press (cage center right) and ball press (cage center left) devices.

be rewarded with food from motor driven automated glass food hoppers that descend from cylindrical glass hopper guides that cap the cage. In the rat cage, the E field is horizontal, and the ground plane is defined by the central guard ring that bisects the cage vertically; this places metal-free watering and feeding devices and the radiotelemetry antenna in the center of the ground plane. The cage is housed in a sound dampened booth within a controlled environment room along with nine other cages. Two such rooms are projected, and 8-track programs of the sounds of rat room activity will be broadcast constantly to the 20 animals housed in the two rooms. Booths are surrounded by aluminum foil shielding on sides and tops, but are covered by aluminum screening ( 7 holes/cm mesh) at front and rear to permit ventilation and the entrance of light for photo-entrainment. 


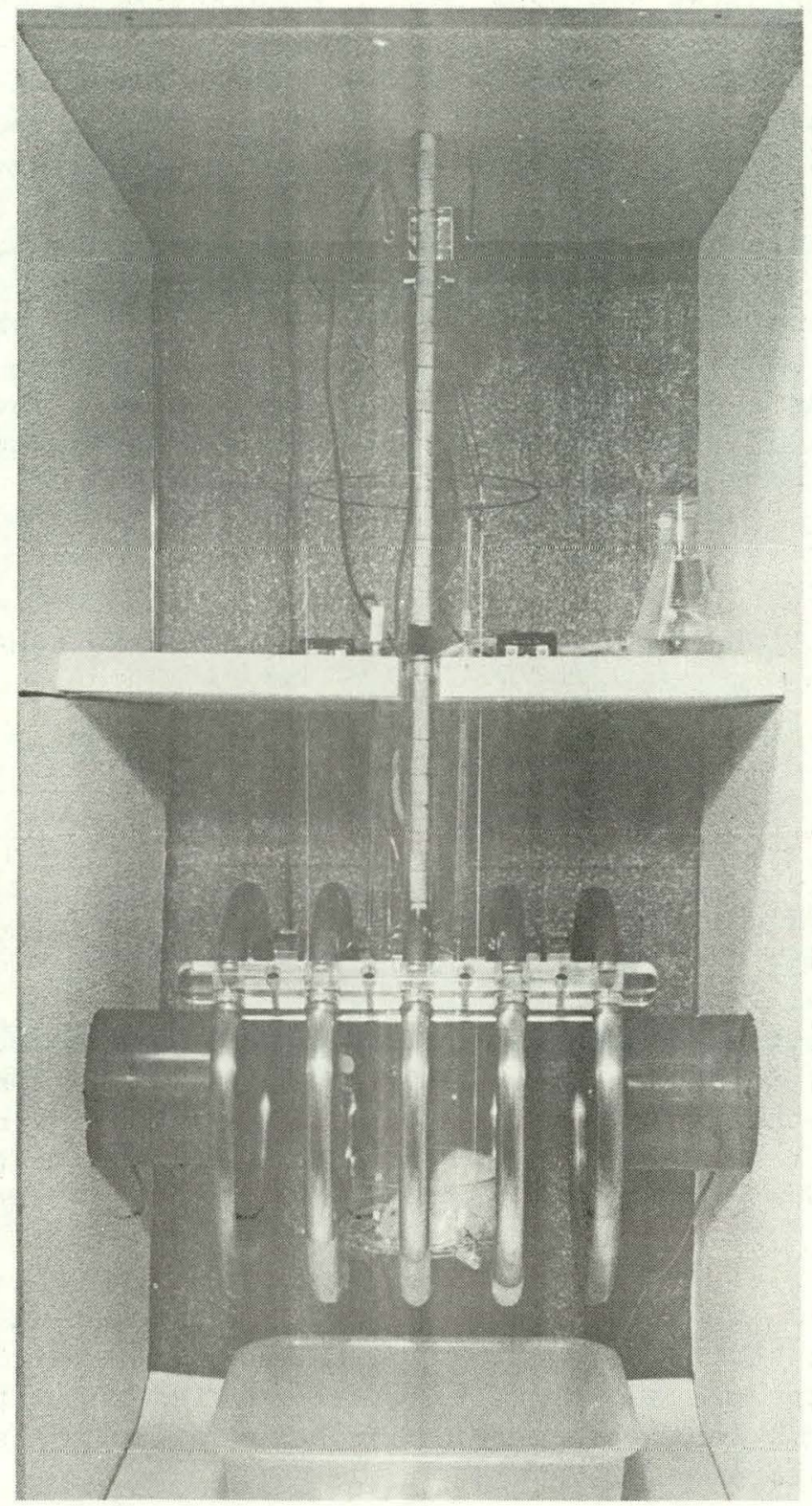

Fig. 10.2. Complete horizontal field generator unit. The lower portion shows the exposure facility consisting of the basic field generator and the caged rat within it. The rat sits on a glass grid suspended by nylon cords from a force transducer (see upper portion, ceiling). The food hoppers enter from the top of the cage. The water supply bottle is in upper right and enters the cage area as a spigot in the top cage center (cannot be seen). Limit switches in the upper portion are connected to bar-press devices for operant-controlled conditioning experiments. 
An on-line controller and data acquisition system is used for programming and monitoring the various environmental factors and measured outputs. Each installation (cage) in the electric field facility produces three analog signal outputs--one for behavior, one for activity, one for temperature--which are collected automatically at variable intervals by a programmable microcomputer. Circadian variations in behavior are monitored by counting bar presses in response to audible cues given at various circadian phases, with food as a reward. Circadian activity and body weight f1uctuations are recorded from impulses that originate in the force transducer described above. Signals relevant to circadian fluctuations in deep body temperature, broadcast by implanted transmitters and received by the antennae described above, are then enhanced by individual pre-amplifiers, converted from frequency to voltage, digitized, and stored as data.

EFFECTS OF HIGH-VOLTAGE FIELDS IN ENERGY METABOLISM AND BEHAVIOR OF MICE

G. A. Sacher, P. H. Duffy, and J. J. Russe11

The major efforts in this project were directed toward the design and construction of cage facilities for the exposure of mice to high voltage $60-\mathrm{Hz}$ electric fields, and for monitoring the diel cycles of energy metabolism, motor activity, and thermoregulation (the MAT system).

The MAT system provides automatic logging of oxygen consumption, carbon dioxide production, motor activity, and body temperature continuously on each of eight mice simultaneously for periods up to 10 days (Figure 10.3). The use of the MAT variables for defining physiological health status was established in prior publications (Sacher, G. A., and P. H. Duffy, Fed. Proc. 38, 184, 1979).

Cages and watering devices were constructed, utilizing materials with high dielectric constants, and minimizing the use of metals, to maintain field uniformity. The exposure and monitoring are carried out within 1 ight- and temperature-programmable environmental chambers to isolate subjects from ambient noise and vibrations.

The electric field generator employs a circular upper electrode and three guard rings to produce a uniform electric field within the metabolism module (Figure 10.4). A subsequent field mapping, utilizing the electric field probe developed by Martin Misakian of the National Bureau of Standards, showed that the field varies by no more than 3 percent within the empty cage (Figure 10.5). A high voltage patch-panel permits flexible power distribution from two $35-\mathrm{kV}$ transformers to the eight individual field generators. A carefully designed interlock system prevents electrical hazards. High voltage connections are made by means of flexible high voltage cable, and cable terminations are made with a newly developed multilayer taping process. These procedures provide compact and corona-free installation. 


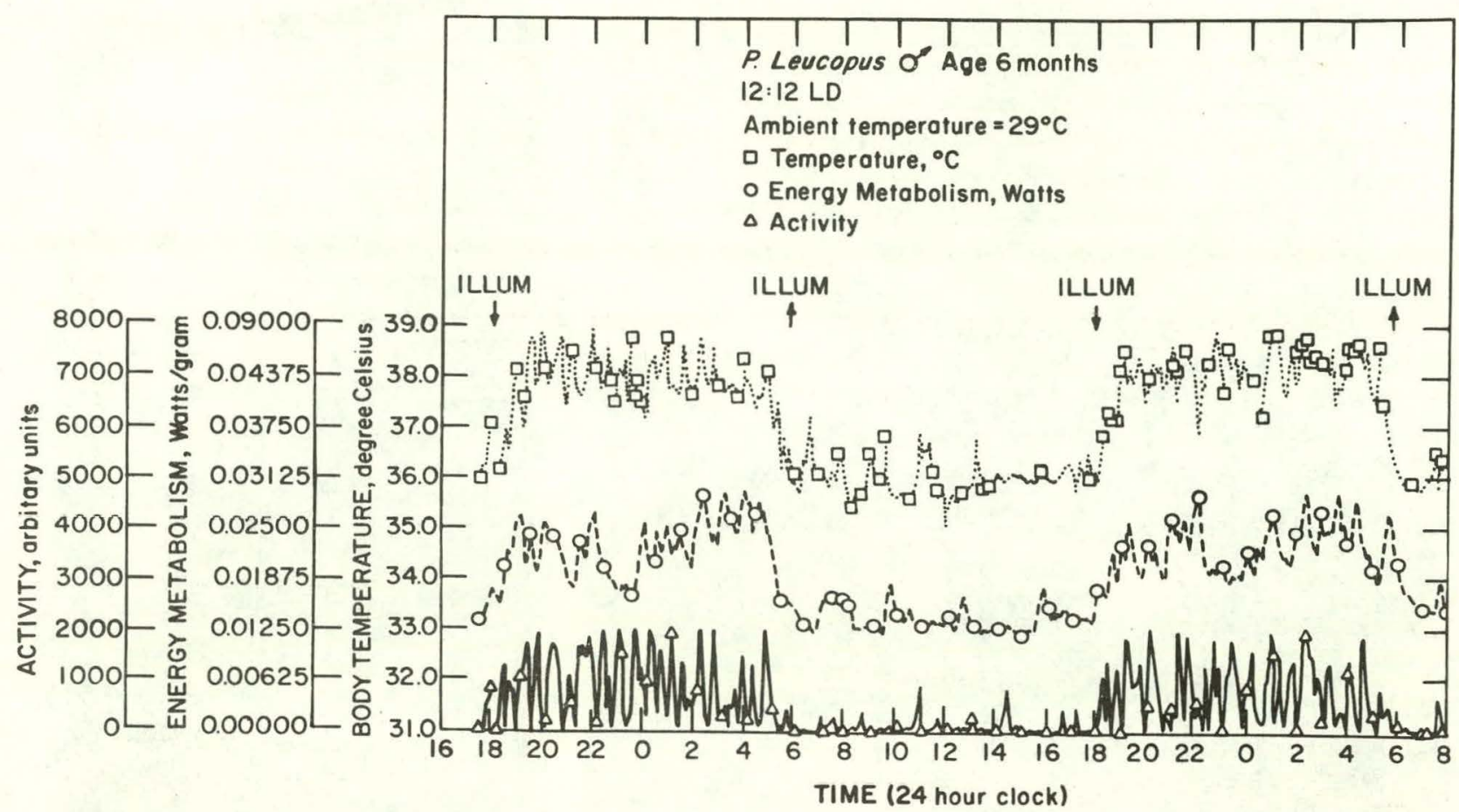

Fig. 10.3. A 40-hour sample of the energy metabolism and activity of an individual mouse. The three variables monitored are, from bottom to top: motor. activity, measured as the kinetic energy of movement in the metabolism cage; rate of energy metabolism in watts per gram, estimated from rate of oxygen consumption; and deep body temperature in degrees Celsius, measured by radiotelemetry from a small temperature transducer transmitter implanted in the peritoneal cavity of the mouse. The animal subject is a young white-footed mouse, Peromyscus leucopus. The light-dark cycle is 12 hours of darkness

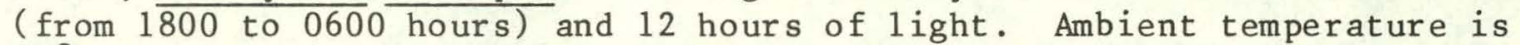
$29^{\circ} \mathrm{C}$, which is within the thermoneutral zone for this species. Laboratory mice and wild mice give similar records under these conditions. 


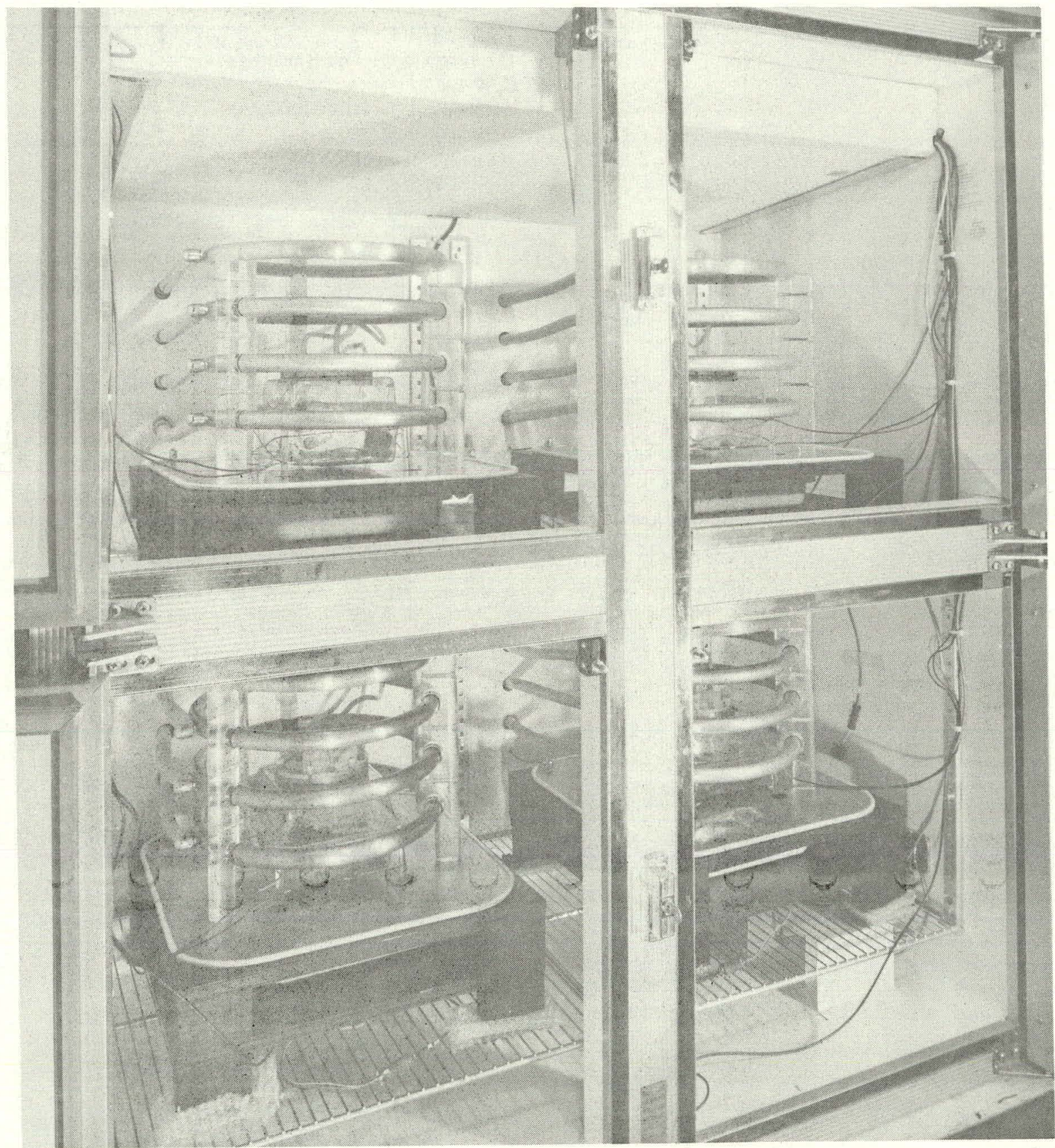

Fig. 10.4. Four individual modules for monitoring energy metabolism and activity of mice in high-voltage electric fields, shown in place within the environmental chambers. A total of eight mice can be monitored in the chamber, each equipped with independent high voltage supply and control systems. The upper electrode with $2.5-\mathrm{cm}$ diameter annular edge, and the three $2.5-\mathrm{cm}$ diameter guard rings are shown with high-voltage cables connected. The metabolism cage is insulated from the ground plane electrode, and is mounted on a spring and dashpot suspension below the ground electrode. The antenna for pickup of the telemetered temperature signal can be seen wrapped around the outside of the upper left metabolism cage. 


\section{E-FIELD VERTICAL}

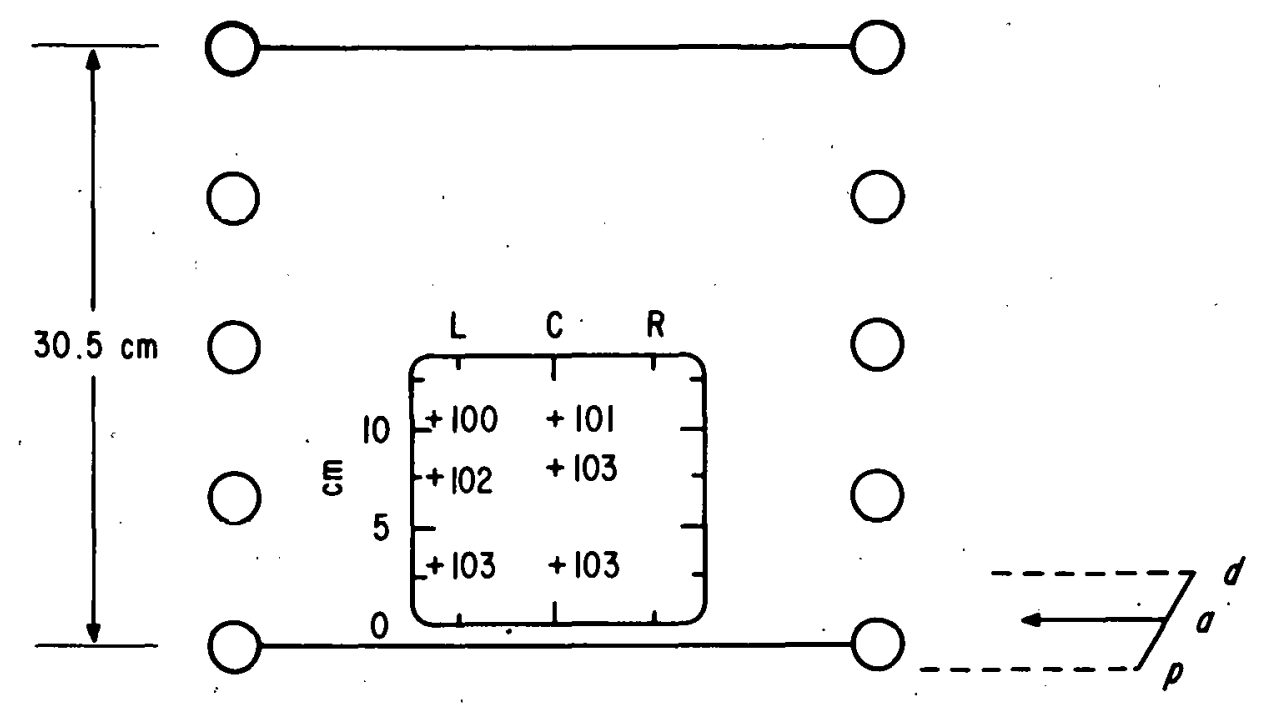

Fig. 10.5. Schematic cross-sectional view of exposure module, to show the variation of field strength within the empty metabolism cage. The field intensity in the empty field, in units of volts per meter $(\mathrm{V} / \mathrm{m})$, has about a $3 \%$ range of variation within the space that the mouse will occupy. However, this is only a confirmation of the design specifications and not an indication of the field experienced by the living animal, for the presence of the animal grossly distorts the field, and every change of position of the animal alters its local field.

A 32-channel data acquisition system controlled by an LSI-11 microcomputer has been developed for system management and data processing. Data as acquired will be stored in a magnetic tape cassette storage system. separate microcomputer system for data plotting and simple statistical analysis incorporates a twin-disk mass storage system. The newly developed computer software emphasizes user convenience, and greatly reduces experimenter time in comparison to our previous data-management programs. More complex statistical procedures, such as time series analysis, will be carried out by the central computer in the Applied Mathematics Division. 
EFFECTS OF HIGH-VOLTAGE FIELDS ON BEHAVIOR IN THE MOUSE

W. Obermeyer ${ }^{1}$ and G. A. Sacher

Our behavioral study in mice of the effect of imposition or presence of extremely low frequency electric fields has three foci: determination of (1) perceptual and aversive thresholds; (2) changes in ongoing behavior, both in itself and as an indication of physiological change; and (3) changes in electrophysiological parameters as measures of behavioral state and brain activity.

Two Hotpack incubators have been modified to serve as controlled environment experimental enclosures. Each of these is capable of containing two experimental chambers and one is currently capable of containing two field generators around the chambers. Experimental chambers are a part of the MAT system as described in the preceding report. One of these has been modified by the addition of a metal grid which is capable of delivering a mild aversive electric shock stimulus of known intensity to the experimental animal.

In order to measure bar-press response in determining thresholds of perception and aversion, an optical switch has been designed and built which is compatible with MAT measurement and minimal field distortion. Massey-Dickinson logic modules have been assembled and programmed to permit data acquisition and experimental control for the first experimental paradigm for determination of perceptual threshold. Software parameters for eventual control of these experiments by current computer hardware have been specified. For determination of physiologic changes, a protocol has been written to use activity as a measure of the effect of electric fields on permeability of the blood:brain barrier to quatefnary amines. For studies of behavioral state and brain activity, a polygraph for data acquisition and a stereotaxic instrument for electrode placement have been acquired. 
11. MOLECULAR BIOPHYSICS

INTRODUCTION

Steven S. Danyluk

In Molecular Biophysics, our efforts are committed to basic research in areas of molecular biology/biochemistry, biophysics, and chronobiology, coupled with supportive research for Divisional programs in toxicology and health effects of environmental pollutants generated by alternate energy technologies. Two main themes are encompassed in these studies; one deals with development of fundamental structural and biophysical information for biological systems, and the second is concerned with basic molecular and physiological mechanisms of circadian rhythms. In both instances the emphasis is on problems of major contemporary interest, namely the molecular basis of biological organization and causality.

In the structural area a range of biophysical methods, including $\mathrm{X}$-ray crystallography and magnetic resonance spectroscopy, are being used to probe three-dimensional structures and properties of important classes of biological molecules. Further progress has been made in refinement of the X-ray diffraction structure for the Mcg Bence-Jones dimer. Using the interactive computer graphics system at the University of North Carolina, the coordinates were refined for nearly all of the nonhydrogen atoms of the molecule. The results have enabled a better definition of key structural features, such as the immunoglobulin fold, and have identified an anomalous region of minimal electron density arising from one of the hypervariable loops. Work is also under way on the X-ray structure determination for (Fin), a:k-type Bence-Jones protein, and preliminary results have already been obtained for the angle between variable and constant segments of the molecule. An attempt is now being made to solve the Fin structure by molecular replacement methods.

With completion of the base-line conformational analyses of di-ribonucleoside monophosphates, our attention has shifted to the impact of base modification upon conformational properties. Of particular interest here are the effects of alkylating mutagens and photohydration upon overall structure, and the consequences of the effects on function: NMR results obtained to date show that $\mathrm{N}-1$ methylation of adenine rings causes major disruption in ordered, base-stacked conformations of adenylate dimers. Implications of these findings for tRNA and mRNA structures are now under exploration. Success was achieved in synthesis of a new class of compounds in which a potent antitumor drug such as arabinocytidine (arac) is coupled via a pyrophosphate linkage to 1,2-dipalmitin. These molecular depot drugs hold promise of improved efficacy of the antitumor agent while permitting selective tissue targeting. Initial tests: in the $\mathrm{L} 1210$ system and in the MCP-11 mouse myeloma 
cell line show that araCDP-dipalmitin is indeed acting as a molecular depot or prodrug. Further testing on whole animal systems is now under way at Roswell Park.

New initiatives undertaken in the past year in the bio-structure area include the application of solid state NMR methods and development of a pulsed neutron small-angle diffractometer. Using cross-polarization and magic-angle spinning techniques originally developed for solid state studies, wel1-resolved high-resolution ${ }^{13} \mathrm{C}$ spectra have been obtained for biological molecules in intact tissue. These measurements, if verified by work now in progress, open up possibilities for direct structure/conformation investigations in cells and tissues under in vivo conditions. The small-angle diffractometer, scheduled for installation on the ZING-P' pulsed neutron source early in 1980, is primarily deslgned for exploration of operational characteristics of a pulsed diffractometer and will serve as a prototypc for an instrument to be constructed at the Argonne intense pulsed spallation neutron source IPNS-1,

In the circadian studies, a particularly 1nteresting finding relates to the elfect of chronic administration of the chronobiotic phenobarbital in rats. On the basis of circadian criteria alone, it was possible to characterize a complete habituation, addiction, and withdrawal sequence. The sequence consists of (1) an early habituation effect, characterized by transient circadian dyschronlsm; (2) a "steady-state" tolerance or addiction effect, with remarkably stable amplitude enhancements and psi-shifts, dependent in magnitude upon phase-ratio of the zeitgeber; and (3) an abstinence syndrome characterized by severe dyschronism when the chronobiotically active drug 1 s withdrawn.

\section{REGULAR STAFF}

Ainswul Ll, Clinton F. (Sclentific Assistant)

Borso, Charles S. (Assistant Blophysicist)

Danyluk, Steven S. (Senior Chemist)

Ehret, Charles F. (Senior Diulugisc)

Groh, Kenneth R. (Scientific Asststant)

MacCoss, Malcolm (Assistant Biochemist)

Meinert, John C. (Scientific Assistant)

Schiffer, Marianne (Biophysicist)

Westholm, Florence A. (Scientific Assistant)

TEMPORARY STAFF DURING 1978

Ryu, Eung K. (Postdoctoral Appointee)

Schwartz, Herbert M. (Postdoctoral Appointee)

Stevens, Fred J. (Postdøctoral Appointee)

Tewari, Ravindra (Postdoctoral Appointee) 


\section{ALKYLATION EFFECTS ON NUCLEIC ACID CONFORMATIONS}

S. S. Danyluk, C. F. Ainsworth, and M. MacCoss

Alkylation of nucleic acids by chemical mutagens and carcinogens produces a multiplicity of products depending upon the nature of the base ring, electrophilicity of the alkylating agent, and the presence of activating enzymes. For example, alkylation of adenine nucleotides can occur at six sites (Figure 11.1); strong electrophiles such as $\mathrm{N}$-methy $1-\mathrm{N}-$ nitrosourea and $\mathrm{N}$-methyl-N ${ }^{1}-\mathrm{nitro}-\mathrm{N}-$ nitrosoguanidine react with available oxygen donors, whereas weak electrophiles dimethyl sulfate and methyl methane sulfonate show a higher tendency to methy1ation at $\mathrm{N} 1, \mathrm{~N} 3$, and $\mathrm{N} 7$. While the chemical modification of nucleotides by methylating agents has been studied in considerable detail (Singer, B., and J. T. Kusmierek, Biochemistry 15, 5052, 1976), less is known about the impact of base methylation upon nucleic acid conformation and structure. This aspect has now been explored for several base-modified diribonucleoside monophosphates.

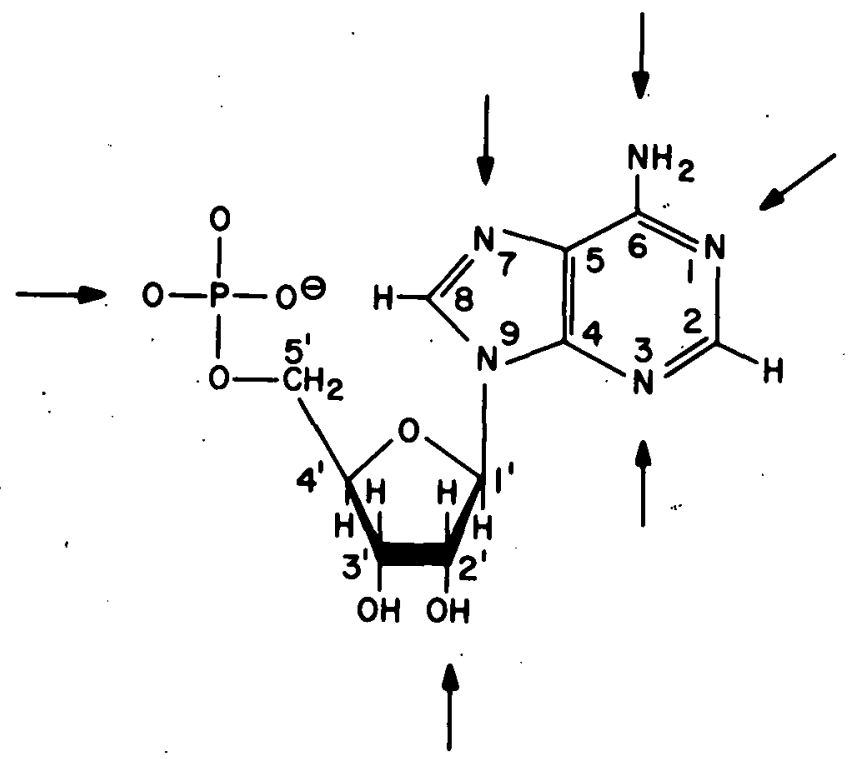

Fig. 11.1. Putative methylation sites on an adenine nucleotide.

Using the powerful alkyating mutagen dimethyl sulfate, selective methylation (Brinacombe, R. L. C., et al., Biochemistry 11, 2452, 1965) was achieved at the N1 adenine position of ApA, ApU, and UpA. High-resolution proton NMR spectra were recorded at $220 \mathrm{MHz}$ for each of the methylated dimers ${ }^{\mathrm{Me}}{ }_{\mathrm{Ap}} \mathrm{Me}_{\mathrm{A}}$, $\mathrm{Me}_{\mathrm{ApU}}$, and $\mathrm{Up} \mathrm{Me}_{\mathrm{A}}$ in $\mathrm{D}_{2} \mathrm{O}$ under varying conditions of $\mathrm{PD}$ and temperature. An evaluation of conformational properties from NMR parameters followed proce dures developed in earlier dimer studies (Kondo, N. S., and S. S. Danyluk, Blochemistry $15,756,1976)$.

Methylation of the adenine ring produces a profound alteration in dimer conformation, the change being most striking for the adenylate dimer. Thus, covalent linkage of the methyl group at $\mathrm{N} 1$ with concomitant introduction of a positive charge into the purine ring causes substantial destacking of bases 
in ${ }^{\mathrm{Me}}{ }_{\mathrm{Ap}} \mathrm{Me}_{\mathrm{A}}$ relative to $\mathrm{ApA}$, i.e., $8 \%$ versus $38 \%$. Accompanying the destacking are shifts in ribose pucker from ${ }^{3} \mathrm{E}$ to ${ }^{2} \mathrm{E}$ and detectable decreases in guacheguache populations about $\mathrm{C} 4^{\prime}-\mathrm{C} 5^{\prime}$ and $\mathrm{C} 5^{\prime}-05^{\prime}$ bonds. All of these effects are consistent with a less ordered conformation for the methylated dimer. Similar trends are observed for ${ }^{\mathrm{Me}} \mathrm{ApU}$ and $\mathrm{Up}^{\mathrm{Me}} \mathrm{A}$, but the extent of conformational perturbation is less marked due in part to the absence of repulsive electrostatic interaction between adjacent positively charged base rings, and the existence of an initial less ordered structure for unmodified purine-pyrimidine and pyrimidine-purine dimers.

Based on these results and in view of the ubiquitous presence of methylated bases in naturally occurring polynucleotides, it is tempting to assign a role for methylated adenylate residues, and by inference $\mathrm{N}-7 \mathrm{Me}$ guanine bases, as conformational mediators between ordered and open structural domains of tRNA and mRNA molecules. From this perspective, methylation of availablc base sites by carcinogens pronturos irrevoroiblc conformatiund clianges wich accompanying disruption of biological function. Experiments are currently. under way to test this hypothesis.

HIGH-RESOLUTION MAGNETIC RESONANCE SPECTROSCOPY OF INTACT BIOLOGICAL MATERIALS

S. S. Danyluk and H. M. Schwartz

High-resolution MMR spectroscopy of condensed state materials such as organic solids, biopolymers, and intact biological systems (cells, tissue) has been a long-standing goal of investigators in this field. Its attainment has been held back by extensive line broadening of signals for solids and ordered polymeric states ( 1 ine widths of $100-1000 \mathrm{~Hz}$ are typical. for ${ }_{\mathrm{H}}$ and ${ }^{13} \mathrm{C}$ nuclei as compared with $<1 \mathrm{~Hz}$ widths in solutions of small organic and biological molecules), and by extremely low sensitivity, an especially critical concern for nuclel with low natural abundance such as ${ }^{13} \mathrm{C}$. These problems have been resolved to a considerable degree by recent theoretical (Pines, A., M. G. Gibby, and .T. S. Waugh, J. Chem. Phys. 59, 569, 1973) and Instrumental developments (Schaefer, J., E. O. Stejskal, and R. Buchdahl, Macromolecules, 8. 291, 1975). Using a combination of cross-polarization (CP) and magic-angle spinning techniques, dramatic reductions in ${ }^{13} \mathrm{C}$ line widths accompanied by marked enhancements in signal to noise ratio have been obtained for various polycrystalline solids and polymers. We have now extended the CP magic-angle NMR approach to measurement of high-rcsolution ${ }^{13} \mathrm{C}$ spectra for biological tissue samples.

An example of the spectral resolution achieyable by CP magte-angle spectroscopy is given in Figure 11.2 where the ${ }^{13} \mathrm{C}$ natural abundance spectrum is shown for canine Achilles tendon. Tendon was selected as the test material because of its relative molecular homogenlety, $1 . e ., 70-75 \%$ collagen, and the high degree of orientational order in the tissue. Under conditions of the experiment (see Figure 11.2 for details), a remarkably wel1-resolved spectrum is obtained with signal 1ine widths approaching those for blological molecules in solution. Definttive assignments can be made of signals arising from specific amino actd groups, as noted in Figure 11.2. Two particulary distinct, narrow signals centered at $159.0 \mathrm{ppm}$ and $44.0 \mathrm{ppm}$ are unmistakably due to 
$C_{\zeta}$ atoms of arginine/tyrosine and glycine $\alpha$-carbon atoms, respectively. All of the signals broaden when the spinning axis orientation is set at $B=0^{\circ}$, with the largest change seen for arginine/tyrosine $C_{\zeta}$, consistent with large chemical shift anisotropies for this carbon nucleus.
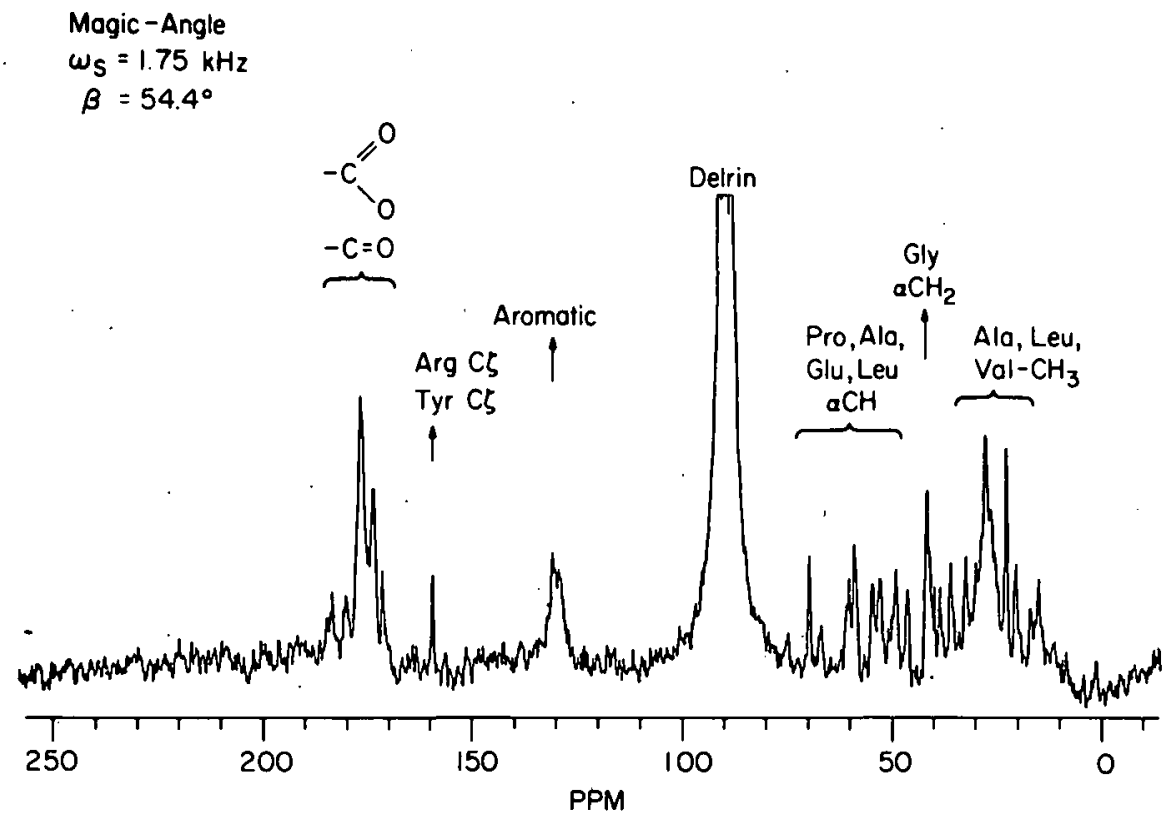

Fig. 11.2. ${ }^{13} \mathrm{C}$ natural abundance spectrum for canine Achilles tendon measured with rapid magic-angle spinning. Tissue samples were tightly packed with the long axis of the tissue vertically oriented in the rotor. The spectrum was recorded at ambient temperature on a Nicolet $\mathrm{NT}-150 \mathrm{CP}$ spectrometer at a ${ }^{13} \mathrm{C}$ resonance frequency of $37.735 \mathrm{MHz}$ and a constant spinning rate of $\omega_{s}=1.75 \mathrm{kHz}$. A proton dipolar decoupling field $\gamma \mathrm{H}_{2} / 2 \pi \sim 35 \mathrm{kHz}$ was used, and the spectrum represents 2,000 accumulated free induction decays. No cross-polarization contact was employed in obtaining the tendon spectrum.

These "range-finding". spectroscopic measurements demonstrate that the means now exist for studying structures of biological molecules directly in tissue, and, by extension, in other biological systems--cells, organs, etc.-with a resolution and precision hitherto possible only for solutions of much smaller organic and biological molecules. Areas where the above approach may be especially useful are in definition of tertiary structures for biological molecules, e.g., protetns, nucletc actds, in whole biological systems, and in comparison of these structures with $\mathrm{X}$-ray crystallographic results. Such studles are currently in progress. 
NEW SYNTHETIC USES FOR ADENOSINE $\mathrm{N}^{1}$-OXIDE DERIVATIVES

M. MacCoss, E. K. Ryu, R. S. White, ${ }^{1}$ and R. L. Last ${ }^{2}$

The introduction of novel functionalities into the sugar moiety of nucleoside derivatives is usually accomplished by nucleophilic displacement of suitable leaving groups with an appropriate nucleophile. In the adenosine series, a major problem has been the concomitant formation of $\mathrm{N}^{3} \rightarrow$ sugar intramolecular cyclized products: 'l'he presence of an acyl group at $\mathrm{N}^{6}$ decreases the nucleophilicity of $\mathrm{N}^{3}$ and reduces cyclization products but in turn imposes restrictions on the synthetic options available. In the past year, we have shown that $\mathrm{N}^{1}$-oxides similarly prevent intramolecular cyclization during nucleophilic substitution reactions and that reduction to the parent nucleoside can be readily achieved using Raney nickel or hexachlorodisilane. The synthet1c utillty

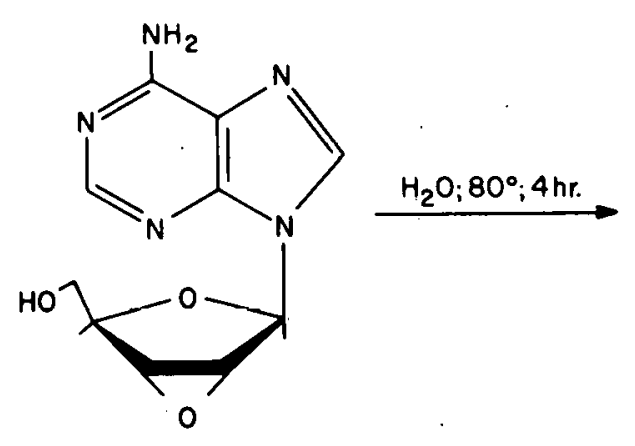

(14)

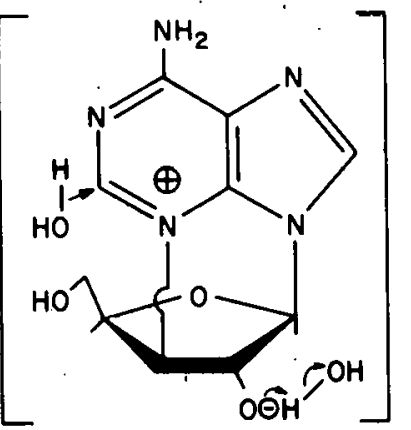

(15)

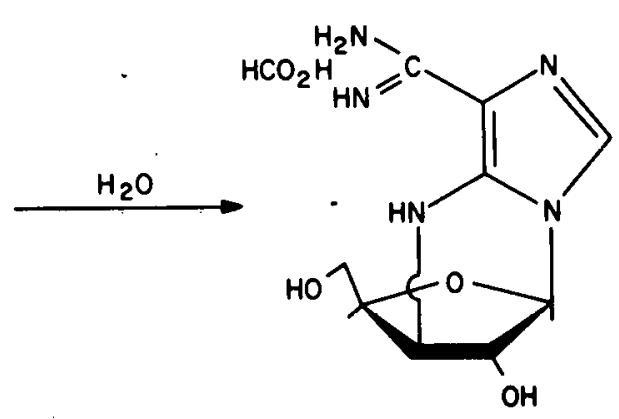

(16)

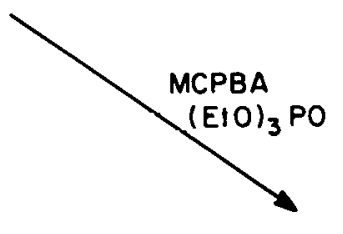

₹ $\mathrm{H}_{2} \mathrm{O} ; 80^{\circ} ; 4 \mathrm{hr}$.<smiles></smiles>

(17)

Fig. 11.3.

${ }^{1}$ Spring 1979 participant in the Undergraduate Honors Research Program, Northern Illinois University.

2 Fal1 1978 participant in the Undergraduate Honors Research Program, Ohio Wesleyan University. 
has been demonstrated by the synthesis of $5^{\prime}$-iodo-5'deoxy-2', $3^{\prime}-0$-isopropylideneadenosine- $\mathrm{N}^{1}$-oxide and $5^{\prime}$-azido-5'-deoxy-2, $3^{\prime}-0$-isopropylideneadenosine-N $\mathrm{N}^{1}$ oxide from $5^{\prime}-0$-tosy $1-2^{\prime}, 3^{\prime}-0$-isopropylideneadenosine-N $\mathrm{N}^{1}$-oxide, and $2^{\prime}, 3^{\prime}$-anhydroadenosine-N ${ }^{1}$-oxide from $2^{\prime}, 3^{\prime}$-anhydroadenosine (see Figures.

11.3 and 11.4). In addition, an improved general synthesis of $\mathrm{N}^{1}$-oxides (using m-chloroperbenzoic acid in triethylphosphate) has been developed.

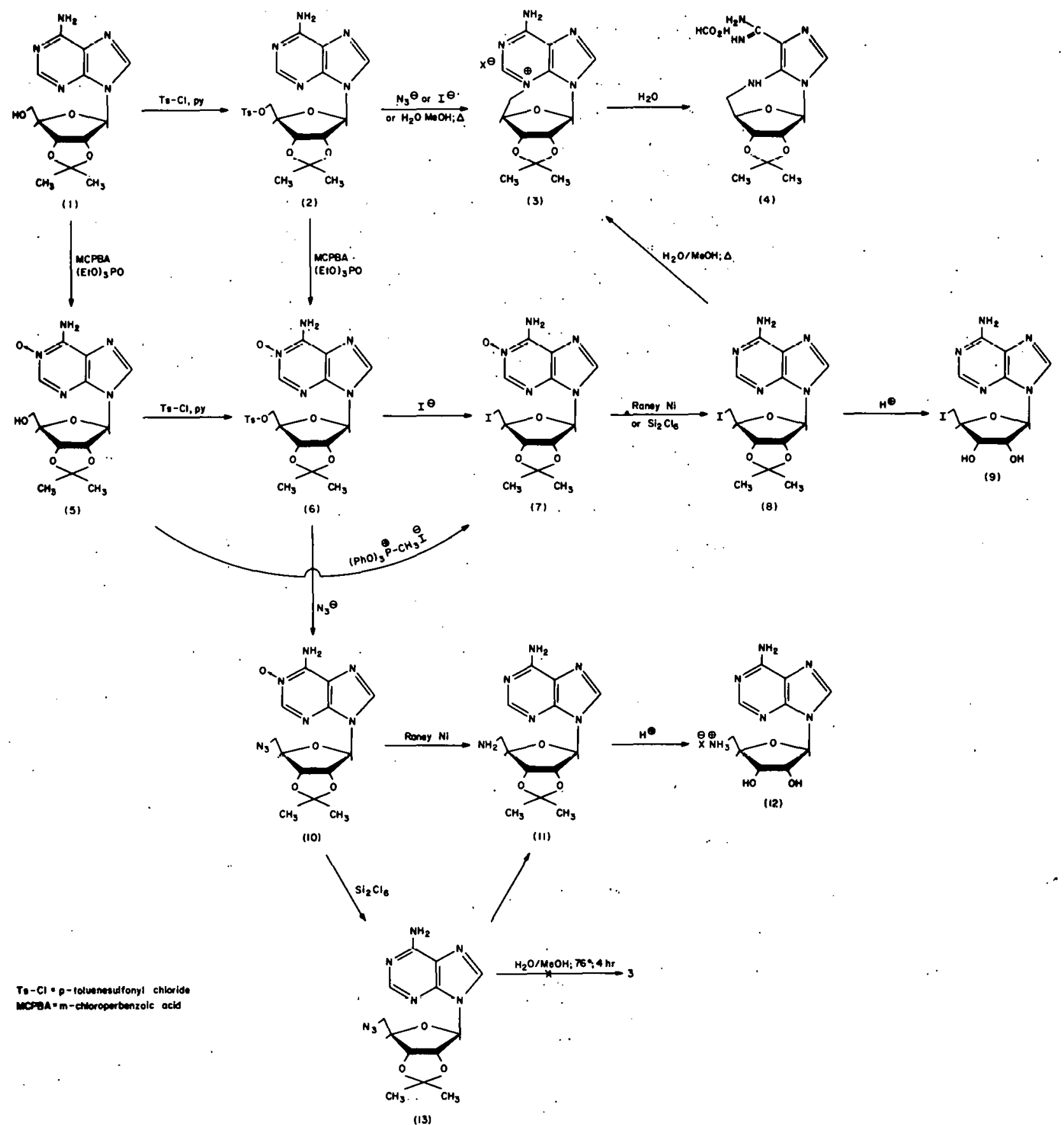

Fig. 11.4 
SYNTHESIS OF POTENTIAL ANTIMETABOLITES AND MOLECULAR DEPOT DRUGS

M. MacCoss and E. K. Ryu

In an effort to increase the chemotherapeutic efficacy of the nucleoside analogues arabinocytidine, arabinoadenosine, and tubercidin, these nucleosides have been attached to 1,2-dipalmitin, via a pyrophosphate linkage to produce araCDP-dipalmitin (MacCoss, M., et al., Biochem. Biophys. Res. Commun. 85, 714, 1978), araADP-dipalmitin, and: TuDP-dipalmitin, respectively. These prodrugs, as sonicated solutions, have been evaluated in the mouse myeloma MCP-11 ce11 line, in collaboration with T. Matsushita (see Section 14 of this report), and in the L-1210 test system, in collaboration with C. I. Hong, Roswell Park Memorial Institute, Buffalo, NY. Such sonicated solutions of araCDP-dipalmitin and TuDP-dipalmitin showed good activity (Table 11.1) whereas araADP-dipalmitin is insoluble in all solvents so far examined. In addition, carefil preinrilbation studies of the prodrug in the cell culture media and reversal of inhib1tion using deoxycytidine (in the araCDP-dipalmitin case) have verified that these phospholipid derivatives are acting as prodrugs or "molecular depots" of the parent drug which is then being șlowly. released by enzymatic hydrolysis. Also, it has been possible to show that release of the drug is occurring intracellularly and not in the culture medium prior to uptake by the cell.

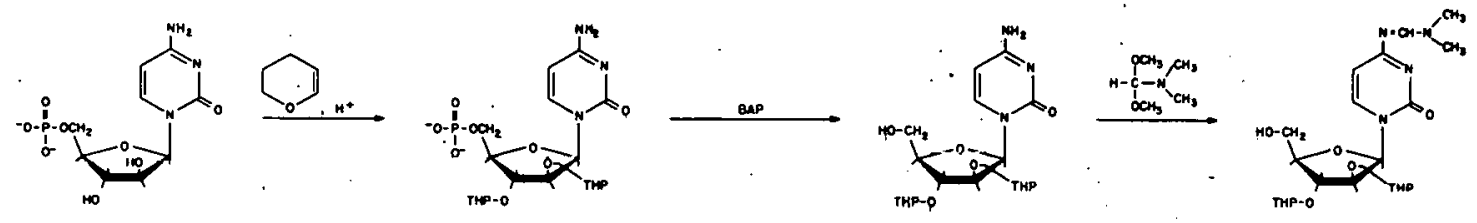

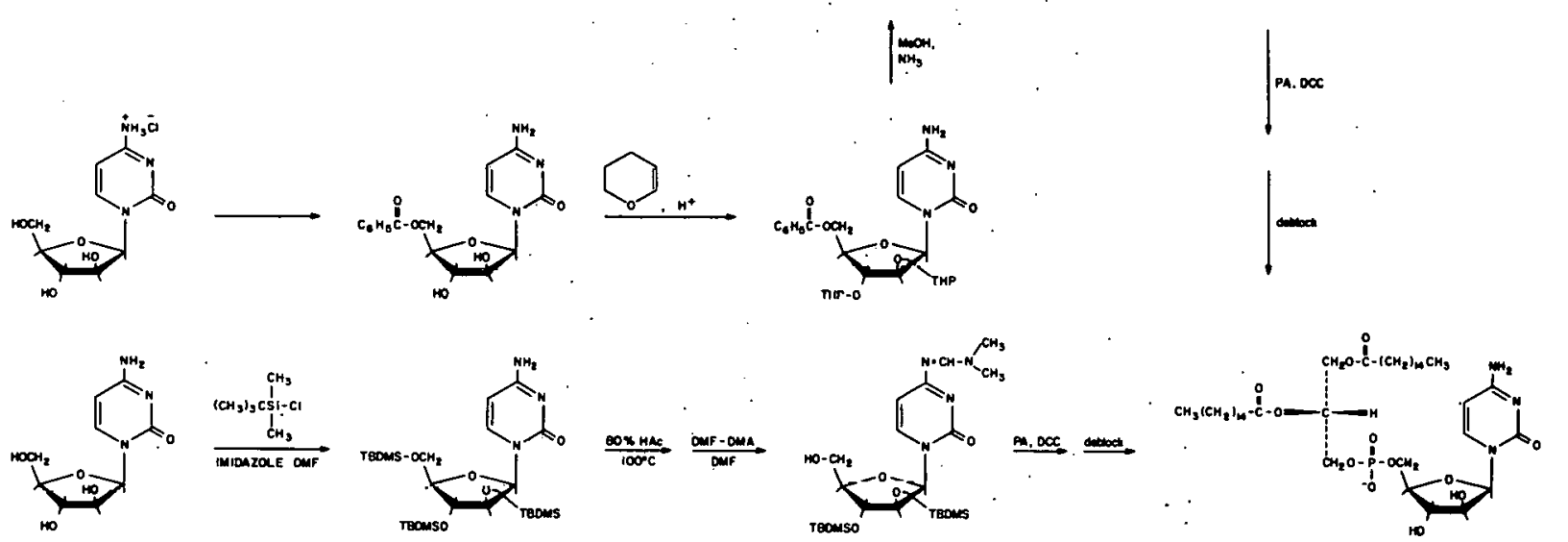

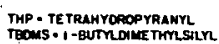

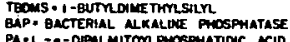

Fig. 11.5 . 
Table 11.1. Fifty Percent Inhibition of Mouse Myeloma (MPC 11. Subclone 66.2) and L1210 Cell Lines by Selected Nucleoside Analogues

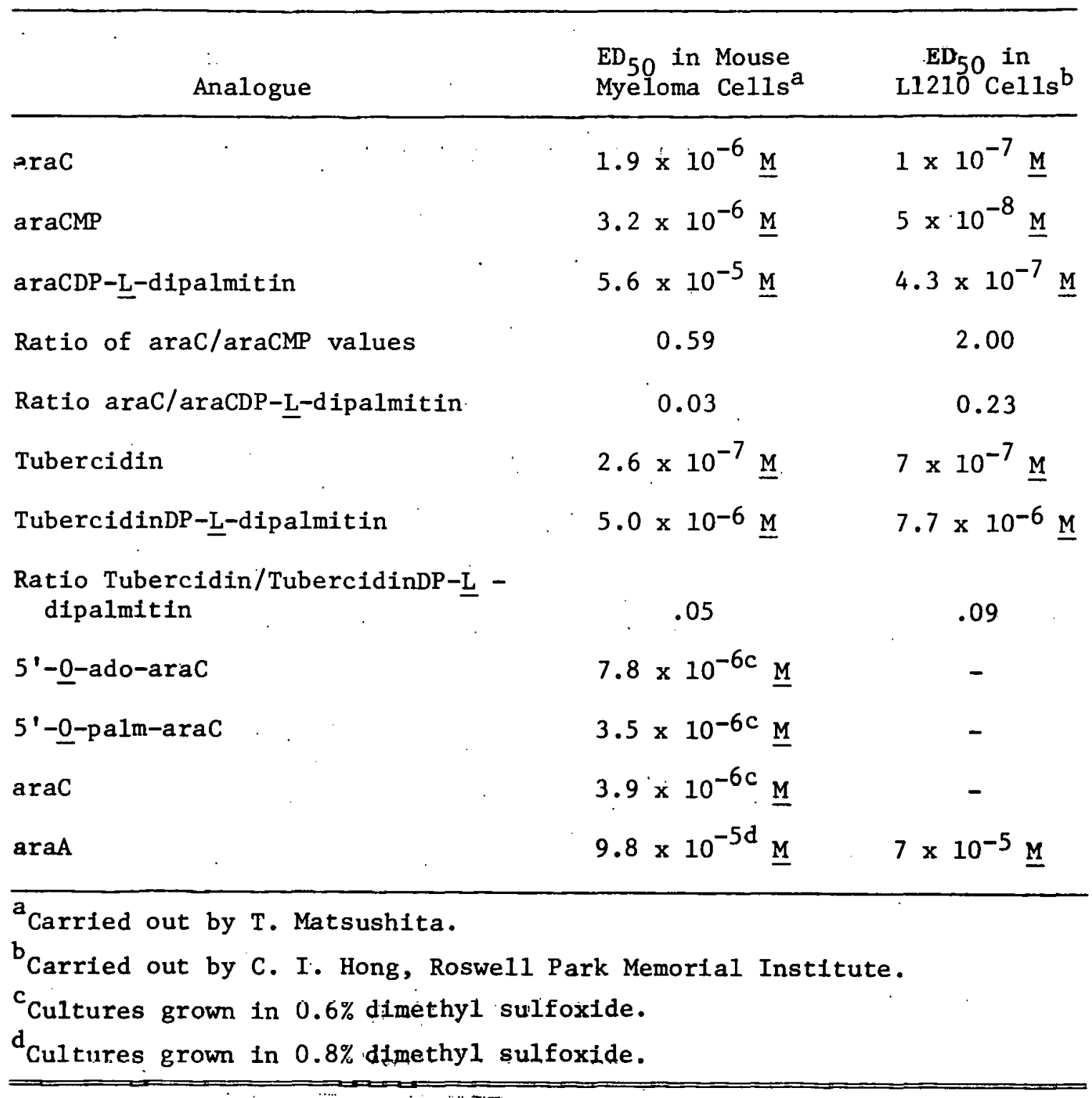

Much effort has been devoted this year to preparation of monophosphatelinked analogues and several different synthetic approaches have been tried. Two factors must be taken into consideration in the selection of a reaction sequence leading to these derivatives. First, the final condensation must be between phosphatidic acid and a suitably protected nucleoside, since a condensation carried out in the reverse sense (i.e., between dipalmitoylglycerol and a 5'-nucleotide) would lead to migration of the palmitoyl groups and thus lead to a mixture of products. Second, the protecting groups present on the nucleoside portion must be removable under nonbasic conditions, since use of the more commonly used acyl protecting groups would lead to concomitant cleavage of the palmitoyl residues during the deblocking step. With these factors in mind, our initial approaches to the synthesis of monophosphate-linked derivat1ves are shown in Figure 11.5. Simflar schemes have been attempted for 
arabinoadenosine. The approach currently being followed utilizes the tetrahydropyranyl (THP) group to protect the $2^{\prime}$ - and $3^{\prime}-\mathrm{OH}$ groups (see Figure 11.5) since removal of the t-butyldimethylsilyl (TBDMS) group from the final product (using $\mathrm{Bu}_{4} \mathrm{~N}^{+} \mathrm{F}^{-}$) gave unexpected degradation products.

The predicted advantages of phospholipid derivatives as prodrugs include (1) potential for targeting to specific tissue, (2) potential for activity against resistant cell lines, and (3) resistance to catabolizing enzymes.

CRYSTALLOGRAPHIC REFINEMENT OF THE Mcg $\lambda$-TYPE BENCE-JONES DIMER

M. Schlffer

The principal objective of the refinement is to obtain the musl accurate coordinates for the more than 3,000 nonhydrogen atoms derivable from the diffraction data of the Bence-Jones dimer. Accurate 3-D structures are essential for comparison of structural features such as the immunoglobulin fold with those of other immunoglobulin fragments. The refinement will aid in the correlation of the amino acid sequence with the binding site conformation. It will also facilitate the use of the Mcg protein as a search structure to determine structures of other immunoglobulin fragments by molecular replacement methods.

The crystallographic refinement is the last phase of the structural study. Up to now we have used the method of "constrained crystallographic refinement." The resulting molecular model was then compared with the calculated electron density map (see Figure 11.6). Manual changes in the model were made with the aid of an interactive computer graphics system, GRIP-75, 1 at the University of North Carolina. To get a better fit to the last map examined, the positions of 31 residues were adjusted; this required altering the main chain orientation in those positions. Electron density was visible for 19 more atoms of the structure. The conformations of c-terminal residues 215 and 216, including the disulfide bund connecting the two monomers, wcrc questionable and therefore left out of subsequent calculations. Their position will be determined from difference Fourier maps after further refinement. Although the refinement improved the quality of the electron density map, no density is yet seen for 205 out of the 3222 nonhydrogen atoms of the molecule. These atoms are part of side chains such as lysine on the surface. Also, there is very little electron density for one of the hypervariable loops, which might be a characteristic of the structure.

Following the incorporation of the above changes, four cycles of refinement brought the $\mathrm{R}$-factor to $29.5 \%$.

${ }^{1}$ GRIP-75 developers included E. G. Britton, F. P. Brooks, Jr., J. Hermans, J. S. Lipscumb, J. E. McQueen, M. E. Pique, and W. V. Wright. 
(A)

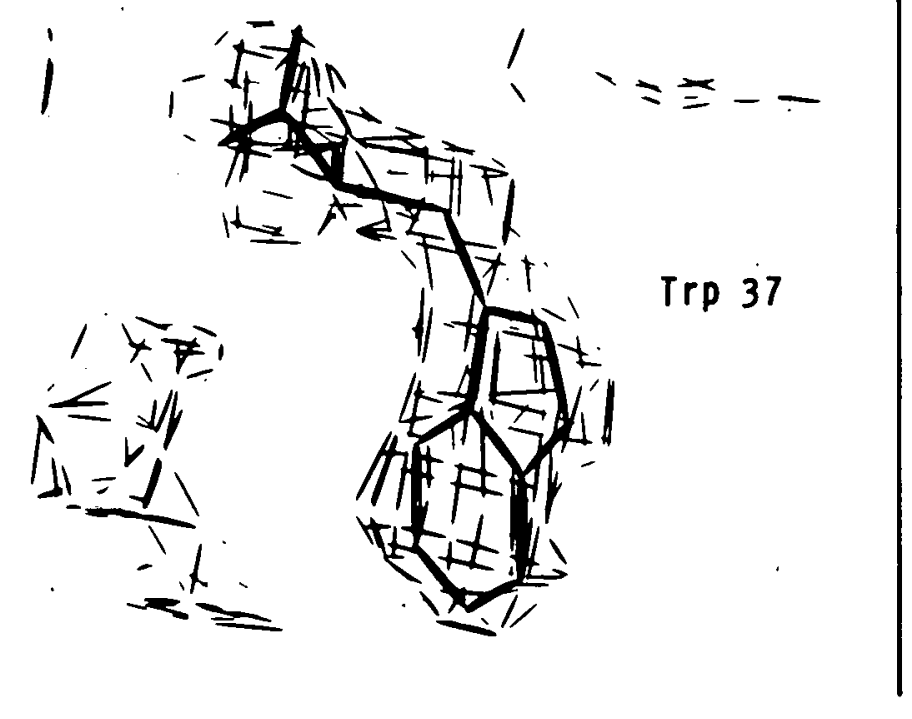

(B)

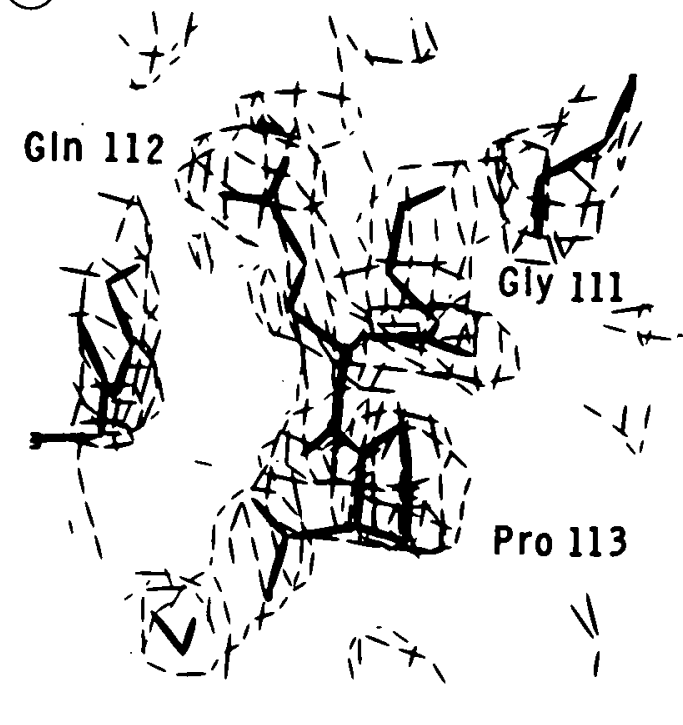

Fig. 11.6. A and B, examples of fit of sections the molecular model (dark lines) to the calculated electron density envelope. Photographs taken at the University of North Carolina.

STRUCTURE DETERMINATION OF THE $\kappa_{\text {II }}$ TYPE BENCE-JONES PROTEIN FIN

M. Schiffer, N. Panagiotopoulos, F. A. Westholm, F. J. Stevens, and A. Solomon ${ }^{2}$

Structure determination has started on the protein Fin, the first complete $k$-type Bence-Jones protein every crystallized. Solving the structure of this protein is of special interest hecause Fin is a complete $k$-chain consisting of two noncovalently bound monomers and because it is a light chain of a $k$-chain subgroup, $K_{I I}$. This subgroup is characterized by proteins possessing an insertion of up to six amino acid residues between positions 29 and 30 in the first hypervariable region. Crystals of the protein Fin obtained from ammonium sulfate solutions have the orthorhombic space group $P 2{ }_{1}{ }_{1}{ }^{2} 1$ with ce11 dimensions $\underline{a}=132.0 \AA, \underline{b}=93.3 \AA$, and $\underline{c}=42.3 \AA$. The asymetric unit consists of a dimer of polecular weight $\sim 46, \overline{0} 00$ daltons and the diffraction pattern extends to 2.7 A spacing (Schiffer, M., et al., ANL-78-90, 1978, p. 180).

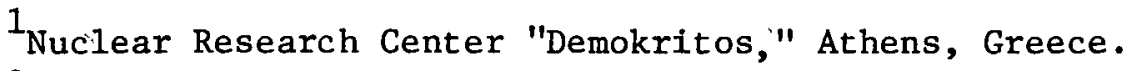

2 Memorlal Research Center, University of Tennessee, Knoxville. 
Molecular replacement methods were applied in an attempt to deftermine the structure of the Fin protein. Crowter's rotation function with 6 A data was used to locate the orientation of the variable and constant regions of the Fin molecule. Rei $V$ fragment dimer $\left(K_{I}\right)$ and $C$ dimer of Mcg $\lambda$ chain were.used as search structures after the residues, which are expected to be different in the Fin molecule, were removed. Possible orientations for both variable (V) and constant (C) regions were found. Both rotation peaks required by the twofold axis of the $V$ and $C$ :regions werelocated. The angle formed by the twofold axis of the $\mathrm{V}$ region with the twofold axis of the $\mathrm{C}$ region is either $106^{\circ}$ or $140^{\circ}$, depending on which symmetry equivalent rotation peak is chosen. These angles compare well with the equivalent angle of the Mcg dimer $\left(113^{\circ}\right)$ and the McPC 603 Fab fragment $\left(135^{\circ}\right)$.

SELF-ASSOCIATION OF $K_{I}$-IMMUNOGLOBULIN LIGHT CHAINS

F. J. Stevens, F. A. Westholm, A. Solomon, ${ }^{1}$ and M. Schiffer

Bence-Jones proteins are immunoglobulin light chains found in the urine of patients with multiple myeloma. The ${ } I$ proteins, a subgroup of the BenceJones proteins, constitute the largest single group of light chains, representing about $35-40 \%$ of the light chains in human sera. Because there is better than $70 \%$ homology among the amino acid sequences of the different $\kappa_{I}$ chains, a comparison of the association properties of light chains from the $K_{I}$ subgroup is of particular interest, as differences must result from relatively few changes in primary structure.

Gel electrophoresis and molecular sieve chromatography were used to compare 14 different $\kappa_{I}$-type Bence-Jones proteins including two for which the amino acid sequence is known. Although electrophoresis in the presence of sodium dodecyl sulfate found uniformity of covalent dimer and monomer molecular welghts, Sephadex chromatography under nondissociating conditions showed monomers to elute with different apparent molecular weights. The apparent molecular weight was dependent on protein concentrations. Computer simulation of associating systems during molecular sieve chromatography was used to understand the behavior of these proteins. Based on the simulation, it was found that the dimerization constants of the light chains studied varied from $10^{6} \mathrm{M}^{-1}$ to less than $10^{3} \mathrm{M}^{-1}$ and therefore that this variability was the cause of the observed differences in apparent molecular weights.

The variable region and more speciffcally the third hypervariable region appear responsible for this variation in dimerization constant. Association properties of light chains of known sequence suggest that the presence of an aromatic or hydrophobic residue at position 96 enhances dimer formation, while a charged residue at that position results in inhibition of dimer formation in light chains. Hypervariable residue 96 may be at the beginning of the $J$ segment. If so, this segment may be one of the sources of the variability of self association of light chains.

I

Memorial, Research Center, University of Tennessee, Knoxville. 
DESIGN AND DEVELOPMENT OF A SMALL-ANGLE DIFFRACTOMETER FOR A PULSED NEUTRON SOURCE

C. Borso

A large-scale multidivisional program is under way at Argonne National Laboratory to develop an intense pulsed spallation neutron source (IPNS-1) sultable for studies in condensed states including biological systems. This facility is scheduled to become operational in 1981 and will provide thermalneutron fluxes of $10^{15}$ neutrons per square centimeter per second. A prototype of this source, i.e., ZING-P', which became operational in FY 1979, has permitted beam measurements and design studies for a variety of instruments to be incorporated at IPNS-1.

Initial design studies for a small angle neutron scattering (SANS) diffractometer indicated that an effective high resolution time of flight SANS diffractometer could be constructed at the proposed IPNS facilities. The instrument will feature a converging slit collimator and $20 \times 20 \mathrm{~cm}$ twodimensional position sensitive detector and has a wide range of accessible $Q$ values with approximately constant resolution over most of the range.

In order to develop final design concepts and project performance characteristics for the IPNS-1 instrument, design and construction was undertaken of a prototype SANS diffractometer for ZING-P', incorporating time of flight principles, and optimized for scattering studies on biological systems. Factors taken into account included physical limitations imposed by the target area, moderator, shielding, and experimental facilities, as well as limitations imposed by the source spectrum.

Using seven tapered S\&ller collimators, as illustrated in Figure 11.7, a SANS instrument coupled to $Z I N G-P^{\prime}$ is projected to have the following characteristics:

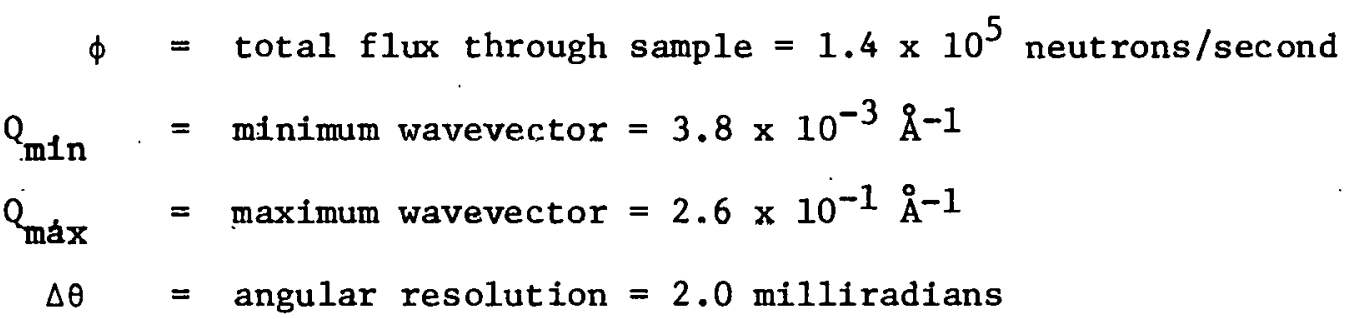

These characteristics are based upon utilizing a two-dimensional position sensitive detecter $(17 \times 17 \mathrm{~cm}$ in size, with a spatial resolution of $5 \mathrm{~mm})$ which is patterned after the Oak Ridge detector and which is currently undergoing testing by the ANL Chemistry Division. The characteristics enable investigation of biological macromolecules in the range of 10,000 to 250,000 daltons. If this prototype meets the above design specifications, the expected increase in flux for the IPNS-1 instrument opens the way for a higher resolution SANS diffractometer extending the range of investigation to macromolecules from 10,000 to $2,500,000$ daltons. 


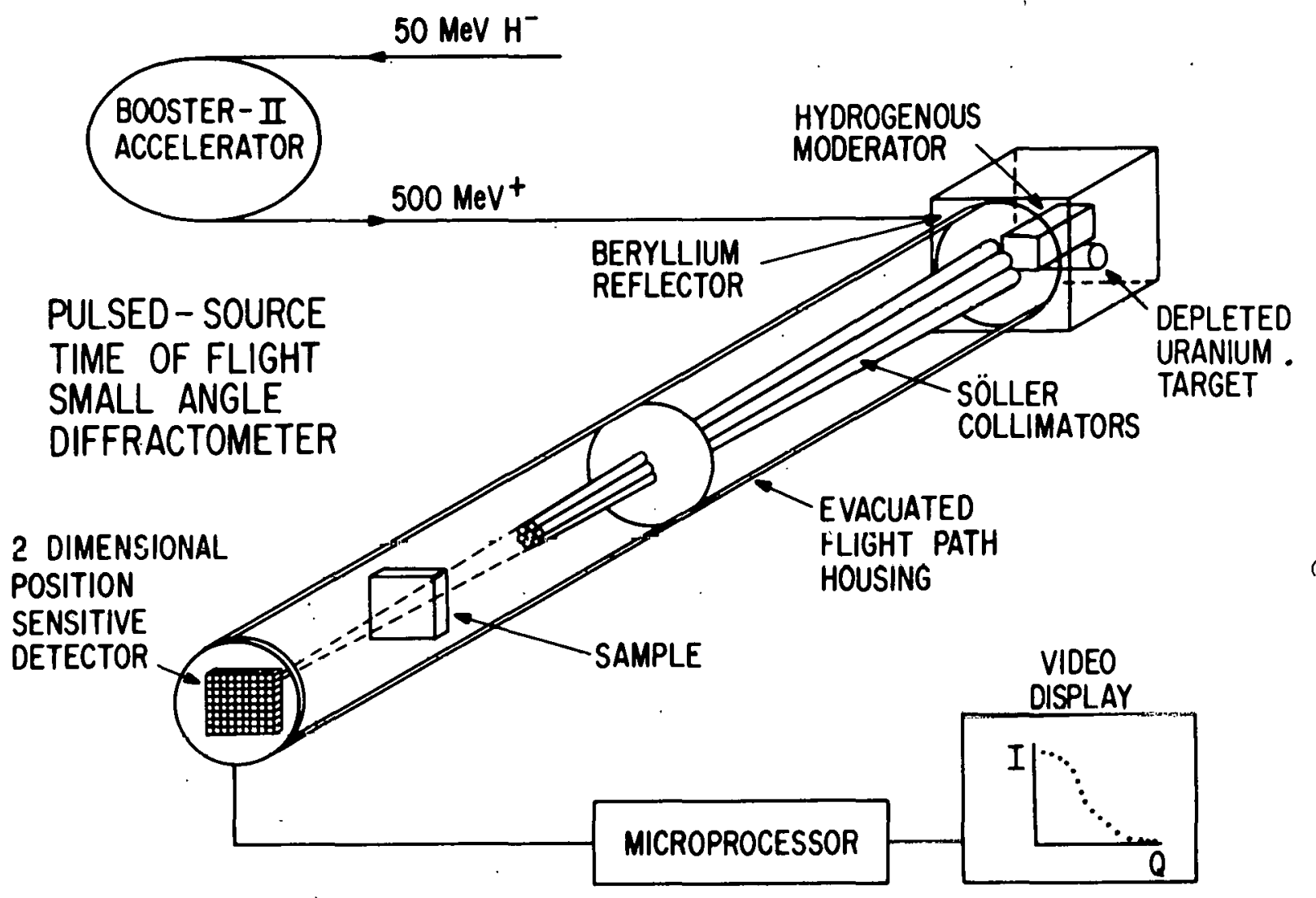

Fig: 1.1.7. Söller collimator design for the ZING-P " neutron small angle diffractometer.

CIRCADIAN PHYSIOLOGICAL MANIFESTATIONS OF BARBITURATE ADDICTION AND WITHDRAWAL IN THE RAT

C. F. Ehret, C. Peraino, 1 J. C. Meinert, and K. R. Groh

When administered in a punctate fashion,pentobarbital is a chronobiotic, i.e.,it phase-shifts chronotypically the circadian rhythm. (Ehrct, C. F., et a $1 .$, Science $188,1212,1975)$. Chronic administration of dietary phenobarbital (0.3\%) in the absence of other temporal cues results in dyschronism, i.e., the loss of circadian synchrony, within the first 5 or 6 days of the start of the habit (Ehret, C. F., and K. W. Dobra, in Proceedings of the Third International Sympnsium on the Dctection and Prevention of Cancer, H. E. Nieburgs, ed., Marce1 Dekker, New York, 1977, pp. 1101-1114)...The

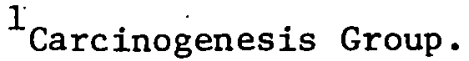


present study extends: these observations to include diverse habituation and drug Ingestion circumstances, including a comparison of the effect of preentralnment cycles (FS $7: 17$, DL $17: 7$ vs FS $12: 12$, DL $12: 12$ ) 1 and subsequent conditions of exposure (FF, DL 12:12 vs FF, DD and FF, DL 17:7) of duration sufficient to permit a "steady-state" in the appearance of circadian patterns derived from core temperature telemetry and from automated food consumption measurements. Finally, measurements were permitted to continue long enough after the drug was withdrawn from the diet to allow characterlzation of an abstinence syndrome, indicative of addiction.

In nearly every case following the ingestion of dietary phenobarbital (0.25\% in this series), marginal or total dyschronism was observed for 2 to 5 days; this was much more acute in rats in continuous dim light than in DL rats. The latter, which had been entrained by 12:12 dark 1ight cycles, readily achieved a "steady state" circadian oscillation of body temperature. The wave form, however, was dramatically distorted by an increase in amplitude (from $0.7^{\circ} \mathrm{C}$ to $1.2^{\circ} \mathrm{C}$ ) and by a phase angle difference ( $\Psi$ advance) of about 32 degrees, equivalent to an advance of 2.1 hours in the thermal acrophase. This wave pattern then continued even in the absence of a DL zeitgeber (i.e., during DDFF) for 8 days. Similar behavior was seen in rats entrained by DL 17:7 illumination cycles. With this reduced phase ratio for the zeitgeber, few $\Psi$ shifts occurred, and these were smaller than those induced in the DL 12:12 group. In each group, withdrawal of the drug from the diet resulted in an abstinence syndrome of severe dyschronism for 3-6 days even during DL entrainment, before normal circadian patterns were restored. For example, Figure 11.8 shows the dyschronogenic effect of phenobarbital withdrawal on seven rats that had been on dietary phenobarbital for 30 days. Thus, a complete barbiturate effect, with habituation and a withdrawal sequence, is observable from circadian criteria: (1) the chronobiotic or punctate zeitgeber effect upon phase and phase response;. (2) the early chronic effect, dyschronogenesis, recognized as a transient of long duration; (3) the steady state effect, with amplitude enhancements and $\Psi$ shifts dependent in magnitude upon phase ratio of the zeitgeber; and (4) an abstinence syndrome characterlzed by severe dyschronism when the drug is withdrawn. A more detalled view of one portion of this work from the perspective of the cocarcinogentc action of dietary phenobarbital is presented in the first report by Peraino et al. in Section 14.

${ }^{1}$ Abbreviations: FS, feed-starve cycle; DL, dim light-bright.light cycle; FF, continuous feeding (ad libitum); DD, continuous dim light. Ratios indicate the hours per day on the regimens noted. 
PHENOBARBITAL WITHORAWAL

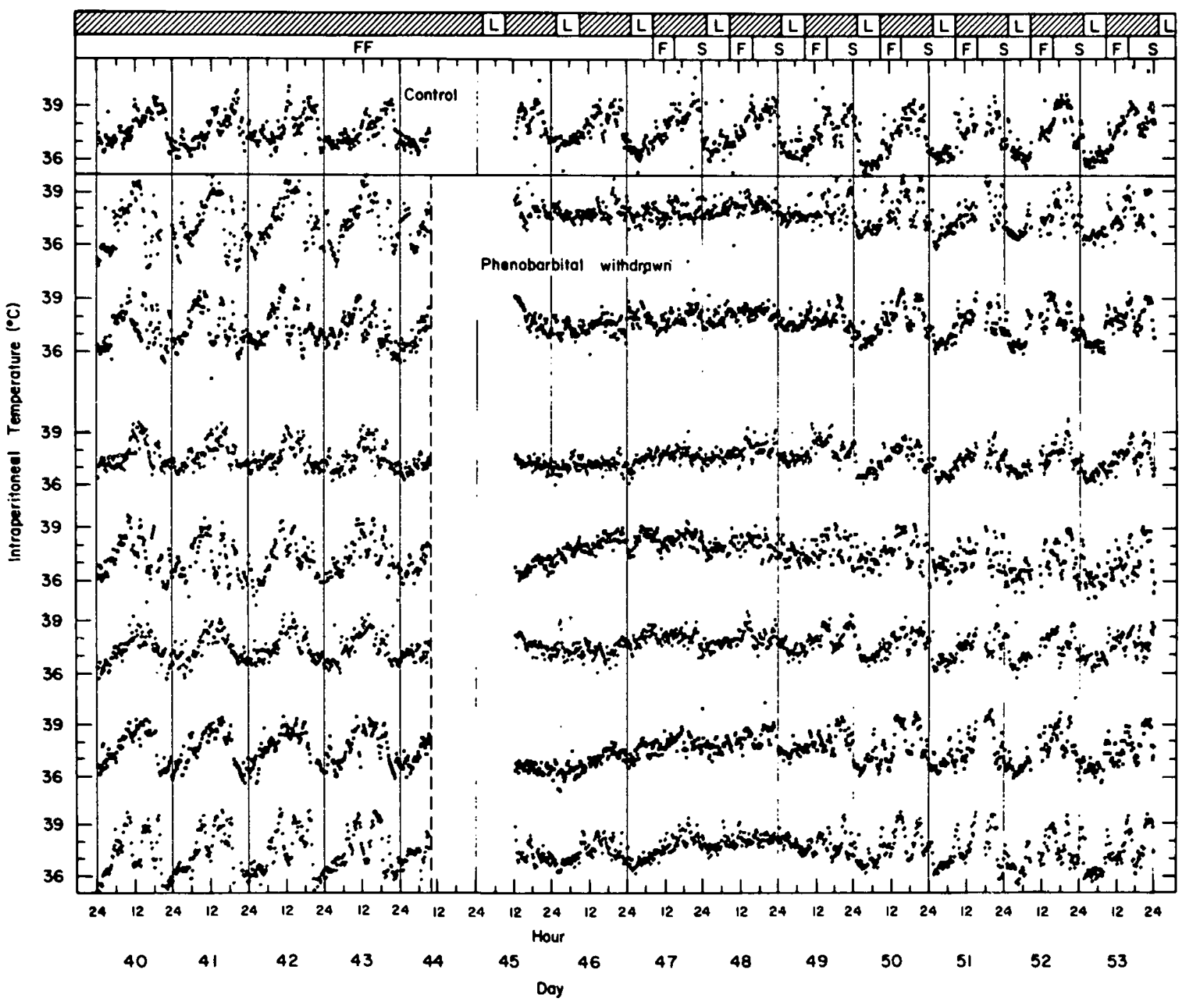

F1g. 11.8, Intraperitoneal temperature measured every 15 minutes for elght animals over 14 days. The regimens for 1 ighting and feeding are given at the top. L = light phase from 0200-0900 hours, $F=$ food avallable, $S$ = food withdrawn. The top animal is a control and the remaining seven animals were exposed to phenobarbital in the diet at a concentration of $0.25 \%$. The phenobarbital diet was removed at the dashed line when feeding on the control diet began. 
CIRCADIAN REGULATION ALONG THE NEUROENDOCRINE AXIS

C. F. Ehret, A. L. Cahill, ${ }^{1}$ N. D. Horseman, ${ }^{1}$ K. R. Groh, and J. C. Meinert

A new approach to our continuing study of circadian regulation was begun in June 1978. Of particular interest are the roles of catecholamines in circadian and infradian decision making and their interplay with hormones of the adrenal cortex and the anterior pituitary. Although coordination of infradian organismic functions by hormonal action in synchrony with a circadian oscillator has been assumed throughout the literature, experimental demonstration of such control is lacking. In our present studies, preliminary results clearly show that the glucocorticoid dexamethasone is a circadian zeitgeber in the rat. When the hormone is administered intraperitoneally $(10 \mathrm{mg} / \mathrm{kg})$ at various phases of the circadian cycle to rats fed ad libitum, and maintained in continuous dim light, a typical phase response curve can be drawn from the resultant phase advances and phase delays; an insensitive phase corresponds to the normal peak of the corticoid circadian rhythm, and phase delays precede phase advances. Similar studies with the pituitary hormone prolactin have also begun.

In the last quarter of the year, high performance liquid chromatography techniques for the quantitation of catecholamines, indoleamines, and their metabolites in biological samples were implemented in the laboratory. Using an electrochemical detector it was possible to quantitate as little as $0.5 \mathrm{ng}$ of each of the separated amines: norepinephrine, epinephrine, dopamine, and 5-hydroxytryptamine. In terms of brain levels, this corresponds to the ability to detect amine concentrations of about $0.1 \mu \mathrm{g} / \mathrm{g}$ in as little as $80 \mathrm{mg}$ of wet brain tissue. The ability to quantitate low levels of these amines and their metabolites is essential to the planned studies on the regulation of the observed circadian fluctuations in catecholamine and indoleamine content of the mamalian central nervous system.

Studies complementary to those described above at the organismic level have been resumed at the cellular level. These studies, which measure direct cellular responses, are aimed at distinguishing interactions between hormones and "master oscillators" in the intact organism. We have perfected the techniques for isolating rat hepatocyte cell lines, and one entire unit of an automated circadian respirometer became operational. Pilot studies with hepatocytes in vitro in the circadian respirometer have shown that, as in Tetrahymena, infradian respiration is photosensitive.

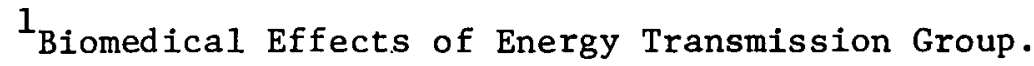




\section{THIS PAGE}

\section{WAS INTENTIONALLY LEFT BLANK}


12. ' MUTAGENESIS:' MOLECULAR AND GENETIC MECHANISMS OF ENVIRONMENTAL MUTAGENS

\section{INTRODUCTION}

Herbert E. Kubitschek

The production of genetic (DNA) lesions is a major deleterious effect of chronic exposure of living cells to pollutants. Genetic lesions are responsible for serious heritable disorders in man and they are generally believed to be responsible for cancer. It has been estimated by the International Agency for Research on Cancer that environmental mutagens cause as many as $80 \%$ of cancers.

Because environmental mutagens act by producing DNA lesions, this genetics program is concerned primarily with the kinds of DNA lesions produced by environmental and energy-related mutagens, the mechanisms of action of these lesions, and their repair. This information is vital to the rational development of improved mutagen testing systems for assessment of human risk and to the development of procedures of reducing mutational damage.

Bacteria are used in our studies of DNA lesions and mechanisms of mutation at the molecular level. These organisms provide by far the best mutational system because of the great amount of information gathered on them in previous mutation studies, their exceptional convenience for laboratory studies, and the fact that their genetic maps are much more complete than those for any other organism. Mouse myeloma cells also are used because these mammalian cells are particularly convenient for short-term cytotoxic and cytogenetic studies and because these cells may have mutagen sensitivities that are likely to be more similar to those in man.

A second major endeavor concerns the improvement of bacterial and mouse myeloma cell systems to assays of biological risk from exposure to effluents of coal technologies. This work includes examination of ongoing testing systems to determine 1 imits of their applicability, and the ongoing development of new and/or improved rapid screening systems. 
REGULAR STAFF

Brown, Mickey S. (Scientific Associate)

Dornfeld, Suzanne S. (Scientific Assistant).

Hass, Bruce S. (Assistant Mi crobiologist)

Kubitschek, Herbert E. (Senior Biophysicist)

Matsushita, Tatsuo (Geneticist)

Shotola, Anita M. (Scientific Assistant)

Venters, Dace (Scientific Assistant)

Webb, Robert B. (Bacteriologist)

Williams, Donna M. (Scientific Assistant)

TEMPORARY STAFF DURING 1978

Griego, Viola M. (Postdoctoral Appointee)

Peak, Meyrick J. (Research Asșociate) 
MUTATIONAL SYNERGISM

H. E. Kubitschek and D. Venters

Many environmental and energy-related pollutants are currently being examined in rapid screening tests with bacteria in many laboratories. The standard procedure is to test pollutants individually. However, such tests may greatly. overestimate or underestimate the effects of mutagens when they are applied simultaneously, either because of chemical interactions between the mutagens, destruction of DNA repair enzymes, or because of interactions at the genetic level. We are concerned here with the latter possibility, synergism in the induction of mutation, which $c$ an arise whenever mutagenesis occurs as a dose-squared function. We have demonstrated that synergism does occur betweentwo particular mutagens that provide a dose-squared response in Escherichiacoli WP2s, namely, ultraviolet 1 ight and nitrous acid. Mutant frequencies were increased by $70 \%$ after exposure to both of these mutagens, as compared to the sum of the individual exposures.

If synergism occurs at the genetic level rather than through destruction of repair enzymes, then the degree of synergism should be independent of the order in which the two mutagens are applied. We have determined that this is indeed the case for the synergistic interaction between ultraviolet 1 ight and nitrous acid.

This support for induction synergism has led to the development of a mathematical model for mutagens that individually follow dose-squared responses. Theoretically, strong mutagens can produce up to $100 \%$ more mutations than expected from their individual actions. However, weak mutagens have no such limitation. Induction synergism between two or more weak mutagens may produce many more mutations than could be accounted for by their individual actions.

\section{REPRODUCIBILITY OF THE AMES SALMONELLA MICROSOMAL ASSAY}

H. E. Kubitschek and D. M. Williams

The Ames Salmonella microsomal assay system is a standard screening system used in laboratories throughout the nation as a prescreen for potential carcinogens and for information on the relative mutagenicity of environmental pollutants. The assay system is rapid, inexpensive, and gives values for mutagenic potency that are in good correlation with carcinogenic potency. The variability that we observed between daily tests with this system, however, led us to examine its reproducibility.

In order to avoid possible variability introduced by use of the liver microsomal ( $(5-9)$ enzyme activation systems, we examined test reproducibility for mutagens that did not require activation. The tests were carried out precisely as prescribed by Ames and co-workers (Ames, B. N., et al., Mutat. Res. $31,347,1975)$ with the exception that the same bacterial culture of Salmonella 
typhimurium TA98 was employed in each test. Aliquots of this culture were withdrawn from the liquid air chest $\left(-190^{\circ} \mathrm{C}\right)$ just prior to testing.

In an initial series of tests, a standard sample of 2-nitrofluorene in dimethyl. sulfoxide was assayed in triplicate daily at $0.1,0.2$, and/or 0.4

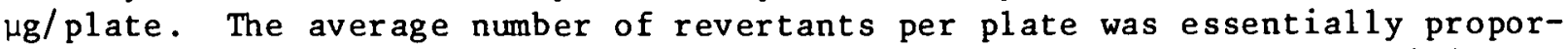
tional to the amount of nitrofluorene per plate. However, the variability was quite 1 arge; the coefficient of variation was about $33 \%$, which was much greater than the expected (Poisson) variability of about $4 \%$. In a second series of tests, a standard dimethyl sulfoxide extract of particulate effluent from a pressurized fluidized bed combustor (Sample A, Table 12.1) was plated independently by three persons and linear responses were obtained. The coefficient of variation of these responses, fitted by least squares, also was 1 arge, $32 \%$. Sample B, an acetone/methanol condensate of the same material, al so had about the same coefficient of variation, $35 \%$. Thus, for each of the three mutagens tested, the variability was observed to be between $32 \%$ and $35 \%$.

Although the source of this intrinsic variability is as yet undetermined, the results indicate that accuracy requires repeated application of the Ames test. To reduce errors to $10 \%$, for example, the test would have to be performed approximately 10 times. Thus estimates of the expense of the test for quantitative applications must be greatly increased.

Table 12.1. Ames Assay Variability Determined from Linear Regressions of Responses of SalmonelZa Strain TA98 without Metabolic Activation to Two Mutagenic Extracts

\begin{tabular}{|c|c|c|c|c|c|c|}
\hline \multirow[b]{2}{*}{ No. ${ }^{c}$} & \multicolumn{2}{|c|}{ Sample $A^{a}$} & \multicolumn{2}{|c|}{ Samp le $\mathrm{B}^{\mathrm{b}}$} & \multirow{2}{*}{$\begin{array}{c}\text { Mutagenicity } \\
\text { Ratio e }\end{array}$} & \multirow[b]{2}{*}{$\mathrm{CV}$} \\
\hline & Mutants/mg & $\mathrm{CV}^{\mathrm{d}}$ & Mutants/mg & $C V$ & & \\
\hline 3 & 288 & $18 \%$ & 7,500 & $30 \%$ & 26 & $27 \%$ \\
\hline 2 & 278 & $18 \%$ & 5,100 & $42 \%$ & 18 & $26 \%$ \\
\hline 3 & 420 & $30 \%$ & 10,000 & $31 \%$ & 24 & $10 \%$ \\
\hline Averages & 335 & $32 \%$ & 8,300 & $35 \%$ & & $23 \%$ \\
\hline \multicolumn{7}{|c|}{$\begin{array}{l}\text { Dimethyl sulfoxide extract of particulate effluent from an experimental } \\
\text { fluidized bed coal combustor. } \\
b \text { Acetone/methanol extract of the same material used in Sample A. } \\
{ }^{c} \text { Number of trials by each different investigator. } \\
d \text { Coefficient of variation. }\end{array}$} \\
\hline
\end{tabular}


DELAYYED REPLICATION OF DIFFERENTIALLY STAINED CHROMOSOMES IN MOUSE MYELOMA. CELLS

T. Matsushita, A. Simms, ${ }^{1}$ and G. Matsushita ${ }^{2}$

The bromodeoxyuridine (BUdR) differential staining technique has mainly been used to measure sister chromatid exchanges, such as those induced by carcinogens and mutagens. However, this technique $c$ an also be used to measure. DNA replication kinetics. We have adapted the BUdR technique to mouse myeloma cells to study the delay in DNA replication induced by far ultraviolet 1 ight $(95 \% 254 \mathrm{~nm})$. A delay of 5 hours was observed with a dose of $7.5 \mathrm{~J} \mathrm{~m}^{-2}$. Parallel growth analysis with a Coulter counter showed an identical delay of 5 hours in growth. Both replication and delay values were independent of parent culture doubling times. After the delay period, irradiated cultures resumed replication at a rate similar to that of the control. These kinetic data suggest that UV-induced damage causes an initial delay in DNA replication but that the persistent DNA damage that remains (pyrimidine dimers) does not affect either the DNA replication or cell division processes.

CELL GROWTH AND PYRIMIDINE DIMER REMOVAL IN MOUSE MYELOMA CELLS

T. Mat sushita and A. M. Shotola

Past studies of pyrimidine dimer removal have shown that mouse cells remove only $10 \%$ of the dimers in their DNA.within 24 hours compared to $70 \%$ in human cells; yet the human cells are more sensitive to far ultraviolet light (UV) than mouse cells. In an effort to determine the significance of this limited removal in mouse cells, we have measured the removal of dimers relative to growth curve position rather than time. These studies revesl two new facts, not obtainable from time course kinetics: (1) There are two classes of dimers; one class ( $35 \%$ ) was removed during the first generation of growth after irradiation while the other (65\%) was not excised for at least three generations of growth. (2) The partial excision of dimers ( $35 \% 1088$ ) begins only after cell numbers start iucreasing. That is, dimers are not removed until the cells are competent to undergo cell division, presumably when the cell has completed repair of lethal damage. These data indicate either that dimers are not lethal lesions in mouse myeloma cells, or that cells can cope with dimers by other DNA repair processes without removing the dimer itself.

${ }^{1}$ Sponsored by the Argonne Affirmative Action Program.

${ }^{2}$ Cytogenetic consultant. 
ELECTRICAL DETERMINATION OF VIABILITY IN MOUSE MYELOMA CELLS

T. Matsushita, A. M. Brendzel, 1 and A. M. Shotola

Suspension of mouse myleoma cells in phosphate-buffered saline (PBS) was found to induce a significant amount of cell death. Cell death was initially detected with a Coulter counter as the increase in the proportion of cells of smaller size, as determined electrically. The accuracy of this method was confirmed by trypan blue exclusion and soft agar cloning. Comparison of a mixture of 1 ive and dead cells by electrical sizing and by trypan blue exclusion showed a high correlation between the results of the two techniques (correlation coefficient: 0.98 ). Sizing of PBS-treated cells by 1 ight microscopy suggests that the altered electrical size distribution (ESD) of the PBStreated cells was due to decreased cell volume as well as increased permeability of cell membranes. To examine the generality of ESD changes as an indicator of lethality, heat-killed rel1s ware alco mcaoured on tle cuuller counter. In contrast to the earlier results, the ESD of heat-killed cells did not differ significantly from that of control cells. Light microscopy studies confirmed the same size distribution for heat-killed cells and unheated control cells. We conclude that electrical sizing is an effective method for determining viability of mouse myeloma cells when cell death is accompanied by a. change in cell size, as in PBS-killed cells, or when cell membrane permeability changes significantly.

MOUSE MYELOMA SUSPENSION CULTURES AS A SYSTEM FOR CYTOTOXIC AND CYTOGENETIC TESTS FOR ENVIRONMENTAL POLLUTANTS

T. Matsushita and G. Matsushita ${ }^{2}$.

Mouse myeloma cells are conveniently grown in suspension cultures and have a moderately short generation time of 16 hours. Two rapid methods, requiring only 2 to 3 days, have been developed using these mammalian cells to screen for potentially hazardous pollutants: (1) the suspension culture cytotoxicity test, and (2) the sister chromatid pychango toot. The applicaliun of the two tests provides a rapid system for combined cytogenetic and cytotoxic effects.

Suspension Culture Cytotoxicity

Using the electronic cell counter method described in the preceding report for distinguishing between 1 ive and dead cells, accurate growth curve and lethality measurements $c$ an be performed electronically on the same culture, obviating the need for laborious and less accurate microscopic and plating techniques. Suspension cultures also enable accurate, multiple sampling

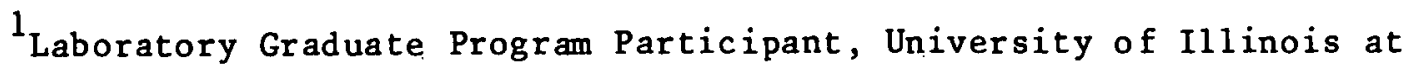
Chicago Circle.

${ }^{2}$ Cytogenetic consultant. 
from a single parent culture, in constrast to the less accurate parallel platings required in monolayer attached cell culture systems to develop kinetic growth curves. Cytotoxic effects on cell growth also can be conveniently determined with a considerable saving of time over that required by at tached cell systems. Representative results are shown in Table 12.2, in which four different condensates from the effluent stream of fluidized bed coal combustion are compared for two cytotoxic end points, growth inhibition (ED 5 ) and lethality $\left(L D_{50}\right)$. These results were obtained with one parent culture, and compare favorably with test results obtained with other eukaryotic systems.

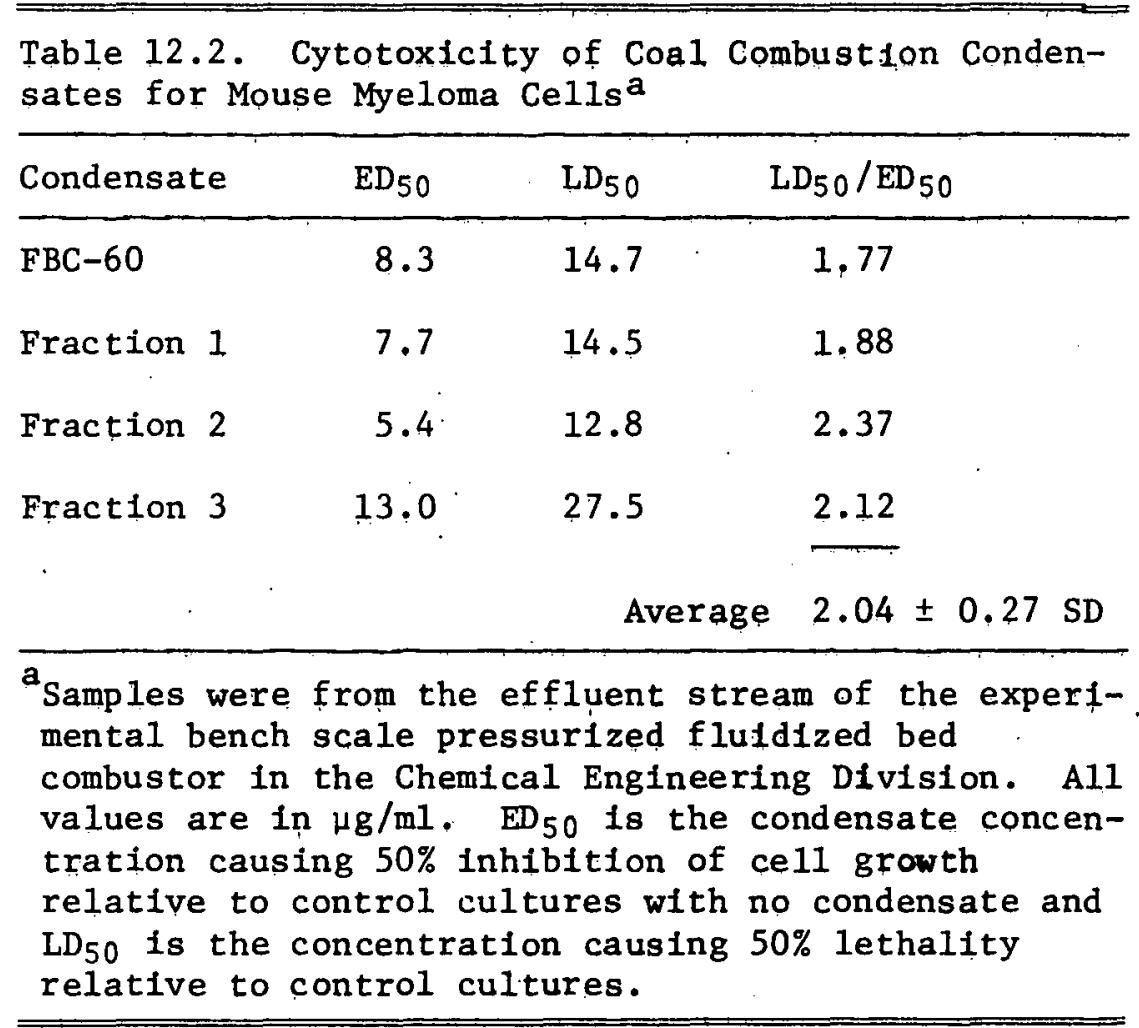

Sister Chromatid Exchange Test

This test, developed with other cell lines, has been adapted to suspension cultures of mouse myeloma cells. In contrast to chromosome aberrations, which $c$ an be induced by nonmutagens, sister chromatid exchanges appear to be induced specifically by mutagens, and are extremely sensitive. Preliminary results indicate that both cytotoxic and cytogenetic effects of chemical mutagens (e.g., methyl methanesulfonate), antitumor drugs (e.g., arabinofuranosylcytosine), coal combustion effluents, coal conversion process streams, and far ultraviolet irradiation can be determined easily and reproducibly in mouse myeloma cells. 
NEAR-ULTRAVIOLET MUTAGENESIS: THE ROLE OF recA $^{+}$lexA ${ }^{+}$REPAIR IN MUTAGENESIS BY MONOCHROMATIC 365-nm AND BROAD. SPECTRUM RADIATION

R. B. Webb

Radiation at $365 \mathrm{~nm}$ is mutagenic for reversion to tryptophan independence in stationary-phase cells of Escherichia coli strains WP2s (uvrA) (Webb, R. B., J. Bacteriol. 133, 860, 1978), "WP2 (wild type), WP6 (polA uvrA ${ }^{+}$); and WP6s (polA uvrA) when the mutant frequency is assayed on minimal plates supplemented with $2 \%(\mathrm{v} / \mathrm{v})$ nutrient proth (SEM plates) (Figure 12.1, Part A). High fluence rates (500-1500 $\mathrm{W} \mathrm{m}^{-2}$ ) at $0^{\circ} \mathrm{C}$ effectively prevent concomitant photoreactivation (Brown, M. S., and R. B. Webb, Mutat. Res. 15, 348, 1972). Tryptophan revertants were below detection in strains WP5 (1 $\overline{\text { exA }}$ ), WP10 (recA), and WP100 (uvrA recA); implicating récA ${ }^{+}$lexA $^{+}$-dependent

error-prone ("SOS") repair in near-UV mutagenesis. Both oxygen-independent (pyrimidine dimers) and oxygen-dependent DNA lesions are implicated in near-UV mutagenesis by the photoreactivation of premutational lesions and the complex oxygen dependence of mutagenesis shown by the strains that were mutated. In contrast to the results with monochromatic $365-\mathrm{nm}$ radiation, only the uvrA strains WP2s and WP6s were mutated significantly by high fluence rate $\overline{(50-100}$ $\mathrm{W} \mathrm{m}^{-2}$ ) fluorescent BLB $(310-405 \mathrm{~nm})$ radiation (Figure 12.1 , Part $\mathrm{B}$ ).

Mutant frequency-fluence relationships with $254-\mathrm{nm}$ radiation in the recA $^{+}$lexA ${ }^{+}$strains followed slopes of approximately 2 on a $10 \mathrm{l}-10 \mathrm{~g}$ plot. However, the same strains and experimental conditions revealed complex mutant-frequency responses at $365 \mathrm{~nm}$ : at relatively low fluences, the mutant-frequency response was linear; at higher fluences, the response followed a slope of 2.5 with WP2s and WP6s, 4.5 with WP6, and 6.5 with WP2.

The absence of broad spectrum near-UV (BLB) mutagenesis in recA ${ }^{+}$ lexA $^{+}$uvrA $^{+}$strains (WP2 and WP6) that are strongly mutated at 254 and $365 \mathrm{~nm}$ cannot be accounted for either by the absence of pyrimidine dimer formation or concomitant photoreactivation of dimers (data not shown). The low leve1 of BLB mutagenesis observed in the excision-proficient strains WP2 (polA ${ }^{+}$uvrA $^{+}$) and WP6 (polA uvrA ${ }^{+}$), in contrast to the high level of mutagenesis observed in the excision-deficient strains WP2s (polA uvrA) and WP6s (polA uvrA), indicates that the uvrA endonuclease is associated with the low levels of BLB mutagenesis obtained in strains that are mutated by 254-nm radiation. The presence or absence of polymerase I did not substantially alter BLB mutagenesis. The near-UV mutational response obtained is consistent with selective damage to components of DNA repair. It is proposed that BLB radiation differentially inhibits the error-prone pathways of DNA in wild-type strains, thereby strongly reducing mutant frequencies in strains capable of error-free repair. 

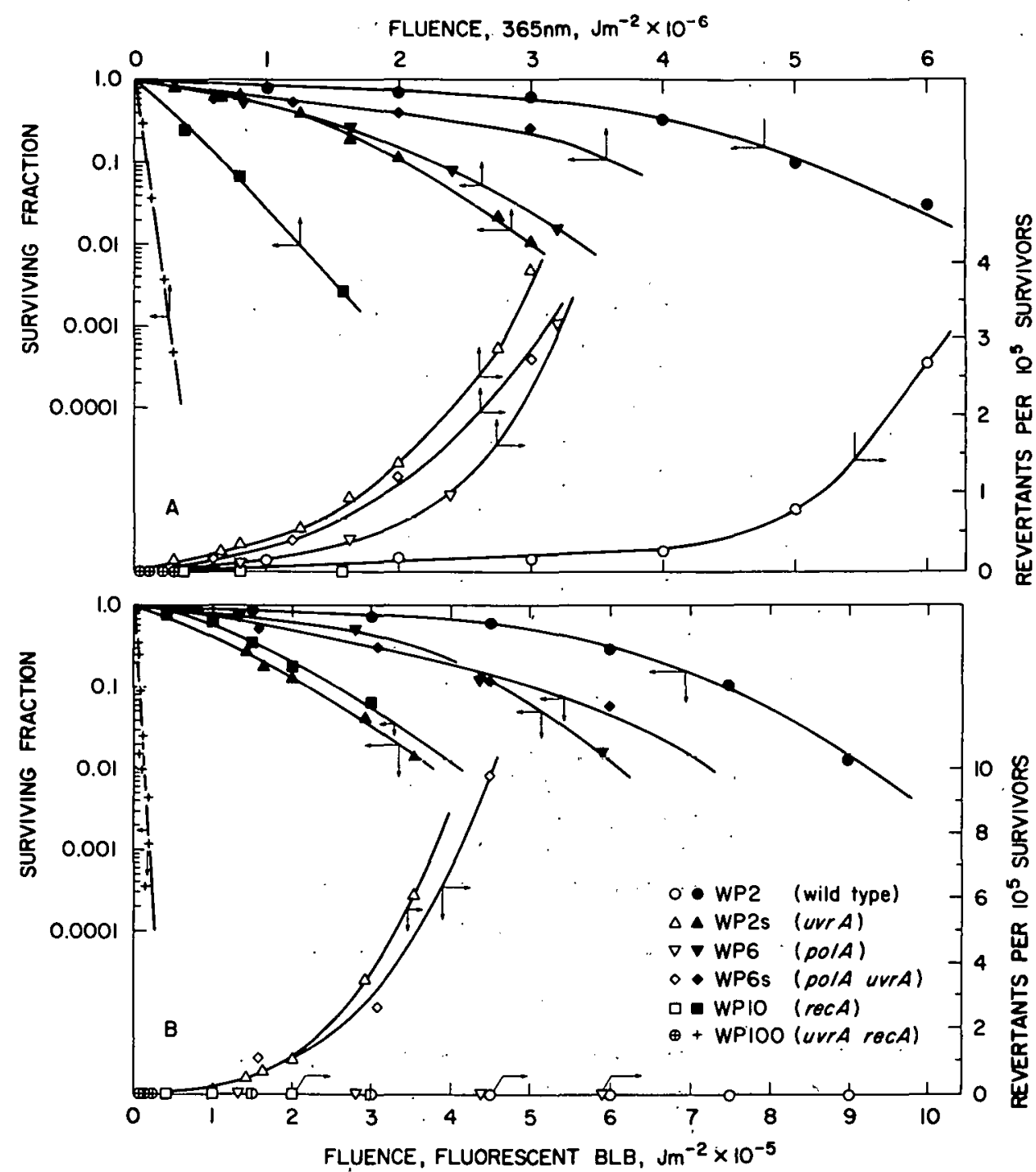

Fig. 12.1. Mutagenesis (trp $\operatorname{trp}^{+}$) and lethal response of seven genetically related strains derived from E. coli $B / r$ that differ in repair capability with monochromatic 365-nm radiation (Part A) or fluorescent BLB $(310-405 \mathrm{~nm}$ ) radiation (Part B). Al1 mutant and lethal assays were done on minimal glucose agar plates supplemented with $2 \%$, nutrient broth. Fluence rates were $800-1200 \mathrm{~W} \mathrm{~m}^{-2}$ with $365-\mathrm{mm}$ radiation and $60-85 \mathrm{~W} \mathrm{~m}^{-2}$ with BLB radiation. Short wavelength stray light was reduced with a Corning $0-52$ filter ( $1 / 2$ thickness) ( $1 \%$ transmittance $336 \mathrm{~nm}$ ). BLB radiation was filtered only with $3 \mathrm{~mm}$ of Pyrex. 
SYNERGISTIC AND ANTAGONISTIC RELATIONSHIPS BETWEEN BROAD SPECTRUM NEAR-UV AND FAR-UV RADIATION IN STRAINS OF ESCHERICHIA COLI WITH DIFFERING REPAIR CAP ABI LITIES

\author{
M. A. Turner ${ }^{1}$ and R. B. Webb
}

Interaction of broad spectrum near-UV (fluorescent BLB) and far-UV (254 $\mathrm{nm}$ ) radiation was studied in Escherichia coli WP2 (wild type), WP2s (uvrA), WP10 (recA), WP6 (polA), WP6s (polA uvrA), and WP100 (uvrA recA). BLB irradiations were carried out at $0^{\circ} \mathrm{C}$ at $\mathrm{f}$ luence rates of approximately $70 \mathrm{~W}$ $\mathrm{m}^{-2}$ to reduce concomitant photoreactivation to a minimum. Mutation induction (reversion to tryptophan independence) was 1 arge with 254 and $365 \mathrm{~nm}$ radiations for strains WP2, WP2s, WP6, and WP6s, whereas with broad spectrum BLB radiation, only WP2s and WP6s demonstrated significant mutagenesis ( $R$. B. Webb; see preceding report). The hypothesis that BLB radiation selectively inhibits error-prone recA ${ }^{+}$lexA $^{+}$repair was tested by sequential fluorescent BLB-254 nm irradiatign of stationary-phase populations. With strain WP2, a fluence of $30 \mathrm{~J} \mathrm{~m}^{-2}$ at $254 \mathrm{~nm}$ induced $1 \mathrm{~s} \times 10^{-h}$ trp $^{+}$ mutants. However, when $1 \times 10^{5} \mathrm{~J}_{+} \mathrm{m}^{-2}$ or more of BLB radiation preceded the $254-\mathrm{nm}$ exposure, no trp ${ }^{+}$revertants could be detected (Figure 12. 2, Part $\mathrm{A}$ ). In contrast, when 254-nm irradiation ( $3 . \mathrm{J} \mathrm{m}^{-2}$ ) was preceded by an exposure to BLB radiation $\left(5-50 \times 10^{4} \mathrm{~J} \mathrm{~m}\right.$ ) with strains WP2s (uvrA) and WP6s (polA uvrA), the revertant yield increased sharply (Figure 12.2, Part B). These results are consistent with our previous studies which demonstrated the inhibition of excision, postreplication, and photoreactivation repair by monochromatic $365-\mathrm{nm}$ radiation (Tyrre11, R. M., and R. B. Webb, Mutat. Res. 19, 361; 1973, Webb, R. B., et al., Radiat. Res. 74,298 , 1978 ).

Data reported here suggest that error-prone and error-free components of DNA repair are differentially inhibited by broad spectrum near-UV radiation: in the repair-proficient strain WP2, BLB radiation selectively inhibits error-prone repair, requiring more of the damage to be processed by error free components of excision repair, thereby decreasing the $254 \mathrm{~nm}$ induced mutant yield; however, in the excision-deficient strains, WP2s and WP6s, the remaining error-free components of repair are selectively inhibited, forcing more of the DNA lesions to be processed by the error-prone "sos" component of postreplication repair, and increasing mutant yields (Figure 12.2, Part B). These data further suggest the possibility that a similar interaction of near-UV (320-400 $\mathrm{nm})$ and $\mathrm{mid}-U V(290-320)$ wavelengths may reduce the mutagenic potential of full spectrum solar ultraviolet light on mammalian cells when compared to that expected with monochromatic radiation in the 290-320 nm wavelength range.

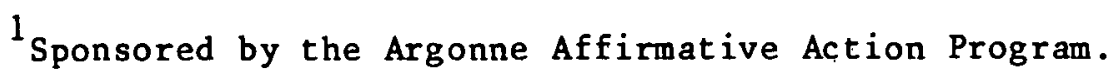




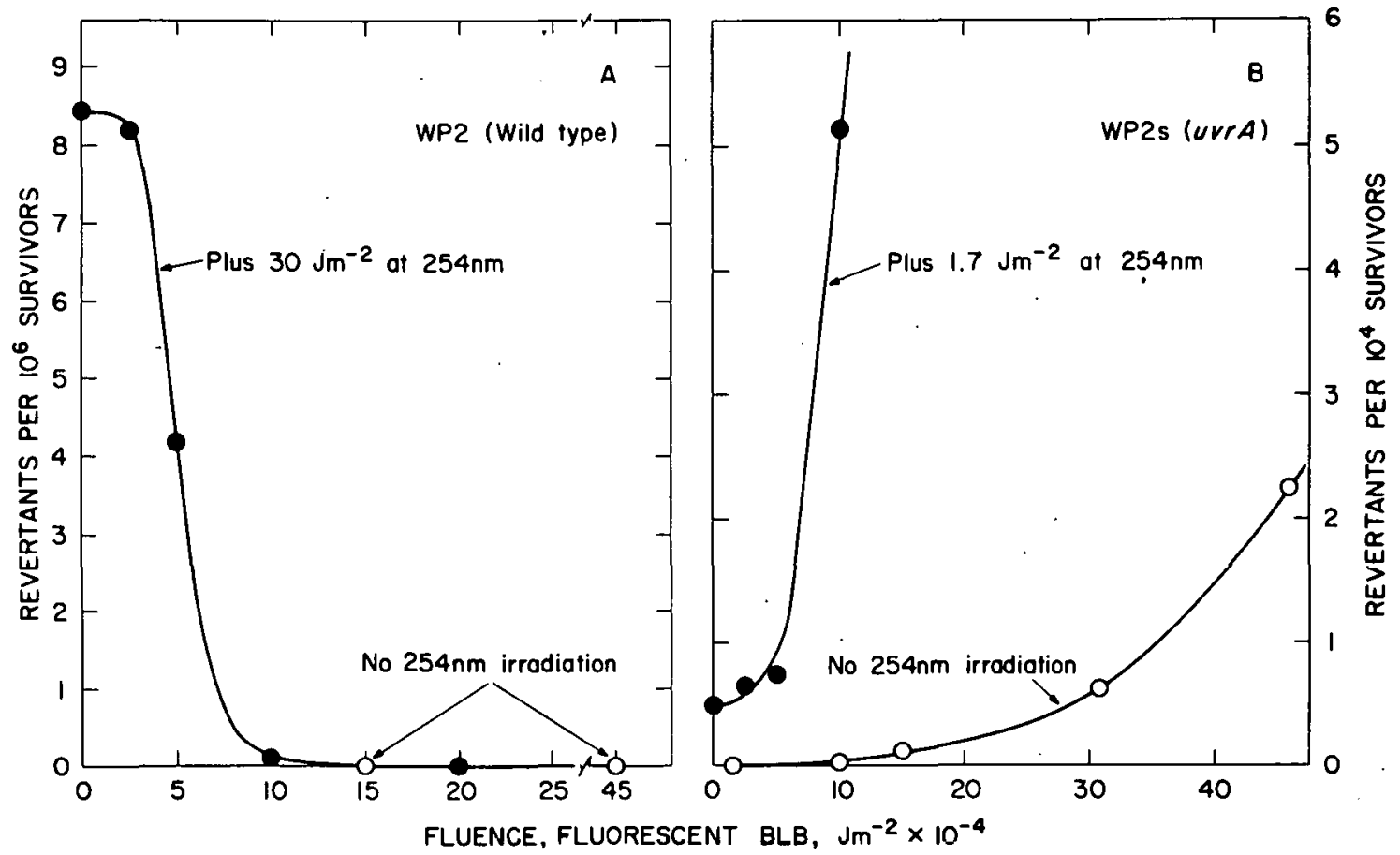

Fig. 12.2. The effect of prior fluorescent BLB (310-405 nm) irradiation on $254 \mathrm{~nm}$-induced tryptophan revertant frequency in E. coli strains WP2 (wild type) (Pane1 A) and WP2s (uvrA) (Panel B). Mutant and total assays were on minimal agar plates supplemented with $2 \%$ nutrient broth. Fluence rates were approximately $65 \mathrm{~W} \mathrm{~m}^{-2}$ with BLB radiation and $0.5 \mathrm{~W} \mathrm{~m}^{-2}$ with $254-\mathrm{nm}$ radiation.

NEAR-ULTRAVIOLET LETHALITY: NONRECIPROCAL SYNERGISTIC INTERACTION BETWEEN A NEAR-ULTRAVIOLET (365 $\mathrm{nm}$ ) AND A VISIBLE (405 nm) WAVELENGTH IN ESCHERICHIA COLI

M. S. Brown and R. B. Webb

Near-UV radiation ( $320-400 \mathrm{~nm})$ induces moderate sensitization of repairproficient and single repair-deficient strains of Escherichia coli to $X$ irradiation (Tyrrel1, R. M., Int. J. Radiat. Biol. 25, 373, 1974), mild $\left(52^{\circ} \mathrm{C}\right.$ ) heat (Tyrrell, R. M., Photochem. Photobiol. 24, 345, 1976), and 254-nm radiation (Webb, R. B., et al., Radiat. Res. 74, 298, 1978). In addition, we have observed recently that a prior exposure to $365-\mathrm{nm}$ radiation at fluences greater than $1 \times 10^{6} \mathrm{~J} \mathrm{~m}^{-2}$ enhances the lethal effects of 405-nm radiation on repair-proficient and uvrA strains of $\underline{E}$. coli to a greater extent than do the other lethal agents that have been tested. Fluentes of 365-nm radiation that yielded a surviving fraction of 0.1 ( $F_{10}$ ) resulted in the following sensitization ratios (ratio of the $F_{37}$ fluence at $405 \mathrm{~mm}$ 
with a prior 365-nm exposure): Strain K12 AB1157 (wild type), 14 (Figure 12.3, Part A); Strain WP2 (wild type), 48; Strain WP2s (uvrA), 12; Strain WP2s (uvrA thy), 265. The maximum sensitization ratios obtained were: Strain K12 $A \overline{B 1157,45}$; Strain WP2, 74; Strain WP2s, 48; Strain Wp2s (thy), 365. Very little sensitization to anoxic $405-\mathrm{nm}$ radiation was observed, suggesting that 365-nm damage interacts with DNA lesions that are produced at $405 \mathrm{~nm}$ by an oxygen-dependent mechanism. DNA single-strand breaks (or alkali-labile bonds) were produced by $\underline{2}_{2} 405-\mathrm{nm}$ radiation at $3.0 \times 10^{-5}$ breaks per $2.5 \times 10^{9}$ daltons per $\mathrm{J} \mathrm{m}^{-2}$ in the polA Strain P3478, while pyrimidine dimers were below detection.
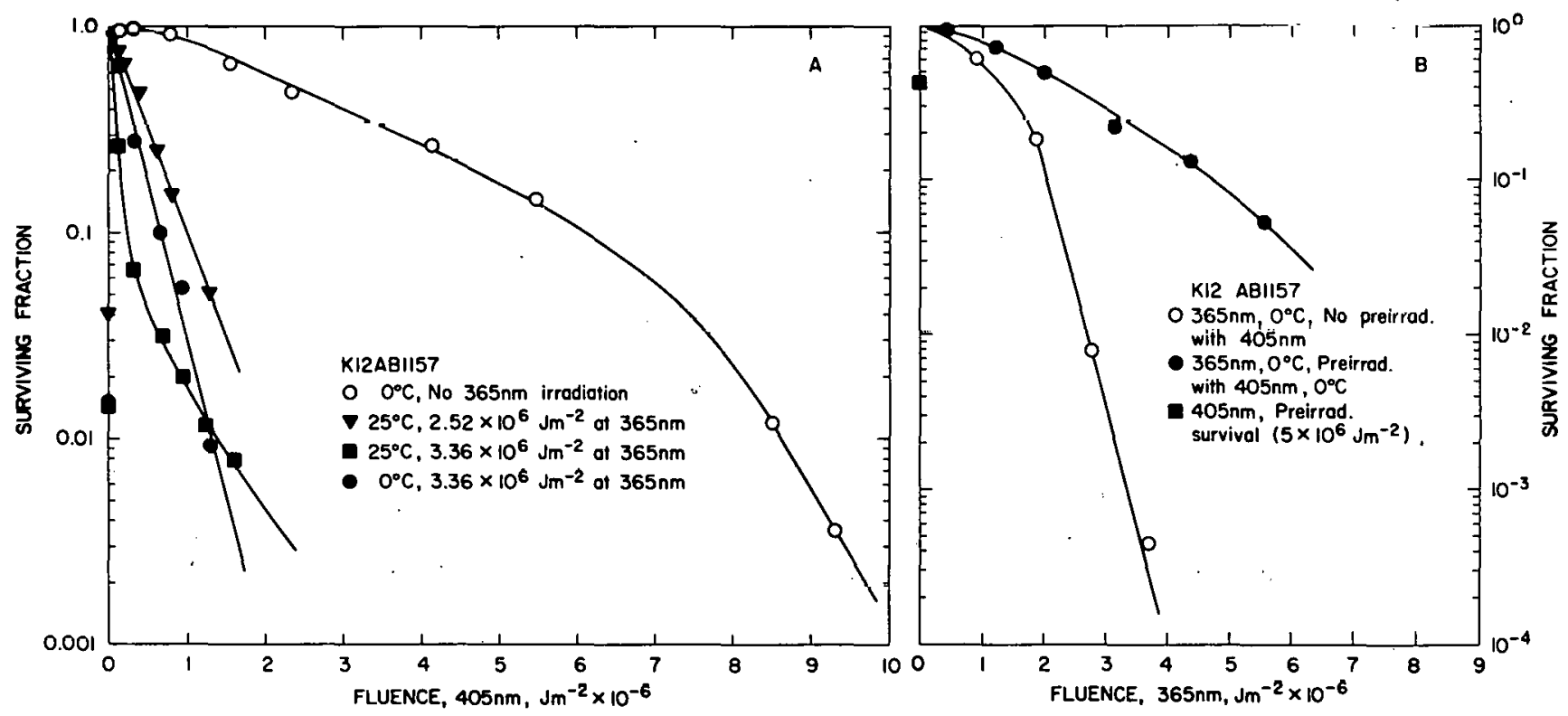

Fig. 12.3. Fluence-survival response of M9-buffer suspensions of stationary-phase cells of $\mathrm{E}$. coli $\mathrm{K} 12 \mathrm{AB} 1157$ (wild type) at $405 \mathrm{~nm}$ (Part A) or $365 \mathrm{~nm}$ (Part B). Part $\Lambda$ : Ccll sugpensions were irradiated at $405 \mathrm{~nm}$ with and without a prior irradiation at $365 \mathrm{~nm}$. Part B : Cell suspensions were irradiated at $365 \mathrm{~nm}$ with and withqut a prior irradiation at $405-2 \mathrm{~nm}$. Fluence rates were $600-1200 \mathrm{~W} \mathrm{~m}^{-2}$ at $365 \mathrm{~nm}$ and $400-650 \mathrm{~W} \mathrm{~m}^{-2}$ at $405 \mathrm{~nm}$. Short wavelength stray light was reduced at $365 \mathrm{~nm}$ by a Corning 0-52 ( $1 / 2$ thickness) absorption filter ( $1 \%$ transmittance $336 \mathrm{~nm}$ ) and at $405 \mathrm{~nm}$ by an Optics Technology LP 400 absorption filter ( $1 \%$ transmittance $370 \mathrm{~nm}$ ).

In striking contrast to the strongly synergistic effect of 365-nm radiation on 405-nm lethality, a prior exposure to 405-nm light reduces the lethal effects at $365 \mathrm{~mm}$ in E. coli K12 AB1157 (Figure 12.3, Part B). This lack of reciprocity indicates that the $365-405 \mathrm{~nm}$ interaction is not a simple interference between two classes of DNA lesions. Furthermore, although inhibition of components of DNA repair by $365-\mathrm{nm}$ irradiation has been demonstrated, such damage cannot account for the decrease in $365-\mathrm{mm}$ lethality produced by prior 
irradiation at $405 \mathrm{~nm}$. However, if the uvrA endonuclease is selectively inhibited by $365-\mathrm{nm}$ radiation, the presence of DNA single-strand breaks that are produced by $405-\mathrm{nm}$ radiation might increase effective excision repair of $365-\mathrm{nm}$ lesions. We propose that the strong sensitizing effect of $365-\mathrm{nm}$ radiation on 405-nm lethality is the consequence of the strong inhibition of specific components of the DNA-repair systems that can remove or bypass $405-\mathrm{nm}$ DNA lesions.

THE B B- CHEMOSTAT IN THE ABSENCE OF EXOGENOUS ACTIVATION AS A SENSITIVE INDICÃTOR OF MUTAGENICITY OF BENZO(A)PYRENE AND COMPLEX MIXTURES FROM HIGH-BTU GASIFICATION PLANT PROCESS STREAMS

$$
\text { B. S. Hass, R. B. Webh, and T. Gambil1 } 1
$$

We have developed chemostat cultures (Kubitschek, H. E., Introduction to Research with Continuous Cultures, Prentice Hall, Englewood Cliffs, NJ, 1970) of Escherichia coli B (lexA uvrB lon) as a new system for measuring bacterial mutagenicity. The system enables measurement of mutant frequency at low toxicant doses as a function of time and without metabolic activation. Benzo(a)pyrene ( $\mathrm{BaP}$ ) is a well-known carcinogen that is also mutagenic to bacteria in the presence of liver microsomal activation. Chemostat cultures of E. coli $B_{-1}$ were exposed to BaP, without any added activation enzyme, and the mutation rates to resistance to bacteriophage $T 5$ were measured (Figure 12.4). A linear relationship as observed between BaP concentration and the mutation rate, expressed either as mutant frequency per day or mutant frequency per generation. The sensitivity of chemostat cultures of $\underline{E}$. coli $\mathrm{B}_{S-1}$ to mutation induction by BaP without exogenous activation was about one third as great as that obtained with the Ames Salmonella assay system with optimal enzyme activation. With the chemostat cultures, BaP at a concentration of 0.2 . M doubled the mutation rate observed without the mutagen (spontaneous). With the Ames technique, using Salmonella typhimurium TA98, BaP at $0.06 \mu \mathrm{M}$ produced a 2 -fold increase in mutant yield over the spontaneous rate at optimal enzyme activation. Solubility of BaP required the presence of ethanol; however, ethanol at concentrations as high as $1 \%(v / v)$ did not alter mutation rate.

Several control experiments indicated no increase in mutagenesis. Benzo(e)pyrene, at most weakly mutagenic in Salmoneila strains, was not mutagenic at a concentration of $5 \mathrm{M}$ (Figure 12.4). Mutation rates in chemostat cultures of E. coli Strains B (wild type) or WP10 (recA) gave no mutational response to $\bar{B} a P$.

A sample from the oil recirculation loop process stream of the HYGAS coal gasification plant was tected in the $B$ chemostat system. The crude material was dissolved in dimethyl sulfoxide $\left(\mathrm{Me}_{2} \mathrm{SO}\right)$ and added, with additional $\mathrm{Me}_{2} \mathrm{SO}$, to the culture medium to yield a final concentration of

$1_{\text {Fall }} 1977$ participant in the Undergraduate Honors Research Participation Program, Eastern Mennonite College. 


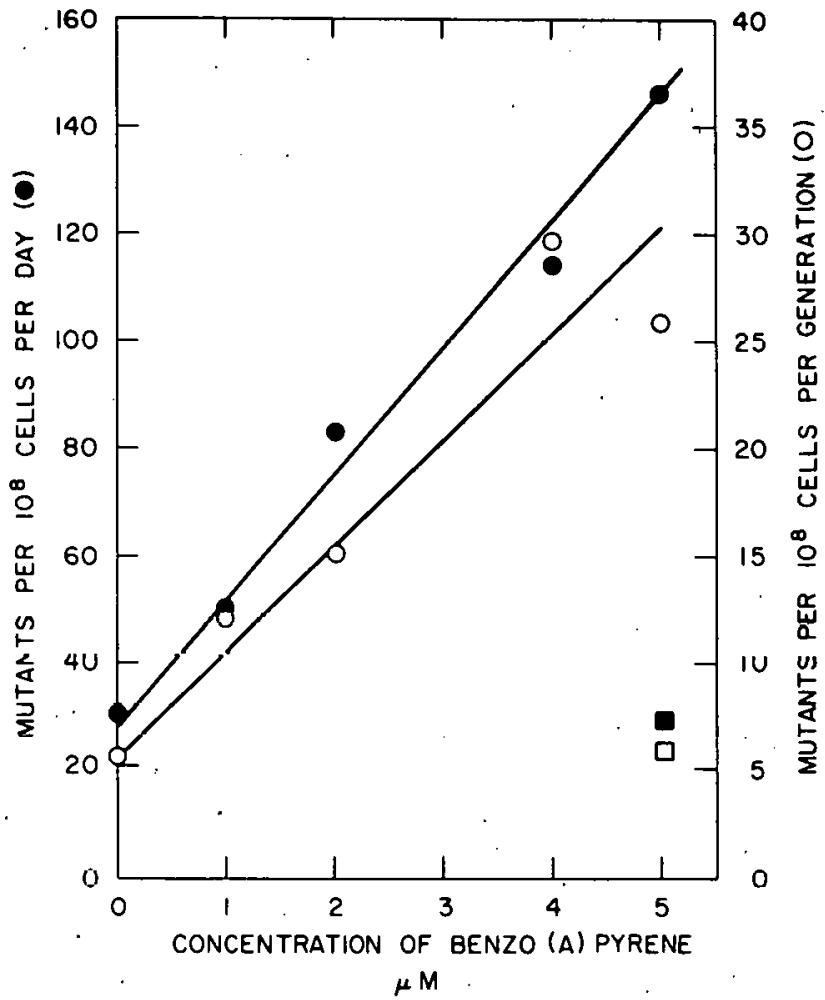

Fig. 12.4. Response of E. coli $\mathrm{B}_{\mathrm{S}-1}$ with a glucose-limited chemostat ( $50 \mathrm{mg} /$ litre) to unactivated $B(a) P$ as a function of chronological time $(\bullet)$ or of cell generation time $(0)$. The symbols a and $\square$ indicate the response of $5 \mu \mathrm{MBeP}$ in terms of chronological and cell generation time, respectively.

approximately $80 \mathrm{\mu g} / \mathrm{litre}$ and an Me So concentration of $0.05 \%$. This $10 \mathrm{w}$ concentration of the crude oil sample mixture in the chemostat $B$ test system, without enzyme activation, induced a mutation rate of $55^{\mathrm{s}}$ mutants per $10^{8}$ cells per day. It was thus at least as sensitive as the Ames Salmonella system with optimal enzyme activation.

A silica gel fraction from the nonvolatile residue of a process stream oil sample also was tested in the B chemostat system; this fraction included phenols, carbonyls, and alcohols. The fraction was added to the culture medium at $1.26 \mathrm{\mu g} / \mathrm{m} 1$, comparable on a weight basis to the earlier concentration of $5 \mu \mathrm{M}$ benzo(a)pyrene. The chemostat results are shown if Figure 12.5. The mutation rate from this fraction was 810 mutants per $10^{8}$ cells/day, corresponding to 643 mutants per $10^{8} \mathrm{cells} / \mathrm{day} / \mu \mathrm{g}$, which is about 25 times the spontaneous rate. In the Ames assay, with required activation, the same concentration increased the spontaneous colony number by slightly less than 2. Thus the chemostat assay, without enzyme activation, was about 20 times more sensitive than the Ames assay with activation. 


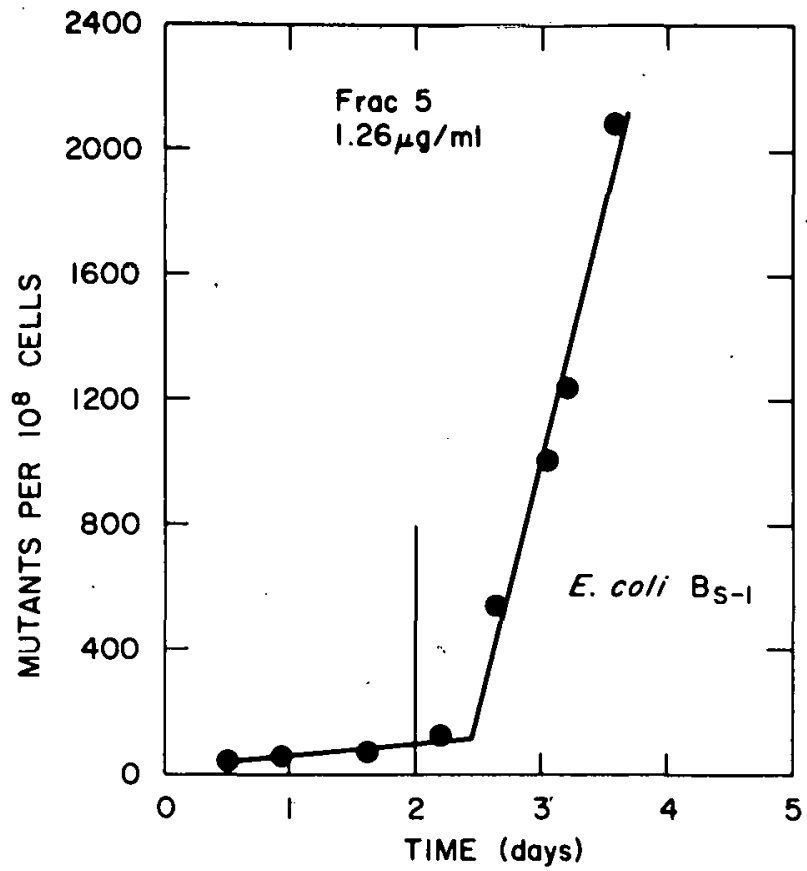

F1g. 12.5. Mutagenic response in the chemostat $B_{S-1}$ system exposed to a fraction from the HYGAS gasification oil recirculation stream eluted on silica gel with ethyl ace tate.

SYNERGISTIC, ADDITIVE, AND ANTAGONISTIC MUTAGENIC EFFECTS OF TWO COMPONENT MIXTURES OF POLYCYCLIC AROMATIC HYDROCARBONS

B. S. Hass, E. Brooks, ${ }^{1}$ K. Schumann, ${ }^{2}$ and S. S. Dornfeld

The interaction of polycyclic aromatic hydrocarbon (PAH) carcinogens with homologous cocarcinogens and noncarcinogens was examined in the Ames Salmonella microsomal assay system. Binary mixtures of PAH's were prepared and tested with Salmonella Strain TA98 in the presence of S-9 rat. 1iver microsomal activating enzymes. Results were considered synergistic when the two compounds together produced more mutants than the sum of the mutants produced individually, additive when the same number of mutants were produced, and antagonistic when fewer mutants were produced by the combined mutagens.

Results of representative examples, indexed by carcinogenic response (cocarcinogens, carcinogens, noncarcinogens), are shown in Table 12.3. The concentration $r$ anges of the test substances were very low and did not exhibit any toxicity in the standard Ames test. The carcinogen benzo(a)pyrene (BaP) and the cocarcinogen benzo(e)pyrene interacted synergistically; in contrast, the cocarcinogen pyrene produced only an additive effect with BaP. Further, the noncarcinogen perylene interacted synergistically with BaP when added in

$1_{\text {Fall }} 1978$ participant in the Undergraduate Honors Research Participation Program, Harding College.

${ }^{2}$ Spring 1979 participant in the Undergraduate Honors Research Participation Program, Skidmore College. 
Table 12.3. Synergism and Antagonism between Mixed Mutagens in the Ames Test with Strain TA98 with Enzymatic Activation

\begin{tabular}{|c|c|c|c|c|}
\hline Mixture & $\begin{array}{l}\text { Concentration } \\
\text { Range ( } \mu \text { g/plate) }\end{array}$ & $\mathrm{N}$ & $\operatorname{Rat} 10^{a} \pm S E$ & Response \\
\hline $\begin{array}{l}\text { Benzo (a)pyrene (carcinogen) } \\
\text { Benzo(e)pyrene (cocarcinogen) }\end{array}$ & $0.25-1.25$ & 28 & $1.61 \pm 0.06$ & Synerg1sm \\
\hline $\begin{array}{l}\text { Benzo(a) pyrene (carcinogen) } \\
\text { Pyrene (cocarcinogen) }\end{array}$ & $0.125-1.25$ & 19 & $0.96 \pm 0.05$ & Additivity \\
\hline Benzo(a) pyrene (carcinogen) & $0.125-1.25$ & 6 & $2.17 \pm 0.24$ & Synergism \\
\hline Perylene (noncarcinogen) & $0.625-2.5$ & 15 & $0.63 \pm 0.05$ & Antagonism \\
\hline $\begin{array}{l}\text { Pyrene (cocarcinogen) } \\
\text { Perylene (noncarcinogen) }\end{array}$ & $0.625-2.5$ & 3 & $0.36 \pm 0.08$ & Antagonism \\
\hline $\begin{array}{l}1,2,3,4-d \text { ibenzanthracene } \\
\text { (noncarclinogen) } \\
1,2,5,6 \text {-dibenzanthracene } \\
\quad \text { (carcinogen) }\end{array}$ & $0.25-2.5$ & 11 & $1.50 \pm 0.12$ & Synergism \\
\hline
\end{tabular}

Me, so to give a concentration range 0.125 to $1.25 \mu \mathrm{g}$ of perylene/plate, but had an antagonistic effect in the concentration range uf 0.625 to 2.5 $\mu \mathrm{g} / \mathrm{plate.}$ Perylene and pyrene also acted antagonistically.

Together, 1,2,5,6-dibenzanthracene, a strong carcinogen but a weak mutagen, and 1,2,3,4-dibenzanthracene, catalogued as a noncarcinogen but a strong mutagen, produced a synergistic response. In addition, observed responses depended upon strain; in Strain TA100, for example, benzo(a)pyrene and benzo(e)pyrene gave only an additive response.

In summary: (1) binary mixtures at very low, nontoxic concentrations of PAH's produce complex mutagenic responses lhat are not prcdicted by their carcinogenic potential; (2) mutagenic responses to the mixtures depend upon the concentrations of the components; and (3) the degree of interaction also depends upon the salmonella strain used. These results indicate that the mutagenic response of a binary mixture is unlikely to represent the sum of responses of its individual components. 
13. MAMMALIAN CELL BIOLOGY

\section{INTRODUCTION}

M. M: Elkind

Damage and repair processes play a critical role in the production of altered cell properties by radiation and other environmental agents. In connection with mutation and transformation, for example, an altered phenotype cannot be expressed if the cell is killed. Hence, at the outset, damage-repair processes relative to cell survival need to be understood in order that similar appraisals may be made for other end points. The research of the Mammalian Cell Biology Group includes, therefore, a major emphasis on mechanisms of cell killing, first because of the relevance of lethality to the expression of other changes, and second because the cellular and molecular biology of nonlethal changes may have elements in common with those of lethality. To this end, we have studied damage and repair after ionizing and nonionizing radiations, and their combination, in respect to cell killing and neoplastic transformation. We have also further pursued the photodynamic properties of polycyclic aromatic hydrocarbons.

REGULAR STAFF

Dainko, Julia L. (Scientific Assistant)

Elkind, Mortimer M. (Senior Biophysicist)

Han, Antun (Biophysicist)

Liu, Chin-Mei (Scientific Assistant)

Sinclair, Warren K. (Senior Biophysicist)

TEMPORARY STAFF DURING 1978

Gould, Michael N. (Postdoctoral Appointee)

Lankas, George R. (Postdoctoral Appointee)

Ross-Riveros, Pepi (Postdoctoral Appointee) 
REPAIR OF POTENTIALLY LETHAL DAMAGE AND "SINGLE-HIT" KILLING

H. Utsumi, P. Ross-Riveros, C. M. Liu, and M. M. Elkind

Actively growing V79 Chinese hamster cells treated with anisotonic phosphate buffered saline (PBS) after X-irradiation show lower survival levels than cells treated with isotonic PBS or cells promptly incubated with complete medium immediately after irradiation. The anisotonic PBS solutions used wcre not toxic in unirradiated cells. The sensitization of irradiated cells results from both hypotonic as well as hypertonic NaCl concentrations in PBS, is strongly dependent on both temperature and time, and is expressed mainly as an increase in the final slope of the single-dose survival curve. Cells at essentially all ages in the division cycle are sensitized. The oxygen enhancement ratios of cells receiving an anisotonic posttreatment are almost equal, suggesting that typical radiochemically induced lesions, rather than nonspecific stress, are responsible for the enhanced lethality. After two $X$-ray dose fractions, the response of cells sensitized after both fractions by anisotonic posttreatment is similar to that obtained for cells treated isotonically after the two fractions and indicates that sublethal damage repair is not influenced by the enhanced expression of potentially lethal damage. Independence of potentially lethal damage repair from sublethal damage repair is further suggested by the more rapid rate of the former compared to the latter. In contrast to the modification of expression of potentially lethal damage in plateau phase cells following lethal exposures to nonionizing radiations, with or without the prior incorporation of 5-bromodeoxyuridine into DNA, essentially no additional damage is expressed after the anisotonic PBS treatment of actively growing cells. Thus, essential differences in the molecular bases of cell killing by nonionizing versus ionizing radiation are suggested. The pro posal is advanced that enhanced expression of potentially lechal damage afier $X$-irradiation results from a destabilization of the structural relationship between DNA and the nuclear envelope, or the nuclear envelope and the nuclear protein matrix, as a consequence of osmotic changes produced by anisotonic treatment.

In addition to demonstrating repair of potentially lethal damage after mid-to-large ionizing radiation doses in repair-competent cells, the technique of postirradiation treatment with anisotonic PBS solutions also yielded information on the repair of such damage after small doses. It is generally acknowledged that the surviving fraction $\underline{S}$ of mamalian cells may be described by

$$
S=e^{-\alpha D}[M(D)] \text {, }
$$

where $\underline{\alpha}$ is a constant and $\underline{M}(\underline{D})$ is a single-valued function of the dose $\underline{D}$ to signify a multievent, damage accumulation mode of lethality. Using fissionspectrum neutrons as well as $X$-rays, we found that enhanced cell killing after small doses could be effected by hypertonic PBS. These data indicate that Chinese hamster cells ordinarily effect the repair of potentially lethal damage throughout the measurable survival range and, in particular, that socalled "single-hit" killing can be subject to modification by cellular repair. 
CHANGE IN REPAIR COMPETENCY AFTER 5-BROMODEOXYURIDINE PULSE LABELING AND NEAR-ULTRAVIOLET LIGHT

M. P. Hagan ${ }^{1}$ and M. M. Elkind

To advance the understanding of the role of DNA damage in cell killing, it is useful to use treatments in which one or another form of DNA lesion(s) is produced with high frequency. Such is the case in respect to the 1 ight sensitivity that results when 5-bromodeoxyuridine (BUdR) replaces thymidine in the genome of a cell. For this reason, studies have been pursued of the mechanism of BUdR photolethality.

Synchronized V79 Chinese hamster cells, pulse-labeled with 5-bromodeoxyuridine, show marked changes in the sensitivity to near-ultraviolet light during the cell cycle. Cells are least sensitive during the remainder of the $S$-phase following the BUdR pulse. They become maximally sensitive in the next cell cycle when the BUdR-labeled DNA presumably serves as the template for replication. A return to relative insensitivity follows during the remainder of that $\mathrm{S}$-phase. When BUdR is given both near the beginning and again near the end of the same $S$-phase, the increase in survival does not occur until DNA synthesis progresses beyond the time when the DNA made during the second pulse serves as a template. Furthermore, cells in the resistant phases of the cell cycle are sensitized by 1-2 mM caffeine. The data support the hypothesis that lesions in the DNA containing BUdR are effectively repaired after semiconservative replication. The data also indicate that saturation of repair capacity and not target multiplicity is responsible for the appearance of a shoulder on the survival curves.

DAMAGE-REPAIR STUDIES OF THE NEOPLASTIC TRANSFORMATION OF MOUSE C3H/10T $1 / 2$ CELLS USING FRACTIONATED DOSES OF X-RAYS AND FISSION-SPECTRUM NEUTRONS

A. Han, C. Hil1, 2 J. L. Dainko; E. M. Buess, and M. M. E1kind

It is well known that dose fractionation results in increased survival of mammalian cells because of the repair of sublethal damage during the interfraction interva1. We have initiated a study of the influence of dose fractionation on neoplastic transformation to determine whether "subtransformation" damage is also repaired.

A mouse embryo-derived cell line, $\mathrm{C} 3 \mathrm{H} / 10 \mathrm{~T} 1 / 2$, was used to measure the frequency of in vitro neoplastic transformation induced by $50-k V P X$-rays and by fission-spectrum neutrons from the JANUS reactor in the Division. The transformation frequency after single $X$-ray doses rises exponentially, reaching a plateau at about $3 \times 10^{-3}$ transformant/survivor. The induction

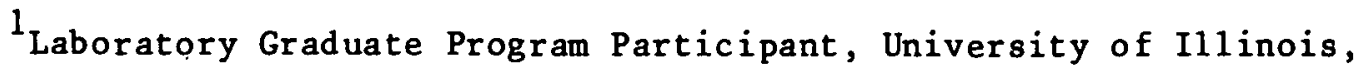
Urbana.

2Resident Associate, Division of Biological and Medical Research. 
curve following single neutron doses, although qualitatively similar, initially rises more steeply and levels off at a maximum of about $6 \times 10^{-3}$ transformant/survivor. For both radiations, transformation frequency varies with changes in the number of viable cells per dish, showing about a 10-fold decrease in transformation frequency when the number of viable cells per 90-mm dish was increased from about 300 to 1000 . Fractionation of a total X-ray dose of 700 rads into two fractions separated by various time intervals from 2 to 16 hours results in an approximately 6-fold increase in survival and reduction in transformation frequency. Fractionation of the total neutron dose of 378 rads by various time intervals from 3 to 24 hours has no effect upon cell survival, and transformation frequency declines by a factor of only about 1.7 at most. Cells derived from transformed foci formed fibrosarcomas when injected into appropriately treated mice.

THE INTERACTION OF DAMAge DUE TO "SUNLIGHT" AND X-RAYS

A. Han, J. L. Dainko, C. M. Liu, and M. M. E1kind

We are all exposed to the radiations from sunlight during most of our lifetimes. Since the incidences of basal and squamous cell skin cancer have increased appreciably during the past several decades, it is important to determine whether damage resulting from sunlight interacts with damage from other agents. To this end, a study was made of the combined lethal actions of a sunlight-simulating source of near-UV light and X-rays.

Enhanced cell killing due to the combined exposure of "sunlight" (Westinghouse Sun Lamps, FS20) and X-rays, indicative of damage interaction, is observed at all stages of the cell cycle. The greatest interaction is observed in the middle of the DNA synthetic phase. At equal survival levels, "sunlight" damage is only partly additive to $\mathrm{X}$-ray damage and vice versa. Loss of damage interaction between radiations is more rapid after a first dose of X-rays than after a first dose of sunlight. The data indicate that the damage due to near-UV and X-rays interacts and is partly additive.

A second study of the combined action of possible environmental agents and sunlight concerns polycyclic aromatic hydrocarbons ( $\mathrm{PAH}^{*} \mathrm{~s}$ ). A number of $\mathrm{PAH}^{\prime}$ 's are coal derived and are known to be carcinogens. With the prospect of our increasing reliance on coal as a fuel for power production, we have started a study of the influence that certain photochemically active PAH"s have on cell killing caused by a filtered and unfiltered source of the sunlight-simulating near-UV light. 
PHOTODYNAMIC CYTOTOXICITY IN MAMMALIAN CELLS EXPOSED TO SUNLIGHT-SIMULATING NEAR-ULTRAVIOLET LIGHT IN THE PRESENCE OF THE CARCINOGEN 7, 12-DIMETHYLBENZ ( A) ANTHRACENE

H. Utsumi, G. R. Lankas, J. L. Dainko, and M. M. E1kind

The coal-derived carcinogen 7,12-dimethylbenz(a) anthracene (DMBA) added to cultures of V79 Chinese hamster, mouse $\mathrm{C} 3 \mathrm{H} / 10 \mathrm{~T} 1 / 2$, and human HeLa cells enhances photolethality induced by the sunlight-simulating emission from Westinghouse Sun Lamps (FS20, 290-400 nm). The enhancement occurs only in the presence of oxygen and only when the DMBA precedes the irradiation; treatment of cells with DMBA after irradiation is without lethal effects. The endoperoxide of DMBA is ineffective both before as well as after irradiation, and DMBA incubation before far-UV exposure $(254 \mathrm{~nm})$ is protective. Cells rendered photosensitive by incubation with DMBA rapidly lose their sensitivity (in less than 10 minutes at $37^{\circ} \mathrm{C}$ ) if incubated in a DMBA-free solution containing serum, but maintain their sensitivity at least for several hours if a serum-free solution is used. Although DMBA enhances light-induced killing of cells in all phases of the cycle, those undergoing DNA synthesis are sensitized the most. The data support photodynamic lethality due to one or both of the following: (1) the reaction with DNA of either DMBA radicals followed by oxidation, or DMBA-produced single oxygen; or (2) the peroxidation of lysosomal membranes followed by the release of hydrolases, include DNAses. 
THIS PAGE

WAS INTENTIONALLY

LEFT BLANK 
14. CARCINOGENESIS

\section{INTRODUCTION}

Christopher A. Reilly, Jr.

Many of the chemical, physical, and biological agents known to cause cancer are now present in our environment. In addition, there are numerous other agents that, although not carcinogenic themselves, increase tumor incidence by interacting with carcinogens. The possibility of such interactions must be taken into consideration for proper assessment of the human cancer risk. Thus, to evaluate accurately the effects. of environmental contamination with cancer-causing materials from the existing and emerging energy technologies, it is necessary to understand the nature and underlying mechanisms of carcinogen/cocarcinogen interactions. The general objective of the Carcinogenesis Program is to examine these mechanisms. At the same time we are also attempting to develop rapid and reliable methods for assessing the tumorigenic risk from potential carcinogenic and cocarcinogenic energy-related effluents. These efforts complement and extend ongoing Divisional toxicology studies in coal, radiation, and energy storage and transmission.

Particularly noteworthy accomplishments during the year include the following. (1) Further insight into the role of phenobarbital as a promoter of hepatic tumors induced by a chemical carcinogen was achieved with the demonstration that the observed effect is due to the appearance of new tumors, not to the accelerated growth of tumors already present. (2) The recent adaptation of liver cells to growth in an in vitro culture system will greatly facilitate studies on the regulation of liver enzymes. (3) The question of whether retroviruses are involved in the induction of tumors by radiation has come closer to an agswer with the demonstration that most, if not all, bone cancers induced by ${ }^{9} \mathrm{Sr}$ in $\mathrm{CF} \equiv 1$ and $\mathrm{X} / \mathrm{Gf}$ mice contain such viruses. Animal tests suggest that some of these viruses can cause sarcomas. (4) Significant progress has been made in developing several systems for early detection of carcinogenic and cocarcinogenic agents. These include the demonstration that rat livers are responsive to polycyclic aromatic hydrocarbons and that there are new chromosomal proteins in hepatic tumors that $c$ an be detected immunologically.

The following report is organized into two sections, the first dealing with mechanisms of cocarcinogenesis and the second with the development of test systems. 
REGULAR STAFF

Cerny, Elizabeth A. (Scientific Assistant)

Chan, Emerson W. (Assistant Biochemist)

Dale, Phylis J. (Scientific Assistant)

Feinstein, Robert N. (Senior Biochemist)

Finkel, Miriam P. (Senior Biologist)

Greco, Isabel I. (Scientific Assistant)

Grube, Donald D. (Scientific Associate)

Haugen, David A. (Assistant Biochemist)

Lee, Chung $\mathrm{K}$. (Assistant Biologist)

Lombard, Louise S. (Veterinary Pathologist)

Ludeman, V. Ann (Scientific Assistant)

$O^{\prime}$ Connor, Timothy E. (Senior Biologist)

Pahnke, Vernon A. (Scientific Assistant)

Peraino, Carl (Biochemist)

Prapuolenis, Aldona M. (Scientific Assistant)

Rahman, Yueh-Erh (Biologist)

Reilly, Jr., Christopher A. (Microbiologist)

Rockus, Gabrielle (Scientific Assistant)

Sallese, Anthony R. (Scientific Assistant)

Sedita, Beverly A. (Scientific Assistant)

Staffeldt, Everett F. (Scientific Associate)

Wright, Betty Jean (Scientific Associate)

TEMPORARY STAFF DURING 1978

Beales, Nadine N. (Postdoctoral Appointee)

Bodoni, Laszlo (Postdoctoral Appointee)

Ekelman, Karen B. (Postdoctoral Appointee)

Mitchen; Joel R. (Research Associate)

Patel, Kanaiyalal (Postdoctoral Appointee) 


\section{MECHANISMS OF COCARCINOGENESIS}

This section includes the description of experiments on the role of gene regulation in rat hepatic neoplasia, on tumor promotion, on the interaction of viruses and radiation in the induction of murine bone tumors, and on modulating factors in skin carcinogenesis .

CIRCADIAN REGULATION OF ORNITHINE AMINOTRANSFERASE AND SERINE DEHYDRATASE SYNTHESIS IN RAT LIVER

K. B. Ekelman, C. Peraino, A. M. Prapuolenis, and D. P. Peterson ${ }^{1}$

Studies on rat liver enzyme regulation have involved the comparison of the responses of two amino acid catabolizing enzymes, ornithine aminotransferase and serine dehydratase, following exposure of rats to dietary and hormonal stimuli. Previous investigations in this laboratory have demonstrated that circadian oscillations in the synthesis of the two enzymes persist in rats maintained on a high protein diet, and that the phase of the synthesis cycles determines the response of the enzyme regulatory system to hormonal stimuli.

A series of experiments are now in progress that will enable us to determine which of several possible stimuli (i.e., dietary protein, light, and steroid availability) are responsible for the maintenance and phasing of circadian enzyme synthesis in rat liver. The results of an investigation designed to determine the effects of a 12-hour out-of-phase meal schedule on ornithine aminotransferase and serine dehydratase synthesis cycles suggest that this meal shift altered the phasing of the ornithine aminotransferase synthesis cycle and eliminated circadian fluctuations in serine dehydratase synthesis; these responses, do not appear to depend on differences in the amount of food consumed by rats during the restricted meal feedings.

Stomach emptying experiments performed on rats maintained on 2-hour restricted meals suggest that rats fed at or near the commencement of the light phase do not adapt metabolically to a restricted meal as well as do rats fed at or near the commencement of the dark phase of the light/dark cycle.

Reports of the persistence of cyclic liver enzyme levels in cultures of isolated rat hepatocytes have suggested that primary control of these enzyme fluctuations is regulated within the cell and not by the action of periodic extracellular stimuli in vivo. For this reason the in vivo regulation studies have been accompanied by in vitro experiments on rat hepatocytes maintained in primary culture. A sensitive high pressure liquid chromatographic assay for the presence of ornithine aminotransferase has been developed for the detection of enzyme levels in cultured hepatocytes.

$1_{\text {Toxicity of Energy Storage Systems Group. }}$ 
A comparison of ornithine aminotransferase regulation in primary hepatocyte cultures and in the $\mathrm{H}-35$ hepatoma cell line is presently being undertaken, and an attempt will be made to relate specific observed alterations to the transformed character of the cell line.

DIETARY PHENOBARBITAL EFFECTS ON FOOD UTILIZATION EFFICIENCY AND CIRCADIAN CYCLING OF FOOD INTAKE AND DEEP-BODY TEMPERATURE IN RATS

C. Peraino, C. F. Ehret, ${ }^{1}$ K. R. Groh, ${ }^{1}$ J. C. Meinert,

G. D'Arcy-Gomez, 2 and A. M. Prapuolenis

In recent experiments comparing tumorigenic enhancing effects of phenobarbital at various dietary concentrations, we observed that $0.25 \%$ dietary phenobarbital reduced the growth rate of the rats and produced noticeable somnolence between approximately 11:00 a.m. and 3:00 p.m. daily. The most obvious interpretation of these observations is that the behavioral changes induced in the rat by the high dietary phenobarbital probably caused a reduction in food intake with a consequent slowing of growth. This interpretation required verification, however, since it was necessary to determine whether our tumorigenesis studies would be complicated by phenobarbital-mediated changes in the level of food intake. The present study, therefore, analyzed the effects of $0.25 \%$ dietary phenobarbital on growth rates and food intake levels in rats. In addition, in view of the cyclic behavioral changes noted above, phenobarbital effects on the circadian fluctuations in deep-body temperature and food intake were measured by means of an automated monitoring system.

The results showed that the daily food intake was similar in untreated control rats and those receiving $0.25 \%$ dietary phenobarbital, but the efficiency of food utilization for growth was $20 \%$ lower in the phenobarbital-treated rats. Further, the amplitude of the circadian oscillation of deep body temperature in the rats fed phenobarbital was twice that in the controls and the attainment of peak body temperatures was advanced by approximately 2 hours. A comparison of food intake patterns showed that rats fed the control diet eat around the clock, albeit at a greater rate during dark than during light phase, whereas rats on phenobarbital start to eat earlier in the dark phase and confine their feeding almost exclusively to early dark phase. These results suggest that high dietary phenobarbital produces hitherto unsuspected metabolic regulatory and nutritional effects. Certain of these effects may influence susceptibility to tumorigenesis in the liver. This possibility is supported by our recent observation that $0.25 \%$ dietary phenobarbital enhanced tumorigenesis more than lower doses, but only after a prolonged lag interval during which tumorigenesis was lower than that with the lower phenobarbital doses.

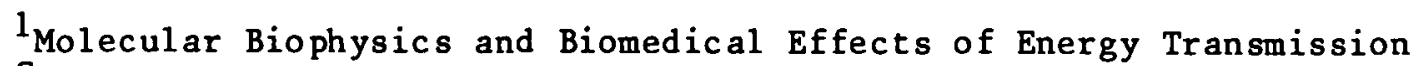
Groups .

Fall 1976 participant in the Undergraduate Honors Research Participation Program, Associated Colleges of the Midwest. 
EFFECTS OF VARYING THE DIETARY CONCENTRATION OF PHENOBARBITAL ON ENHANCEMENT OF 2-ACETYLAMINOFLUORENE-INDUCED HEPATIC TUMORIGENESIS

C. Peraino, E. F. Staffeldt, V. A. Ludeman, K. A. Rettman,

D. A. Haugen, 1 and R. J. M. Fry ${ }^{2}$

In prior studies we demonstrated that the short-term exposure of rats to 2-acetylaminofluorene (AAF), a liver carcinogen (tumor initiator), produced a low incidence of liver tumors. When the AAF treatment was followed by the feeding of a phenobarbital-supplemmented diet the incidence of these tumors was markedly increased. Several experiments have been conducted to define the characteristics of the tumorigenic enhancing effect of phenobarbital in an effort to gain insight into mechanisms underlying the postinitiation stage of tumorigenesis. The present investigation was designed to compare the tumorigenic enhancing effect of four different dietary concentrations of phenobarbita1, $0.002 \%, 0.01 \%, 0.05 \%$, and $0.25 \%$. This study has just been concluded and evaluation of the data is not yet complete, but the following preliminary interpretations are possible.

1) Although the onset of tumorigenesis was delayed in comparison with that in previous experiments, the final tumor incidence level resembled that in previous experiments. This suggests that the time to first appearance of tumors and level of: tumor incidence are not necessarily linked.

2) A computer-based statistical comparison of the tumor incidence kinetics for the $0 \%, 0.01 \%$, and $0.05 \%$ phenobarbital treatment groups indicates that the times to first tumor appearance and the attainment of plateau levels of tumor incidence were similar among the three groups although the plateau levels increased with increasing phenobarbital dosage. These data suggest that phenobarbital increases tumor incidence without accelerating tumor growth.

3) A dietary phenobarbital concentration of $0.25 \%$ had the greatest tumorigenic enhancing effect, but only after a prolonged lag interval during which tumorigenesis was lower than with the lower phenobarbital doses. The 1 ag suggests that the high phenobarbital dosage produced metabolic changes that temporarily interfered with the enhancement phenomenon.

1 Toxicity Program for Coal Combustion and Conversion Effluents.

2 Biology Division, Oak Ridge National Laboratory. 
EFFECTS OF BUTYLATED HYDROXYTOLUENE ON HEPATIC MICROSOMAL CYTOCHROME P-450.

D. A. Haugen ${ }^{1}$ and J. P. Hardwick ${ }^{2}$

Cytochrome $\mathrm{P}-450$ is a hemoprotein that is part of the microsomal monooxygenase system that metabolizes carcinogens, drugs, and environmental chemicals. The concentration of hepatic cytochrome $\mathrm{P}-450$ can be increased by administration of a variety of drugs including phenobarbital, a promoter of 1 iver hepatic tumors (Peraino, C., et al., Cancer Res. 31, 1506, 1971). The present study compares the biochemical effects of two promoters, phenobarbital and the food preservative BHT (butylated hydroxytoluene), on the level of microsomal cytochrome P-450.

The concentration of cytochrome $\mathrm{P}-450$ can be measured spectrophotometrically due to the presence of the chromophoric heme moiety. In rats receiving dietary phenobarbital, the amount of cytochrome P-450 increased in a dose-dependent manner, with stable levels achieved after 5 to 7 days. Dietary administration of BHT caused only a transient increase in the concentration of cytochrome $P-450$ so that after 3 to 4 days no effect was detected despite continued administration.

The cytochrome P-450 can also be detected electrophoretically, but in this method the heme is dissociated from the protein so that only the apoprotein is observed. Administration of either phenobarbital or BHT caused a characteristic dose-dependent increase in the levels of several microsomal proteins," including the apoprotein(s) of cytochrome P-450. The pattern of these changes was indistinguishable for the two treatments. Thus, although BHT caused an increase in the level of the apoprotein(s) of cytochrome P-450, it did not cause an increase in the level of the complete hemoprotein, as detected spectrophotometrically.

Experiments were designed to explore the possibility that BHT interferes with heme metabolism at the level of heme synthesis, degradation, or its incorporation into the apoprotein. Administration of BHT caused an increase in both heme synthesis and degradation, as indicated by increased levels of $\delta$-aminolevulinate synthetase and heme oxygenase, respectively. The level of free heme was not altered by BHT treatment. Addition of heme to microsomes from BHT-treated animals increased the concentration of cytochrome $\mathrm{P}-450$ as detected spectrophotometrically, suggesting that heme had combined with apocytochrome P-450. Simultaneous administration of BHT and phenobarbital did not decrease the effectiveness of phenobarbital in its induction of cytochrome $\mathrm{P}-450$.

Although the effect of BHT is obviously complex, and not yet well understood, the present results suggest that it causes induction of the apoprotein of cytochrome $P-450$, but interferes with the incorporation of the heme which is required for the formation of the complete cytochrome.

${ }^{1}$ Toxicity Program for Coal Combustion and Conversion Effluents. ${ }^{2}$ Participant in the 1978 Summer Institute in Cell Biology, I1linois State University. 
TWO-DIMENSIONAL ELECTROPHORETIC ANALYSIS OF RAT LIVER AND NOVIKOFF HEPATOMA PROTEINS

K. E. Willard, ${ }^{1}$ T. E. O'Connor, and N. G. Anderson ${ }^{2}$

Proteins from rat 1 iver and Novikoff hepatoma cells have been mapped by isoelectric focusing in the first dimension and sodium dodecyl sulfate electrophoresis in the second, using the ISO-DALT system developed in the Molecular Anatomy Program (Section 17). However, this conventional isoelectric focusing did not give satisfactory resolution of the more basic proteins, which appeared as streaks. The BASO technique was designed to obtain complete resolution of these basic proteins in the first dimension. In this technique, samples were solubilized in a mixture of phosphatidyl choline and urea, loaded at the acid end of the gel, and electrophoresed for 3200 to 4000 volt-hours instead of the 10,000 volt-hours used in isoelectric focusing. Use of this technique followed by sodium dodecyl sulfate electrophoresis (i.e., the BASODALT system) enabled identification of the spots corresponding to the five histones (Figure 14.1A).

Considerable differences in the protein patterns of rat 1 iver and Novikoff hepatoma have been detected in both the cytosol and nuclear fractions (Figure 14.1). The proteins found to be common among the patterns are the major cellular proteins which are found in most tissues. Therefore, it is concluded that Novikoff hepatoma cells are greatly different from normal liver and suggested that differences could be due to malignant transformation and/or to changes that have occurred because of long-term transfer of the tumor in the ascitic form.

\section{PHOTOCHEMICAL INDUCTION OF SKIN TUMORS}

D. D. Grube, K. A. Rettman, and R. J. M. Fry ${ }^{3}$

Certain of the furocoumarins such as 8-methoxypsoralen (8-MOP) are chemical sensitizers that photoreact with nucleic acids when exposed to long wavelength ultraviolet 1 ight (320-400 $\mathrm{nm}$ ), extending the ultraviolet light (UV) action spectrum for lethal, mutagenic, and carcinogenic effects. By examining the UV dose-response relationship with or without chemical photosensitizers as a function of molecular lesions (psoralen bifunctional adducts--interstrand cross-1inks), acute cutaneous responses, and the initiation and expression of tumors in the skin of hairless mice, it should be possible to identify and quantitate the wavelength spectra and specific adducts involved in photocarcinogenesis. In addition, by using a chemical promoter, it is possible to determine whether exposure requirements differ between initiation and expression of tumors.

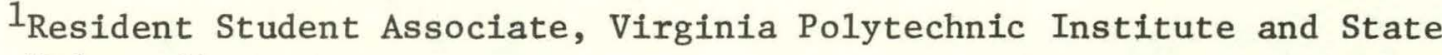
University.

2Molecular Anatomy Program.

30ak Ridge National Laboratory.
} 

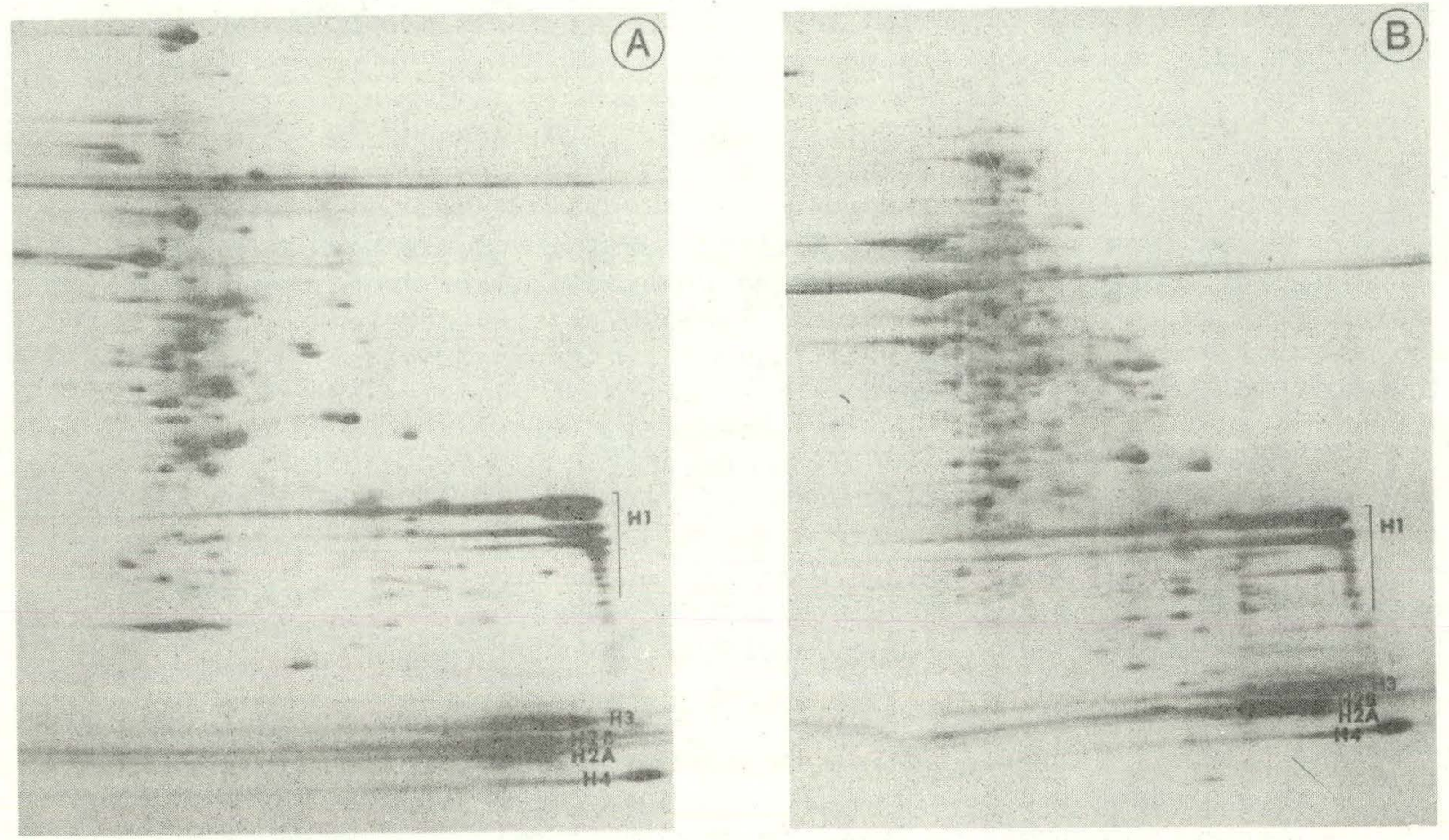

Fig. 14.1. BASO-DALT patterns of isolated nuclei from rat liver cells and Novikoff hepatoma cells. The first dimension gels were electrophoresed for 3200 volt-hours using LKB 3.5-10 ampholines in the ISO-DALT apparatus. The gels are oriented with the basic end to the right and the acidic end to the 1eft. (A) BASO-DALT pattern of rat liver nuclei. (B) BASO-DALT pattern of Novikoff hepatoma nuclei. The histones $\mathrm{H} 1, \mathrm{H} 2 \mathrm{~A}, \mathrm{H} 2 \mathrm{~B}, \mathrm{H} 3$, and $\mathrm{H} 4$ are identified.

The induction of psoralen adducts in epidermal DNA and cytokinetic responses were used to (1) define fluence adjustments for inducing biologically equivalent damage with 8-MOP compound and different spectra of UV, and (2) determine the 1 imits of exposure that induced stabilized cutaneous damage from which cumulative doses could be estimated. The preliminary results in Figure 14.2 show an increase in percent of mice with malignant skin tumors as a function of cumulative UV irradiation. Within a defined but tumorigenic 


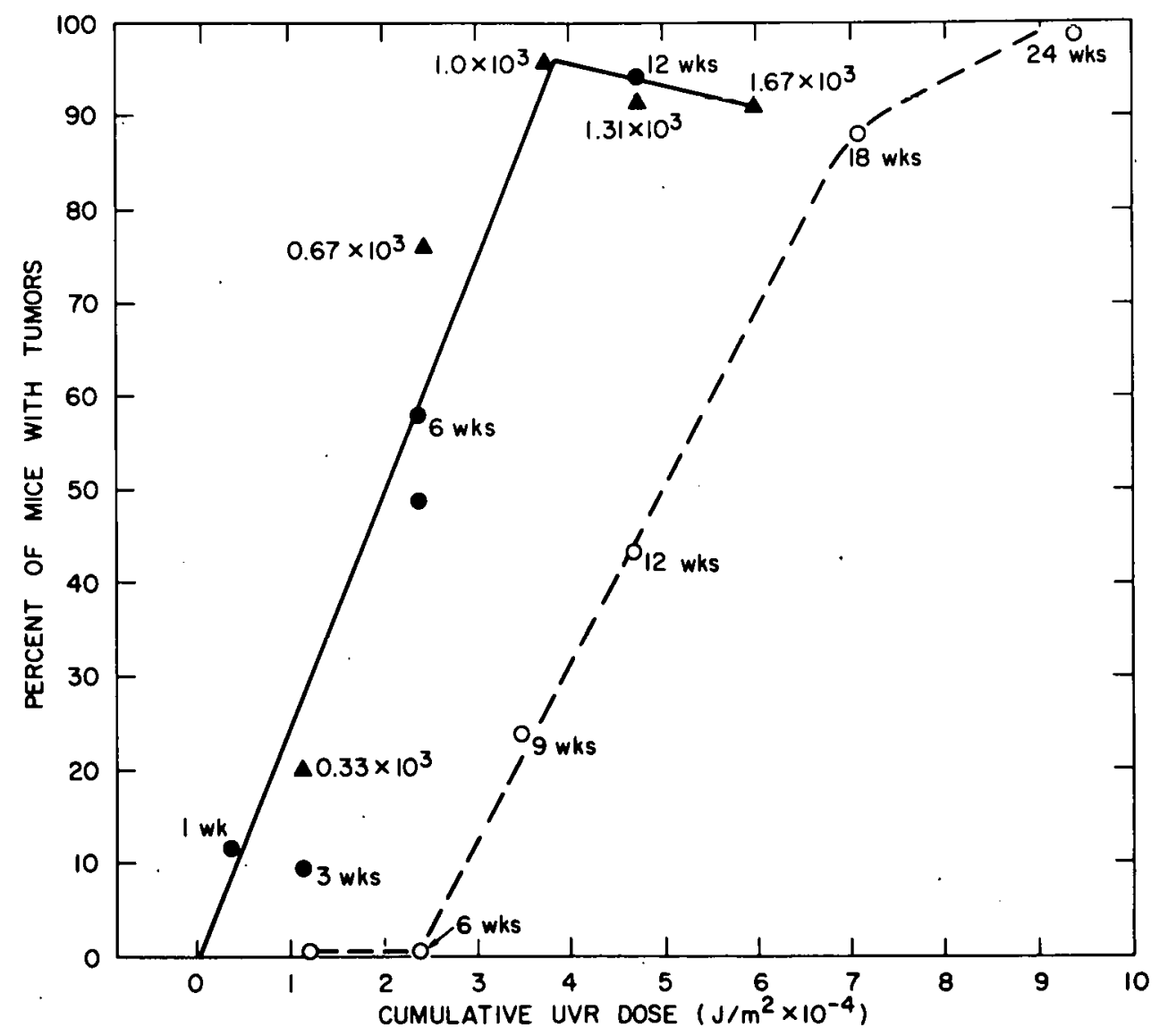

Fig. 14.2. 'Cumulative percent of SKH:hairless-1 female mice with one or more epidermal carcinomas induced by fractionated exposures, $\cdot 3 \mathbf{x} /$ wk for the number of weeks noted, to combined treatments of 250 Hg 8-MOP (topically) followed 45 minutes 1 ater by either (1) $1.31 \times 10^{3} \mathrm{~J} \mathrm{~m}^{-2}, 320-400 \mathrm{~nm}$ UV radiation $(0,0)$, or (2) exposures $3 x / w k$ fqgr 12 wefks to $0.33,0.67,1.0,1.31$, or $1.67 \times 10^{3} \mathrm{~J}$ $\mathrm{m}^{-2}$ 320-400 nm UV radiation (A). In selected exposure regimens $(\boldsymbol{O}, \Delta)$, groups of mice additionally received topical applications of 5 ig TPA, $3 \mathrm{x} /$ wk for 52 weeks; this treatment was initiated one week after the termination of 8-MOP plus UV. treatments. 
range of fractionated UV exposures $\left(0.33 \times 10^{3} \mathrm{~J} \mathrm{~m}^{-2}\right.$ to $1.31 \times 10^{3}$ $\mathrm{J} \mathrm{m}^{-2}$ ), the number of psoralen adducts per cell (data not shown) and the number of epidermal carcinomas increased proportionately as a function of the cumulative radiation dose. Exposure to only UV radiation or 8-MOP, alone, or either treatment followed by promotion with

12-0-tetradecanoy 1-phorbo1-13-acetate (TPA) was ineffective in the induction of tumors. Further, with fractionations of $3 \mathrm{x} / \mathrm{wk}$, equal total doses differing only in the fluence per fraction or interval of exposure appear to be equally effective in the induction of tumors when animals were additionally treated with TPA. As shown in Figure 14.2, promotion with TPA effectively reduced the UV dose requirements for the induction of skin tumors, and the results suggest that the later exposures in the nonpromoted groups of mice are associated with both initition and expression events. The promotion experiments using TPA show that photocarcinogenesis, as chemical carcinogenesis, is a multistage process and the data strongly implicate psoralen adducts as the lesion underlying initiation events. Recently completed experiments with the furocoumarin 4,5'8-trimethoxypsoralen support these observat1ons.

BIOCHEMICAL AND BIOPHYSICAL CHARACTERIZATION OF FBJ AND FBR MURINE OSTEOSARCOMA VIRUSES

E. W. Chan, P. J. Dale, I. L. Greco, C. K. Lee, and K. Rupprecht ${ }^{1}$

The fundamental properties of two carlier murine osteosarcoma viral isolates, FBJ (Finkel, M. P., et al., Science 151, 698, 1966) and FBR (Finkel, M. P., et al., Proceedings of the Twenty-fourth Symposium of the Colston Research Society, Vol $\cdot 24$ of the Colston Papers, Butterworths Scientific Publications, London, $1 \overline{973}, \overline{\mathrm{p}} . \overline{353} \overline{\text { ) have been }}$ determined. In sucrose, they band at 1.16 $\mathrm{g} / \mathrm{ml}$. Their genomes consist of a $70 \mathrm{~S}$ RNA that dissociates readily on heating into 34-35s subunits. They possess a reverse transcriptase that shows a preference for $\mathrm{Mn}^{+2}$ over $\mathrm{Mg}^{+2}$. The enzyme is capable of catalyzing the synthesis of faithful and specific H-DNA probes that are complementary to their associated viral RNA genome.

Molecular hybridization studies with such probes show that the two viruses are genomically very closely related to each other but are totally unrelated to other nonmurine Type $C$ viruses of chicken, cat, baboon, woolly monkey, and gibbon ape origin. Extensive reciprocal hybridization data between FBJ and FBK and other murine Type $C$ viruses indicate they form a group distinguishable from the five previously established murine viral subgroups. They are very closely related to the AKR, and BALB/c endogenous viruses but are only partially related to the NIH Swiss endogenous, Rauscher, and Moloney subgroup viruses.

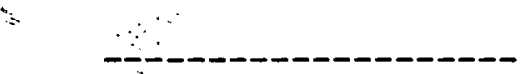

${ }^{1}$ Participant in the 1978 Summer Research Institute in Cell Biology, University of Notre Dame. 
These data indicate FBJ and FBR viruses have the biochemical and biophysical properties of Type $C$ murine retroviruses, of which they.constitute a distinctly identifiable subgroup.

IMMUNOLOGICAL CHARACTERIZATION OF MURINE OSTEOSARCOMA VIRUSES FBJ AND FBR

L. Bodoni, J. R. Mitchen, B. Amsler, I E. W. Chan, M. P. Finkel, and

C. A. Reilly, Jr.

We are currently determining the immunological properties of FBJ virus. (Finkel, M. P., et al., Science 151, 698, 1966) and FBR virus (Finkel, M. P., et al., Proceedings of the Twenty-fourth Symposium of the Colston Research Society, Vol. 24 of the Colston Papers, Butterworths Scientific Publications, London, $1 \overline{973}, \overline{\mathrm{p}} . \overline{353} \overline{)}$. Fractionation of the viral proteins of FBJ and FBR by polyacrylamide gel electrophoresis resulted in electrophoretic patterns similar to thg $999_{1}$ of other murine retroviruses. Apart from the large envelope pro-. teins $8 \mathrm{p} 971$, the major $\mathrm{p} 30$, and the low molecular weight p10, FBJ and FBR have a pll protein that is apparently a unique size class. Both viruses lack a pl5 protein.

Rabbit anti-FBJ and anti-FBR sera were cross-reactive with the p30 proteins of FBJ, FBR, and two strains of murine leukemia viruses, Rauscher and AKR, in a double gel immunodiffusion assay. The precipitin lines of identity indicated that FBJ and FBR viruses have the group-specific antigen of murine retroviruses.

Sensitive competitive radioimmunoassays have been developed for the p30 proteins of FBJ and FBR yiruses. Viral proteins were prelabeled to a high specific activity with 125 by an enzymo-bead procedure, fractionated by slab gel electrophoresis, and isolated quantitatively by elution from appropriate slices of the gef 25 Competitive radioimmunoassays were set up using limiting quantities of ${ }^{25} \mathrm{I}-\mathrm{p} 30$ and pretitrated antisera. Such assays could detect nanogram quantities of unlabeled homologous viral protein. Competition by other murine Type $C$ viruses, such as Rauscher and AKR, gave profiles and slopes identical to those for FBJ and FBR. These data are consistent with those from the immunodiffusion studies. Similar competitive radioimunoassays that should contain unique antigenic determinants are being developed for the p1l and p10 proteins. These should provide assays för specific detection of FBJ and/or FBR viruses.

${ }^{1}$ Participant in the 1978 Summer Research Institute in Cell Biology, University of Wisconsin, Milwaukee. 
IN VITRO PROPERTIES OF A BENIGN MURINE BONE TUMOR VIRUS

C. K. Lee, E. W. Chan, G. Rockus, V. A. Pahnke, R. Updegrove, 1

M. P. Finke1, and C. A. Reilly, Jr.

A virus isolated in our laboratory, $R F B$, has the unique property of inducing osteomas. This benign bone tumor virus came from the same CF非 1 mouse strain from which the malignant bone tumor virus FBJ was isolated. We are now comparing this most interesting pair of viruses, benign and malignant, especially with respect to transformation.

RFB and FBJ showed similar host range specificities in cell culture. Both infect and replicate to high titers. in whole embryonic cell cultures derived from CF非1, CBA, and NIH Swiss mice, but not from X/Gf mice. Like FBJ, RFB virus infects only murine cell lines and is not infectious for cell lines of hamster, rabbit, cat, mink, dog, sheep, cow, monkey, and human origin. Various murine cell lines are being tested for suitability for mass production of the benign bone tumor virus. Preliminary testing showed that RFB-infected cells are capable of growth in soft agar, an in vitro indicator of cell transformation. However, unlike FBJ, RFB virus faile to induce morphologic transformation in cultures from susceptible hosts, although both readily induced XC plaques. Therefore, at tempts are being made to develop a colony transformation assay in soft agar for this benign virus.

ISOLATION AND CHARACTERIZATION OF RETROVIRUSES FROM ${ }^{90}$ ST-INDUCED OSTEOSARCOMAS

M. P. Finke1, C. K. Lee, E. W. Chan, L. S. Lombard, G. Rockus, V. A.

Pahnke, I. L. Greco, P. J. Dale, M. F. Williams, and C. A. Reilly, Jr.

The hypothesis that radiation causes cancer by gftivating endogenous viral information is being tested in a system using ${ }^{9} \mathrm{Sr}$ to induce bone cancer in CF非 1 and X/Gf mice. From each of these strains we have previously isolated osteosarcoma viruses that are being used 58 develop specific probes and antibodies to monitor virus expression during ${ }^{9} \mathrm{Sr}$-induction of bone cancer (see preceding reports).

Current data indicate that probably al1 ${ }^{90} \mathrm{Sr}$-induced bone sarcomas produce RNA virus, primarily of the helper or associated type. The experimental approaches have been: (1) to propagate the bone tumors in cell culture either directly or after cloning in soft agar; (2) to infect susceptible mouse cell lines, Sc-1 or D55, with tumor extracts; and (3) to cocultivate tumor

$1_{\text {Fal1 }} 1978$ participant in the Undergraduate Honors Research Participation Program, College of St. Francis. 
cells with Sc-1 or D55 cells. Spent culture media frcm these cells are then tested for progeny virus by assaying for reverse transcriptase (the specific enzyme of retroviruses) and the ability to produce plaques on XC cells (an indicator of helper or associated virus) or foci of transformation in cultures of appropriate cells (an indicator of sarcoma virus).

As shown in Table 14.1 reverse transcriptase and the XC plaque assay have been positive in almost all cases; the focus assay has been negative. Further testing in mice, however, indicates the presence of sarcoma activity in CF非. bone tumors and leukemia activities in $\mathrm{X} / \mathrm{Gf}$ bone tumors. The in vivo test is done by injecting the spent tissue culture medium into newborn mice, which are then watched for tumor development. In the CF非 1 strain there has been a marked increase over normal in the number of sarcomas (Figure 14.3). To date there have been 15 osteosarcomas, 5 fibrosarcomas, 1 liposarcoma, 1 leiomyosarcoma, 1 malignant hemangiopericytoma, and 1 neurofibrosarcoma. In the $\mathrm{X} / \mathrm{Gf}$ strain the increase has been in the number of tumors of the reticular tissues; the incidence in one group is now $70 \%$, with 6 of 33 mice still alive. It is important t ${ }_{80}$ note here that in the initial isolation of the X/Gf osteosarcoma virus from ${ }^{90} \mathrm{Sr}$-induced osteogenic sarcomas, tumors of the reticular tissues, not osteosarcomas, appeared in the first and second cell-free passages.

Table 14.1. In Vitro Tests for Presence of Retroviruses (number of. positive tests/total number of tests).

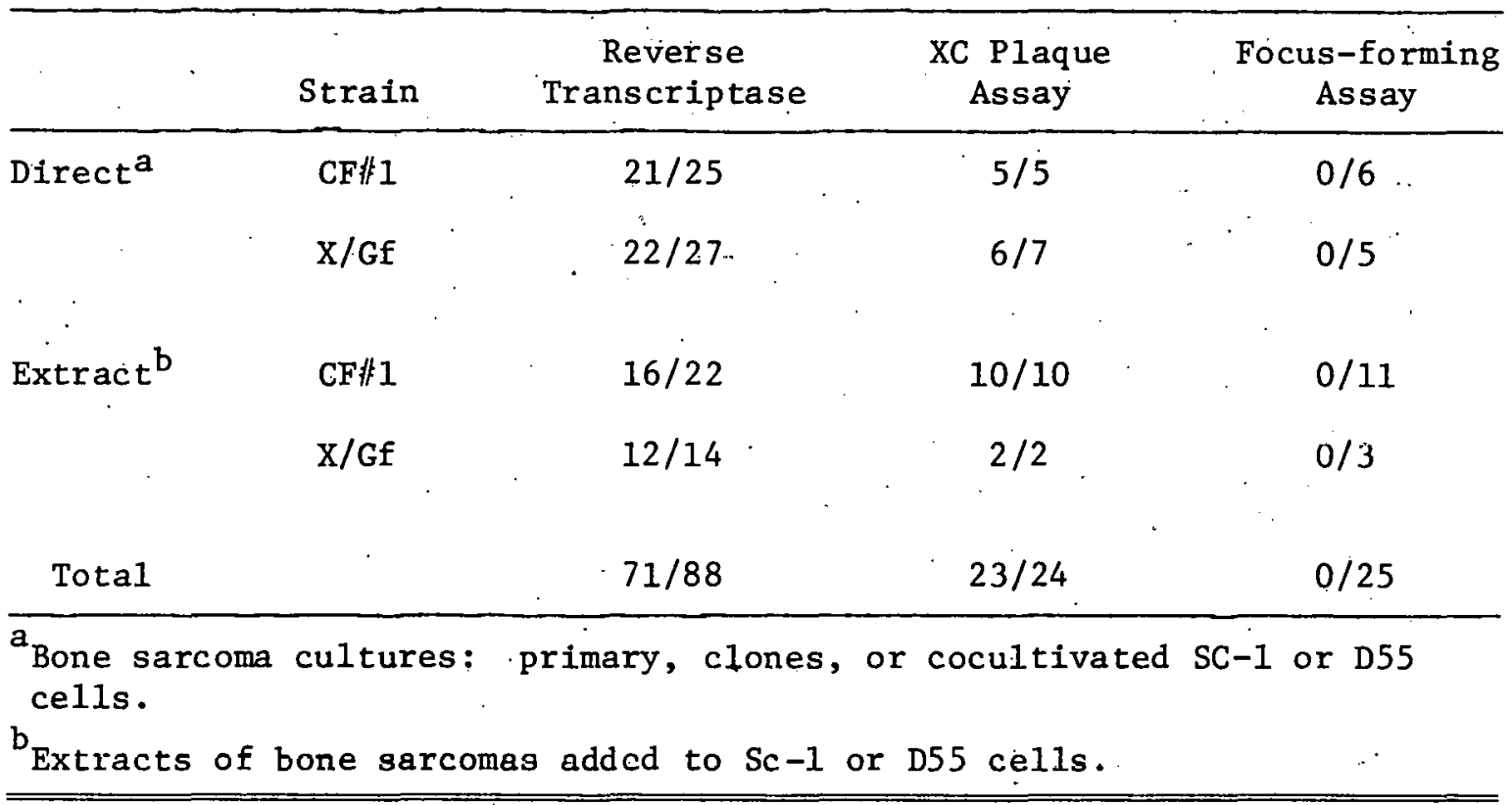




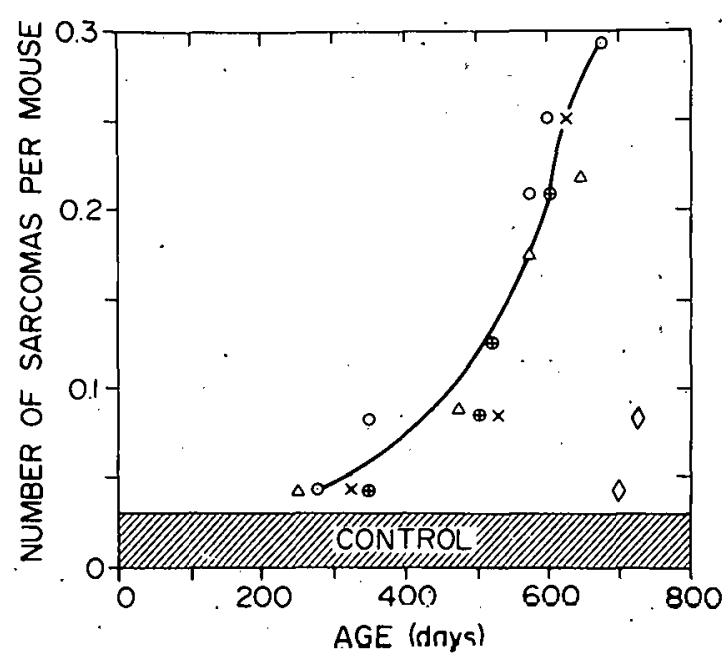

ENHANCEMENT OF REVERSE TRANSCRIPTASE AND OTHER POLYMERASE ACTIVITIES BY POLYETHYLENE GLYCOL

E. W. Chan, P. J. Dale, I. L. Greco, J. G. Rose, ${ }^{1}$ and T. E. O'Connor

Polyethylene glycol (PEG), a high molecular weight, water-soluble polymer, forms a colorless, neutral, and viscous solution in water. Among its many uses, PEG is used to concentrate bacteriophages and DNA and RNA viruses. In using the PEG concentration procedure for retroviruses, we wished to determine whether PEG had an effect on viral reverse tranccriptase activity is important for virus replication and detection, and for synthesis of labeled complementary DNA probes. We found that PEG enhanced the activity of reverse transcriptases, augmenting both the rate and duration of polymerization. The effective mean molecular weight of PEG was 6000 and the optimal concentration was $12 \%(w / w)$. PEG was effective on the reverse transcriptases of all 10 Type B, C, and D viruses tested under a variety of exogenous, endogenous, and reconstitution assay systems, including the highly efficient conditions involving calf thymus DNA oligonuclȩotide primers. By three methods of synthesis, PEG stimulated the yield of ${ }^{3}$-cDNA by a factor of 1.8-6.5. PEG did not alfer the divalent $c$ ation requirements or the specificity of the enzyme. The ${ }^{3} \mathrm{H}-\mathrm{CDNA}$ 's made in the presence of PEG were indistinguishable in terms of size and sequence complementarity from those made

${ }^{1}$ Participant in the $1977^{\circ}$ Sumer Research Institute in Cell Biology, University of Maine, Orono. 
without PEG. The stimulatory effect was partly due to the ability of PEG to stabilize reverse transcriptase and to prevent early termination. Preliminary tests indicated PEG could also stimulate other nucleotide polymerases such as the DNA-dependent DNA and RNA polymerases of Escherichia coli and the terminal transferase of calf thymus. The improved synthesis of specific nucleic acids attainable in the presence of $P E G$ has significant potential applications.

ANTIVIRAL PROPERTIES OF POLY (1-METHYL-6-THIOINOSINIC ACID)

E. W. Chan, C. K. Lee, and K. Nortridge

The antifumor polynucleotide analogue, poly (1-methyl-6-thioinosinic acid) [poly(m $\left.\mathrm{s}^{6} \mathrm{I}\right)$, synthesized by A. Broom, Department of Medicinal Chemistry, University of Utah] is a potent inhibitor of viral reverse transcriptase. At a concentration of $10 \mu \mathrm{g} / \mathrm{m} 1$, the analogue totally inhibits the enzyme activity in a standard exogenous template assay involving disrupted avian myeloblastosis virions and oligo $(\mathrm{dG})_{8-12}=$ Poly(rC). Results of experiments varying the order of addition, the ratio of analogue to template, and determining the time course are consistent with a strong, complete, and noncompetitive type of inhibition.

Iphibition was not 1 imited to the avian myeloblastosis viral enzyme. Poly(ms $\mathrm{m}^{\mathrm{L}} \mathrm{)}$ al so completely inhibited the reverse transcriptase of a mammalian woolly monkey simian sarcoma virus. Furthermore, it is very effective in the endogenous reaction where the natural genomic viral RNA is being transcribed in the absence of an exogenous synthetic template.

At a subtoxic level of $50 \mu \mathrm{g} / \mathrm{ml}, \operatorname{poly}\left(\mathrm{m}^{1} \mathrm{~s}^{6} \mathrm{I}\right)$ effectively and totally stops the production of the FBJ osteosarcoma virus by a chronically infected, high virus-producer cell line for a 2-week test period. Removal of poly $\left(\mathrm{m}^{1} \mathrm{~s}^{6} \mathrm{I}\right)$ restored virus production to its previous high titer.

In the continued presence of $50 \mu \mathrm{g} / \mathrm{ml}$ of poly $\left(\mathrm{m}^{1} \mathrm{~s}^{6} \mathrm{I}\right)$, susceptible D55 cel1s, derived from a normal Swiss mouse embryo, become resistant to infection by FBR murine ostesarcoma virus. There was potent inhibition of acute infection as determined by $\mathrm{XC}-\mathrm{plaque}$ and reverse transcriptase assays for virus progeny in infected cultures.

The antireverse transcriptase and the antiyizal properties of this substituted polyribonucleotide suggest that poly(m $\left.{ }^{6} I\right)$ may be effective in the inhibition of the induction of osteosarcoma by FBR virus in vivo.

${ }^{1}$ Summer 1978 participant in the Undergraduate Honors Research Participation Program, Northern Illinois University. 


\section{TEST SYSTEMS}

Four carcinogen/cocarcinogen detection test systems are under development. These are (1) the quantitative measurement of the release of hydrolytic lyosomal enzymes from cultured rat alveolar macrophages; (2) the identification of morphological and biochemical changes in cultured rat tracheal.rings; ( 3 ) the histochemical identification of preneoplastic liver foci; and (4) the biochemical or immunological detection of changes in chromatin that accompany neoplasia.

ALVEOLAR MACROPHAGES: ROLE IN LUNG DAMAGE INDUCED BY PARTICULATE AND NONPARTICULATE TOXICANTS

Y. E. Rahman, C. Peraino, A. M. Prapuolenis, and E. A. Cerny

The respiratory system is one of the major pathways through which air pollutants, including carcinogens, are introduced into the human body. Alveolar macrophages play a primary role in the defense mechanism against such agents. However, the biochemical nature of this defense mechanism is largely unknown; particularly unclear is the role of various hydrolytic enzymes, e.g., those of lysosomes, which are especially abundant in these phagocytic cells. The unimpaired activity of an enzymatic defense system should be essential for effective protection against lung damage induced by various airborne toxicants. Rat alveolar macrophages are obtained by lung lavage and incubated in 1640 culture medium with $5 \%$ fetal calf serum in the presence of various levels of test toxicants. In the first experiments with this technique, cell viability, as measured by dye exclusion, was reduced to $50 \%$ when alveolar macrophages were exposed for 24 hours to a $0.1 \mathrm{mg} / \mathrm{ml}$ ronrentratinn of $\mathrm{fly}$ ar.h from the pressurized fluidized bed combustor in the Chemical Engineering Division, and to $10 \%$ at a concentration of $0.5 \mathrm{mg} / \mathrm{ml}$.

Subsequently we determined the cytotoxicity of extracts of the condensed effluent from the fluidized bed combustor (see report by Kuhitsrhek et al. in Section 7). In this case, cells were examined for viability at different intervals not only by dye exclusion but also by their lactic dehydrogenase activity. In addition, lysosomal activation was measured by the release of

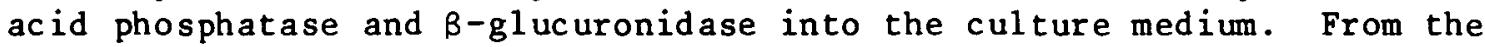
results obtained after a 24-hour exposure to condensate extracts of 10,20 , 40 , and $80 \mu \mathrm{g} / \mathrm{m} 1$ of medium, it was concluded that lysosomes of alveolar macrophages were not specifically activated by the extracts; the decrease of acid phosphatase and. $\beta-$ glucuronidase in exposed macrophages was very closely correlated with the level of cell death. Further, using this alveolar macrophage system to compare two fractions of the extract that had shown different direct mutagenicities in the Ames Salmonella assay with strain TA98 (25 and 8.9 revertants/ug; unpublished data of $\mathrm{H}$. E. Kubitschek et al.), we found that the two fractions had essentially the same effect on cell viability ( $\mathrm{LD}_{50}$ in 24 hours of about $60 \mu \mathrm{g} / \mathrm{m} 1$ ) and on enzyme activity. 
RAT TRACHEAL RING CULTURES USED FOR THE EVALUATION OF ONCOGENIC ACTIVITY OF POLYCYCLIC AROMATIC HYDROCARBONS

N. N. Beales and C. A. Reilly, Jr.

Rat tracheal rings exposed in vitro to the chemical carcinogens benzo(a) pyrene, benzanthracene, and dimethylbenz(a) anthracene develop hyperplasia and keratinizing squamous metaplasia of the epithelium within 14 days of exposure (Table 14.2). The direct relationship between the observed histologic changes and dose of carcinogen is best illustrated by the benzanthracene data. In contrast, a noncarcinogenic analogue of benzo(a)pyrene, benzo(e)pyrene, does not induce these changes. Sham-treated controls also fail to exhibit a proliferative response. We are assessing the potential usefulness of this system for evaluating the toxic and oncogenic properties of pollutants from energy-related technologies. Results of preliminary studies using condensate of fluidized bed combustor effluent (Table 14.2) indicate that these complex mixtures of polycyclic aromatic hydrocarbons are also able to induce similar proliferation of the tracheal epithelium.

USE OF LIVER FOR THE RAPID SCREENING OF ENVIRONMENTAL POLLUTANTS FOR TUMOR . INITIATING OR PROMOTING ACTIVITY

C. Peraino, E. F. Staffeldt, V. A. Ludeman, A. R. Sallese, K. A. Rettman, and R. N. Feinstein

Tumorigenesis studies in our laboratory over the last several years suggest that liver may be sensitive to a broader range of carcinogens and tumor promoters than any other single tissue, and $c$ an therefore be used to test environmental contaminants for tumor initiating or promoting activity. Evidence is also accumulating that indicates that foci of altered hepatocytes appear in the livers of carcinogen-treated rats long before the emergence of hepatic tumors. These foci are characterized by one or more of several changes including the reappearance of enzymes normally present in fetal or embryonic liver (e.g., $\gamma$-glutamyltranspeptidase, diaphorase, alkaline phosphatase) as well as by the disappearance of enzymes normally found in mature hepatocytes (e.g., glucose-6-phosphatase and adenosine triphosphatase). It remains to be determined which of the various types of these histochemical foci are accurate predictors of subsequent tumor formation, and can thereby serve as end points in a rapid assay of environmental contaminants for tumorigenic potential. In preliminary studies, still in progress, partially hepatectomized rats werc given either the known liver carcinogen diethylnitrosamine (DEN) or the polycyclic hydrocarbon carcinogen dimethylbenzanthracene (DMBA) by stomach tube. Two dose levels of each agent were used. Half the rats in each group were then placed on a diet containing $0.05 \%$ phenobarbital while the remainder were fed a control diet. Thus far, the number of foci positive for $\gamma-g$ lutamyltranspeptidase in the 1 ivers of these animals have been monitored, and data indicate that the numbers of such foci are directly related to DEN or DMBA dosage and that phenobarbital increases the incidence of these foci severalfold in both the DEN and DMBA groups. If these foci can 
Table 14.2. Effect of Polycyclic Aromatic Hydrocarbons on Tracheal Rings In v1tro

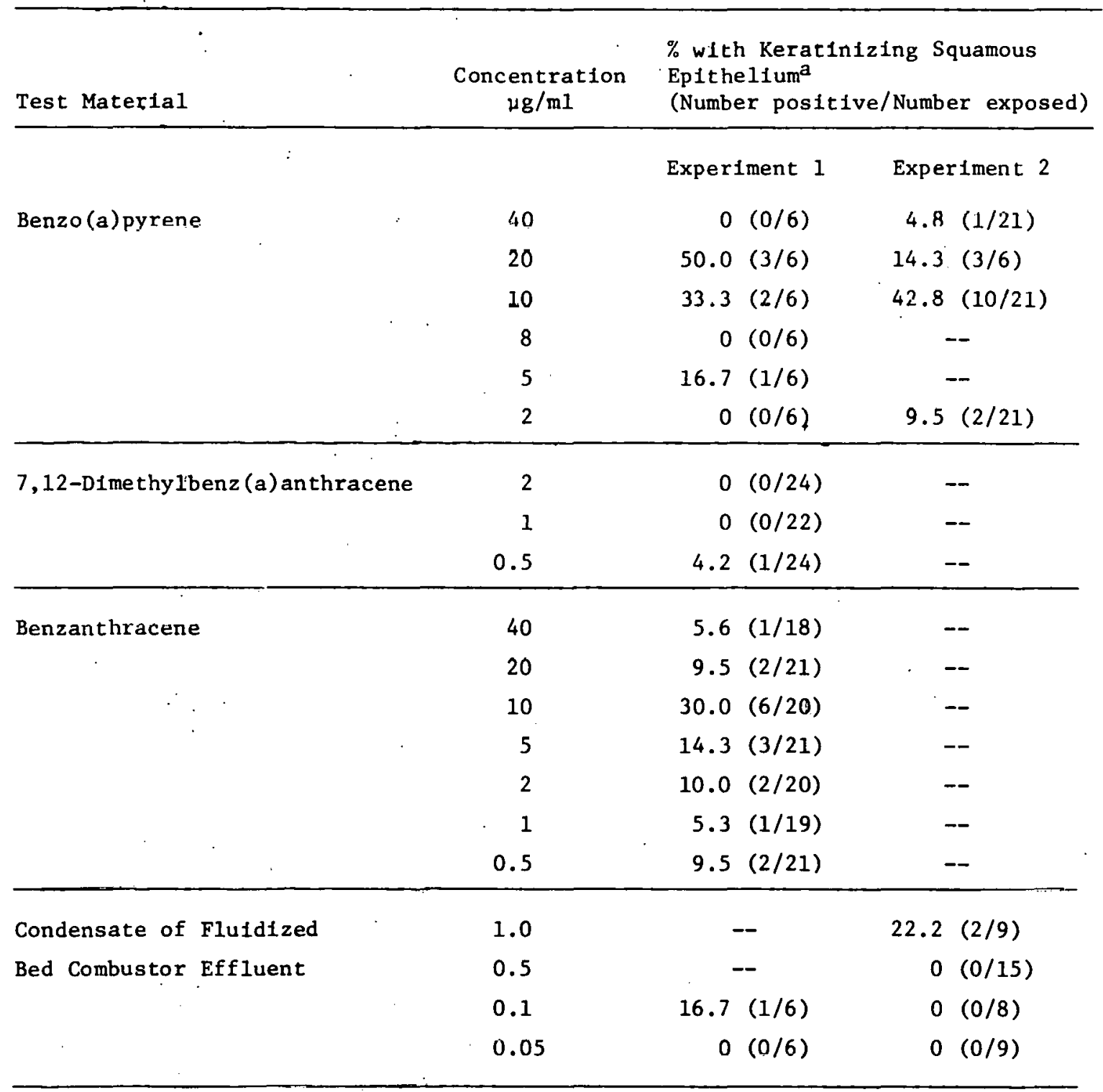

${ }^{a}$ Control cultures were used in each experiment in numbers similar to those in test groups. Control rings were sham-treated with acetone in amounts ranging from 0.5 to $2.0 \%(\mathrm{v} / \mathrm{v})$. In benzo(a) pyrene experfments the noncarcinogenic analogue, benzo(e)pyrene was used over the same dose range as an additional control. No proliferative response was observed in any of the controls. 
be considered as truly preneoplastic, the results suggest that the liver $c$ an be used to test hydrocarbons for tumorigenic potential; previously the liver was considered refractory to the tumorigenic action of these agents. In addition, the occurrence of a dose response suggests that the monitoring of foci numbers may be useful in assessing the relative tumorigenic potency of differ-. ent agents.

\section{BIOCHEMICAL AND IMMUNOLOGICAL MARKERS OF DİFFERENTIATION AND NEOPLASIA}

T. E. O'Connor, B. A. Sedita, K. A. Rettman, and K. E. Willard

A we11-documented finding from previous research in cancer is that each tumor induced by a chemical or radiation carcinogen shows a unique profile of transplantation and cell-surface antigens irrespective of the specific inducing carcinogenic agent. In contrast, virus-induced tumors show virus-related nuclear antigens and also frequently virus structural antigens in both cytoplasm and cellular membranes. This discrepancy has posed a serious block to utilization of immunological methods in detection of carcinogen-induced :cancers.

Recent literature reports suggest that either differentiation or neoplastic alteration of tissues involves changes in cellular chromatins which can be detected biochemically or immunologically, but current interpretations of these findings are 1 imited by a number of uncertainties. We are studying the biochemical and immunological properties of chromatins from rat Novikoff hepatoma, a tumor originally induced by 4-dimethylaminoazobenzene, and normal rat liver with a view to resolving these uncertainties.

Novikoff hepatoma cells are processed under mild biochemical procedures to yield a chromatin fraction and then dehistonized chromatin and nonhistone chromosomal protein fractions are derived. Sera are raised in rabbits to intact chromatins, dehistonized chromatins, and nonhistone chromosomal proteins of Novikoff hepatoma and normal rat liver. Such sera show increased binding to the homologous chromatin or dehistonized chromatin antigens as compared to the heterologous antigens, as judged by the Levine microcomplement fixation assay. Selected sera can, in some instances, be adsorbed to the heterologous chromatin. Complement-fixation titrations of such adsorbed antiNovikoff sera show negligible reaction with chromatin antigen of normal rat liver and a reaction pattern with Novikoff hepatoma chromatin that shows a sharp maximum and a rapid decline in regions of either excess antigen or antiserum (Figure 14.4). This complement fixation pattern resembles that obtained with other pure protein antigens and their specific antisera. In contrast, the titration pattern of the anti-Novikoff. serum with Novikoff dehistonized chromatin shows a higher level of complement fixation but fails to reveal a region of antigen excess. These differences may reflect a greater

${ }_{1}^{1}$ Resident Student Associate, Virginia Polytechnic Institute and State University. 


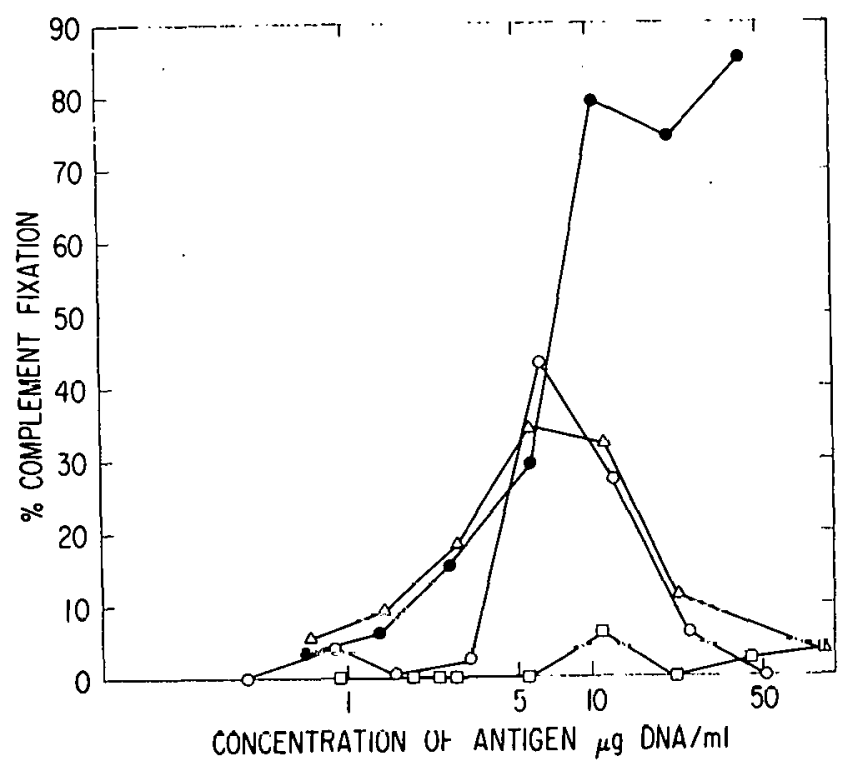

Fig. 14.4. Complement fixation by chromatin antigens with rabbit serum raised to dehistonized Novikoff hepatoma chromatin after adsorption with normal rat liver chromatin. Antigens: solid circles, dehistonized Novikoff hepatoma chromatin; open triangles, Novikoff hepatoma chromatin; open circles, chromatins from acetylaminofluorene-induced $t r a b e c u l a r$ hepatocarcinomas of rat; squares, normal. rat livor chromatios.

availability of the protein antigenic determinants in the dehistonized chromatin but with a reduced level of correct stereoconfiguration. of particular interest is the observation that chromatin antigens prepared from a composite of primary rat 1 iver tumors supplied by Dr. Carl Peraino showed a complementfixation pattern with the adsorbed anti-Novikoff serum that coincided with that of the Novikoff chromatin antigen. These tumors resulted from exposing rats to a diet of acetylaminofluorene and were classified histologically as well-differentiated trabecular carcinnmas. These findings indicate that hepatocarcinomas differing in origin and pathological classification contain an average equivalent amount of a neochromatin antigen not present in normal rat liver cells. Immunochemical and immunocytochemical procedures are now being further developed to define the molecular nature of the neochromatin antigen(s) of both normal liver and hepatocarcinomas and to explore their role in normal differentiation and carcinogenesis. The utility of antisera to these neoantigens in early detection of neoplasia arising from exposure to radiation or chemical carcinogens is also under study. 
15. LIPOSOMES AS BIOLOGICAL CARRIERS

\section{INTRODUCTION}

Yueh-Erh Rahman

This program is concerned with studies seeking to develop 1 iposomes as biological carriers for the targeted delivery of drugs. Liposomes are microscopic lipid vesicles that are formed by mixing aqueous solutions of various electrolytes or drugs with lipid materials under appropriate conditions. Larger size, multilamellar 1 iposomes $(0.2$ to $>5 \mu \mathrm{m})$ can be prepared by shaking and smaller size, unilamellar liposomes $(<0.1 \mu \mathrm{m})$ are prepared by sonication.

Drugs can be incorporated into 1 iposomes either within the aqueous center space and between the lipid bilayers of the liposomes or within the lipid bilayers. Various approaches have been used to direct 1 iposomes to target organs, including varying the size and surface charge of 1 iposomes, attachment of a specific antibody, or varying the 1 ipid constituents of the liposomes.

In addition to being an attractive and versatile tool for aproaching many basic problems in the field of biological research, liposomes have the potential for being useful in future clinical applications for drug delivery. At the present time, our research is centered mainly around the use of liposomes for the delivery of two categories of drugs--metal chelating agents and antitumor drugs.

Since October 1977 , the program related to the use of antitumor drugs has been supported by a grant awarded by the National Cancer Institute. Another grant, specifically supporting the work on liposome application to iron overload, has been awarded by the National Institute of Arthritis, Metabolism, and Digestive Diseases. Although the Division's studies of 1 iposomes are currently supported by the grant system, they are also related to the objectives of the Department of Energy. Causative substances for both metal poisoning and cancer are emitted into the environment in part as pollutants produced by various energy-related technologies.

In the last few years, since the introduction of liposomes as drug carriers, there has been a surge of interest in the development of new techniques for drug targeting. A variety of biological carriers has been introduced with the hope of achieving drug delivery to specific sites of the animal body. In our laboratory, the use of 1 iposomes varying in lipid constituents, particularly the use of 1 ipids that contain one or more sugar moieties, is emphasized to achieve in vivo cell targeting. Our results have shown considerable promise and we therefore $\mathrm{plan}$ to expand our targeting studies with glycolipid 
liposomes and to identify further the different cell types in a given organ that have a specifically high affinity to a particular type of 1 iposome.

Gradient centrifugation techniques will be used to fractionate various cell types of an organ, and their uptake of a specific glycolipid liposome will be determined. Our choice of glycolipids will be largely based upon the identification by several laboratories of specific sugar moieties responsible for mediating recognition sites found on the surface of various cell systems.

Our current program therefore has two major objectives: (1) to develop 1 iposomes with specific sugar groups that would enhance their in vivo cell selectivity, and (2) to deliver drugs by a particular type of 1 iposome to a specific target cell.

Significant results obtained during the past year include the following. (1) Liposomes with high selectivity to spleen and bone marrow have been developed. (2) Liposome encapsulation of Ara-c resulted in a $40 \%$ survival in mice bearing a solid tumor of the lung; no controls or mice receiving nonencapsulated Ara-c survived. This is the first time that a liposome-encapsulated antitumor drug has been shown effective against a solid tumor. (3) Liposomes containing galactocerebroside were found to be significantly more effective in removing storage iron from the hepatocyte compartment of the liver, whereas liposomes without the glycolipid were more effective in removing iron from cells of the reticuloendothelial system.

\section{REGULAR STAFF}

Cerny, Elizabeth A. (Scientific Assistant)

Rahman, Yueh-Erh (Biologist)

Wright, Betty J. (Scientific Associate)

TEMPORARY STAFF DURING 1.978

Pate1, Kanaiyalal R. (Postdoctoral Appointee) 


\section{LIPOSOMES IN CANCER CHEMOTHERAPY}

Y. E. Rahman, K. R. Pate1, M. M. Jonah, 1 and E. A. Cerny

The main objective in our use of 1 iposomes to deliver antitumor drugs is to prepare liposomes with high selectivity for a particular organ or a particular cell type, primarily by varying the lipid constituents. So far, liposomes have been prepared with various glycolipids, and lipids extracted from various mouse organs. We have previously found that liposomes containing galactocerebroside have high uptake in the liver. We now report that the presence of esterified steryl glucoside, phosphatidyl inositol, and monogalactosyl diglyceride has increased the spleen uptake of 1 iposome-encapsulated methotrexate by 2-, 3-, and 5-fold, respectively, compared to liposomes prepared without these glycolipids. The results also indicate that the presence of mouse kidney lipids results in a 2-fold increase of 1 iposome uptake in the bone marrow compared to 1 iposomes prepared without kidney lipids.

The chemotherapeutic effect of 1 iposome-encapsulated and nonencapsulated cytosine arabinoside (Ara-c) in BDF mice on Lewis lung carcinoma has also been investigated. Treatment with fiposome-encapsulated Ara-c at a dose of 25 $\mathrm{mg} / \mathrm{kg}$ given on Days 1,4 , and 7 after intravenous inoculation of $10^{5}$ live Lewis lung carcinoma cells resulted in 40 to $80 \%$ increase of the average survival over that of both the untreated controls and controls receiving Ara-c in nonencapsulated form. Intraperitoneal administration of 1 iposome-encapsulated Ara-c was significantly more effective than either the intravenous or subcutaneous route. The average survival time for both the control groups was 25 days and there were no long-term survivals. The average survival time was increased $44 \%$ by subcutaneous Ara-c 1 iposomes, and $54 \%$ by intravenous Ara-c liposomes, but there were no long-term survivors. In contrast, intraperitoneal administration resulted in $78 \%$ increase in average survival time, and $40 \%$ of the animals survived for at least 90 days, the cutoff point for this experiment.

\section{LIPOSOMES IN METAL CHELATION THERAPY}

Y. E. Rahman, E. H. Lau, ${ }^{2}$ B. J. Wright, and E. A. Cerny

Accumulation of heavy metals in the human body, whether through the inhalation of dust particles or through the ingestion of contaminated food, has become an increasing health problem, often of a chronic nature. Our research program is concerned with the search for new therapeutic approaches that would improve the efficiency of existing chelators in removing toxic metals from the animal body. Liposomes have been used to enhance the uptake of chelators by target cells, thereby increasing the excretion of the toxic metals.

$1_{2}$ Faculty. Research Participant, Rosary College.

2 Faculty Research Participant, College of DuPage. 
Recently, experimental iron overload has been used as a model system to test the applicability of 1 iposomes for removal of excess storage iron. Desferrioxamine (DF), an iron chelator extracted from streptomyces pilosus, is used. Non-hygertransfused ang hypertransfused mice are experimentally labeled with either ${ }^{39} \mathrm{Fe}$-ferritin or ${ }^{59} \mathrm{Fe}$-heat damaged erythrocytes ( 59 Fe-RBC's). Ferritin is known to be predominantly taken up by parenchymal cells, while damaged RBC's are mainly phagocytosed by Kupffer cells. Multilamellar and unilamellar liposomes containing DF and made of dipalmitoyl phosphatidyl choline (Dipalm-DF) and galactocerebroside, (GC-DF) were prepared. Multilamellar liposomes had an average diameter of $0.5 \mu \mathrm{m}$ when sized in a Coulter counter. Unilamellar liposomes examined by electron microscopy after negative staining revealed an average diameter of $0.08 \mu \mathrm{m}$. Increased uptake and retention of DF in mouse liver was observed when DF was encapsulated in all types of liposomes, injected intravenously. The highest uptake occurred with multilamellar GC-DF liposomes, at $69 \%$ of the injected DF in 1 iver. With multilamellar Dipalm-DF liposomes the liver uptake was $37 \%$ and with unilamellar Dipalm-DF 1 iposomes it was $30 \%$, while only $1.5 \%$ of the nonencapsulated DF was found in the liver.

A single intravenous injection of $D F$ at a dose of $50 \mathrm{mg} / \mathrm{kg}$, in Dipalm-DF or $\mathrm{GC}-\mathrm{BF}$ liposomes, enhanced urinary excretion of ${ }^{59} \mathrm{Fe}$ by $3-$ to $15-$ fold

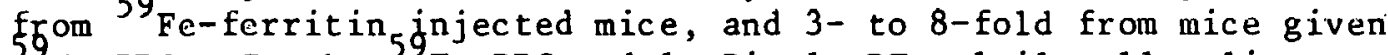
${ }^{59} \mathrm{Fe}-\mathrm{RBC}$. In the ${ }^{59} \mathrm{Fe}-\mathrm{RBC}$ model, Dipalm-DF multilamellar liposomes significantly reduced the iron content of 1 iver, spleen, small intestine, and bgne marrow. Multilamellar and unilamellar GC-DF liposomes removed more ${ }^{59} \mathrm{Fe}$ from mice injected with ${ }^{59} \mathrm{Fe}$-ferritin than the Dipalm-DF 1 ipo-

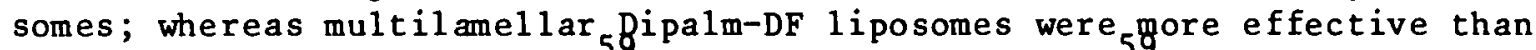
GC-DF 1 iposomes in removing ${ }^{59} \mathrm{Fe}$ from mice receiving ${ }^{59} \mathrm{Fe}-\mathrm{RBC}$. These observations suggest that GC-DF liposomes may have higher affinity for parenchymal cells of the liver, whereas the Dipalm-DF liposomes may have higher affinity for Kupffer cells.

Electron microscopic examination of liver sections from mice receiving either ferritin or RBC showed a surprising increase of collagen fibers. The fibers were in an unusual location, between parenchymal cells, and had a rather disordered arrangement. 
16. ENVIRONMENTAL PHYSIOLOGY

\section{INTRODUCTION}

George A. Sacher

The assessment of long-term effects of environmental factors has tended to focus on terminal effects such as excess cancer incidence or 1 ife shortening. The present program is focused instead on the long-term effects of energy by-products on productivity and on the integrity of the daily cycle of activity and metabolism. This is appropriate because it can be reasonably conjectured that environmental factors other than ionizing radiation are likely to have their major impacts in terms of chronic degradation of work performance and other aspects of 1 ife quality, instead of in terms of increased terminal cancer incidence. Although this program is still in an early stage, the findings to date support the hypothesis stated above.

REGULAR STAFF

Duffy, Peter H. (Scientific Assistant)

Russell, John J. (Scientific Associate)

Sacher, George A. (Senior Biologist) 
ENVIRONMENTAL INFLUENCES ON LIFE-SPAN, LIFETIME PERFORMANCE, AND DISEASE MORBIDITY

G. A. Sacher, P. H. Duffy, J. J. Russel1, W. Obermeyer, 1 and R. Killeen ${ }^{2}$

Our approach to the evaluation of the effects of environmental pollutants on lifetime performance is based on four instrumentalities that are used in various combinations.

1) Genetic and constitutional differences between genotypes. To examine the genetic differences in sensitivity among individuals and genotypes within species, we have developed a diallel model in which all possible crosses of five inbred mouse strains are made and the male and female progeny of these crosses are used as experimental populations. This model system has been thoroughly defined by means of anatomical, physiological, and pathological measurements on samples of all these genotypes in a variety of environmental. conditions, including the conventional laboratory environment, chronic gamma radiation fields, and a cold environment to apply a mild physiological stress to the animals. Some significant findings with this model system are presented separately below.

2) Constitutional differences between species as the basis for species differences in resistance to toxic agents. This model system employs two small rodent species, Mus musculus, the house mouse, and Peromyscus leucopus, the. white-footed mouse. In our defining phase we showed that these two species differ by a factor of 2.5 in average life-span, i.e., 600 days for Mus and approximately 1450 days for Peromyscus. The use of this model is based on the hypothesis that Peromyscus leucopus is an intrinsically long-1ived species, and that this long life characteristic is due to genetic factonrs governing the capacities for protection, regulation, and repair. This monel is being used to determine whether a long-lived species differs in its response to environmental stress from a similar short-lived species. Several experiments along this line have been completed or are under way.

3) Controlled environment. An environmental chamber has been constructed that makes it possible to regulate temperature down to $0^{\circ} \mathrm{C}$ and control humidity within the comfort range. This enables us to put a metabolic load on the mice, and thereby to assess responses to toxic agents in a more realistic fashion than $c$ an be done in the conventional laboratory environment with its minimal metabolic load.

4) Measures of physiological performance. We have developed instrumentation that enables us to measure four variables--oxygen consumption, carbon dioxide production, motor activity, and deep body temperature--in quasicontinuous fashion for a week or longer on 12 mice simultaneously, and to $\log$ the data automatically on magnetic tape for subsequent computer analysis. This

${ }_{2}^{1}$ Resident Student Associate, University of Chicago.

2 Summer 1978 participant in the Undergraduate Honors Research Participation Program, Northern Illinois University. 
MAT (metabolism, activity, temperature) instrument will be used to monitor physiological performance and work productivity in animals subjected to various environments. (See also the report by G. A. Sacher et al. in Section 10.)

DIEL PATTERNS OF MOTOR ACTIVITY, ENERGY METABOLSIM, AND BODY TEMPERATURE

G. A. Sacher, P. H. Duffy, and J. J. Russell

A major experiment has been completed in which the 25 genotypes in the diallel genetic design (Item 2 in the preceding report) were examined in the MAT system (Item 4 in the preceding report). The 24-hour cycles of oxygen consumption were determined for male mice of each genotype and at two ages, approximately 6 months and approximately 24 months. From these data we estimated the minimum, or resting metabolic rate, the maximum rate, and the average rate over the 24-hour period, based on data from a 48-hour run for each mouse. Body weights were measured at the time of the metabolism measurements. Mean life-spans had been determined on separate samples of 20-50 of each genotype, and the subsequent survival of each mouse in the metabolism study was determined. A previous report (Sacher, G. A., and P. H. Duffy, ANL-78-90, 1978, p. 153) gives our findings on the relation of genotype mean life-span to the genotype mean levels of minimum and average metabolic rate and body weight for the 25 genotypes in the diallel design. Findings were essentially as follows. (1) There is a significant negative correlation between genotype mean life expectation and. the average value of the minimum or the average metabolic rate for the genotypes. (2) There is a significant positive association of genotype mean life-span with' the average body weights of the genotypes either at the young or old age of measurement. (3) A derived variable was constructed, given by the ratio of the average metabolic rate to the resting metabolic rate for each individual mouse. This variable, the activity index (AI), estimates the fraction of the total metabolic energy expended by the mouse that is utilized for motor activity and behavior in general. We found that (1) there is a significant variation between genotypes in the value of the AI, and (2) that there is a positive association between the average AI value for a genotype and its average life expectation.

In the past year we were able to assemble the data on the subsequent survival of the 85 mice used in the metabolism study. The relation of 1 ife-span to the metabolic variables was reexamined using these data, and the correlations obtained confirmed the previous study based on genotype means.

As a result of this second analysis we are now able to say that the parameters of the daily cycles of metabolism and activity of individual mice have significant capacity to predict the subsequent survival of those mice on an individual basis. This provides the basis for the design of new experimental assays of the effects of environmental pollutants on physiological rhythms and disease susceptibility. 
THE EFFECTS OF A COLD ENVIRONMENT ON THE LIFE-SPAN AND TUMOR INCIDENCE OF LABORATORY MICE

J. J. Russe11 and G. A. Sacher

The extent to which normal environmental stressors, such as low ambient temperature, interact with environmental pollutants to influence the 1 ife-span and tumorigenesis of animals or man is unclear. The possibility exists that a cold-induced increased metabolic rate, when combined with toxic environmental pollutants, may act as a promoter of tumorigenesis. Accordingly, groups of mice from 25 genotypes obtained from $F$ crosses of five inbred mouse strains plus groups of wild Mus musculus and Peromyscus leucopus were housed

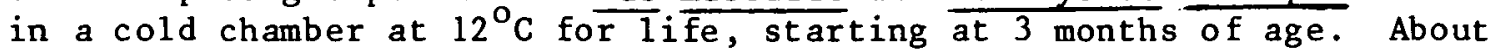
$90 \%$ of the 1 aboratory mouse genotypes and wild Mus are dead, whereas about $70 \%$ of the Peromyscus are still alive. The data obtained at necropsy are being analyzed to provide the following information:

1) A complete 1 ife table (for all mice).

2) The number of tumors per genotype for both males and females.

3) The types of tumors per genotype for both males and females.

4) The frequency of multiple tumors per mouse per genotype.

When completed, these data will help to elucidate whether or not the 2-fold increase of metabolic rate induced by the cold environment was expressed physiologically as 1 ife shortening and/or increased tumor incidence, and also indicate the extent of genetic variation in response to cold.

These studies will serve as a model for future experiments in which the combination of a cold-induced increased metabolic rate and a toxic environmental pollutant is investigated. 
17. 'MOLECULAR ANATOMY PROGRAM

\title{
INTRODUCTION
}

\author{
Norman G. Anderson
}

The objective of the Molecular Anatomy Program is to provide the basic and applied research necessary to detect and measure at the molecular level the effects of radiation and of energy related mutagens, carcinogens, teratogens, and toxic agents. The scope of the work thus spans from the very basic to the applied. It includes efforts to foster development of systems and methods applicable to field measurements in nuclear or other accidents, and techniques applicable to populations at risk from low level exposure to hazardous agent.s.

The central functions of the human genetic apparatus (DNA) are to code for the estimated 30,000 to 50,000 protein gene products (PGP's) found in human cells and to program the expression of the genes involved. If one could examine all of the PGP's in human cells one could see how they are affected by irradiation and chemical agents at three levels: the mutational. level (are there sequence alterations in PGP's?), the programming or gene expression level (are genes or gene sets switched on or off in an abnormal manner as in the case of cancer?), and the cellular level (as when PGP's are redistributed inside a cell, or leak from it). The fundamental requirement is for a very high resolution analytical method that will resolve a very large fraction (ideally al1) of human PGP's. Two-dimensional electrophoresis using isoelectric focusing in the first dimension and electrophoresis in the presence of sodium dodecyl sulfate in the second has provided such a method. Each of these methods has a resolution of approximately 100, and when used two dimensionally the resolution of the system approaches the product of the two separately (i.e., 10,000). This stunning fact, made apparent by the work of 0 'Farrell, and the development of two-dimensional electrophoresis into the ISO-DALT system at Argonne (Anderson, N. G., and N. L. Anderson, Anal. Biochem. 85, 331, 1978; Anderson, N. L., and N. G. Anderson, Anal. Biochem. 85, 341, 1978) makes possible the efforts described in the following reports.

The Molecular Anatomy Program is concerned with the following studies:

1) Devclopment of analytical systems. To develop high-resolution twodimensional electrophoresis into a clinically useful system capable of handling large numbers of samples it will be necessary to examine in detail the theoretical basis of the separations and the factors limiting resolution. Also required are methods for calibration and precise spot localization and identification, methods for reliable sample identification, techniques for extending the limits of detection, automation, and computerized image analysis and data reduction. All are now under investigation or development. 
2) Mapping of human protein gene products. High-resolution PGP maps of human body fluids, tissues, and individual cell types are basic to this program. Progress is being made in mapping plasma, muscle, red cell lysates, lymphocytes, brain tissue, saliva, seminal fluid, and hair follicle cells. Methods have been developed for spot identification using the centrifugal fast analyzer in concert with methods for protein fractionation, including heat denaturation.

3) Mutation rate monitoring. To use charge shifts for mutation rate studies it is necessary to demonstrate that single charge differences can be detected in each spot examined, and methods for doing this have been developed. The number of samples required for mutation rate estimates or to detect changes is inversely proportional to the number of PGP's examined. Present high resolution methods drastically reduce the number of samples required for analysis.

4) Cancer-associated changes. Mapping of cancer cells allows PGP's characteristic of malignancy to be discovered and characterizcd. The objec= tive is to find indicators either of cancer or precancerous states useful for screening. Thus far the problem is not to find potential indicators--rather the problem is to determine which ones will be useful.

5) Urinary protein mapping. Cytotoxic injury as distinguished from genetic damage almost invariably produces cell leakage, and many of the proteins leaked are small enough to pass the kidneys and appear in the urine. Tumor cells are also known to shed proteins and some of these also find their way into urine. Hence urine contains a surprising number of potential indicators of disease and of organ damage. The diagnostic possibilities inherent in these facts have not previously been fully exploited because suitable analytical methods were lacking.

Translation of the promising findings obtained thus far into use in clinical laboratories and in laboratories concerned with screening populations at risk from nuclear accidents, fallout, or exposure to injurious chemical agents will require a variety of efforts in basic chemistry, biology, optics, mechanics, electronics, photoprocessing, image analysis, and computerized data reduction. These efforts we have now defined. Over 16,000 two-dimenstonal gels have now been run, several collaborative laboratories in clinical settings have been organized, and considerable progress has been made in the transfer of our technology to industry.

\section{REGULAR STAFF}

Anderson, Norman G. (Senior Physiologist)

Anderson, N. Leigh (Assistant Biophysicist)

Hickman, Barbara J. (Scientific Assistant)

Nance, Sharron L. (Sctentific Associate)

Tollaksen, Sandra L, (Scientific Assistant)

TEMPORARY STAFF DURING 1978

Edwards, Jesse J. (Postdoctoral Appointee)

Smith, Carol F, (Postdoctoral Appointee) 
DEVELOPMENT OF TECHNTQUES FOR HIGH RESOLUTION PROTEIN MAPPING

N. L. Anderson and B. J. Hickman

Methods for the two-dimensional electrophoretic mapping of radiolabeled human lymphocyte proteins were improved, and initial family studies have been undertaken. An average heterozygosity for major cellular proteins was obtained that is far lower than that observed in the plasma proteins and the housekeeping enzymes considered by classical human genetics.

Methods for the isolation of immunoglobulins from serum using protein A Sepharose microcolumns were developed and applied to the two-dimensional analysis of mouse and human immunoglobulins. Groups of inbred mice raised in the same cage were shown to give highly (70-80\%) reproducible light chain patterns of about 100 spots, while the light chain pattern in outbred mice (as in Figure 17.1) or in humans was shown to consist of a much larger number of unresolved components.

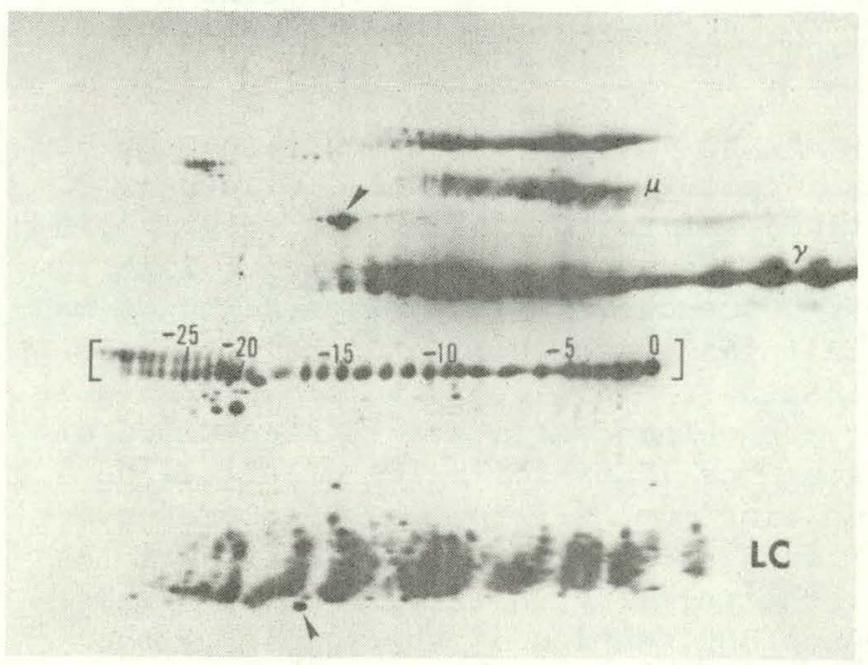

Fig. 17.1. High resolution two-dimensional (ISO-DALT) separation of serum immunoglobulins from a wild whitefooted mouse, Peromyscus sp. LC, light chains; $\mu, \gamma$ are heavy chains of IgM and IgG; downward pointing arrow indicates contaminating albumin and upward pointing arrow indicates Apo A-1 1ipoprotein. The spots in the numbered horizontal row are creatine phosphokinase carbamylation charge standards.

A technique for progressive thermodenaturation of protein mixtures was developed and applied to the analysis of soluble proteins from rabbit muscle and human leukocytes. By comparing enzyme activity profiles with abundances of spots on two-dimensional gels, it was possible to correlate specific activities with specific protein spots. It was further found that addition of substrate thermostabilized specific enzymes and made possible identification of classes of spots, for example spots binding $\mathrm{NADH}$, without regard to specific function. In the course of this. work, it was discovered that $\beta$ and $\alpha$ cytoplasmic actins bind ADP differently. This is the first functional difference that has been found between these analogous and ubiquitous proteins.

In order to standardize the isoelectric focusing dimension of the ISO-DALT two-dimensional system, a series of charge-shift pI standards was developed. These now allow assignment of a reproducible, internally standardized isoelectric position to each protein in such a separation. 
VERY HIGH SENSITIVITY PROTEIN STAINING

S. L. Nance

We have modified a method for silver staining of proteins in acrylamide gels (Switzer, R. C. III, C. R. Merril, and S. Shifrin. A highly sensitive silver stain for detecting proteins and peptides in polyacrylamide gels. Anal. Biochem., in press) in several ways to decrease cost and operator exposure to toxic chemicals. The technique is approximately one hundred times more sensitive than the standard method of staining gels with Coomassie Blue. Because some tissue proteins are present in only minute amounts and others apparently do not stain with Coomassie Blue, silver staining is proving quite useful in extending the limits of detection of proteins in the ISO-DALT system.

TWO-DIMENSIONAL ELECTROPHORETIC MAPPING OF BASIC PROTEINS: THE BASO-DALT SYSTEM

K. E. Willard ${ }^{1}$ and N. G. Anderson

High-resolution separations of proteins and protein subunits aan be obtained by two-dimensional polyacrylamide gel electrophoresis. 0'Farrell et al. (Ce11, 12, 1133, 1977) have described a first dimension electrophoresis procedure to resolve basic proteins which they call a NEPHGE (nonequilibrium $\mathrm{pH}$ gradient electrophoresis). In this procedure, improved separation of many basic proteins resulted from loading samples at the acidic end of the focusing ge1 and running for 1600 volt-hours instead of the 10,000 volt-hours used in isofocusing. We were unable, however, to obtain satisfactory resolution of the basic proteins from Novikoff hepatoma cells by following O'Farrell's procedure; the histones were not solubilized by O'Farrell's sodium dodecyl sulfate (SDS) and NP-40 lysis buffers, and a considerable proportion of the total protein applied failed to enter the gel (Figure 17.2, Part B). This phenomenon could be due to inadequate solubilization of the sample by the SDS/NP-40 method and/or the inability of the sample to enter the gel because of the attached SDS. In our system, samples for the first dimensional electrophoresis (BASO) are solubilized in a mixture of $0.5 \%$ dipalmitoy 1 L- $\alpha$-phosphatidy1 choline (PC), $9.5 \mathrm{M}$ urea, $2 \%$ ampholines, and $1 \%$ mercaptoethanol with the $\mathrm{pH}$ adjusted to 2.8 with $\mathrm{H}_{3} \mathrm{PO}_{4}$. The samples are then centrifuged for 1 hour at $20^{\circ} \mathrm{C}$ and $50,000 \mathrm{rpm}\left(\omega 2 \mathrm{t}=85 \times 10^{7}\right)$ to sediment all particles with an $\mathrm{S}$ value greater than 12. After electrophoresis for 3200 volt-hours (Figure 17.2, Part A), we obtained more complete patterns of the basic proteins (including the histones) in Novikoff hepatoma cells. This system is called the BAS0-DALT system, since the second (SDS) dimension is identical with that used in the ISO-DALT system.

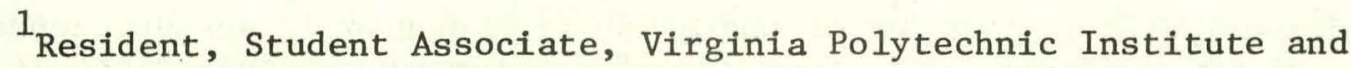
State University. 

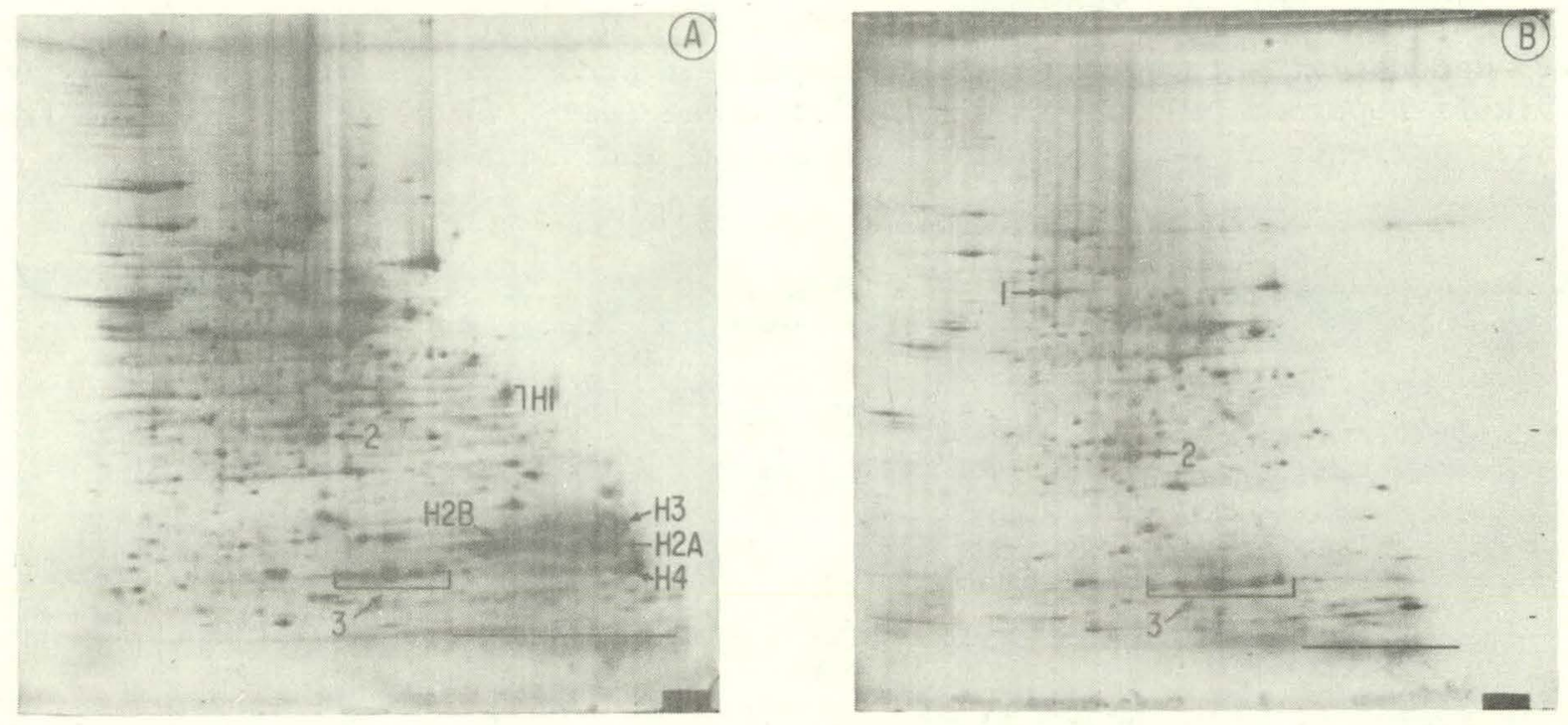

Fig. 17.2. Two dimensional electrophoresis patterns of Novikoff hepatoma ce1ls illustrating different methods of solubilization. Samples were electrophoresed for 3200 volt-hours using LKB 3.5 - 10 ampholines in the ISU-DALT apparatus. The gels are oriented with the basic end to the right and the acidic end to the left. (A) Cells were lysed in the PC/urea mixture, allowed to stand at room temperature for 1 hour, and then centrifuged for 1 hour at 50,000 rpm. (B) Cells were mixed 1:1 with the SDS 1ysis buffer described by 0'Farre11 and allowed to stand for $10 \mathrm{~min}$. This mixture was then diluted 1:1 with O'Farre11's NP-40 1ysis buffer; the final protein concentration equaled that of the samples in $\mathrm{A}$. The histones $\mathrm{H} 1, \mathrm{H} 2 \mathrm{~A}, \mathrm{H} 2 \mathrm{~B}, \mathrm{H} 3$, and $\mathrm{H} 4$ are identified in A. Selected proteins are labeled 1-3 for reference purposes in both $A$ and B. The area above the bar represents the greatest difference between the gels.

Isoelectric point standards for the ISO-DALT system based on carbamylation of proteins by heating at $95^{\circ} \mathrm{C}$ in $9.5 \mathrm{M}$ urea have been described (Anderson, N. L., and B. J. Hickman, Anal. Biochem. 93, 312, 1979). Carbamylated creatine phosphokinase (CK) has been chosen as a provisional standard for the ISO-DALT system (see Figure 17.1). However, because the isoelectric point of CK is about 6.1 , the most basic species migrates only about halfway across the BASO gel. It was necessary to develop new, more basic isoelectric point standards for internal standardization of the BASO system. Carbamylation mixtures of glyceraldehyde-3-phosphate dehydrogenase yielded trains of we11-defined, evenly spaced spots which run about halfway down the SDS slab gel. Although minor spots appear between the first three charge shifts, and two minor trains with higher SDS molecular weight values appear toward the acid end of the gel, this protein yields a train of spots suitable for internal standardization of the BASO system.

In addition to Novikoff hepatoma cells, the BASO-DALT system has been used to examine the basic proteins in muscle samples, concentrated urinary proteins, liver proteins, and serum proteins. Utilizing this system we have demonstrated that human urine contains proteins that retain their biological activity 
and can stimulate de novo protein synthesis in Novikoff hepatoma cells. Figure 17.3 demonstrates the concentration-dependent production of these proteins in Novikoff hepatoma cells. This stimulatory activity was detected in urine from cancer patients as well as urine from normal individuals.

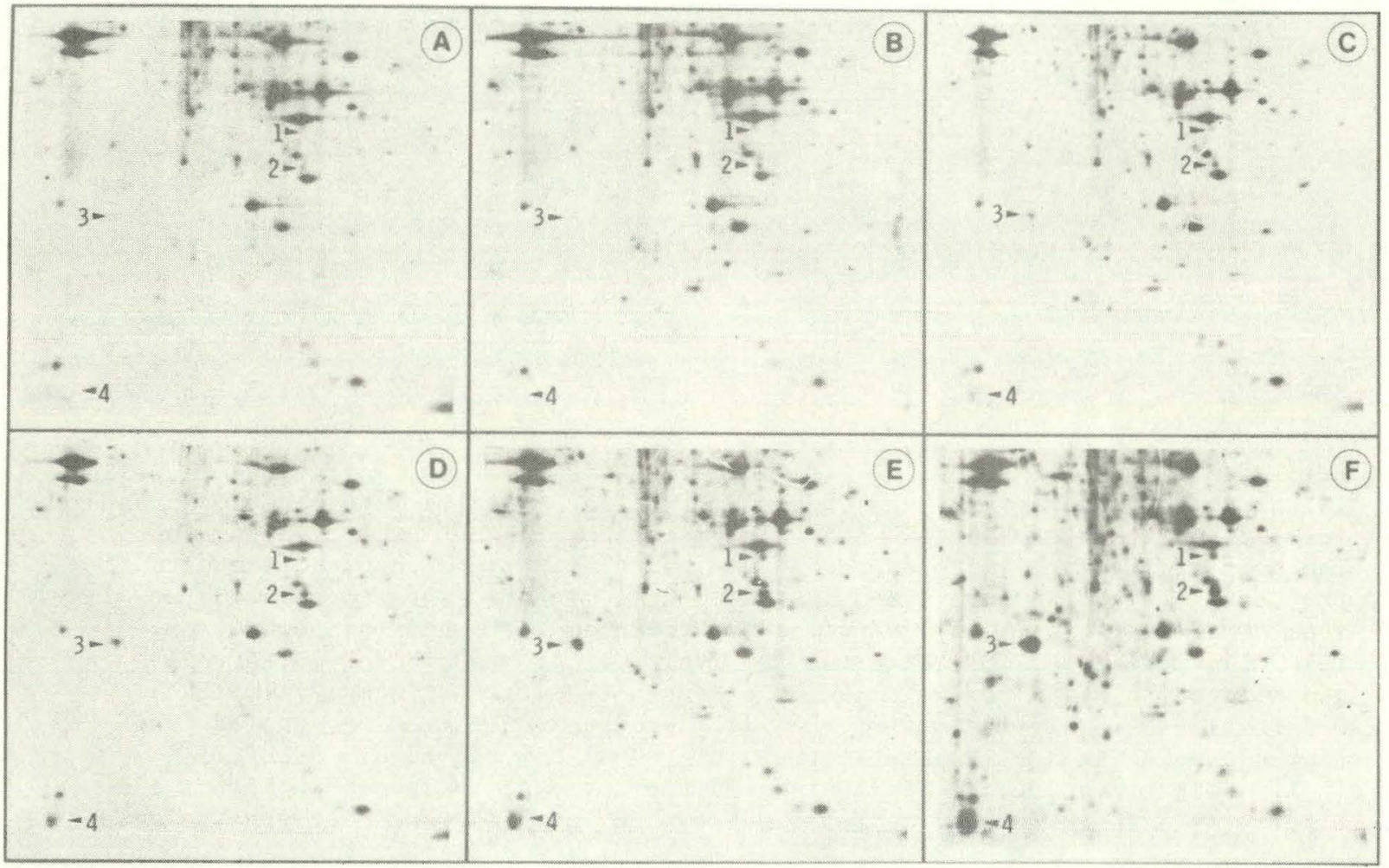

Fig. 17.3. Each panel represents a portion of a BASO-DALT pattern of Novikoff hepatoma cells cultured with increasing concentrations of human urinary proteins. Cells were cultured for 48 hours in serum-free medium 479 containing 35 S-methionine. Radioactive cell samples were solubilized as described in Figure 17.1A. Samples were electrophoresed for 4000 volt-hours using LKB 3.5 - 10 ampholines. The second dimension gels were dried and then placed on film for 10 days. Autoradiographs of cells cultured with increasing concentrations of urinary proteins, are as follows: (A) control, (B) 0.0001 $\mathrm{mg} / \mathrm{ml}$, (C) $0.001 \mathrm{mg} / \mathrm{ml}$, (D) $0.01 \mathrm{mg} / \mathrm{ml}$, (E) $0.1 \mathrm{mg} / \mathrm{ml}$, and (F) $1.0 \mathrm{mg} / \mathrm{ml}$. The gels are oriented as in Figure 17.1. Selected proteins are labeled 1 to 4 for cross reference.

The BASO-DALT technique should provide a better means for analysis of basic protein mixtures found in tissues and cells. Except for the histones, there have been relatively few studies of these basic proteins. Use of the conventional ISO procedure and the BASO technique described here provides a comprehensive mapping technique, showing histones as well as other basic proteins necessary to catalog human protein gene products. 


\section{TWO-DIMENSIONAL ELECTROPHORETIC ANALYSIS OF HUMAN URINARY PROTEINS}

N. G. Anderson, S. L. Tollaksen, and N. L. Anderson

Human urine contains small amounts of protein which may be classified into eight groups, according to origin: (1) normal plasma proteins or fragments of them, (2) proteins originating in the kidney, (3) proteins arising in the remainder of the urogenital tract, (4) tissue leakage proteins reaching the urine through the circulation, (5) hormones or other signal substances, (6) proteins produced by the placenta or fetus, (7) tumor-associated proteins, and (8) products of bacterial or viral infection. Several hundred proteins are resolved using two-dimensional electrophoresis to analyze human urinary protein concentrates; hence the possibility exists for finding among them indicators of a wide variety of types of disease or injury. The effects of energy-related chemical pollutants and radiation would include the presence of tissue proteins in urine leaked from damaged tissues, presence of new mutant proteins not found in either parent, proteins indicating cancerous or precancerous conditions, or alterations in the ratio of high and low molecular weight proteins due to glomerular or tubular damage (the latter being often due to heavy metal intoxication). Methods for concentrating urinary proteins and for mapping them twodimensionally have been developed and applied to a variety of urines. As expected, marked alterations are found in kidney injury, in several types of cancer, and after irradiation. This survey work indicates the importance of detailed study and identification of as many proteins as possible, and the development of scanning systems that will permit quantitative analysis.

TWO-DIMENS IONAL ELECTROPHORETIC MAPPING OF MUSCLE PROTEINS

C. Smith, N. L. Anderson, and N. G. Anderson

The objectives of this work are to develop clinically useful methods for the analysis of human muscle biopsy material by two-dimensional electrophoresis and to identify the proteins separated by this technique. Using rabbit psoas muscle as a model, we have developed methods for sample acquisition and preparation. A modification of the first dimension separation in the ISO-DALT system is sometimes used for two-dimensional electrophoresis. The separation in the first dimension is either by isoelectric focusing (ISo, for resolution of acidic and neutral proteins) or by nonequilibrium $\mathrm{pH}$ gradient electrophoresis (NEPHGE, for resolution of neutral and basic proteins), and is then followed by separation in the second dimension using sodium dodecyl sulfate (SDS) electrophoresis, as in the ISO-DALT system. The peptide components of ten enzymes and of myosin, actin, tropomyosin, and troponin have been identified in the rabbit psoas muscle two-dimensional electrophoresis patterns.

Figure 17.4 shows the two-dimensional electrophoresis pattern when isoelectric focusing is used for the first dimension separation. Figure 17.5 shows the same sample separated by the NEPHGE technique in the first dimension. In the NEPHGE, samples are loaded at the acidic end of the first dimension gel instead of the basic end as in the case of the ISO technique. This technique 
results in higher resolution of basic proteins as can be seen by comparing the aldolase (ALD) and glyceraldehyde-3-phosphate dehydrogenase (GAPDH) patterns in Figures 17.4 and 17.5. The NEPHGE also permits detection of very basic proteins such as myokinase (MK) and the inhibitory subunit of troponin ( $\operatorname{Tn} I$ ) (Figure 17.5) which do not enter gels when isoelectric focusing is used for first dimension separation (Figure 17.4). Identification of proteins in two-dimensional electrophoresis patterns of rabbit muscle is being used as the foundation for the mapping of human muscle proteins. Preliminary work has shown definite similarities in the patterns of rabbit and human skeletal muscle and some tentative identifications in the human patterns have been made (Figure 17.6).

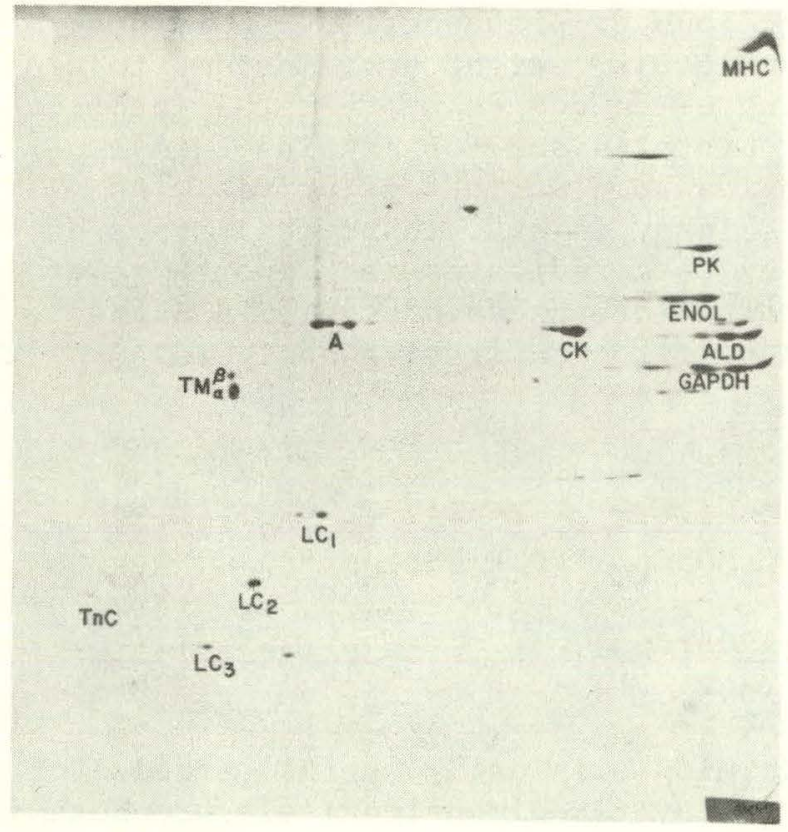

Fig. 17.4. Two-dimensional patterns of rabbit psoas muscle whole homogenate $(200 \mu \mathrm{g}$ protein) using isoelectric focusing in the first dimension followed by SDS electrophoresis. Isoelectric focusing was done using Brinkman 2-11 ampholines in the ISO-DALT apparatus. The gel is oriented with the acidic side to the left and the basic side to the right. A, actin; $\alpha \mathrm{TM}$ and BTM, tropomyosin; MHC, myosin, heavy chain; $\mathrm{LC}_{1}, \mathrm{LC}_{2}$, and $\mathrm{LC}_{3}$, myosin light chains; TnC, calcium-binding troponin subunit; PK, pyruvate kinase; $\mathrm{CK}$, creatine kinase; ENOL, enolase; ALD, aldolase; GAPDH, glyceraldehyde-3-phosphate dehydrogenase. 


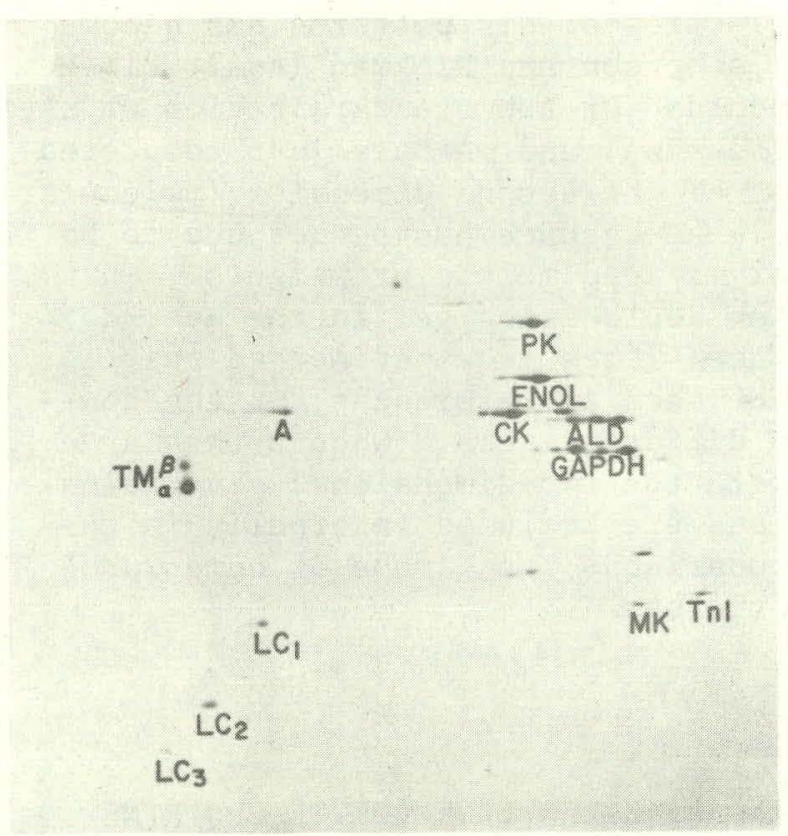

Fig. 17.5. Two-dimensional patterns of rabbit psoas muscle whole homogenate (200 $\mu \mathrm{g}$ protein) using nonequilibrium $\mathrm{pH}$ gradient electrophoresis (NEPHGE) in the first dimension. Samples were separated in the first dimension using the modified NEPHGE technique in gels containing Brinkman 2-11 ampholines. After electrophoresis for 4000 volthours, the proteins were separated in the second dimension using sodium dodecyl sulfate electrophoresis. The gel is oriented as in Figure 17.4. The symbols are as identified in Figure 17.4, with the addition of the following: TnI, inhibitory troponin subunit and MK, myokinase.

Fig. 17.6. Two-dimensional electrophoresis pattern of human ske1etal muscle whole homogenate. A human muscle biopsy sample was analyzed using isoelectric focusing in the first dimension. Two hundred $\mu \mathrm{g}$ of protein was applied to the isofocusing gel. The symbols are as identified in Figure 17.4 (TM = tropomyosin $)$, and the gel is oriented as in Figure 17.4 .

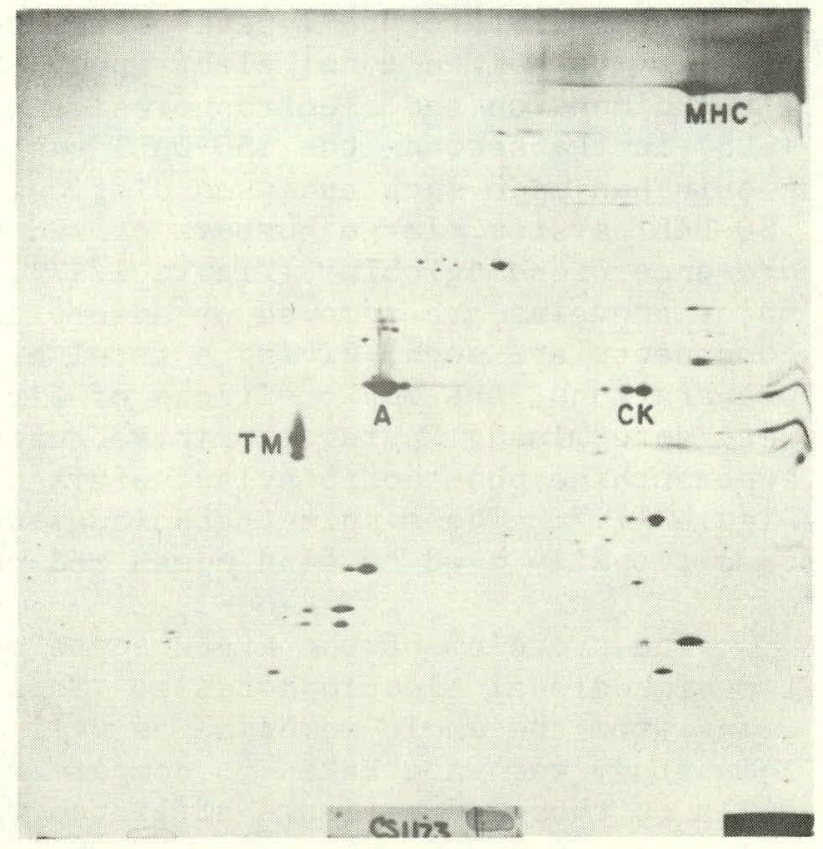


Standardization of two-dimensional electrophoresis patterns has become important for the comparison of samples. Anderson and Hickman (Anal. Biochem. 93, 312, 1979) have described charge standards for the standardization of the first dimension separation (isoelectric focusing) and we have just completed development of markers for standardization of the second dimension (molecular weight separation). Rat heart muscle whole homogenate has been found to be a reliable source of proteins having evenly spaced molecular weights. When this mixture is used in combination with an isofocusing gel in the second dimension separation, a pattern of horizontal lines is superimposed over the final spot pattern. These lines can be used as references for the comparison of different samples separated on different gels. When both charge standards and rat heart muscle are used with the two-dimensional separation of a sample, coordinates for both dimensions are included internally in the gel. This technique will be helpful in comparisons among maps of human protein gene products from muscle and other tissues.

RED CELL PROTEINS: TWO-DIMENSIONAL MAPPING OF HUMAN ERYTHROCYTE PROTEINS

J. J. Edwards, N. G. Anderson, S. L. Nance, and N. L. Anderson

Human erythrocyte lysate proteins were resolved into over 250 discrete spots by two-dimensional electrophoresis using isoelectric focusing in the first dimension and electrophoresis in the presence of sodium dodecy 1 sulfate (SDS) in the second--the ISO-DALT system. The overwhelming excess of hemoglobin has made such analyses difficult in the past. However, with the ISO-DAL' system, large numbers of red cell proteins can be mapped even in the presence of hemoglobin (Figure 17.7). When hemoglobin and several other major proteins are removed by adsorption to DEAE-cellulose, additional minor components are seen, giving a total of over 275. With the use of purified preparations, the map positions of five red cell enzymes or their subunits were determined: pyruvate kinase, catalase, glucose-6-phosphate dehydrogenase, hypoxanthine phosphoribosyltransferase, and carbonic anhydrase, as shown in Figure 17.7. The mapping techniques described complement and extend those traditionally used to find human red cel1 protein variants.

The proteins of the erythrocyte membrane are currently being analyzed by two-dimensional electrophoresis. This study involves the separation of proteins from the whole membrane as well as the analysis of purified components. This study was undertaken to compare the proteins of membranes from normal cells to those of patients afflicted with Duchenne musrilar dystrophy. 


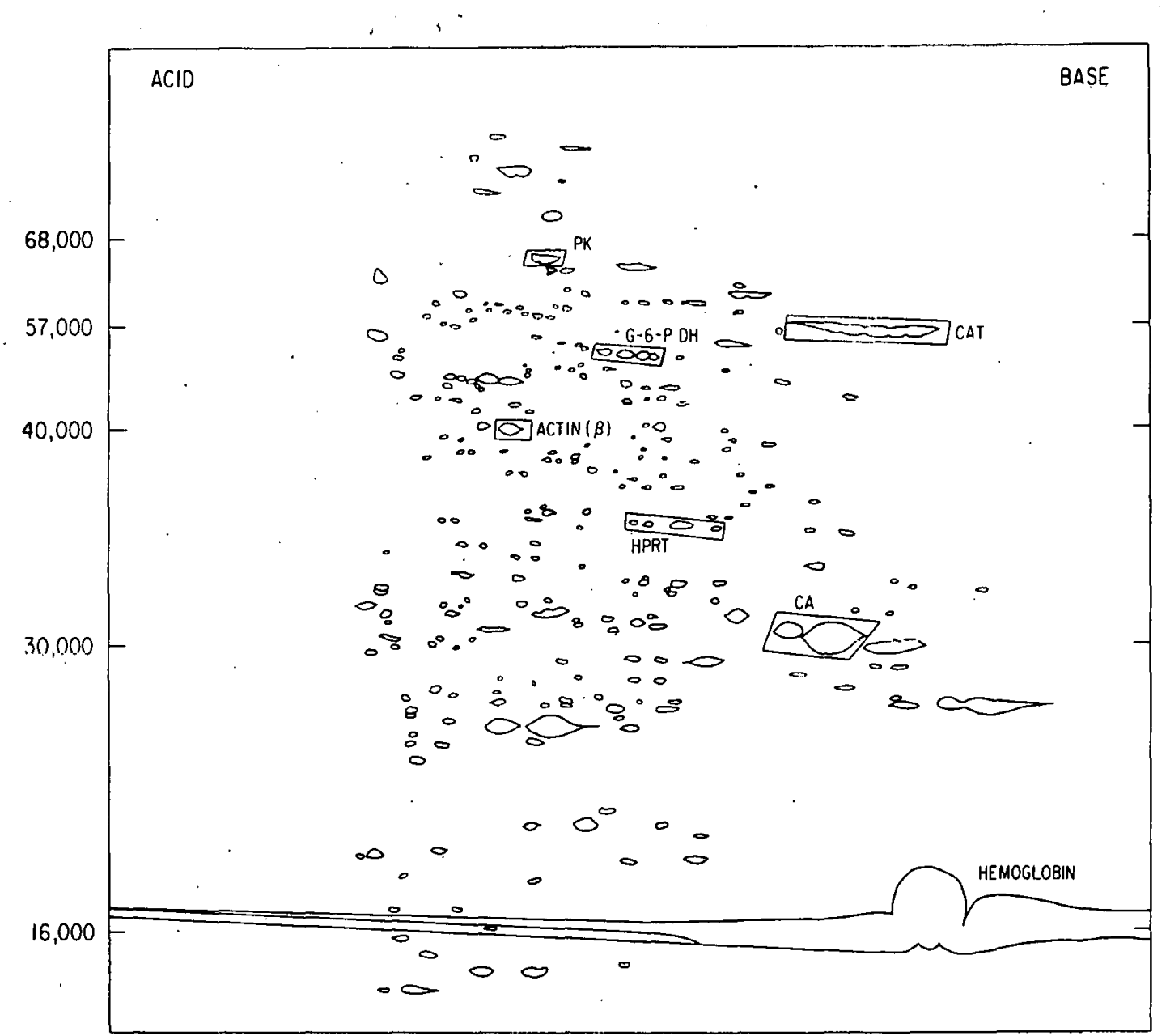

Fig. 17.7. Two-dimensional electrophoretic separation of human erythrocyte lysate proteins. The sample was $12.5 \mu 1$ of fresh lysate denatured in an equal volume of buffer containing $2 \%$ SDS/5\% dithiothreitol. Isoelectric focusing was from right to left and molecular weight separation from top to bottom. The map. locations of known erythrocyte enzymes are labeled. CAT = catalase; $\mathrm{PK}=$ pyruvate kinase; G-6-P DH = glucose-6-phosphate dehydrogenase; HPRT = hypoxanthine phosphoribosyltransferase; $\mathrm{CA}=$ carbonic anhydrase. Hemo.globin and actin are also labeled. Molecular weight values (ordinate) were determined by SDS electrophoreis of known proteins. 
COMPUTERIZED REDUCTION OF TWO-DIMENSTONAL GEL DATA

N. L. Anderson, John Taylor, Jr., ${ }^{1}$ B. S. Coulter, ${ }^{1}$ A. Scandora, ${ }^{2}$ and M. Kempf ${ }^{2}$

The human eye can accurately compare two complex patterns in great detail, but the mind cannot readily deal with comparisons among large numbers of such patterns. For this reason, 1 t has proved essential to develop a computerized system for cataloguing and quantitating the thousands of spots visible on twodimensional (ISO-DALT) protein gene product maps. During 1978, work was begun on such a system based on a PDP $11 / 60$ minicomputer, with image input from a high-speed, two-dimensional microdensitometer (Optronics P-1000) and image display on a 512 × 512 element color television (Grinnell GMR-27). The system is designed to find and quantitate all the spots in a pattern (after initial smoothing and background subtraction), using a two-dimensional Gaussian fitting technique. It is anticipated that the ability to measure and intercorrelate the abundances of thousands of proteins in a variety of types of cells and body fluids will enable us to explore gene regulation, differentiation, and cancer in much greater detail than has heretofore been possible.

${ }^{1}$ Applied Mathematics Division.

${ }^{2}$ Science Applications, Inc. 
18. THE ARGONNE B IOANALYTICAL CENTER FOR THE STUDY OF STABLE ISOTOPE APPLICATIONS IN HUMAN HEALTH AND DISEASE

INTRODUCTION

$\therefore, \because$

. Peter D. Klein

This program has five.major aspects: first, the development of analytical instrumentation of adequate sensitivity, stability, and simplicity to ${ }^{\circ}$. conduct stable isotope measurements in a routine manner; second, the development of appropriately labeled compounds for metabolic investigations, initially through custom syntheses but eventually to be made available through commercial sources; third, development of analytical methodology to isolate, purify, and determine the isotopic content of specific organic com-: pounds reflecting metabolic or disease states; fourth, collaborative development of clinical applications and testing, on a routine basis, through a network of clinical centers around the country; and finally, the collection and dissemination of stable isotope information on an international scale through survey publications and conferences.

A new, more sensitive gas chromatographic system for analysis of hydrogen, carbon dioxide, oxygen, and nitrogen in breath has been developed. This instrumentation is used in the detection and quantitation of carbohydrate malabsorption. We have shown that relating the observed level of hydrogen to the concentration of carbon dioxide in the same sample achieves a significant reduction in the variability of this measurement, and reduces the dependence of values on the breath collection technique.

New procedures for the quantitation and.study of tracer kinetics of methadone and of taurine have been developed. In the first instance; three isotopic variants of the unlabeled compound are used to determine the endogenous level of the unlabeled drug and to provide independent measurements of the rates of metabolism of the individual optical 1somers. In the second instance, procedures for the recovery and measurement of isotopic abundance in the putative neurotransmitter taurine have been developed. The complete failure of previous efforts in this area has been shown to be due to a novel "invisibility" of taurine derivatives in conventional gas chromatographic detection systems, which is overcome by mass spectrometry.

Studies of bile acid kinetics with ${ }^{13} \mathrm{C}$-labeled bile acids in pregnant women, seeking to find the basis of an increased cholelithiasis (gallstone formation) in this population have shown that, contrary to expectations, the total quantity of bile acids in the enterohepatic circulation is increased during the first and second trimester of pregnancy. Similar studies are also under way to investigate the effect of oral contraceptive steroids in women of childbearing age. 
Stable isotopes of metals are potentially powerful tools to be used in studying trace metals that are essential for human nutrition or that are toxic by-products from energy production. We are currently developing methods for the isolation of metals and for the determination of their isotopic abundance.

The activities of this program contribute to the medical applications of stable isotopes as nonradioactive, noninvasive probes of specific metabolic processes that may be affected by environmental contaminants. This program provides a means of studying the metabolism and tate of pollutants in the examination of disease states and lays the basis for estimating levels of human exposure through clinical studies of selected populations. These studies can be extended into epidemiological examinations of occupational and general populations as the techniques prove to have significant diagnostic values.

Finally, this program represents the confluence of a number of research programs within DOE and also in various Institutes of the National Institutes of Health, and it serves to link the network of stable isotope users within a national and an international framework.

REGULAR STAFF

Hachey, David L. (Chemist)

Klein, Peter D. (Senior Biochemist)

Szczepanik-Van Leeuwen, Patricia A. (Biochemist)

TEMPORARY STAFF DURING 1978

DeMark, Bruce R. (Postdoctoral Appointee)

Irving, Charles S. (Postdoctoral Appointee)

Hiu, Isien chi (Postdoctoral Appointcc)

Stellaard, Frans (Research Assoclate)

Tserng, Kou-Yi (Postdoctoral Appointee) 
INSTRUMENTATION

D. A. Schoeller ${ }^{1}$ and H. C. Niu

The automated $\mathrm{CO}_{2}$ purification system and isotope ratio analyzer has been installed in the Stable Isotope Facility at The University of Chicago Hospitals and Clinics. As of January 1979, it has been in use for the analysis of breath $\mathrm{CO}_{2}$ for 7 months as part of the ${ }^{13} \mathrm{CO}_{2}$ breath test program. The instrument has been reliable, analyzing between 30 and 40 samples per day with operator intervention only at 4-hour intervals. Cost and time of the analysis are comparable with scintillation counting of ${ }^{14} \mathrm{CO}_{2}$.

Our dual source gas chromatograph-mass spectrometer (GC-MS) has been upgraded with the addition of a molecular separator which reduces the helium flow into the ion source. The reduced helium flow has improved operation of the electron impact ion source and resulted in greater sensitivity and stability of operation. The copper gas lines used for introduction of reagent gas during the chemical ionization mode have been replaced with stainless steel. The stainless steel lines enable the use of reagent gases, such as ammonia, that would corrode the copper lines.

\section{ORGANIC SYNTHESES}

D. L. Hachey and K. Y. Tserng

Synthetic preparation work has been substantially curtalled by the departure of Dr. K. Y. Tserng to a permanent position elsewhere. Before the conclusion of his appointment, he prepared several large scale batches of 24-13C-1abeled bile acids for the bile acid kinetic studies currently under way. In addition, work was completed on the synthesis of the 7- and 12-monosulfates of bile acids, and their glycine and taurine conjugates. This work, which concludes the syntheses of bile acid sulfates, has permitted the determination of their chromatographic mobllities and separation characteristics. In addition, they have been used by Dr. Alan Hofmann (University of California, San Diego) to ascertain the forms of sulfated chenodeoxycholic acid formed in human studies. A large scale batch of methacetin-13C was synthesized to provide sufficient material for approximately 100 clinical studies. Finally, several Schiff base chelating agents were prepared to test their suitability for the chromatographic separations of zinc and copper. Using these and other chelating agents, a number of metal chelates have been prepared for magnesium, calcium, iron, copper, zinc, and cadmium to test their suitability for mass spectral isotope ratio measurements.

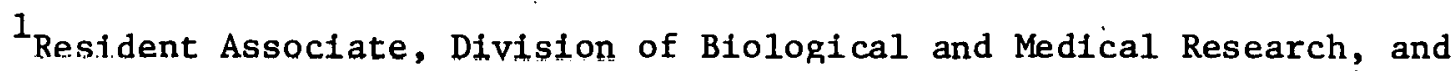
Research Associate (Assistant Professor), The University of Chicago. 


\section{ANALYTICAL METHODOLOGY}

The following reports present the progress made during the year in the development of analytical methods designed to solve problems in using stable isotopes in specific biological and clinical applications.

STUDIES WITH STABLE ISOTOPES OF METALS

D. L. Hachey and J. C. Blais ${ }^{1}$

Stable isotopes of metals are potentially powerful tools for studying trace metals that are essential for human nutrition or that are toxic byproducts from energy production. Techniques have been developed to wet chemical ash biological samples using strong oxidizing acids, since the blological matrix in which metals are entrained interferes with mass spectrometric analysis. Wet chemical ashing is adequate for studying the more abundant elements, such as magnesium, calcium, iron, copper, and zinc which are of Interest in nutritional studies. Another problem is to identify chelating agents that efficiently extract metal ions from aqueous solution and that, in addition, have good mass spectral properties, e.g., good volatility and stability, convenient ions for isotope ratio studies, and freedom from isotope memory effects.

For plasma and urinary magnesium and calcium, mass spectral studipa have been conducted using a fluorinated $\beta$-diketone as the chelating agpnt. For the alkaline earth serles, electron ionization mass spectrometry (EI-MS) is most useful; under chemical ionization (CI-MS) conditions only ions related to the free chelating agent are observed. Preliminary isotope ratio studies using the PE-270 mass spectrometer indicate a severe isotopic memory effect, which apparently is due to isotope exchange with insulating material used in manufacture of the direct insertion probe. Use of an all-glass system should ellminate the problem. Both magnesium and calcium isotope ratio studies indiçate that it is possible to obtain prccise isotope ratio measurements $( \pm 0.06 \%)$ and to obtain accurate natural abundances $( \pm 0.2-0.8 \%)$ after correction for isotope contributions from the chelating agent.

For analysis of transition metals (iron, copper, zinc) a much wider selection of chelating agents and ionization techniques is available. Fluorinated $\beta$-diketones have only limited use becauec of extensive isotupic memory effects; the only notable exception is chromlum trifluoroacetylacetonate. One must resort to various exotic chelating agents containing oxygen, nitrogen, and sulfur ligands, or use the more stable organometallic compounds. Ferrocene, an organometallic derivative of iron, has ideal properties for 1sotope ratio analysis by GC-MS; however, it is difficult to prepare

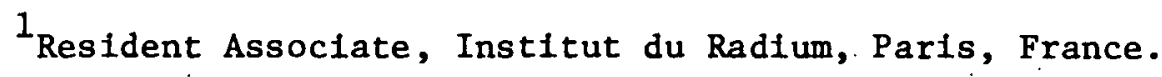


on a microgram scale. Ferrocene is best analyzed by EI-MS; under CI-MS conditions it contains a mixture of ions formed by proton transfer $\left(\mathrm{MH}^{+}\right)$and by charge exchange oxidation to the ferricinium ion $\left(M^{+}\right)$. Copper can be analyzed as a fluorinated Schiff base chelate, using isobutane CI-MS. Zinc is best analyzed using chelating agents containing sulfur, such as diethyldithiocarbamate (DDC) or monothio-trifluoroacetylacetone. There is some difficulty with an isotopic memory effort when $\mathrm{Zn}(\mathrm{DDC})_{2}$ is analyzed by CI-MS, but the problem seems to be small under EI-MS conditions. Isotope ratio studies have achieved a precision of $\pm 0.05-0.30 \%$ for simultaneous measurement of all five naturally occurring zinc isotopes. Similarly, we have obtained experimental precision of $\pm 0.12-0.72 \%$ for simultaneous measurement of all eight cadmium isotopes by CI-MS. Absolute accuracy for a cadmium natural abundance isotopic standard ranges between $\pm 0.01-0.48 \%$, corrected for isotopic contributions from the chelating agent. Similar experimental accuracy and precision results have been obtained for iron trifluoroacety1acetonate, but this compound is unsuitable for isotope tracer studies by CI-MS because of exchange with iron used in the manufacture of ion source components.

METHADONE PHARMACOKINETICS

D. L. Hachey and K. Nakamura ${ }^{1}$

Multiple isotopic tracer studies for plasma methadone pharmacokinetics required improved isolation techniques for recovering methadone from plasma. Dr. Kanichi Nakamura has developed techniques for isolating methadone using a short, disposable $\mathrm{C}_{18}$-silica gel cartridge. The extraction procedure is more rapid, drug recoveries have been improved nearly 2-fold, and purity has been increased by 5-fold. Techniques have been refined to the point where plasma drug level, multi-isotope kinetic studies are routinely possible. Novel chemical ionization reagent gases are being examined because they enhance sensitivity and specificity for analysis of methadone.

\section{ANTIEPILEPTIC DRUGS}

B. R. DeMark

The response of patients with epileptic seizures to drug treatment is difficult to predict or assess on the basls of dosages used. A conventtonal dose may overcontrol or undercontrol seizure frequency, and in the absence of clinical pharmacological information, adjustment of the dose is difficult.

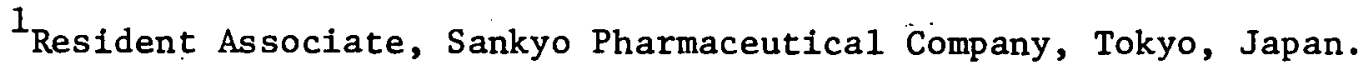


Further, plasma levels of a particular metabolite may be of more consequence than levels of the parent drug. Dr. Dorothy Schottelius (University of Iowa) required the ability to detect and quantitate the drugs and metabolites of phenobarbital, phenytoin, valproic acid, and several other antiepileptic compounds. Derivatization, GC separation, and mass spectrometric identification of these compounds have been carried out. Detection by selected ion monitoring and quantitation by GC-MS-computer techniques have been done on standard mixtures. Patient samples are now available for preliminary exploration of extraction and identification techniques. When these are completed, analysis of samples of patients in clinical studies will be undertaken.

\section{TAURINE KINETIC MEASUREMENTS}

C. S. Irving

Taurine (aminoethane sulfonic acid) is a product of cysteine metabolism which has been postulated to be an essential amino acid for the neonate human. In addition to it's function in bile acld conjugation, it is a putative neurotransmitter, although this function has not been shown in direct observations. It is an ideal compound for amino acid kinetic measurements, because it is not further metabolized. For clinical studies with Dr. Gerald Gaull, New York Institute for Basic Research on Mental Retardation, it was necessary to develop derivatization, gas chromatographic, and mass spectrometric methods for isotope ratio measurements on taurine. A small quantity of taurine-1,2${ }^{13} \mathrm{C}$ was obtained commercially, and material for cilnical scudies $1 \mathrm{~s}$ belng supplied by the Stable Isotope Resource at Los Alamos. Methods were developed for quantitative derivatization and for GC-MS analysis of taurine. A characteristic of taurine derivatives is that they give no response in the flame Ionization detector used for gas chromatography. Hence, derivatized taurine can only be recognized and studied by GC-MS. Th1s explains the fallure of most analytical methods to quantitate taurine by gas chromatography. When suftable gas chromatographic conditions had been established, isotope ratio measurements were carried out on standard samples. These show that it should be possible to detect taurine at dilutions as low as 1 part in 1000 to 1 part in 3000 in samples of $10 \mu \mathrm{g}$. Extraction and purification techniques for taurine in blological samples are being developed.

\section{PYRIDOXINE REQUIREMENTS}

B. R. DeMark and.J.C. Blais ${ }^{1}$

Dr. Steven Coburn (Fort. Wayne State Hospital) has sought to establish methods for determining nutritional requirements of the vitamin pyridoxine in man, using pyridoxines labeled with stable isotopes. Synthesis of stable

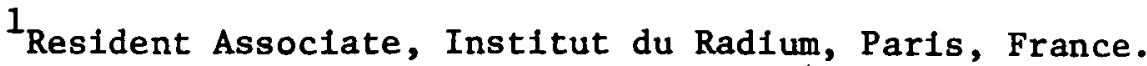


isotope-labeled forms appears feasible, and we have established the gas chromatography methodology and obtained mass spectra of the various metabolites of pyridoxines. Isotopic abundance measurements on the unlabeled material have been carried out in order to estimate the dilution that can be detected with single or multiple forms of the vitamin. Application of these techniques, particularly to patients with Down's syndrome, will hinge on development of suitable extraction and recovery procedures from urine and plasma. This development is being undertaken by Dr. Coburn; when completed, it will be part of a joint collaboration in the study of pyridoxine kinetics in normal and disease states.

\title{
CARBOHYDRATE MALABSORPTION
}

H. C. Niu

\begin{abstract}
Assessment of carbohydrate malabsorption from the intestine, a disorder that may have serious consequences on the patient's nutritional status, is now possible through very precise measurements of breath hydrogen. In association with Dr. Alfred Baker (Department of Medicine, The University of Chicago), we have refined previous gas chromatographic procedures for separation of hydrogen from other breath constituents and improved its quantitation to the point where hydrogen can be detected in concentrations as low as 2 parts per million in expired air. It can be quantitated at levels of $5 \mathrm{ppm}$; at levels of $120 \mathrm{ppm}$, the precision is $1 \%$. It is possible to collect breath samples for subsequent analysis using Vacutainers in an out-patient clinic. Techniques for collecting breath samples have been investigated and it has been found that the absolute levels of hydrogen fluctuate with the conditions of exhalation. However, the internal comparison of breath hydrogen to breath $\mathrm{CO}_{2}$ levels has shown a constant ratio; so that standardizing the reporting of breath hydrogen values against a constant $\mathrm{CO}_{2}$ concentration will significantly reduce the variation.
\end{abstract}

\section{CLINICAL STUDIES}

The Argonne Bioanalytical Center continues to occupy a central position in the study of bile acid kinetics. The capability to provide precise kinetic measurements utilizing deuterium- and ${ }^{13} \mathrm{C}-1$ abeled bile acids and advanced GC-MS-peak switching techniques has attracted clinicians across the country. Current collaborative projects are described in the following reports. 
GALLSTONE FORMATION

P. A. Szczepanik-Van Leeuwen and B. R. DeMark

Two separate studies aim to establish the factors that increase the risk of gallstone formation in women. In previous collaboration with Drs. Alan Hofmann and Peter $\mathrm{Ng}$, then at Mayo Clinic, we have examined the bile acld kinetics in several pregnant women from the fifth to eighth week of pregnancy and in healthy, nonpregnant women with and without contraceptive steroid administration. The results of this study indicated that bile acid composition is drastically altered during pregnancy.

These studies have been expanded under the collaboration of Dr. Fred Kern, Jr., University of Colorado Medical Center, to measure duodenal bile aclds during all three trimesters of pregnancy, and again after the bile arid pool has returned to normal. The data obtained from this study are yielding unique information about the role of sex hormones in the formation nf lithogenic bile and subsequent gallstone formation.

STUDIES OF BILE'ACIDS IN LIVER DISEASE

P. A. Szczepantk-Van Leeuwen and F. Stellaard

The identification of the bile acid constituents of the serum, bile, urine, and stool of patients with liver disease has increased in importance with the continuing development of newer GC-mass spectrometric-computer methods for their analysis. We have recently shown that atypical bile acids can be readily identified with great sensitivity using chamfrat inntzationselected ion monitoring techniques. Therefore, we are in a position to provide the analytical expertise to a number of clinical collaborators who wish to apply this methodology to the study and diagnosis of liver disease.

Ut prime importance have been two investigations of shildren with Zellweger's Syndrome in collaboration with Dr. Russell Hanson, University of Minnesota, and Dr. John Watkins, Harvard Children's Hospltal. Analysis of the biological fluids from children with this disease has uncovered evidence of several c-27 bile actds - trihydroxycoprostanic, dihydroxycoprostanic, and varanic acids. The presence of these compounds, normally found only in reptiles and -lower antmal forms, along with the detection of abnormal mitochondrial structure in these patients, suggests that mitochondrial oxidation is necessary for the formation of $\mathrm{C}-24$ bile acids (chenodeoxycholic and cholic acids) and indicates that a defect in the mitochondrial function may be responsible for the accumulation of $\mathrm{C}-27$ bile acids in Zellweger's Disease.

Byler's"disease, a genetic cholestatic liver disease which can be traced to descendants of Jacob Byler, is under investigation in collaboration with Dr. Charles Huang, Baylor Medical College, and with Dr. John Watkins. 
Dr. Huang has examined bile levels in serum and urine samples from a child with this type of intrahepatic cholestasis, and compared these samples with two other children with a Byler's-like cholestasis. Hyocholic acid, B-muricholic acid, and four compounds thought to be tetrahydroxy-bile acids were identified in the bile, serum, and urine of this child from samples taken over a period of several years. The atypical bile acids detected do not appear to be formed as a result of any drug therapy given this patient.

\section{SYNTHETIC DIETS}

P. A. Szczepanik-Van Leeuwen and C. S. Irving

A collaborative project with Drs. Nels Räihä, Helsinki, Gerald Gaull, New York Institute for Basic Research on Mental Retardation, and John Watkins, Harvard Children's Hospital, to evaluate the effect of synthetic diets on the growth and development of newborn infants is under way. The pool sizes and fractional turnover rates of chenodeoxycholic and cholic acids are being determined in infants during the first week of life and again after 2 to 3 weeks on a prescribed feeding regime. A total of 20 infants will be studied: 5 on pooled mothers' milk, 5 on a synthetic $60: 40$ whey:casein diet, 5 on the synthetic diet plus taurine, and 5 on the synthetic diet supplemented with taurine plus cholesterol. Because taurine is essential for infant development, this study will seek to determine whether differences in development can be detected between groups fed mothers' milk and synthetic formulas and, secondly, whether taurine and/or taurine plus cholesterol affect the synthesis and interluminal concentration of bile acids.

\section{METHADONE STUDIES}

D. L. Hachey and K. Nakamura ${ }^{1}$

Methadone pharmacokinetic studies are continuing in collaboration with Dr. Mary Jeanne Kreek at Rockefeller University. We have completed our single isotope studies of urinary excretion of $\mathrm{R}-(-)$ and $\mathrm{S}-(+)$-methadone. We have begun concentrating our efforts on plasma drug level pharmacokinetics using multiple isotopic tracers. Such studies have been hindered in the past because of contamination that interfered with isotope ratio analysis. The problem has been largely overcome and samples are being prepared for analysis. We have completed one multiple isotope study. Cumulative urinary drug excretion data and rate data are consistent with our earlier finding that the two enantiomers of methadone are metabolized differently. It appears that

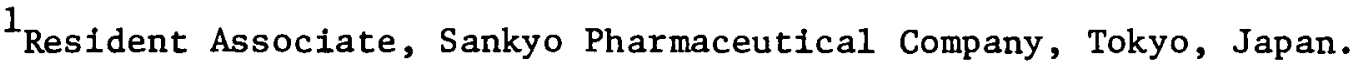


isotope ratfo data provide a much more consistent indication of the drug metabolism than does measurement of the amount of drug excreted or measurement of plasma drug levels.

BREATH TESTS AND FECAL COMBUSTION STUDIES

P. D. Klein and D. A. Schoeller ${ }^{1}$

Evaluation of three ${ }^{13} \mathrm{Co}$ breath tests employing ${ }^{13} \mathrm{C}$-labeled fats have been completed in collaboration with Dr. John Watkins and Dr. Barbara Kirschner (The University of Chicago). $13 \mathrm{C}$-labeled.triolein, trioctanoin, and palmttic acid were given on successive days tn 6 shildren with an intestinal mucosal disorder, 5 with an intraluminal phase disorder, 5 with a pancreatic disorder, and 4 normal children. The triolein brcath test clearly identified the 16 abnormals, demonstrating it to be a superior screening test for fat malabsorption. The palmitic acid breath test, in combination with the triolein breath test, was specific for pancreatic disorders and may be a noninvasive alternative to the pancreatic stimulation test which requires intubation. The trioctanoin breath test was the least specific, giving poor separation of children with mucosal or intraluminal disorders from normals.

A 2-year longitudinal study of liver function in patients after jejunal/ ileal bypass surgery for the treatment of morbid obesity has begun in colla-. boration with Drs. John Schnelder and Alfred Baker (The University of Chicago). The aminopyrine breath test will be performed along with the standard liver function tests before and at $3,6,12,18$, and 24 months after bypass surgery. Fifteen subjects have entered the protocol. of these, one has developed hepatic complications that occur in about $10 \%$ of bypass patients. The presurgery aminopyrine breath test of the subject who devel- . oped hepatic complications was lower than the 14 who did not, and breath tests showed a further loss of liver function before the other liver tests indicated hepatic complication. Further subjects will be included in the protocol to see whether the breath test continues to identify those subjects at risk.

A fecal assay for the detection of unabsorbed bile acids has been developed and applied to the detection of bile acid malabsorption in efght children in collaboration with Dr. John Watkins. Feces are lyophilized and combusted to $\mathrm{CO}_{2}$, and the excess ${ }^{13} \mathrm{C}$ from the labeled bile arid is detected by tsotope ratio analysis. The test can detect less than $1 \%$ bile acid malabsorption. The fecal test is used in conjunction with a breath ${ }^{13} \mathrm{CO}_{2}$ test to detect intestinal bile acid deconjugation. Nefther the breath test nor fecal test. alone can be used for the diagnosis of intestinal bile salt disorders.

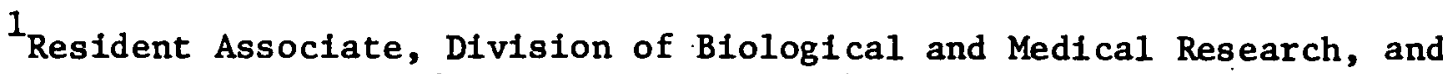
Research Associate (Assistant Professor), The University of Chicago. 


\title{
INFORMATION DISSEMINATION AND TRAINING
}

\author{
P. D. Kleln, E. R. Klein, ${ }^{1}$ D. A. Schoeller, ${ }^{2}$ and D. L. Hachey
}

The Third International Conference on Stable Isotopes was held May 2326, 1978 at Oak Brook, Illinois. There was a total of 190 attendees representing industry and academic institutions from the United States and many European countries, including East Germany, as well as Japan and Australia. Of the 37 attendees representing industry, 10 were exhibitors; of the 153 attendees representing academic institutions, 20 were graduate students whose attendance was supported by a generous grant from the Argonne Universities Association. Seventy papers were given during the conference which dealt with environmental, clinical, pharmacological, biochemical, and methodological applications of stable isotopes. A poster session was held covering the same general range of topics. The editing of the papers presented is nearing completion, and the papers will be published by Academic Press as "Stable Isotopes: Proceedings of the Third International Conference." The publication will appear in 1979.

There appears to be a demand for an update of the selected bibliographies of blomedical and environmental applications of $2_{\mathrm{H}}, 13_{\mathrm{C}}, 15_{\mathrm{N}}, 17_{0}, 18_{0}$, and $34 \mathrm{~S}$. The data base used previously and the response from readers indicate that every 2 years there is an increase of $50 \%$ in the numbers of publications dealing with stable isotopes. This number may be even greater for papers dealing with multiple isotope usage in environmental applications. Our update will emphasize the increase in environmental applications and will cover 1976-1978. As before, the references will be indexed by author and subject to increase utility.

Ms. Makiko Suehiro, of the Tokyo Metropolitan Geriatric Hospital, Department of Nuclear Medicine, completed her year as a Visiting Scientist and has returned to establish a Laboratory of Stable Isotopes. We are continuing to maintain advisory liaison in the selection and installation of isotope ratio equipment. Two Visiting Scientists are spending FY 1979 at the Argonne Bioanalytical Center, under the sponsorship of their home institutions, to obtain training and experience in the application of stable isotopes and GC-MS to clinical and biochemical problems. These individuals are Dr. Kanichi Nakamura from Sankyo Pharmaceutical Company, Tokyo, Japan, and Dr. Jean-Claude Blais from the Institut du Radium, Paris, France. Continued exchange with the Japan Stable Isotope Committee and with the Japanese Society for Medical Mass Spectrometry was fostered by their sponsorship of a tour by Peter Klein during November, 1978.

${ }^{1}$ Resident Associate, Division of Biological and Medical Research.

${ }^{2}$ Resident Associate, Division of Biological and Medical Research, and Research Associate (Assistant Professor), The University of Chicago. 
THIS PAGE

\section{WAS INTENTIONALLY \\ LEFT BLANK}


19. SUPPORT FACILITIES

\section{ANIMAL FACILITIES}

James G. Linsley, Thomas E. Fritz, Patricia C. Brennan, William G. Keenan, Calvin M. Poole, Richard C. Simkins, and David V. Tolle

James G. Linsley assumed the operational responsibilities of the Animal Facilities when he joined the Division as Manager of Animal Facilities on June 1, 1978. Dr. T. E. Fritz returned to ful1-time research, but remains as Chairman of Animal Health and Clinical Services Committee.

The Laboratory Animal Facilities, including the central area in Building 202 and the satellite facility specifically utilized for viral oncology in Building 340 , comprise approximately $33.8 \%(39,532$ square feet $)$ of the total usable space in the Division.

The closed breeding colony of beagles utilizes 9,630 square feet. Six kennels contain 380 runs and housed an average of 750 dogs in 1978. Each run consists of a heated indoor compartment plus an outdoor exercise area. Technical equipment area allocated for the support of the dog programs occupies another 8,230 square feet. This includes three ganma exposure rooms, two dog treatment rooms, an operating room, necropsy room, and X-ray room. "The remaining 45\% (17,860 square feet) of the Animal Facilities consists of 47 animal rooms and rooms for cage and bottle washing, sterilization, and injection of radioactive materials. Each of the animal rooms is capable of holding laboratory animals under controlled conditions of temperature, humidity, and lighting.

During 1978, approximately 26 staff members of the Division were involved in various studies utilizing in excess of 30,000 rodents and other laboratory animal species.

The supporting facilities for the husbandry and clinical monitoring of the resident animals and the responsible personnel include:

1) Automated cage and bottle washing and filling machinery (Animal Care Specialists)

2) Steam and gas autoclaves for sterilization of equipment, instruments, and media

3) Diagnostic X-ray facilities and darkrooms (C. M. Poole, W. G. Keenan)

4) Clincial pathology laboratory (D. V. To1le, R. C. Simkins) 
5) Hematology Laboratory (D. V. Tolle)

6) Diagnostic microbiology laboratory (R. C. Simkins, P. C. Brennan)

7) Necropsy laboratory (T. E. Fritz)

8) Surgical suite with inhalation anesthesiology equipment (C. M. Poole, W. G. Keenan)

9) Gnotobiotic isolators for germ-free technology (J. G. Linsley, L. 0. Bibbs)

Funds have been allocated for the renovation and modernization of the kennels, the engineering and design work has been completed, and work is scheduled to begin in the spring of 1979. The renovations will remove the fiberglass tub liners and provide new run dividers, gutters, doors, and gates. The design of the new dividers and gates will enable use of aulullaled ileaning equipment and will result in more efficient cleaning procedures and better sanitation. In addition, renovations to $\mathrm{E}$ wing have been largely completed and this new facility will be reoccupied early in the next year. This facility includes 26 animal holding and breeding rooms for rodents and other small laboratory animals. The renovations included entirely new light, heating, cooling, and humidity control and air filtration equipment.

An important aspect of the success of any animal research program is the health of its animal population. To assure a supply of acceptable high quality animals, the Facility has concentrated on breeding its own healthy, disease-free animals. Most of the rodents, particularly mice, and all dogs are bred in the Facility. The rodenl bieedlig is managed by LeRoy 0 . Bibbs and Jane M. Angerman. The beagle breeding is supervised by Calvin M. Poole and William G. Keenan, who are also responsible for the clinical and surgtcal care of the dogs. The beagle colony has been a closed colony for more than 19 years, and extensive computerized records are maintained on all aspects of the colony, Including reproduction, genetics, hematology, pathology, and disease Incidence.

As important as the physical plant and its support facilities are the staff available to manage, monitor, treat, and evaluate the animals. The personnel provide a complete range of services to users of the experimental animals. Care of the animals is performed by a group of Animal Care Specialists, listed below, under the supervision of Durward D. Banister and William H. Hart.

The Animal Care Specialists during 1978 were the following:

Earl R. Allen

Roberta R. Buller

Mose Burrel1

Car1 C. Colegrove ${ }^{1}$

Claude C. Colegrove ${ }^{1}$

${ }^{1}$ Group Leader 
Lucille E. Daley

Leo C. Farcus ${ }^{1}$

Charles J. Fowler

Carrey R. Herringer

Edward W. Jackson 1

James L. Johns

William G. McDade, Jr. ${ }^{1}$

Ann L. Mize

Kenneth R. Muller

Cathleen. L. Nelson

William 0. Robinette

Bernard A. Royer

Richard M. Santarelli

Susan L. Santarelli

Leon L. Stewart

Diane M. Thomas

Rudolph H. Tiedt

Joseph N. Wilson

COMPUTER SUPPORT FACILITIES

Frank S. Williamson, Jeanne A. Blomquist, and Carol A. Fox

Computer support is centered on the Remote Access Data Station (RADS), which is equipped with a $10001 \mathrm{pm}$ printer, $1000 \mathrm{cpm}$ reader, and a $300 \mathrm{cps}$ paper tape reader with 500-foot spools. The RADS is located in a data preparation room.with four 029 key punches (two of which interpret), a storage vault for archival magnetic tapes, card files, and a $30 \mathrm{cps}$ interactive terminal principally used for job inquiry and routing. An adjacent room provides work space for users, with a documentation library and a consultant's office, plus file storage for programs and their documentations.

Approximately 50 users in the Division continue to depend on these facil1ties and the consultation on job management, programing, and data management that we provide.

\section{ELECTRON MICROSCOPE CENTER}

Thomas M. Seed and G. Theodore Chubb

The facility has approximately 2,600 square feet of working laboratory space, and includes two fully equipped photographic darkrooms, sectioning and autoradiographic facilities, six microscope cubicles, and five transmission 
electron microscopes and one Cambridge scanning electron microscope equipped with an X-ray energy dispersive analytical system. Ancillary specimen preparative equipment includes vacuum evaporators, freeze-drying and freeze-etching equipment, ultramicrotomes, and assorted photographic and light microscopic equipment.

The Electron Microscope Center and 1 ts personnel provide specialized electron microscope services to both, the Division and the Laboratory as a whole. G. T. Chubb continues to maintain EM-related equipment and to provide needed technical assistance to all users of the Center. Active collaborative interaction between the Center and various Divisional research groups continues (e.g., the Cellular Indicators Program; see Section 3). Ultrastructural data were presented at various local, national, and international meetings (e.g., 9th International Congress for Electron Microscopy, Toronto, Canada, 1978). In addition, the Center has, through the active support of Argonne's Center for Educational Affairs and with Western Michigan University, established à technical training program for postgraduate individuals interested in pursuing a career in electron microscopy.

During 1978 there were some 25 researchers who made active use of the available facilities. They included 11 regular staff members, 2 postdoctoral appointees, 3 graduate students, and 4 visiting scientists. The remainder of the users were from other Argonne divisions, including Radiological and Environmental Research, Environmental Impact Studies, Chemistry, Physics, and Solid State Science. 
20. EDUCATIONAL ACTIVITIES

\section{POSTGRADUATE TRAINING}

During 1978, a total of 32 postdoctoral appointees and research assoclates contributed to the research programs of the Division. Fifteen of these were new appointments in 1978, one less than the number who finished their assignments during the year.

The temporary appointees, their schools, and the staff members with whom they were affiliated were as follows:
N. Leigh Anderson ${ }^{1}$
Cambridge University, England
Nadine N. Beales
University of Illinois at the Medical Center
Laszlo Bodoni
Donna M. Buchholz
Loyola University, Chicago
University of Illinois at the Medical Center
Anne L. Cahill
University of Michigan, Ann Arbor
Bruce R. DeMark .$^{-i}$
Jesse J. Edwards
Karen B. Ekelman
Michae1 E. Ginevan.
Michael N. Gould
Viola M. Griego
Wayne R. Hanson
Nelson D. Horseman
University of Southern. California
University of Alabama, Birmingham
Ohio State University
University of Kansas
University of Wisconsin, Madison
Washington State University
University of Iowa
D. Grahn
Louisiana State University, Baton Rouge
Charles S. Irving
Fredertck R, Kirchner
Weizmann Institute, Israel
University of Iowa
University of Cincinnat.i
George $\bar{R}$. Lankas
Chung Hee Ryu Lee ${ }^{2}$
University of Illinois, Urbana
C. Peraino
C. A. Reilly
T. M. Seed
C. F. Ehret
P. D. Klein
N. G. Anderson
C. Peraino
D. Grahn
M. M. Elkind
R. B. Webb
C. A. Reilly
C. F. Ehret
P. D. Klein
P. C. Brennan
M. M. Elkind
D. Grahn

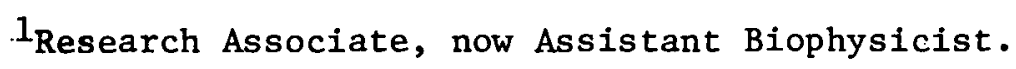
${ }^{2}$ Research Associate. 
Joel R.. M1tchen ${ }^{1}$

Chester N. Newman

Hsien-Chi Niu

Kanaiyalal R. Patel

Meyrick J. Peak ${ }^{1}$

Pepi Ross-Riveros

Eung K. Ryu

Herbert M. Schwartz

Carol F. Smith

Elsie M. Sorensen

Frans Ste1laard ${ }^{1}$

Fred J. Stevens

Ravindra Tewar1

Kou-Y1 Tserng

Hiroshi Utsumi
Life Sclences, Incorporated, St. Petersburg

Indiana University Medical Center, Indianapolis

University of Missouri, Kansas City

University of South Dakota

Rhodes University, South Africa

University of California, Berkeley

Michigan Cancer Foundation, Detroit

Brandeis University

University of Illinois at the Medical Center

University of 'lexas, Austin

Untversity of Technology,

The Netherlands

Michigan State University, East Lansing

Tata Institute of Fundamental Research, Bombay, India

Untversity of Michigan

Kyoto University, Japan
C. A. $\operatorname{Re} 111 \mathrm{y}$

H. E. Kubits chek

P. D. Kleln

Y. E. Rahman

H. E. Kubits chek

M. M. Elkind

M. Mac Coss

S. S. Danyluk

N. G. Anderson

A. Lindenbaum

P. D. Klein

M. Schiffer

S. S. Danyluk

P. D. Klein

M. M. Elkind

In addition, there were nine Faculty Research Participation appointments, supported by the Argonne Center for Educational Affalrs (CEA) and four VisitIng Scientists; these appointments enable college and university faculty members to participate in the research activities of the Laboratory in order to broaden their perspectives for teaching and research on their home campuses. The names of the Faculty Research Participants and Visiting Scientists during 1978, their schools, and their staff sponsors were as follows:

Jay B. Best

Fredertc A. Giere

Ronald D. Humphrey

Margaret M. Jonah

Ellen H. Lau

Eugene W. McArdle

John P. Neenan

Daniel G. Oldfield

Nicolas Panagiotopoulos 2

Ramaswamy H. Sarma ${ }^{2}$

John R. Seed ${ }^{2}$
Colorado State University

Lake Forest College

Prairie View A\&M University

Rosary College

College of DuPage

Northeastern Illinois . University

Illinois Benedictine College

Depaul University

Nuclear Research Center, Athens, Greece

State University of New York at Albany

Texas A\&M University
G. A. Sacher

N. G. Anderson

C. A. Reil1y

Y. E. Rahman

Y. E. Rahman

C. F. Ehret

M. MacCoss

T. M. Seed

M. Suhiffer

S. S. Danyluk.

T. M. Seed

$1_{\text {Research Assoclate. }}$

2visiting Scientist. 
S. Peter Spragg ${ }^{1}$

Timothy A. Stabler
University of Birmingham, Birmingilam, England

Indiana University Northwest, Gary
N. G. Anderson

M. M. Elkind

\section{SUMMER RESEARCH INSTITUTE IN CELL BIOLOGY}

Eleven students from nine different universities were enrolled during the Summer of 1978 in this graduate level program offered by the Division of Biological and Medical Research in cooperation with the Argonne Center for Educational Affairs. Dr. Mortimer M. Elkind served as organizer and coordinator, with the assistance of M. McCoy. The program, which ran for 12 weeks, featured a lecture series covering a variety of topics, including lethality and mutagenesis, DNA repair, neoplastic transformation, radiation and the cardiovascular and hematopoietic systems, responses to effluents of coal combustion, metabolism of chemical carcinogens, and mechanisms of therapy of metal poisoning. The lectures were given by Drs. M. H. Bhattacharyya, P. C. Brennan, E. Chan, A. Han, D. A. Haugen, T. Matsushita, Y. E. Rahman, C. A. Reilly, T. M. Seed, S. P. Stearner, and R. B. Webb.

The lectures were supplemented by informal discussions and visits to laboratories as appropriate. Each student spent the remainder of his time working in a laboratory of a staff member.

The students, their schools, and their staff sponsors were as follows:

\section{Barbara A. Amsler}

Terry M. Bricker

Mary A. Gabriel

James Hardwick

Louis M. Lissuzzo

Dawn Palter

Terry Riss

Kevin Rupprecht

E11en Saltz

David Simpson

Albert Sorrell

\author{
University of Wisconsin, \\ Milwaukee \\ Miami University \\ University of Dallas \\ Illinois State University \\ Loyola University, Chicago \\ University of Texas, Austin \\ Illinois State University \\ University of Notre Dame \\ University of Wisconsin, \\ Whitewater \\ University of Illinois, \\ Urbana \\ State University of New York \\ at Plattsburgh
}

C. A. Reilly

Y. E. Rahman

T. E. Fritz

D. A. Haugen

P. C. Brennan

T. M. Seed

S. P. Stearner

E. Chan

M. Bhat tacharyya

A. Han

T. Matsushita

\section{OTHER GRADUATE PROGRAMS}

Four graduate students were Laboratory Graduate Participants working in the Division on research for their $\mathrm{PhD}$ degrees in a program administered and supported by the Center for Educational Affairs. The Laboratory Graduate Participants, their schools, and their staff sponsors were as follows:

$I_{\text {Visiting Scientist. }}$ 
Thomas H. Cunningham

Steven H. Gray

Michael P. Hagan

Bruce Hammer
University of Illinols at
the Medical Center

Univers1ty of Illinois at the Medical Center

University of Illinois, Urbana

Northwestern University
D. Grahn

M. MacCoss

M. M. Elkind

S. S. Danyluk

A related program, called Thesis Parts, is supported by the Center for Educational Affairs. It enables graduate students to perform pertinent parts of their research at Argonne. In 1978, two students held such appointments in the Division:

Dawn Palter.

Roger G. Ulrich
University of Texas, Austin

Western Michigan University
T. M. Seed

T. M. Seed

In addition, six graduate students carried out research in the Division as Kesident Student Assóciatès, sup̈ported directly by the ilvision unless otherwise noted.

Michael D. Brown ${ }^{1}$

James J. Collins Hyojoon Hahn ${ }^{2}$

Paul Maffuid

W11liam Obermeyer

Karen E. Willard

\author{
University of Illinois at \\ the Medical Center \\ Universtty of Illinois, Urbana \\ Medical University of South \\ Carolina \\ St. Michael's College \\ University of Chicago \\ Virginia Polytechnic Institute \\ and State University
}

T. E. Fritz

D. Grahn

N. G. Anderson

S. S. Danyluk

G. A. Sacher

T. E. O'Connor/

N. G. Anderson

\section{UNDERGRADUATE TRAINING}

During 1978, a total of 37 college undergraduates recelved training in the Division of Blological and Medical Research through the CEA-sponsored Spring, Summer, and Fall Undergraduate Research Participation Programs. The students, their schools, and their staff supervisors are 11sted below:

BPRING PROGRAM

John X. Fritz

Mary A. Gabriel

Alan H. Gorri

Jennie R. Hahn

Jeffrey Holmgren

Jônn : Johnston

Cregory Leo

Tamf Levitt

Elalne M. Mader

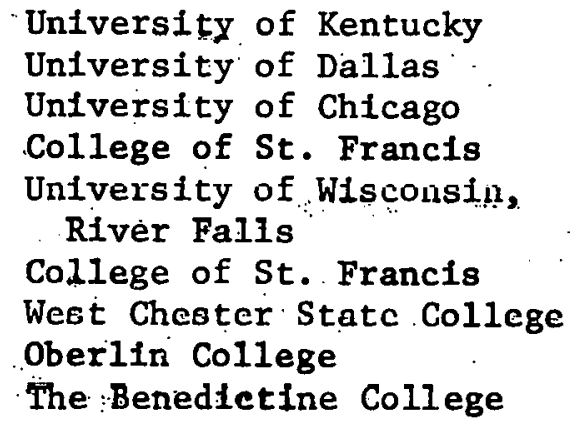

University of Kentucky

UnIversity of Dallas

Untversity of Chicago

College of St. Francis

University of Wisconsin,

River Falls

College of St. Francis

West Chester Statc College

Oberlin College

The Benedictine College

B. S. Hass

T. E. Fritz

P. D. Klein

B. S. Hass

B. 3. Hass

D. L. Hachey

M. MacCoss

C. F. Ehret

B. S. Hass

${ }^{1}$ Sponsored by the Argonne Affirmative Action Program.

2 Sponsored by Abbott Laboratories. 
Martha J. Monnett

Maureen Schilb

Marcia L. Zucker

Lisa Antonelli

Helen C. Burke Gary Duckwiler John M: Fritz Jerald Hendrix Steven Holland Jeffrey Holmgren

Robert Killeen .,

Sunny Kim Lai-Yet Lam Tami A. Levitt Edward Lewandowski Doriane C. Miller

James R. Milstead Kimberly Nortridge Rachel Pocinki Anita Rae L1nda Ross

Michae1 Skinner

Richard S. Skyer

Aurelia V. Smith

Paul Underwood Luz Venta Craig Zabel

Wende11 Bauman Emily Brooks Robert Last Randall Updegrove
University of North Carolina at Greensboro

College of St. Francis

Rensselaer Polytechnic Institute

SUMMER PROGRAM

\section{Southeastern Massachusetts University \\ University of San Diego \\ Claremont Men's College \\ University of Kentucky \\ Shorter College}

St. John's College, Annapolis

University of Wisconsin, River Falls

Northern Illinois University

Northwestern University

Dickinson College

Oberlin College

University of Chicago

Illinois Institute of Technology

Southern Illinois University

Northern Illinois University

Swarthmore College

University of Portland

Rochester Institute of Technology

Georgla Institute of Technology

Rochester Institute of Technology

Mississippi Valley State University

Morehouse College

Northwestern University

Northern Illinois University

FALL PROGRAM

Nebraska Wesleyan University Harding College

Ohio Wesleyan University

University of. Rhode Island
B. S. Hass

P. D. Klein

C. A. Reilly
C. F. Ehret

C. F. Ehret

M. MacCoss

B. S. Hass

M. Schiffer

T. E. O'Connor

B. S. Hass

C. F. Ehret

S. S. Danyluk

T. M. Seed

C. F. Ehret

T. E. Fritz

T. E. O'Connor

D. A. Haugen

M. P. Finkel

C. F. Ehret

C. A. Reilly

N. G. Anderson

G. A. Sacher

S. P. Stearner

M. M. E1kind

C. Peraino

H. E. Kubitschek

Y. E. Rahman
D. A. Haugen

B. S. Hass

M. MacCoss

C. A. Reilly

\section{JOINT ARGONNE-UNIVERSITY APPOINTMENTS}

During 1978, 19 staff members held a total of 28 faculty appointments at universities in the Chicago area. These appointments usually comprise limited teaching activities at the graduate level, generally of a specialized nature, 
which involve regular contact with students. They have led to cosponsorship of graduate students and to collaborative research efforts with faculty members, some of which are described in this report.

The affiliations with Chicago area universities were as follows:

\author{
University of Chicago \\ Mortimer M. Elkind \\ Timothy E. O'Connor \\ Robert N. Feinstein \\ George A. Sacher \\ David. L. Hachey \\ Warren K. Sinclair \\ Peter D. Klein \\ Patricia Szczepanik-Van Leeuwen \\ University of Illinois at Chicago Circle \\ Douglas Grahn \\ Herbert E. Kubitschek \\ Warreu K. Olinlatr \\ Car1 Peralno \\ John F. Thoms on
}

Loyola University

Thomas E. Fritz

Arthur Lindenbaum

Northern I1linols University

Maryka H. Bhattacharyya

Yueh-Erh Rahman

Thomas E. Fritz

Christopher A. Reilly, Jr.

Douglas Grahn

Warren K. Sinclair

Herbert E. Kubitschek

. Car1 Pera1no

John F. Thoms on

Robert B. Webb

Northwestern University School of Medicine

Peter D. Klein

University of Health Sciences/Chicago Medical School

Antun Han

University of Illinois at the Medical benter

Steven S. Danyluk 
21. DIVISIONAL SEMINARS DURING 1978

During the first half of 1978; the Division of Biological and Medical Research Seminar Committee consisted of M. H. Bhattacharyya, D. L. Hachey, A. Han, M: MacCoss, D. V. Tolle, and T. M. Seed, Chairman. For the 1978-1979 seminars, the Committee consisted of L. S. Lombard, R. T. Lundy, C. Peraino, T. M. Seed, M. MacCoss, Vice Chairman, and A. Han, Chairman.

In addition to the regular Thursday afternoon seminars by Argonne and visiting scientists, the 1977-1978 Committee initiated a Distinguished ANL Scientist Lecture Series in which Argonne researchers who have made important scientific contributions over the years in their respective fields of biology were invited to address the Divisional staff and the Laboratory at 1 arge to review the evolution in their fields, the speaker's own contributions, and their speculations on the future of their areas. The first speaker in the series was Joseph J. Katz, Chemistry Division, who spoke on September 29, 1977, on "Chlorophyll Function in Photosynthesis." In 1978, the second lecture in the series was given by George A. Sacher on March 9, and was entitled "Energy and Life: The Relation of Longevity to Metabolic Rate and Body Size in Mice." The third. was presented by Miriam P. Finkel on June 29, and was entitled "Experimental Induction of Bone Tumors."

The Seminar Program for 1978, selected by the Committee on the basis of recommendations from the staff, was as follows:

Dr. Thomas M. Seed, Division of Biological and Medical Research, Argonne National Laboratory

"Hemopathological Consequences of Protracted Gamma Irradiation: Preclinical Phases of Leukemia Induction"

January 3,1978

Dr. Gerald C. Mueller, McArdle Laboratory for Cancer Research, Madison "DNA and Chromatin Replication--Possible Coupling in. Cell Differentiation" January 5, 1978

Dr. D, Fleming, At lantic Richfield Company, Harvey, IL

"Energy for the Future--A Research Appraisal"

January 10,1978 
Dr. Gordon Niswender, Colorado State University, Fort Collins

"Endocrine Regulation of Ovarian Function" January 12,1978

Dr. Wayne R. Hanson, Division of Biological and Medical Research, Argonne National Laboratory

"Effects of High Specific Activity ${ }^{3}$ HTdR and Hydroxyurea in Combination with Colcemid and Radiation on Intestinal Stem Cells" January 17,1978

Dr. Garth Nicolson, University of California, Irvine

"Cellular Interactions during Blood-borne Tumor Metastasis" January 19,1978

Dr. Robert B. Webb, Division of Biological and Medical Research, Argonne National Laboratory

"Lethal and Mutagenic Effects of Solar Ultraviolet Radiation" January 31,1978

Dr. Alphonse E. Sirica, University of Wisconsin, Madison

"Primary Cultures of Adult Rat Hepatocytes on Floating Nylon Meshes Coated with a Thin Collagen Matrix: Expression of Fetal Liver Cell Properties"

February 2, 1978

Drs. Christopher A. Reilly, Jr., Miriam P. Finkel, and Emerson Chan, Division of Biological and Medical Research, Argonne National Laboratory

"Role of Retroviruses in Radiation Tumorigenesis" February 7, 1978

Dr. Alan Jeffrey, Columbia University

"Benzo(a)pyrene Nucleic Acid Interactions" February 9, 1978

Dr. Kenneth Wilzbach, Chemistry Division, Argonne National Laboratory

"Environmental Control Technology--Power Generation Program" February 14, 1978

Prof. Arthur D. Broom, University of Utah "Polyribonucleotides Containing Thiopurines: Synthesis, Characterization, and Biological Activity"

February 16, 1978

Drs. Dale A. Schoeller, David L. Hachey, Kou-Yi Tserng, and Peter D. Klein, Division of Biological and Medical Research, Argonne National Laboratory

"Being Useful to Clinicians: Methods in Our Madness" February 21, 1978

Dr. P. Nelson, Chemical Engineering Division, Argonne National Laboratory

"The Future of Electric Vehicles"

February 28, 1978 
Dr. James N. Ihle, Frederick Cancer Research Center, Maryland

"The Role of C-Type Virus in Murine Leukemias"

March 2, 1978 ,

Drs. David A. Haugen and Carl Peraino, Division of Biological and Medical Rescarch, Argonne National Laboratory

"Carcinogens: Identification and Mechanisms of Action (A Report of the

31 st Annual M. D. Anderson Hospital Symposium)"

March 7, 1978

Mr. George A. Sacher, Division of Biological and Medical Research, Argonne Naţional Laboratory

"Energy and Life: The Relation of Longevity to Metabolic Rate and Body

Size in Mice"

March 9, 1978

Dr. R. G. Matlock, Office of the Director, Argonne National Laboratory

"ANL Solar Programs"

March 14, 1978

Prof. Elwood v. Jensen, "Ben May Laboratory, Chicago

"Hormone Dependency in Mammalian Tissues and Tumors"

March 16, 1978

Dr. Michael J. Dewey, The Institute for Cancer Research, Philadelphia

"Mosaic Mice Produced from Mutant Teratocarcinoma. Cells"

March 23; 1978

Dr. Peter C. Uden, University of Massachusetts, Amherst

"Modern Peak Identification Methods. for Gas and High Pressure Liquid. Chromatography"

March 30,1978

Dr. Malcolm MacCoss, Mr. Paul Maffuid, and Dr. Ravindra Tewari, Division of Biological and Medical Research, Argonne National Laboratory

"Aspects of Molecular Studies Research".

April 4, 1978

$\mathrm{Dr}$. Janardeen K. Reddy, Northwestern University

"Hepatic Peroxisome Proliferation: Role in the Development of Hypolipidemia, Hepatomegaly, and Hepatocellular Carcinoma" Apri1 6, 1978

Mr. Michael P. Hagan, Division of Biological and Medical Research, Argonne National Laboratory

"Near-Ultraviolet Light Effects on Chinese Hamster Cells Pulse-Labeled

with Broundeuxyuridine"

Apri1 11, 1978

Dr. Gary Van Zant, University of Chiçago

"Regulation of Erythroid Differentiation"

Apri1 12, 1978 
Dr. G. T. Kartsounes, Energy And Environmental Systems Division, Argonne National Laboratory

"Mechanical Energy Storage: Compressed Air and Underground Pumped Hydro" April 18, 1978

Prof. Hector Deluca, University of Wisconsin, Madison

"New Developments in the Metabolism and Function of Vitamin D" April 24, 1978

Dr. Robert T. Lundy, Division of Biological and Medical Research, Argonne National Laboratory

"Modelling the Effects of Energy-Related Effluents on Human Health or Is

Coal Addictive?"

Apri1 25, 1978

Dr. William Campbell, Mayo Clinic

"Isolation and Characterization of a Variant Primate Retrovirus" Apri1 27; 1978

Dr. C. C. Baker, Energy and Environmental Technology Division, Argonne National

Laboratory

"Argonne's Fusion Power Program"

May 2, 1978

Dr. Pamela McAthey, University of Edinburgh, Scotland

"Mutation Studies on Continuous Cultures of the Fission Yeast, Schizosaccharomyces pombe"

May $4, \frac{1978}{197}$

Dr. James Rodgers, Tufts University Medical School

"Physical Considerations for Localised Hyperthermia with RF Electric Currents"

May 8, 1978 (joint seminar with Radiological and Environmental

Research Division)

Dr. Siegmund J. Baum, Defense Nuclear Agency, Bethesda

"Regulation of Hematopoiesis, in Vitro"

May 11, 1978

Dr. Lawrence E. Scheving, University of Arkansas Medical Center

"Chronobiology and Its Applications in Experimental Cancer Chemotherapy" May 18,1978

Dr. Jay B. Best, Colorado State University

"Modeling Radiation Responses"

May 24, 1978

Dr. Ruth Ben Ishei, Rutgers University

"DNA Repair in Isolated Human Cel1 Nuclei"

May 25, 1978 
Dr. R. Schoenborn, Brookhaven National Laboratory

"Low Angle Neutron Scattering of Biological Molecules"

May 26, 1978

Dr. Ronald E. Davies, Temple University School of Medicine

"Biochemistry of Hydrocarbons and Carcinogenic Effects" June 1,1978

Dr. Eliezer Huberman, Oak Ridge Național Laboratory

"Carcinogenesis, in Vitro"

June 8, 1978

Dr. David R. Woods, Rhodes University, South Afriça

"Regulation of Collagenase Production in Achromobacterer sp." June 15,1978

Dr. Miriam P. Finkel, Division of Biological and Medical Research, Argonne National Laboratory

"Experimental Induction of Bone Tumors"

June 29,1978

Dr. Johann Deisenhofer, Max-Planck Institut, Munich; West Germany

"Three Dimensional Structure of Immunoglobulins"

August 7,1978

Dr. G. Zaccai, Inștitute Max von Laue-Paul Langevin, Grenoble, France

"Applications of Neutrons to Biological Structure Problems". August 10, 1978

Dr. Theodor M. Fliedner, University of Ulm, West Germany

"Collection, Storage, and Use of Blood Derived Hemopoietic Ștem Cells for

Bone Marrow Reconstitution in Lethally. Irradiațed Beagles"

August $24,197.8$

Dr. R. K. Poole, University of London, Engl and

"Oscillatory Respiration During the Cell Cycle of Yeast in E. coli"

September 14,1978

Dr. Tatsuo Matsushita, Division of Biological and Medical Research, Argonne

National Laboatory

"DNA Repair and Sister Chromatid Exchanges in Mouse Myeloma Cells"

September 28,1978

Dr. Jung-Chung Lin, The University of North Carolina; Chapel Hill

"Biochemical Markers for Premalignant Hepatgcytes During Liver

Carcinogenesis"

Octuber 5, 1978

Prof. R. Schulte Hermann, University of Marburg, Lahn, Germany

"Effects of Mitogenic Agents and Nutrition on Growth Control in Normal and Preneoplastic Rat Liver"

October 12,1978 
Prof. M. Sundaralingam, University of Wisconsin, Madison

"Nucleotide Conformations and The ir Relationship to t-RNA Structures" October 19,1978

Dr. James I. Garrels, Cold Spring Harbor Laboratory, New York

"Differentiation of Culture Nerve and Muscle Cells: A Study by Quantitative Two-Dimensional Gel Electrophoresis"

November 2, 1978

Dr. Robert B. Painter, University of California, San Francisco

"Inhibition of DNA Replicon Initiation by Carcinogens"

November 9, 1978

Dr: Robert 0. Poyton, University of Connecticut, Farmington

"Mitochondrial Membrane Biogenesis: Co-ordination of Mitochondrial and Nucleo-Cytoplasmic Genetic Systems in the Assembly of Cytochrome $c$ Oxida"se"

November 16,1978

Dr. Maryka H. Bhattacharyya, Division of Biological and Medical Research, Argonne National Laboratory

"I. A Mechanism for the DTPA-Induced Removal of Hepatically Deposited Plutonium. "II. A Brief Perspective on the Battery Assessment Program" November 30,1978

Dr. Leo T. Furcht, University of Minnesota Medical School, Minneapolis

"Membrane Immuriocytochemical and Structural Changes in Cellular"Transformation and Differentiation"

December 7, 1978

Dr. Martin A. Hamilton; Montâna State University, Bozeman

"The Detection of Synergistic Effects in Carcinogenesis" December 14,1978

In addition; a number of informal seminars in specialized subjects were held during the year: The se included the following:

Dr. Robert w. Tuveson, Univererity of Illinois, Urbana

"Evidence for a Gene Controlling Black Light Independent of the recA Gene in the Strain of E. coli K12", January $11 ;=1978$

Dr. Laszlo Bodoni, Loyola University

"The Interactions of Thioxanthenones with DNA and Their Effects on Temp-

late Activity" January 20," 1978 
Dr. Nadine Beales, University of Illinois at the Medical Center, Chicago

"Transformation-Defective Viable Deletion Mutant of SV40"

February 16, 1978

Dr. Karen Ekelman, The Ohio State University

"The Effects of Benzo(a)pyrene and 7,12-Dimethylbenz(a)anthracene on

Human Fibroblasts in Vitro"

February $24, \overline{19} 7 \overline{8}$

Dr. Erik Boye, Norwegian Radium Hospital, Norway

"Repair of DNA Double-Strand Breaks in E. coli"

March 1, 1978

Dr. Gary Van Zant, University of Chicago

"Interactions of Erythropoietin with Responsive Stem Cells"

March 1, 1978

Dr. Curtis Graeber, Walter Reed Hospital

"Effects of Meal Timing on Human Circadian Rhythms"

March 27, 1978

Dr. Frederick R. Kirchner, University of Iowa

"Detection, Partial Characterization and Partial Purification of a Small

Intestinal Chalcone"

March 31, 1978

Dr. Melissa Woan, University of Illinois, Urbana

"Dose Dependent Activation of Cytotoxic Lymphocytes by Vaccinia Virus

Enhancers"

March 31, 1978

Dr. Robert M. Sklar, University of Chicago

"Linked Mutation Induction"

Aprị 4, 1978

Dr. Neena B. Schwartz, Northwestern University

"A New Non-Steroid Hormone from the Ovary: Folliculostatin" April 7, 1978

Dr. Nelson D. Horseman, Louisiana State University, Baton Rouge

"Temporal Hormone Synergisms: Consequences and Possible Mechanisms" Apri 1 3, 1978

Dr. Byung-Moo Soh, Illinois Institute of Technology

"Control of Glutamine Synthetase mRNA by Hydrocortisone during Embryonic Development of Chick Retina"

Apri1 28, 1978

Drs. James Lipscomb and Michael Pique, University of North Carolina, Chapel Hil1

"Computer Graphics and Crystallography"

May 1-3, 1978 
Ms . Viola Griego, Washington State University

"Properties of the Insecticidal Bacterium Bacillus thuringiensis" May 5, 1978

Dr. Kenneth P. Samue 1, Georgetown University

"DNA-Nickase Associated with Avian Myeloblastosis" May 19,1978

Dr. Charles Borso, Princeton University

"New Techniques in Structure Determination of Macromolecules Using X-Ray and Neutron Scattering"

May 31, 1978

Dr. Thomas W. Bednar, Michael Reese Medical Center, Chicago

"Chemical Carcinogenesis: A Peroxidative Activation Mechanism" June 15,1978

Dr. John W. Bornhoeft III, Loyola University Medical Center, Maywood

"Lytic Cycle Replicative Intermediates of Prophage P1 and P Dlac" June 28,1978

Dr. Ronald Watson, Purdue University

"The Secretory Immune System of the Dog" Juily 14,1978

Dr. Robert Heintz, State University of New York, Plațtsburgh

"Ribosomal GTP Hydrolysis"

August $\overline{14}, 1978$

Dr. Michael Rush, Florida State University, Tallahassee

"Inhibin--The Newest Gonadal Hormone"

Sept ember 20, 1978

Dr. Marius Teodorescu, University of Illinois Medical Center, Chicago

"Use of Bacteria for the Identification of Functionally Different Lympho-

cyte Subpopulations in Blood Smears"

Dec ember 12, 1978 
22. OUTSIDE TALKS BY DIVISIONAL STAFF DURING 1978

Anderson, N. G. "The Molecular Anatomy and Characterization of Tissue Proteins." Department of Human Oncology, Wisconsin $\mathrm{Cl}$ inical Cancer Center, University of Wisconsin, Madison, WI, January 17, 1978.

Anderson, N. L. "High Resolution 2-D Electrophoresis of Human Hair Follicles and Lymphocytes: Application to Genetic Screening." Joint Biophysical Society-American Physical Society Meeting, Washington, DC, March 27-30, 1978.

Bhattacharyya, M. H. "Plutonium Metabolism and Therapy." Department of Biological Sciences, Northern Illinois University, DeKalb, IL, March 2, 1978 .

Bhattacharyya, M. H. "Demonstration of a Direct Chelation Mechanism for DTPA-induced Excretion of Pu into Rat Bile." 26th Annual Radiation Research Society Meeting, Toronto, Canada, May 14-18, 1978.

Bhattacharyya, M. H. "Internal Emitters." Department of Biological Sciences, Northern Illinois. University, DeKalb, IL, November 6, 1978.

Brown, M. S. "Action Spectrum for the Induction of Photoreactivable Events in a Double Mutant of Escherichia coli K12." 78th Annual Meeting of the American Society for Microbiology, Las Vegas, NV, May 14-19, 1978.

Brown, M. S. "Action Spectrum for the Protection Against Far-Ultraviolet Lethality by Quinacrine." 78 th Annual Meeting of the American Society for Microbiology, Las Vegas, NV, Máy 14-19, 1978.

Buchholz, D. M. "Early Lymphocyte Responses in Radiation-induced Canine Leukemia." Mid-West Aut umn Immunology Conference, Detroit, MI, November $6-7,1978$.

Chan," E. W. "The Search for Onco-RNA-Viruses." Northwest Center for Medical Education, Indiana University School of Medicine, Gary, IN, February 3, 1978.

Chan, E. W. "The Search for Onco-RNA-Viruses." Cancer Research.Laboratory, University of Western Ontario, London, Ontario, Canada, February 21, 1978.

Curtiss, J. R."B. "Methodology for the Assessment of Human Health Effects from the Coal Fuel Cycle." Seminar, Department" of Energy Staff, Washington, DC, June 19, 1978 . 
Danyluk, S. S. "Conformational Properties of Nucleic Acids in Solution: A Reexamination of Glycosyl Torsion Angles." Biomolecular Symposium, Madras, India, December 30, 1977.

Danyluk, S. S. "Applications of Nuclear Magnetic Resonance Spectroscopy in Biological Structure Determinations." Madras Winter School, Madras, India, January 2, 1978.

Danyluk, S. S. "Conformational Analysis of Oligonucleotide Structures." State University of New York, Albany, NY, February 23, 1978.

Danyluk, S. S. "Investigation of Glycosyl Torsion Angles in Model Pyrimidine Nucleosides: Variation in Spin-Lattice Relaxation Times." Joint Biophysical Society-American Physical Society Meeting, Washington, DC, March $27-30,1978$.

Danyluk, S. S. "Methylation Effects on Nucleic Acid Conformations." 11 th Jerusalem Symposium, Tel Aviv, Israel, March 31, 1978.

Danyluk, S. S. "Aspects of Nucleic Acid Conformations." Centre d'Etude Nucleaires de Saclay, Gif-sur-Yvette, France, March 31-April 14, 1978. (Al so included in this trip were seminars in Israel and England).

Danyluk, S. S. "Conformational Studies of Oligonucleotides in Solution." 61 st Canadian Chemical Conference and Exhibition, Winnipeg, Manitoba, Can ada, June 4-7, 1978.

Dixon-Davis, D. "Standardization of Mortality for Variation in Socioeconomic Status." 1lth Annual Meeting of the Society tor Épidemiological Research, Iowa City, IA, June 14-16, 1978.

Edwards, J. J. "Mapping of Human Red Cell Lysate Proteins by Two-Dimensional Electrophoresis." Federation of American Societies for Experimental Biology Annual Meeting, Atlantic City, NJ, Apri1 9-14, 1978.

Ehret, C. F. "The Chronopharmacology of L-DOPA: Implications for Orthochronal Therapy in the Prevention of Circadian Dyschronism." International Symposium on Clinical Chronopharmacology, Chronotherapeutics, and Chronopharmacy, Tallahassee, FL, February 10, 1978.

Ehret, C. F. "Circadian Regulation: Basic Mechanisms, and the Role of Nutritional Factors and of Drugs as Environmental Zeitgebers." Department of Biological Sciences, De Paul University, Chicago, IL, February 24, 1978.

Ehret, C. F. "The Circadian Connection to Regulatory Physiology and to Orthochronal Medicine." Department of Zoology and Physiology, Louisiana State University, Baton Rouge, LA, March 2, 1978.

Ehret, C. F. "The Influence of Nutrition and Drugs on Circadian Regulation in Mammals: Implications for the Control of Jet Lag in Transmeridianal Travel." Walter Reed Army Institute of Research, Walter Reed Army Medical Center, Washington, DC, June 20, 1978. 
Ehret, C. F. "Molecular Mechanisms in Circadian Regulation." First Gordon Research Conference in Chronobiology, Plymouth, NH, July 3-7, 1978.

Ehret, C. F. "Circadian Rhythm Research on the Effects of ELF Electric Fields on Small Rodents." USA-USSR International Effort, Department of Energy, Washington, DC, July 14, 1978.

Ehret, C. F. "The Importance of Fundamental Research in Chronobiology to Human Health." National Conference on Health Research Principles, National Institutes of Health, Bethesda, MD, October 3-4, 1978.

Ehret, C. F. "Exposure and Data Collection Facilities for Circadian Studies of Electric Field Effects upon Behavior, Thermoregulation, and Metabolism in Small Rodents." 18 th Annual Hanford Life Sciences Symposium, Richland, WA, October 16-18, 1978.

Ehret, C. F. "The Role of Diet in Phase Shifting of Circadian Rhythms during Jet Trave1--Studies with Experimental Animals and with Humans." Department of Food Sciences and Nutrition, University of Minnesota, St. Paul, MN, October 23, 1978 .

Ehret, C. F. "Elements of Circadian Regulation." Department of Botany, University of Minnesota, St. Paul, MN, October 24, 1978.

E1kind, M. M. "Cellular and Molecular Processes in Radiation Lethality." Department of Statistics, University of California, Berkeley, CA, January $16,1978$.

Elkind, M. M. "Sublethal Damage and Potentially Lethal Damage, Are They Connected?" Lawrence Berkeley Laboratory, University of Cal ifornia, Berkeley, CA, January 17, 1978.

Elkind, M. M. "DNA Damage and Mammalian Cell Killing." ICN-UCLA Symposium on DNA Repair Mechanisms, Keystone, CO, February 19-24, 1978.

Elkind, M. M. "Molecular and Cellular Radiation Damage-Repair Processes." Loyola University Medical Center, Maywood, IL, March 8, 1978.

Elkind, M. M. "Carcinogen + 'Sunlight' Interactions: Combined Effects of 7,12-Dimethylbenz(a)anthracene and Near Ultraviolet Light on Cultured Mammalian Cells." Ben May Laboratory, The University of Chicago, Chicago, IL, April 18, 1978.

E1kind, M. M. "Implications of the Initial Portion of the Survival Curve for Low Dose Rate Teletherapy." International Cancer Research Workshop on Low Dose Rate Teletherapy, Milwaukee, WI, May 4-5, 1978.

Elk1nd, M. M. "In Vitro Neoplastic Transformation: Its Dependence on Radiation Quality and Repair Processes." Eric Hall Symposium, 26th Annual Radiation Research Society Meeting, Toronto, Canada, May 14-18, 1978.

Elkind, M. M. "Radiation Induced in Vitro Neoplastic Transformation and Its Relationship to Repair Processes." Armed Forces Radiobiology Research Institute, Bethesda, MD, June.26, 1978 . 
Elkind, M. M. "Photosensitized Cytotoxicity by Polycyclic Aromatic Hydrocarbons and Coal-burning Effluents in Cultured Mamalian Cells." Division of Biomedical and Environmental Research, Department of Energy Contractor Workshop, Boca Raton, FL, November 11-14, 1978.

Finke1, M. P. "Bone Cancer Induction by Radiation and Virus." Symposium on the Cancer Problem, American Association for the Advancement of Science, Houston, TX, December 26, 1978.

Fritz, T. E. "Dose and Dose Rate Effects of Whole-Body Protracted Irradiation." Department of Biology, Harvard University, Cambridge, MA, February 22,1978 .

Fritz, T. E. "Early and Late Effects of Continuous Low Level Radiation Exposure." Annual Meeting of the European Late Effects Project Group, U1m, Germany, March 1, 1978.

Fritz, T. E. "Relationship of Dose Rate and Total Dose to Responses of Continuously Irradiated Beagles." IAEA International Symposium on the Late Biological Effects of Ionizing Radiation, Vienna, Austria, March 13-17, 1978.

Fritz, T. E. "Continuous Whole-Body Irradiation: Myelogenous Leukemia and Other Dose and Dose Rate Effects." Donner Laboratory, University of California, Berkeley, CA, April 19, 1978.

Grahn, D. "Analytical Approaches to and Interpretations of Data on Time, Rate and Cause of Death of Mice Exposed to External Gamma Irradiation." IAEA International Symposium on the Late Biological Effects of Ionizing Radiation, Vienna, Austria, March 13-17, 1978.

Grahn, D. "Genetic Effects of ${ }^{239}$ Pu." Radiobiology Laboratory, Medical Research Council, Harwel1, England, March 30, 1978.

Grahn, D. "Genetic and Cytogenetic Effects of Gonadal Burdens of Plutonium." Department of Biology, Northern Michigan University, Marquette, MI, April $24-25,1978$.

Grahn, D. "Cytogenetic Damage if Spermatogonia of Mice from ${ }^{239} \mathrm{Pu}$, External Fission Neutrons, and "Co Gamma Radiations." 26th Annual Radiation Research Society Meeting, Toronto, Canada, May 14-18, 1978.

Grahn, D. "COSPAR's Reorganization." Committee on Space Research, Innsbruck, Austria, June 6, 1978.

Grahn, D. "Health Aspects of Nuclear Electric Power." Redeemer Lutheran Church Men's Group, Elmhurst, IL, October 16, 1978.

Grahn, D. "Genetic Effects of Radiation." Department of Biological Sciences, Northern Illinois University, DeKalb, IL, October 30, 1978.

Hachey, D. L. "High Precision Metal Isotope Ratio Measurements Using Volatile Metal Chelates and Chemical Ionization Mass Spectrometry." 3rd International Conference on Stable Isotopes; Oak Brook, IL, May 23-26; 1978. 
Hachey, D. L. "Stereoselective Disposition of $\mathrm{R}-(-)$ and $\mathrm{S}-(+)$-Methadone in Man.." 3rd International Conference on Stable Isotopes, Oak Brook, IL, May 23-26, 1978.

Hagan, M. P. "DNA Maturation in Synchronized Chinese Hamster Cells." Joint Biophysical Society-American Physical Society Meeting, Washington, DC, March 27-30, 1978 .

Han, A. "Repair of Radiation Induced Damage in Mammalian Ce11s." University of Heal.th Sciences, Chicago Medical School, Chicago, IL, February 3, 1978 .

Han, A. "Cell Cycle Dependent Radiation Responses of Mammalian Cells." VA Hospital, Hines, IL, February 10, 1978.

Han, A. "Radiobiological Characteristics of Neutron Beams in Chicagoland Area." American Association of Physicists in Medicine, Evanston, IL, Apri1 8, 1.978.

Han, A. "Neutron RBE of Neoplastic Transformation in Vitro and the Effects of Dose Fractionation." 3rd Meeting on Fundamental and Practical Aspects of the Application of Fast Neutrons and Other High-LET Particles in Clinical Radiotherapy, The Hague, The Netherlands, September 12-16, 1978.

Hass, B. S. "Comparative Mutagenicities of Coal Combustion Sources." Division of Biomedical and Environmental Research, Department of Energy Contractor Workshop, Boca Raton, FL, November 11-14, 1978.

Kaspar, L. V. "Effects of Endotoxin Stress on Cellular and Humoral Responses in Dogs Exposed to Chronic Gamma Irradiation." 7 th Annual Conference of the International Society for Experimental Hematology, Chicago, IL, August 27-31, 1978 .

Klein, P. D. "A Fecal ${ }^{13} \mathrm{C}$ Measurement for Quantitating Intestinal Malabsorption." 26th Annual Conference on Mass Spectrometry and Allied Topics, St. Louis, MO, May 28-June 2, 1978.

Klein, P. D. "A Stable Isotope Menu--A 1a Carte or Price Fixe." Human Nutrition Committee, Department of Medicine, The University of Chicago, Chicago, IL, September 6, 1978.

Klein, P. D. "The Use of ${ }^{13} \mathrm{C}$ Isotope Ratio Measurement in Clinical Research and Diagnosis." Japanese Society for Medical Mass Spectrometry, Tokyo, Japan, November 10, 1978.

Klein, P. D. "Stable Isotopes in Clinical Research." Kyushu University, Fukuoka, Japan, November 13, 1978.

Klein, P. D. "Some Recent Developments in Stable Isotope Applications." Kinki University, Osaka, Japan, November 14, 1.978.

Klein, P. D. "Some Recent Developments in Stable Isotope Applications." Stable Isotope Committee of Japan, Tokyo, Japan, November 15, 1978. 
Kubitschek, H. E. "DNA Lesions, Repair, Mutation, and Cancer." Department of Biology, Wheaton College, Wheaton, IL, January 13, 1978.

Kubitschek, H. E. "Cell Growth: Exponential or Linear?" Departments of Physics and Microbiology, Clemson University, Clemson, SC, November 9, 1978.

Lundy, R. T. "A Model for the Analysis of the Comparative Effects of Energyrelated Effluents on Human Health." Population Association of America Meeting, Atlanta, GA, Apri1 13-15, 1978.

Lundy, R. T. "Methodology for Projecting the Health Impact of Air Pollution." Seminar, Department of Energy Staff, Washington, DC, June 19, 1978.

Matsushita, T. "Cytometric and Correndonuclease Analys is of BSA-Protected Mouse Myeloma Cells." ICN-UCLA Symposium on DNA Repair Mechanisms, Keystone, C0, February 19-24, 1978.

Matsushita, T. "Bacterial DNA Replication." Department of Biology, Wheaton College, Wheaton, IL, October 4, 1978.

Matsushita, T. "Recombinant DNA Research." Department of Biology, George Williams College, Downers Grove, IL, October 18, 1978.

O'Connor, T. E. "Cancer Virology." University of Illinois, Champaign, IL, February 8-9, 1978.

Peak, M. J. "A Study of UV Reactivation of Ultraviolet Treated Transforming DNA by Competent Bacillus subtilis Cells." 22nd Wind River Conference on Genetic Exchange, Philadel phia, PA. June 9-13, 1978.

Peak, M. J. "Inactivation of Transforming DNA by Far- and Near-Ultraviolet Light." International Workshop-Meeting on Solar Radiation Damage and the Induction of Skin Cancer, Lausanne, Switzerland, September 26-29, 1978.

Peraino, C. "Detection of Tumorigenic Potential in Energy-related Pollutants." Division of Biomedical and Environmental Research, Department of Energy Contractor Workshop, Boca Raton, FL, November 11-14, 1978.

Rahman, Y. E. "Potential of Liposomes in Metal Poisonings and Metal Storage Diseases." Symposium on the Potential of Liposomes as Drug Carriers, Geneva, Switzerland, March 2-3, 1978.

Rahman, Y. E. "Liposomes Containing Desferrioxamine (DF) and Rhodotorulic Acid (RA) in Experimental Hemochromatosis." 2lst Meeting of the American Society of Hematology, New Orleans, LA, December 2-5, 1978.

Russe11, J. J. "Comparison of Plutonium Distribution and Radiation Dose Received by Mouse and Dog Testis." 23rd Annual Meeting of the Health Physics Society, Minneapolis, MN, June 18-23, 1978.

Russe11, J. J. "Effect of Early and Delayed DTPA Therapy on Retention of Plutonium Citrate in Mouse and Dog Testis." 23rd Annual Meeting of the Health Physics Society, Minneapolis, MN, June 18-23, 1978. 
Ryu, E. K. "The Synthesis and Biological Activity of New Membrane-Targeted Molecular Depots of Nucleoside Analogues." Midwest Regional Meeting of the American Chemical Society, Fayetteville, AR, October 26-27, 1978.

Sacher, G. A. "The Present Situation in Biogerontology." Kansas State University, Manhattan, KS, February 8-9, 1978.

Sacher, G. A. "The Quadratic Low-LET Dose-Effect Relation for Life Shortening in Mammals: Implications for the Assessment of the Low-Dose Hazard to Human Populations." IAEA International Symposium on the Late Biological Effects of Ionizing Radiation, Vienna, Austria, March 13-17, 1978.

Sacher, G. A. "The Role of Gerontology in Geriatric Education." National Academy of Sciences-Institute of Medicine, Washington, DC, March 20, 1978.

Sacher, G. A. "Why poes Peromyscus Live Twice as Long as Mus?" Michigan State University, East Lansing, MI, April 2-3, 1978.

Sacher, G. A. "Genetic Relation of Life-Span to Metabolic Rate for Five Mouse Strains and Their Hybrids." Federation of American Societies for Experimental Biology, Atlantic City, NJ, April 9-14, 1978.

Sacher, G. A. "Biological Gerontology." Kansas State University, Manhattan, KS, May 31, 1978.

Sacher, G. A. "Aging or Longevity: The Central Dialectic of Gerontology." University of Washington Institute on $\mathrm{Ag}$ ing, Seattle, WA, June 12, 1978.

Sacher, G. A. "Mammalian Life Histories: Their Evolution and Molecular-Genetic Mechanisms." Given Institute of Pathobiology, Aspen, CO, July 29-August 4, 1978.

Sacher, G. A. "Comparisons of Life Shortening in Different Mammalian Species Given Low-LET Radiation." XIth International Congress of Gerontology, Tokyo, Japan, August 20-25, 1978.

Sacher, G. A. "Physiological and Molecular Factors in Lifespan Differences within and between Rodent Species." XIth International Congress of Gerontology, Tokyo, Japan, August 20-25, , 1978.

Sacher, G. A. "Evolutionary-Genetic Factors Governing Differences in the Rate-of-Aging and Vulnerability Factors between and within Species." Symposium on Perspectives in the Modification of the Rate of Aging, Kyoto, Japan, August 30-September 1, 1978.

Sacher, G. A. "The Constitutional Basis of Longevity in the Cetacea: Do the Whales and the Terrestrial Mammals Obey the Same Laws?" International Conference on Determining Age in Odontocete Cetaceans, La Jolla, CA, September $5-7,1978$.

Sacher, G. A. "Unmet Needs of the Aging Population." Geriatric Workshop, Ohio State University, Columbus, OH, September 14, 1978. 
Sacher, G. A. "Contribution of Gerontology to Geriatric Training." Ohio Network of Consultants in Aging, Akron, OH, September 18, 1978.

Sacher, G. A. "Physical Activity and Its Role in Aging." University of Illinois Aging Program Retreat, Harvey, IL, October 16, 1978.

Sacher, G. A. "The Evolution of Longevity." Dalhousie University, Halifax, Nova Scotia, November 2, 1978.

Sanderson, M. H. "The Effect of Daily Prenatal Gamma Irradiation on Ovarian Cortex of Beagle Puppies." 9th International Congress of Electron Microscopy, Toronto, Canada, August 1-9, 1978.

Seed, T. M. "Hemopathological Consequences of Protracted Gamma Irradiation in the Beagle: Pre-clinical Phases of Leukemia Induction." IAEA International Symposium on the Late Biological Effects of Ionizing Radiation, Vientla, Austria, March 13-17, 1970.

Seed, T. M. "The Biology of Malaria." Department of Biology, St. Francis College, Joliet, IL, May 2, 1978.

Stearner, S. P. "Cardiovascular Degeneration in the Aging, Irradiated Mouse." AAAS Annual Meeting, Washington, DC, February 12-17, 1978.

Stearpgr, S. P. "Comparative Effects of Fission Spectrum Neutrons and "Co Gamma Rays on Long-Term Cardiovascular Changes." 26th Annual Radiation Research Society Meeting, Toronto, Canada, May 14-18, 1978.

Stellaard, F. "Identification of Abnormal Bile Acids in Disease States and Their Detection by Gas Chromatography-Mass Spectrometry-Computer Techniques." Vth Bile Acid Meeting, Freiburg, Germany, June 12-13, 1978.

Stellaard, F. "Identification of Atypical Bile Acids by Gas Chromatography/Mass Spectrometry/Computer. Sth International Symposium in Biochemistry and Medicine, Rimini, Italy, June 19-21, 1978.

Suehif̧, M. "Ipyestigation of an Apparent Isotope Effect between ${ }^{\mathrm{CO}}{ }_{2}$ and ${ }^{14} \mathrm{CO}_{2}$ in Trioctanoin Breath Test." 3rd International Conference on'Stable Isotopes, Oak Brook, IL, May 23-26, 1978.

Szczepanik-Van Leeuwen, P. A. "Identification of Abnormal Bile Acids in Disease States and Their Detection by Gas Chromatography-Mass Spectrometry-Computer Techniques." 26th Falk Symposium, Vth Bile Acid Meeting, Freiburg, Germany, June 13-14, 1978.

Tewari, R. "Theoretical Complications of Conformational Preferences in Dinucleoside Monophosphates. Implications for Recognition by Exonucleases." Joint Biophysical Society-American Physical Society Meeting, Washington, DC, March 27-30, 1978.

Tewari, R. "Conformational Preferences in Dinucleoside Diphosphates: Influence of Charge." 11 th Midwest Theoretical Chemistry Conference, Columbus, OH, . May, 18-20, 1978. 
Tewari, R. "Theoretical Calculations of Conformational Preferences in Dinucleoside Triphosphates." American Conference on Theoretical Chemistry, Boulder, CO, June 25-30, 1978.

Tolle, D. V. "Irradiation-induced Canine Leukemia--A Proposed New Model. Incidence and Hematopathology." 7 th Annual Conference of the International Society for Experimental Hematology, Chicago, IL, August 27-31, 1978.

Tolle, D. V. "Acute Radiation-induced Monocytic Leukemia in the Beagle." 7 th Annual Chicago-Metropolitan Milwaukee Interbranch Meeting, AALAS, Bloomingdale, IL, September 8, 1978.

Tolle, D. V. "Consequences of Continuous Low Dose Whole-Body Gamma Irradiation in the Beagle: Early and Late Effects on the Hematopoietic System." Department of Experimental Hematology, Armed Forces Radiobiology Research Institute, Bethesda, MD, October 26-29, 1978.

Tolle, D. V. "An Experimental Approach to the Study of Leukemia: Description of an Animal Model and Comments on the Diagnosis of Human Blood Diseases." Department of Biological Sciences, George Williams College, Downers Grove, IL, November 15, 1978.

Tserng, K. Y. "Quantitation of Keto Bile Acids in Biological Samples by Sodium Borodeuteride Reduction Prior to Isolation and Isotope Ratio Measurements on Hydroxyl Bile Acids." 3rd International Conference on Stable Isotopes, Oak Brook, IL, May 23-26, 1978.

Tserng, K. Y. "The Influence of Solvents on Deuterium Incorporation into Ketones during Sodium Borodeuteride Reduction." 3rd International Conference on Stable Isotopes, Oak Brook, IL, May 23-26, 1978.

Utsumi, H. "Photodynamic Lethality and DNA Damage: Effects of 7,12-Dimethylbenz(a)anthracene Plus :Sunlight: in Cultured Mammalian Cel1s." 26th Annual Radiation Research Society Meeting, Toronto, Canada, May $14-18,1978$.

Webb, R. B. "Effect of Near-UV Damage to DNA Repair Systems on Far-UV and Near-UV Mutagenesis in Strains of Escherichia coli that Differ in Repair Capability." 6th Annual Meeting of the American Society for Photobiology, Burlington, VT, June 11-16, 1978.

Webb, R. B. "Effects of Radiation on Microorganisms." Department of Biology, Northern Illinois University, DeKalb, IL, September 18, 1978. 


\section{THIS PAGE}

\section{WAS INTENTIONALLY LEFT BLANK}




\section{PUBLICATIONS APPEARING IN CALENDAR YEAR 1978}

\section{JOURNAL ARTICLES}

Anderson, L., and N. G. Anderson. High Resolution Two-Dimensional Electrophoresis of Human Plasma Proteins. Proc. Nat. Acad. Sci. USA 74, 5421-5425(1977).

Anderson, N. G. Construction of Tygon Manifolds and Connectors. Anal: Biochem. 86, 337-338 (1978).

Anderson, N. G. The Future of Clinical Chemistry. Am. J. Med. Tech. 44, 233-237 (1978).

Anderson, N. G., and N. L. Anderson. Analytical Techniques for Cell Fractions. XXI. Two-Dimensional Analysis of Serum and Tissue Proteins: Multiple Isoelectric Focusing. Anal. Biochem. 85, 331-340 (1978).

Anderson, N. L., and N. G. Anderson. Analytical Techniques for Cell Fractions. XXII. Two-Dimensional Analysis of Serum and Tissue Proteins: Multiple Gradient-S1ab Gel Electrophoresis. Anal. Biochem. 85, 341-354 (1978).

Barr, R. G., J. A. Perman, D. A. Schoeller, and J. B. Watkins. Breath Tests in Pediatric Gastrointestinal Disorders: New Diagnostic Opportunities. Pediatrics 62, 393-401 (1978).

Bhattacharyya, M. H., D. P. Peterson, and A. Lindenbaum. Action of DTPA on Hepatic Plutonium. I. Quantitation of the DTPA-induced Biliary Excretion of Plutonium in the Rat. Radiat. Res. 74, 179-185 (1978).

Bhattacharyya, M. H., D. P. Peterson, and A. Lindenbaum. Action of DTPA on Hepatic Plutonium. II. DTPA-induced Removal of Monomeric Plutonium from Mouse Liver Parenchymal Cel1s. Radiat. Res. 76, 180-186 (1978).

Brown, M. S. Biological Evidence for the Destruction of the Photoreactivation Enzyme by $365 \mathrm{~nm}$ Radiation in Escherichia coli. Mutat. Res. 49, 133-137 (1978).

Christian, E. J. B. Inter/Micro 77. Microscope 25, 273-277 (1978).

Elkind, M. M., and A. Han. DNA Single-Strand Lesions Due to "Sunlight" and UV Light: A Comparison of Their Induction in Chinese Hamster and Human Cells, and Their Fate in Chinese Hamster Cells. Photochem. Photobiol. $27,717-724$ (1978). 
Elkind, M. M., A. Han, and. C.-M. Chang-Liu. "Sunlight"-induced Mammalian Cell Killing: A Comparative Study of Ultraviolet and Near-Ultraviolet Inactivation. Photochem. Photobiol. 27, 709-715 (1978).

Ely, K. R., J. R. Firca, K. J. Williams, E. E. Abola, J. M. Fenton, M. Schiffer, N. C. Panagiotopoulos, and A. B. Edmundson. Crystal Properties as Indicators of Conformational Changes during Ligand Binding or Interconversion of Mcg Light Chain Isomers. Biochemistry 17, 158-167 (1978).

Feinstein, R. N. Cinnabarinate Synthase Activity in Normal and Acatalasemic Mice. Proc. Soc. Exp. Biol. Med. 158, 398-401 (1978).

Feinstein, R. N., R. J. M. Fry, and E. F. Staffeldt. Carcinogenic and Antitumor Effects of Aminotriazole on Acatalasemic and Normal Catalase Mice. J. Nat. Cancer Inst. 60, 1113-1116 (1978).

Feinstein, R. N., R. J. M. Fry, and E. F. Staffeldt. Comparative Effects of Aminotriazole on Normal and Acatalasemic Mice. J. Environ. Pathol. Toxicol. 1, 749-790 (1978).

Firca, J. R., K. R. E1y, P. Kremser, F. A. Westholm, K. J. Dorrington, and A. B. Edmundson. Interconversion of Conformational Isomers of Light Chains in the Mcg Immunoglobulins. Biochemistry 17, 148-158 (1978).

Fry, R. J. M. Radiation Carcinogenesis. Int. J. Radiat. Oncol. Biol. Phys . 3, 219-226 (1977).

Guilmette, R. A., E. A. Cerny, and Y. E. Rahman. Pharmacokinetics of the Iron Chelator Desferrioxamine as Affected by Liposome Encapsulation: Potential in Treatment of Chronic Hemosiderosis. Life Sci. 22, 313-320 (1978).

Guilmette, R. A., A. Lindenbaum, A. Friedmall, J. Sullivan, E. Murelli, and J. J. Kussell. Intluence ot Injected Mass of Ylutonium on Its Biological Distribution. Health Phys. 35, 529-536 (1978).

Hachey, D. L., L. Palladino, J. A. Blair, I. H. Rosenberg, and P. D. Klein. Preparation of Pteroylglutamic Acid-3', $5^{\prime}-{ }^{2} \mathrm{H}_{2}$ by acid Catalyzed Exchange with Deuterium Oxide. J. Labelled Compds. Radiopharm. 14 , 479-486 (1978).

Han, A., and M. M. Elkind. Ultraviolet Light and X-Ray Damage Interaction in Chinese Hamster Cells. Radiat. Res. 74, 88-100 (1978).

Harrison, D. E., J. R. Archer, G. A. Sacher, and F. M. Boyce III. Tail Collagen Aging in Mice of Thirteen Different Genotypes and Two Species: Relationship to Biological Age. Exp. Geront. 13, 63-73 (1978). Hass, B. S., and R. B. Webb. Photodynamic Effects of Dyes on Bacteria. I. Mutagenesis by Acridine Orange in the Dark in Excision- and Recombination-deficient Strains of Escherichia coli. Mutat. Res. 51, 279-284 (1978).

Havre, P., M. A. Abrams, R. J. M. Corral1, L. C. Yu, P. A. Szczepanik, H. B. Feldman, P. Klein, M. S. Kong, J. M. Margolis, and B. R. Landau. Quanti- 
tation of Pathways of Ethanol Metabolism. Arch. Biochem. Biophys. 182, 14-23 (1977).

Hofmann, A. F., J. L. Thistle, P. D. Klein, P. A. Szczepanik, and P. Y. S. Yu. Chenotherapy for Gallstone Dissolution. II. Induced Changes in Bile Composition and Gallstone Response. J. Am. Med. Assoc. 239, 1138-1144 (1978).

Holsti, L. R., M. Salmo, and M. M. Elkind. Unconventional Fractionation in Clinical Radiotherapy. Br. J. Cancer 37, (Supp1. III), 307-310 (1978).

Jonah, M. M., E. A. Cerny, and Y. E. Rahman. Tissue Distribution of EDTA Encapsulated within Liposomes Containing Glycolipids or Brain Phospholipids. Biochim. Biophys. Acta. 541, 321-333 (1978).

Kaspar, L. V., and W. P. Norris. Serum Chemistry Values of Normal Dogs (Beagles): Associations with Age, Sex, and Family Line. Lab. Anim. Sci. 27, 980-985 (1977).

Kaspar, L. V., C. M. Poole, and W. P. Norris. Incidence of Struvite Urinary Calculi in Two Ancestral Lines of Beagles. Lab. Anim. Sci. 28, 545-550 (1978).

Klein, E. R., and P. D. Klein. A Selected Bibliography of Biomedical and Enviromental Applications of Stable Isotopes. I. Deuterium 1971-1976. Biomed. Mass. Spectrom. 5, 91-111 (1978).

Klein, E. R., and P. D. Klein. A Selected Bibliography of Biomedical and Environmental Applications of Stable Isotopes. II.-- ${ }^{13}$ C 1971-1976. Biomed. Mass Spectrom. 5, 321-330 (1978).

Klein, E. R., And P. D. Klein. A Selected Bibliography of Biomedical and Environmental Applications of Stable Isotopes. III.-- ${ }^{5}$ N 1971-1976. Biomed. Mass Spectrom. 5, 373-379 (1978).

Klein, E. R., and P. D. Klein. A Selected Bibliography of Biomedical and Environmental Applications of Stable Isotopes. IV. $-{ }_{0}{ }_{0},{ }_{0} 0$, and ${ }^{34} \mathrm{~S} 1971-1976$. Biomed. Mass Spectrom. 5, 425-432 (1978).

Krisch, R. E., F. Krasizg and C. J. Sauri. DNA Breakage, Repair, and Letha1ity Accompanying ${ }^{23}$ Decay in Microorganisms. Curr. Top. Radiat. Res. Q. 12, 355-368 (1977). Kubitschek, H. E., and C. N. Newman. Chromosome Replication during the Division Cycle in Slowly Growing, SteadyState Cultures of Three Escherichia coli B/r Strains. J. Bacteriol. $136,179-190$ (1978).

Ley, R. D., B. A. Sedita, and E. Boye. DNA Polymerase I-mediated Repair of $365 \mathrm{~nm}$-induced Single-Strand Breaks in the DNA of Escherichia culi. Photochem. Photobiol. 27, 323-327 (1978).

Ley, R. D., B. A. Sedita, and D. D. Grube. Absence of Photoreactivation of Pyrimidine Dimers in the Epidermis of Hairless Mice following Exposures to Ultraviolet Light. Photochem. Photobiol. 27, 483-485 (1978). 
Levy, J. A., P. L. Kazan, C. A. Reilly, Jr., and M. P. Finkel. FBJ Osteosarcoma Virus in Tissue Culture. III. Isolation and Characterization of Non-Virus-producing FBJ-transformed Cells. J. Virol. 26, 11-15 (1978).

MacCoss, M., and D. J. Cameron. Facile Detritylation of Nucleoside Derivatives by Using Trifluoracetic Acid. Carbohydr. Res. 60, 206-209 (1978).

MacCoss, M., E. K. Ryu, and T. Matsushita. The Synthesis, Characterization, and Preliminary Biological Evaluation of $1-\beta-D-a r a b$ ino fur anosylcytosine-5'-diphosphate-L-1,2-dipalmitin. Biochem. Biophys. Res. Commun. 85, 714-723 (1978).

MacCoss, M., F. S. Ezra, M. J. Robins, and S. S. Danyluk. Con formational Characteristics of Rigid Cyclic Nucleotides. 2. The Solution Conformation of a-Nucleoside 3',5'-Cyclic Monophosphates and the Role of the 2'-Hydroxyl Group. J. Am. Chem. Soc. 99, 7495-7502 (1977).

MacCoss, M., F. S. Ezra, M. J. Robins, and S. S. Danyluk. Proton Magnetic Resonance Studies of 9-( $\beta-D-X y l o f u r a n o s y l)$ Adenine $3^{\prime}, 5^{\prime}-C y c l$ ic Monophosphate and 9-( $\beta-D-A r a b i n o f u r a n o s y 1)$ Adenine 2',5'-Cyc1ic Monophosphate. Carbohydr. Res. 62, 203-212 (1978).

MacCoss, M., M. J. Robins, B. Rayner, and J.-L. Imbach. A New Aspect of the Use of 2', 3'-0-isopropylidene Ribonucleosides for Investigation of Anomeric Configuration. Carbohydr. Res. 59, 575-579 (1977).

McNitt, R. E., and J. Shen-Miller. Quantitative Assessment of Ultrastructural Changes in Primary Roots of Corn (Zea mays L.) after Geotropic Stimulation. I. Root Cap. P1ant Physiol. 61, 644-648 (1978).

Newman, C. Effect of Cold Storage on Inactivation of Escherichia coli by 313 nm Irradiation. Photochem. Photobiol. 27, 363-365 (1978).

Newnan, C. N., and H. E. Kubitschek. Variation in Periodic Replication of the Chromosome in Escherichia coli B/r TT. J. Mol. Biol. 121, 461-471 (1978).

Ngo, F. Q. H., A. Han, H. Utsumi, and M. M. Elkind. Comparative Radiobiology of Fast Neutrons: Relevance to Radiotherapy and Basic Studies. Int. J. Radiat. Oncol, Biol. Phys. 3, 187-193 (1977).

Peak, M. J., and J. G. Peak. Action Spcctra for the Ultraviolct and Visible Light Inactivation of Phage T7: Effect of Host-Cell Reactivation. Radiat. Res. 76, 325-330 (1978).

Rahman, Y. E., W. R. Hanson, J. Bharucha, E. J. Ainsworth, and B. N. Jaroslow. Mechanisms of Reduction of Antitumor Drug Toxicity by Liposome Encapsulation. Ann. N. Y. Acad. Sci. 308, 325-342 (1978).

Sacher, G. A. Longevity, Aging, and Death: An Evolutonary Perspective (1976 Robert W. Kleemeier Award Lecture). The Gerontologist 18, 112-119 (1978). 
Sacher, G. A. Longevity and Aging in Vertebrate Evolution. BioScience 28, 497-501 (1978).

Schiffer, M., F. A. Westholm, N. Panagiotopoulos, aná A. Solomon. Crystallographic Data on a Complete K-Type Human Bence-Jones Protein. J. Mol. Biol. 124, 287-290 (1978).

Schneider, J. F., D. A. Schpeller, B. Nemchausky, J. L. Boyer, and P. D. Klein. Validation of ${ }^{13} \mathrm{CO}_{2}$ Breath Analysis as a Measurement of Demethylation of Stable Isotope Labeled Aminopyrine in Man. Clin. Chim. Acta 84, 153-162 (1978).

Schoeller, D. A., and P. D. Klein. A Simplified Technique for Collecting Breath $\mathrm{CO}_{2}$ for Isotope Ratio Mass Spectrometry. Biomed. Mass Spectrom. 5, 29-31 (1978).

Schoeller, D. A., J. F. Schneider, N. W. Solomons, J. B. Watkins, and P. D. Klein. Clinical Diagnosis with the Stable Isotope ${ }^{13} \mathrm{C}$ in $\mathrm{CO}_{2}$ Breath Tests: Methodology and Fundamental Considerations. 3. Lab. Clin. Med. 90, 412-421 (1977).

Schubert, J,, E. J. Riley, and S. A. Tyler. Combined Effects in Toxicology--A Rapid Systematic Testing Procedure: Cadmium, Mercury, and Lead. J. Toxicol. Environ. Health 4 , 763-776 (1978).

Seed, T. M., D. V. Tolle, T. E. Fritz, R. L. Devine, C. M. Poole, and W. P. Norris. Irradiation-induced Erythroleukemia and Myelogenous Leukemia in the Beagle Dog: Hematology and U1trastructure. Blood 50, 1061-1079 (1977).

Shen-Miller, J. Spectral Response of Corn (Zea mays) in Root Geotropism. Plant Cel1 Physiol. 19, 445-452 (1978). Shen-Miller, J., and R. E. McNitt. Quantitative Assessment of Ultrastructural Changes in Primary Roots of Corn (Zea mays L.) after Geotropic Stimulation. III. Curving and Noncurving $\overline{\text { Zones of }}$ the Root Proper. Plant Physiol. 61, 649-653 (1978).

Shen-Miller, J., R. E. McNitt, and M. Wojciechowski. Regions of Differential Cell Elongation and Mitosis, and Root Meristem Morphology in Different Tissues of Geotropically Stimulated Maize Root Apices. Plant Physiol. $\underline{61}, 7-12(1978)$.

Solomons, N. W., D. A. Schoeller, J. B. Wagonfeld, D. Otf, I. H. Rosenberg, and P. D. Klein. Application of a Stable Isotope $\left({ }^{13} \mathrm{C}\right)$-Labeled $\mathrm{Gly}-$ cocholate Breath Test to Diagnosis of Bacterial Overgrowth and Ileal Dysfunction. J. Lab. Clin. Med. 90, 431-439 (1977).

Stearner, S. P., and E. J. B. Christian. Long-Term Vascular Effects of Ionizing Radiations in the Mouse: Capillary Blood Flow. Radiat. Res. 73, 553-567 (1978).

Stellaard, F., D. L. Hachey, and P. D. Klein. Separation of Bile Acids as Their Phenacyl Esters by High-Pressure Liquid Chromatography. Anal. Biochem. 87, 359-366 (1978). 
Szczepanik, P. A., D. L. Hachey, and P. D. Klein. Evaluation of Poly S-179 as a Stationary Phase for the Gas-Liquid Chromatography-Mass Spectrometry of Bile Acid Methyl Ester Acetates. J. Lipid Res. 19, 280-283 (1978).

Tewari, R., and S. S. Danyluk. Configurational Effects on Conformational Properties of Cyclic Nucleotides. I. Theoretical Calculations of Conformer Preferences in $\alpha$-Nucleoside $3^{\prime}, 5^{\prime}$ Cyclic Monophosphates. Biopolymers 17, 1181-1196 (1978).

Thomson, J. F., S. L. Nance, and S. L. Tollaksen. Spectrophotometric Assay of Catalase with Perborate as Substrate. Proc. Soc. Exp. Biol. Med. 157, 33-35 (1978).

Tserng, K. Y. A Convenient Synthesis of 3-Keto Bile Acids by Selective Oxidation of Bile Acids with Silver Carbonate-Celite. J. Lipid Res. 19, 501-504 (1978).

Tserng, K. Y., and P. D. Klein. Bile Acid Sulfates: II. Synthesis of 3-Monosultates of Bile Acids and lheir Conjugates. Lipide 13, 479-486 (1978).

Watkins, J. B., A. M. Tercyak, P. Szczepanik, and P. D. Klein. Bile Salt Kinetics in Cystic Fibrosis: Influence of Pancreatic Enzyme Replacement. Gastroenterology 73, 1023-1028 (1977).

Watkins, J. B., D. A. Schoeller, P. D. Klein, D. G. Ott, A. D. Newcomer, and A. F. Hofmann. ${ }^{13}$ C-Trioctanoin: A Nonradioactive Breath Test to Detect Fat Malabsorption. J. Lab. Clin. Med. 90, 422-430 (1977).

Webb, R. B. Near-UV Mutagenesis: Photoreactivation of '365-nm-induced Mutational Lesions in Escherichia coli WP2s. J. Bacteriol. 133, 860-866 (1978).

Webl, R. B., M. S. Brown, and R. M. Tyrrell. Synergism between 365- and 254-m Radiations for Inactivation of Escherichia coli. Radiat. Res. 74, 298-311 (1978).

Webb, R. B., G. H. Yoakum, J. Perou, and A. Eisenstark. Interaction of NearU1traviolet Radiation and Irradiated L-Tryptophan in the Production of Mutations in Escherichia coli. Mutat. Res. 51, 427-432 (1978).

Yang, V. V., S. P. Stearner, and E. J. Ainsworth. Late U1trastructural Ghanges in the Mouse Coronary Arteries and Aorta after Fission Neutron or Co $\gamma$ Irradiation. Radiat. Res. 74, 436-456 (1978). 
BOOKS, REPORTS, AND PROCEEDINGS

Anderson, N. G. The Birth and Early Childhood of Centrifugal Analyzers. Methods for the Centrifugal Analyzer. Eds. J. Savory and R. E. Cross. American Association for Clinical Chemistry, Washington, DC, 1978, pp. $x i i-x v i$.

Anderson, N. G. Critical Steps in the Development of New. Health Technology. Technology and the Quality of Health Care. Eds. R. H. Egdah1 and P. M. Gertman. Aspen Systems Corporation, Germantown, MD, 1978, Chap 9, pp. 135-150.

Ben-Hur, E., M. M. Elkind, and E. Riklis. The Combined Effects of Hyperthermia and Radiation in Cultured Mammalian Cells. Cancer Therapy by Hyperthermia and Radiation. Ed. C. Streffer. Proceedings of the 2nd International Symposium on Cancer Therapy by Hyperthermia and Radiation, Essen, June 2-4, 1977. Urban and Schwarzenberg, Munich, 1978, pp. 29-36.

Danyluk, S. S., C. F. Ainsworth, and M. MacCoss. Methylation Effects on Nucleic Acid Conformations. Nuclear Magnetic Resonance Spectroscopy in Molecular Biology. Ed. B. Pullman. D. Reidel Publishing Co., Dordrecht, Ho11 and, $1978, \mathrm{pp} .111-124$.

Dimitrievich, G. S., S. L. Hausladen, F. T. Kuchnir, M. L. Griem, V. V. Yang, and S. P. Stearner. Radiation Damage and Subendothelial Repair to Rabbit Ear Chamber Microvasculature. An in Vivo, Histological, and Electron Microscopic Study. Bibliotheca Anatomica, No. 15, Recent Advances in Basic Microcirculatory Research. Ed. D. H. Lewis. S. Karger, Base $\overline{1}$, 1977, pp. 337-340.

Doody, T. J. Versatile Multiple Outlet Semi-Ball and Socket Valve. Proceedings of the Twenty-Second Symposium on the Art of Glassblowing, Boston, MA, June 19-13, 1977. The American Scientific Glassblowers Society, Wilmington, DE, 1978, pp. 91-98.

Ehret, C. F., K. R. Groh, and J. C. Meinert. Circadian Dyschronism and Chronotypic Ecophilia as Factors in Aging and Longevity. Advances in Experimental Medicine and Biology, Vol. 108, Aging and Biological Rhythms.

Eds. H. V. Samis, Jr., and S. Capobianco. Plenum Press, New York, 1978, pp. 185-213.

Elkind, M. M. Repair in Mammalian Cells. Summary and Proceedings of a Biology Workshop on Biological Repair Mechanisms and Exposure Standards, Oak Ridge, TN, June 28-30, 1977. Ed. D. Billen. Institute for Energy Analysis, Oak Ridge Associated Universities. ORAU/IEA 78-2(R), 1978, PP. 90-94.

Elkind, M. M. Summarizing Remarks. Summary and Proceedings of a Biology Workshop on Biological Repair Mechanisms and Exposure Standards, Oak

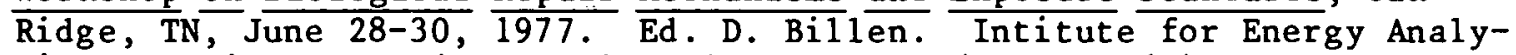
sis, Oak Ridge Associated Universities. ORAU/IEA 78-2(R), 1978, PP. 217-221. 
Hofmann, A. F., and P. D. Klein. Characterisation of Bile Acid Metabolism in Man Using Bile Acids Labelled with Stable Isotopes. Stable Isotopes. Applications in Pharmacology, Toxicology, and Clinical Research. Ed. T. A. Baillie. Macmillan Press Ltd., London, 1978, pp. 189-204.

Klein, P. D., D. A. Schoeller, and J. F. Schneider. The Use of ${ }^{13} \mathrm{C}$ Isotope Ratio Measurements in Clinical Research and Diagnosis. Proceedings of the Third Meeting of the Japanese Society for Medical Mass Spectrome-

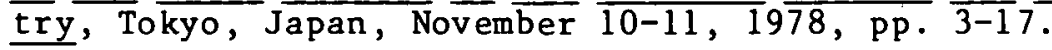

Klein, P. D., D. L. Hachey, M. J. Kreek, and D. A. Schoeller. Stable Isotopes: Essential Tools in Biological and Medical Research. Stable Isotopes. Applications in Pharmacology, Toxicology, and Clinical Research. Ed. T. Baillie. Macmillan Press Ltd, London, 1978, pp. 3-14.

Klein, P. D., P. A. Szczepanik, D. L. Hachey, and D. A. Schoeller. The Argonne Bioanalytical Center. A Resource for Collaborative Biomedical Applications of Stable 1sotopes. Stable lsotopes in the Lite sciences, Proceedings of an International Atomic Energy Agency Technical Committee on Modern Trends in Biological Applications of Stable Isotopes, Leipzig, Germany, February 14-18, 1977. International Atomic Energy Agency, Vienna, 1977 , pp. 313-322.

Lundy, R. T., and C. D. Brown. Health Risks. National Coal Utilization Assessment, An Integrated Assessment of Increased coal Use in the Midwest: Impacts and Constraints, Vol. II, Chapter $9 . \overline{A N} \overline{\mathrm{L} / \mathrm{AA}-1} 1 \overline{\mathrm{Dr}} \overline{\mathrm{ft}}$, 1977, pp.9-1- $\overline{\text {. }}$. 1 .

Lundy, R. T., and D. Grahn. Predictions of the Effects of Energy Production on Human Health. Proceedings of the Social Statistics Section, 1977, Part II, Chicago, August 1977. American Statistical Association, Washington, DC, 1978, pp. 672-677.

Peraino, C., R. J. M. Fry, and D. D. Grube. Drug-induced Enhancement of Hepatic Tumorigenesis. Carcinogenesis, Vol. 2 , Mechanisms of Tumor Promotion and Cocarcinogenesis. Eds. T. J. S1aga, A. Sivak, and $\overline{R . ~ K . ~ B o u t-~}$ well. Raven Press, New York, 1978, pp. 421-432.

Reilly, C. A., Jr., P. J. Dale, D. L. Gutzeit, and M. P. Finkel. Interference by Herpes Simplex Virus of Tumorigenesis by Murine Sarcoma Virus. Advances in Comparative Leukemia Research 1977. Eds. P. Bentvelzen et al. El se vier/North-Holl and Biomedical Press, The Netherlands, 1978, pp. 228-229.

Sacher, G. A. Concluding Comments. Advances in Experimental Medicine and Biology, Vol. 108, Aging and Biological phythms. Eds. H. V. Samis, Jr. and S. Capobianco. Plenum Press, New York, 1978, pp. 325-327.

Sacher, G. A. Evolution of Longevity and Survival Characteristics in Mammals. The Genetics of Aging. Ed. E. L. Schneider. Plenum Press, New York, $1978, \mathrm{Pp} \cdot 151-168$. 
Sacher, G. A. Quadratic Dose Dependence for Life Shortening in Mammals: Experimental Data and a Mechanistic Model. Summary and Proceedings of a Biology Workshop on Biological Repair Mechanisms and Exposure Standards,

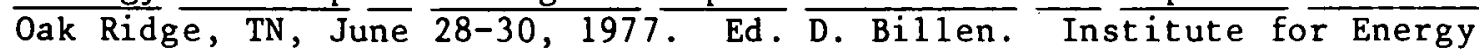
Analysis, Oak Ridge Associated Universities. ORAU/IEA 78-2(R), 1978, pP. 158-176.

Sacher, G. A., and P. H. Duffy. Age Changes in Rhythms of Energy Metabolism, Activity, and Body Temperature in Mus and Peromyscus. Advances in Experimental Medicine and Biology, Vol. 108, Aging And Biological Rhythms. Eds.H. V. Samis, Jr. and S. Capobianco. Plenum Press, New York, 1978, pp. 105-124.

Sacher, G. A., and R. W. Hart. Longevity, Aging and Comparative Cellular and Molecular Biology of the House Mouse, Mus musculus, and the White-Footed Mouse, Peromyscus leucopus. Genetic Effects on Aging. Eds. D. Bergsma and D. E. Harrison. Birth Defects:0riginal Article Series, The National Foundation-March of Dimes, Alan R. Liss, Inc., New York, 1978, pp. 71-96.

Seed, T. M., D. V. Tolle, T. E. Fritz, S. M. Cullen, L. V. Kaspar, and C. M. Poole. Haemopathological Consequences of Protracted Gamma Irradiation in the Beagle. Late Biological Effects of Ionizing Radiation, Vol. 1. IAEA International Symposium on the Late Biological Effects of Ionizing Radiation, Vienna, March 13-17, 1978. International Atomic Energy Agency, Vienna, 1978, pp. 531-545.

Shen-Miller, J. Plant Movements. McGraw-Hill Encyclopedia of Science and Technology, Vol. 10, 4th Edition. McGraw-Hil1, New York, 1977, pp. 417-421. 
ABSTRACTS

Ainsworth, E. J., W. T. Kickels, M. Miller, E. M. Cooke, E. F. Staffeldt, D. L. Jordan, R. J. M. Fry, and G. A. Sacher. Radiation Lethality and Hematological Studies on Peromyscus leucopus. Radiat: Res. 74, 512-513 (1978).

Ben-Hur, E., M. M. Elkind, and R. Riklis. The Combined Effects of Hyerpthermia and Radiation in Cultured Mammalian Cells. Fifth Annual Report of Cancer Research at The University of Chicago, $19 \overline{77-1978, ~ p . ~} 220$.

Bhattacharyya, M. H., and D. P. Peterson. Demonstration of a Direct Chelation Mechanism for DTPA-induced Excretion of Pu into Rat Bile. Radiat. Res. 74, 559-560 (1978).

Brown, M. S., and R. B. Webb. Action Spectrum for the Induction of Photoreactivable Evento in a Double Putant of Escherichia coli K12. Abstracts of the Annual Meeting of the American Society for Microbiology, Las Vegas,

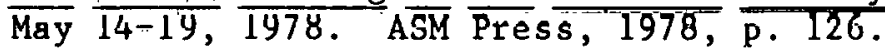

Chan, E. W., C. A. Reilly, Jr., C. K. Lee, J. R. Mitchen, M. P. Finkel, and T. E. O'Connor. Murine Osteosarcoma: A Model for Radiation-Viral Cocarcinogenesis. Fifth Annual Report of Cancer Research at The University of Chicago, $197 \overline{7-1978, \overline{\text { p. } 10}} \overline{3 \text {. }}$

Crouse, D. A., E. J. Ainsworth, J. S. Hulesch, M. Miller, and E. M. Cooke. Late Effects of Radiation on the Hematopoietic Stem Cell Compartment. Radiat. Res. 7.4, 467 (1978).

'E1kind, M. M. DNA Damage and Mammalian Cell Killing, Fifth Annual Report of Cancer Research at The University of Chicago, 1977-1978, p. 221 .

Elkind, M. M., and A. Han. In Vitro Neoplastic Tralsformation: Its Dependence on Radiation Quality and Repair Processes. Radiat. Res. 74 , 572-573 (1978).

Feinstein, R. N., and C. Peraino. The Detection of Initiating, Promoting, and Synergistic Activity among Environmental Pollutants in the Production of Liver Tumors. Fifth Annual Report of Cancer Research at The University

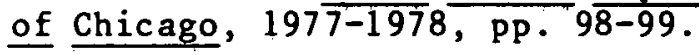

Finkel, M. P. Radiation Pathology and Oncology. Fifth Annual Report of Cancer Research at The University of Chicago, $\overline{1977}-\overline{1978,} \mathrm{pp} \cdot 110-\overline{11} 1$.

Fritz, T. E., L. S. Lombard, C. M. Poole, T. M. Seed, and D. V. Tolle. Radiation Toxicity in Dogs. Fifth Annual Report of Cancer Research at The University of Chicago, $\overline{1977-1} 9 \overline{78, \mathrm{PP}} . \overline{108-1} 0 \overline{9}$.

Fry, R. J. M., R. D. Ley, and D. D. Grube. Skin Carcinogenesis f Fifth Annual Report of Cancer Research at The University of Chicago, 1977-1978, pp. $\overline{101-102}$. 
Fry, R. J. M., E. J. Ainsworth, J. F. Thomson, F. S. Williamson, E. Staffeldt, and $\mathrm{K}$. Allen. The Prevalence of Tumors in Mice and the Effects of Radiation. Radiat. Res. 74, 547-548 (1978).

Grahn, D., C. H. Lee, J J. Russe11, and A. Lindenbaum. Cytggenetic Damage in Spermatogonia of ${ }^{239} \mathrm{Pu}$, External Fission Neutrons, and ${ }^{\text {Co Gamma }}$ Radiations. Radiat. Res. 74, 521-522 (1978).

Guilmette, R. A., E. A. Cerny, and Y. E. Rahman. Effective Delivery of the Iron Chelator, Desferrioxamine, by Liposome Encapsulation: Potential in Treatment of Iron Overload in Cooley's Anemia. Ann. N. Y. Acad. Sci. 308, 438-439 (1978).

Han, A., and M. M. Elkind. Transformation of Mouse C3H/10T1/2 Cells by Single and Fractionated Doses of X-Rays and Fission-Spectrum Neutrons. Fifth Annual Report of Cancer Research at The University of Chicago, 1977-1978, p. 104 .

Hanson, W. R., and R. J. M. Fry. The Effect of Hydroxyurea or High Specific Activity Tritiated Thymidine in Combination with Colcemid on Intestinal Cell Survival in $\mathrm{B}_{6 \mathrm{CF}}$ / /Anl Mice. Radiat. Res. 74,.525 (1978).

Kaspar, L. V., T. M. Seed, S. M. Cullen, D. V. Tolle, and T. E. Fritz. Effects of Endotoxin Stress on Cellular and Humoral Responses in Dogs Exposed to Chronic Gamma Irradiation. Exp. Hematol. 6, (Supp1. 3), 47, (1978).

Klein, P. D., D. A. Schoeller, J. Boyer, B. Kirşhner, I. Rosenberg, J. Schneider, and $\mathrm{J}$. Watkins. Metabolism of ${ }^{13} \mathrm{C}$ Compounds in Digestive Diseases. Fifth Annual Report of Cancer Research at. The University of Chicago, $19 \overline{77-1978, \text { PP. }} \overline{172-173}$.

Rubitschek, H. E. Mutational Synergism of Nitrous Acid and Ultraviolet Light. Mutat. Res. 53, 214-215 (1978).

Mathis, R. K., I. T. Lott, P. A. Szczepanik, and J. B. Watkins. Cholestasis in the Cerebro-Hepato-Renal (CHR) Syndrome: Bile Acid and Mitochondrial Abnormalities. Pediatr. Res. 12, 439 (1978).

Mat sushita, T., A. Shotola, A. Brendzel, and A. Simms. Cytometric and Correndonuclease Analyses of BSA-protected Mouse Myeloma Cells. J. Supramol. Struct., Suppl. 2 , 89 (1978).

Ngo, F. Q. H., A. Han, and M. M. Elkind. On the Repair of Sublethal Damage Resulting from Irradiation with Fast Neutrons or Fast Neutrons Combined with X-Rays in V79 Chinese Hamster Cells. Fifth Annual Report of Cancer Research at The University of Chicagn, 1977-1978, p. 222.

Ngo, F. Q. H., A. Han, H. Utsumi, and M. M. Elkind. Comparative Radiobiology of Fast Neutrons: Relevance to Radiotherapy and Basic Studies. Fifth Annual Report of Cancer Research at The University of Chicago, 1977-1978, p. 210 . 
O'Connor, T. E., D. D.'Grube, and B. A. Sedita. Molecular and Antigenic Markers in Detection and Prevention of Neoplasia. Fifth Annual Report of Cancer Research at The University of Chicago, 1977-1978, p. 105.

Peraino, C., and Y. E. Rahman. Synergisms among Energy-related Pollutants in Carcinogenesis. Fifth Annual Report of Cancer Research at The Univesity of Chicago, 1977-1978, p. 100 .

Rahman, Y. E. Potential of Liposomes in Cancer Chemotherapy. Cancer Immunol. Immunother. (Suppl.), s23 (1977).

Rahman, $\underline{Y}$. E. , and $\underline{K}$. $\underline{R}$. Patel. Liposomes in Cancer Chemotherapy. Fifth Annual Report of Cancer Research at The University of Chicago, $\overline{1977-1978,}$ P. 204.

Seed, T. M., G. T. Chubb, and L. V. Kaspar. Processing and Viewing of Blood Forming Cel1,s Cloned in Soft Agar Cultures. Micron 9, 17-18 (1978).

Sced, T. M., T. E. Fritz, D. V. Tolle, and C. M. Poole. Effects of Myelosuppressive-Leukemogenic Agents on Hemopoietic Tissue Structure and Function: Mechanisms of Leukemia Induction. Fifth Annual Report of Cancer

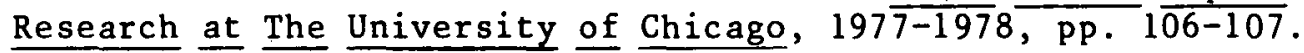

Sacher, G. A., P. H. Duffy, and E. F. Staffeldt. Genetic Relation of LifeSpan to Metabolic Rate for Five Mouse Strains and Their Hybrids. Fed. Proc. 37, 716 (1978).

Sondheimer, J. M., P, Szczepanik, J. F. Perrault, J. R. Hamilton, and J. B. Watkins. Isolated Intestinal Bile Acid (BA) Malabsorption, A Cause of Chronic Diarrhea. Pediatr. Res. 12, 442 (1978).

Stearner, S. P., V. V. Yang, R. L. Devine, E. J. B. Christian, and G. Svihla. Comparative Effects of Fission Spectrum Neutrons and ${ }^{6}$ Co Gamma Rays on Long-Term Cardiovascular Changes. Radiat. Res. 74, 513 (1978)..

Thomas, J. E., M, S, Brown, and R. B. Webb. Action Spectrum for the Protection Against Far-Ultraviolet Lethality by Quinacrine. Abstracts of the Annual Meeting of the American Society for Microbiology, Las Vegas, May 14-19, 1978. ASM Press, 1978, p. 126.

Tolle, D. V., T. M. Seed, and T. E. Fritz. Irradiation-induced Canine Leukemia--A Proposed New Model. Incidence and Hematopathology. Exp. Hematol. 6, (Supp1. 3), 5, (1978).

Utsumi, H., and M. M. Elkind. Photodynamic Lethality and DNA Damage: Effects of 7,12-Dimethylbenz(a)anthracene Plus Sunlight in Cultured Mammalian Cells. Radiat. Res. 74, 539 (1978).

Utsumi, H., and M. M. Elkind. Potentially Lethal Damage Versus Sublethal Damage: Independent Repair Processes in Actively Growing Chinese Hamster Cells. Fifth Annual Report of Cancer Research at The University of Chicago, $\overline{1977}-\overline{1978,}$ p. 223. 
AUTHOR INDEX

Alnsworth, C. F. 81

Allen, K. H. 19

Amsler, B. 129

Anderson, N. G. 125, 147, 149, $150,153,156$

Anderson, N. L. 153, 156, 158

Angerman, J. M. 6,11

Bauman, W. C. 57

Beales, N. N. 135

Bhattacharyya, M. H. 31, 3.3, 34,35

Bla1s, J. C. 162,164

Blomquist, J. A. 173

Bodoni, L. 129

Borso, C. 91

Bourne, S. 12, 40, 47, 50

Brendzel, A. M. 102

Brennan, P. C. $11,41,56,171$

Brooks, E. 111

Brown, C. D. 64

Brown, M. S. 107

Buchholz, D. M. 11, 14, 56

Buess, E. M. 54,115

Cah111, A. L. 95

Cerny, E. A. 134, 141

Chan, E. W. 128, 129, 130, 132 133

Christian, E. J. B. 21

Chubb, G. T. 13, 15, 173

Collins, J. J. 63

Coulter, B. S. 158

Cullen, S. M. 6, 11

Cunningham, P. T. $40,41,43$

Curt1ss, J. R. B. . 63, 64

D'Arcy-Gomez, G. 122

Dalnko, J. L. 115, 116, 117

Dale, P. J. $128,130,132$

Danyluk, S. S. $41,79,81,82$

DeMark, B. R. 163, 164, 166

Devine, R. L. 21

D1xon-Davis, D. K. 63
Dornfeld, S. S. 50, 52, 56, 111

Doyle, D. E. $6,7,11$

Duffy, P. H. 74, 144, 145

Edwards, J. J. 156

Ehret, C. F. 69, 71, 92, 95, 122

Ekelman, K. B. 121

Elkind, M. M. 54, 113, 114, 115, 116,117

Feinstein, R. N. 135

Finke1, M. P. 129,130

Fox, C. A. 173

Fritz, T. E. $3,6,7,11,12,171$

Fry, R. J. M. 123, 125

Frystak, B. H. 25, 26, 29

Gabrie1, M. A. 12

Gambill, T. 109

Ginevan, M. E. 61,62

Grahn, D. 1, 23, 25, 26, 29, 34, 59,63

Greco, I. L. $129,130,132$

Groh, K. R. 71, 92, 95, 122

Grube, D. D. 125

Hachey, D. L. 161, 162, 163, 167, 169

Hagen, M. P. 115

Han, A. 115,116

Hardwick, J. P. 124

Hass, B. S. 50, 52, 109, 111

Haugen, D. A. $47,57,123,124$

Hickman, B. J. 149

Hill, C. 115

Holmblad, G. L. 20

Horseman, N. D. 95

Hulesch, J. L. 19,20

Hutchens, J. $0.41,43$

Irving, C. S. 164, 167

Jirka, A. 12, 40

Johnson, E. G., Jr. 20

Jonah, M. M. 141 
Kaspar; L. V. $6,11,12$

Keenan, W. G. 6, 7, 11, 171

Kempf, M. 158

Kickels, W. T. 41, 56

Killeen, R. 144

Kirchner, F. R. 41, 43, 56

Klein, E. R. 169

Klein, P. D. 159, 168, 169

Kretz, N. D. 6, 12

Kubitschek, H. E. 45, 47, 97, 99

Kucera, E. T. 41

Kumar, R. 43

Langsdorf, A. 71

Lankas, G. R. 54, 117

I.arsen, R. P. .34

Last, R. L. 84

Lau, E. H. 141

Lee, C. H. $25,26,29$

Lee, C. K. 128, 130, 133

Lewandowski, E. 12

Lew1s, R. N. 71

Lindenbaum, A. $25,29,33,34$, 35

Linsley, J. G. 171

Liu, C. M. 114, 116

Lombard, L. S. $6,7,19,130$

Ludeman, V. A. $19,123,135$

Lundy, R. T. 61,63

MacCoss, M. $81,84,86$

Matsushita, G. 101,102

Matsushita, T. $52,101,102$

Meinert, J. C. $71,92,95,122$

Milstead, J. R, 57

Mitchen, J. R. 129

Moretti, E. S. 33, 34, 35

Nakamura, K. 163,167

Nance, S. L. 150,156

Niu, H. C. 161,165

Norris, W. P. $37,41,43,56$

Nortridge, K. 133

0'Connor, T. E. $125,132,137$

Obermeyer, $W$. 78,144

Oldfield, D. G. 15

Oldham, R. D. 34

Pahnke, V. A. 130

Panagiotopoulos, N.

Patel, K. R. . 141

Peraino, C. 92, 121, 122, 123, 134,135
Peterson, D. P. 33, 35, 121

Polk, P. H. 6, 7, 11

Poole, C. M. 6, 7, 11, 171

Prapuolenis, A. M. ${ }^{\cdot} 121,122,134$

Rahman, Y. E. $134,139,141$

Rell1y, C. A., Jr. 119, 129, 13C, 135

Rettman, K. A. 123, 125, 135, 137

Riss, T. 21

Rockus, G. 130

Rose, J. G. 132

Ross-Riveros, P . 114

Rupprecht, K. 128

Russe11, J. J. 25, 29, 33, 34, 74, $144,145,146$

Ryu; E: K. 84,86

Sacher, G. A. $69,71,74,78,143$, $144,145,146$

Sallese, A. R. 19, 135

Saltz, E, 35

Sanderson, M. $6,7,11$

Scandora, A. 158

Schiffer, M. $88,89,90$

Schoel1er, D. A. 161, 168, 169

Schumann, K. 111

Schwartz, H. M. 82

Sedita, B. A, 137

Seed, T. M. $6,7,9,11,12,13$, $14,15,56,173$

Shotola, A. M. 101, 102

Simkins, R. C. 171

Simms, A. 101

Skyer, R. S. 21

Smith, C. 153

Smith, D. M. 50

Solomon, A. 89,90

Sorensen, E.I.M. 35

Staffeldt, E. F. 19, 123, 135

Stearner, S. P. 21, 56

Stellaard, F. 166

Stevens, F. J. 89, 90

Suhrbier, K. M. 57

Svihla, G. 71

Szczepanik-Van Leeuwen, P. A. 166, 167

Taylor, John, Jr. 158

Thomson, J. F. 17, 19, 20, 67

Tollaksen, S. L. 153

Tolle, D. V. $6,7,11,12,171$

Trier, J. E. 20

Tserng, K. Y. 161

Turner, M. A. 106 
1 Ulrich, R. 13

Updegrove, R. 130

Utsumi, H. 114, 117

Venta, L. 45

Venters, D. 47,99

Webb, R. B. 104, 106, 107, 109

Westho1m, F. A. 89,90

White, R. S. 84

Willard, K. E. $125,137,150$

Williams, D. M. 47, 99

Williams, M. F. 130

Williamson, F. S. 19, 20, 173

Wright, B. J. 13, 141 
Distribution for ANL-79-90

\section{Internal:}

W. E. Massey

W. K. Sinclair (3)

M. V. Nevitt

R. V. Laney

R. M. Adams

L. Burris

D. P. O'Neil

R. E. Rowland (2)

P. F. Gustafson

L. S. Markheim

C. F. Ainsworth

K. H. Allen

L. Anderson

N. G. Anderson

J. R. Benson

M. H. Bhattacharyya

C. S. Borso

P. C. Brennan

C. D. Brown

M. S. Brown

E. M. Buess

E. A. Cerny

E. J. Christian

E. Chan

J. R. Curtiss

J. L. Dainko

P. J. Dale

S. S. Danyluk

R. L. Devine

D. Dixon-Davis

S. S. Dornfeld

D. E. Doyle

P. H. Duffy

C. F. Ehret

M. M. Elkind

M. P. Finkel

T. E. Fritz

B. H. Frystak

D. Grahn

D. D. Grube

I. L. Greco

K. R. Groh

D. L. Hachey

A. Han

D. A. Haugen

B. J. Hickman

G. Holmblad

J. S. Hulesch

L. A. Kaspar

W. G. Keenan

P. D. Klein
L. S. Lombard

V. A. Ludeman

R. T. Lundy

M. MacCoss

T. Matsushita

J. C. Meinert

E. S. Moretti

S. L. Nance

T. E. O'Connor

V. A. Pahnke

D. P. Peterson

C. Peraino

P. H. Polk

C. M. Poole

A. M. Prapunlenis

Y. E. Rahman

C. A. Reilly

R. J. Robertson

G. Rockus

M. W. Rosenthal

J. J. Russell

G. A. Sacher "

A. R. Sallese

M. Sanderson

M. Schiffer

B. A. Sedita

T. M. Seed

M. A. Shotola

R. C. Simkins

E. F: Staffeldt

S. P. Stearner

K. M. Suhrbier

P. A. Szczepanik-Van Leeuwen

J. F. Thomson

S. L. Tollaksen

D. V. Tolle

D. Venters

R. B. Webb

F. A. Westholm

D. M. Williams

F. S. Williamson

B. J. Wright

J. M. Angerman

J. A. Blomquist

G. T. Chubb

S. M. Cullen

C. A. Fox

E. C. Johnson

K. A. Rettman

J. E. Trier

M. F. Williams
B. R. DeMark

P. L. Derstine

J. J. Edwards

K. B. Ekelman

M. L. Garriott

M. E. Ginevan

C. S. Giometti.

V. M. Griego

N. D. Horseman

C. S. Irving

F. R. Kirchner

G. R. Lankas

F. H. I.au

N. C. Panagiotopoulos

K. R. Patel

P. Ross-Riveros

E. K. Ryu

H. M. Schwartz

F. J. Stevens

H. Utsumi

S. Bourne

B. S. Coulter

P. T. Cunningham

W. Harrison

C. Hill

R. H. Huebner

J. O. Hutchens

A. M. Jirka

M. M. Innạh

A. A. Innke.

M. Kempf

E. R. Klein

E. T. Kucera

R. Kumar

A. Langsinrf

R. P. Larsen

R. N. Lewis

G. Matsushita

K. Nakamura

W. Obermeyer

D. G. Oldfield

R. D. Oldham

K. Rupprecht

A. Scandora

D. A. Schoeller

J. Taylor, Jr.

K. E. Wilzbach

F. M. Gentille

A. B. Krisciunas (15)

E. N. Pettitt

M. Fieldhouse 
N. D. Kretz

H. E. Kubitschek

J. L. Linsley

C. M. Liu
N. N. Beales

L. Bodoni (340)

D. M. Buchholz

F. M. Buonaguro

A. L. Cahill
BIM Division Office (139)

ANL Contract Copy

ANL Libraries (5)

TIS Files (5)

\section{External:}

DOE-TIC, for distribution per UC-48 (177)

Manager, Chicago Operations and Regional Office, DOE

Chief, Office of Patent Counsel, DOE-CH

President, Argonne Universities Association

U. S. Department of Energy, Washington:

J. H. Abrahams, Office of Energy Technology

N. F. Barr, Office of Environment

L. Brothers, Office of Environment

W. W. Burr, Jr., Office of Environment

M. Carrington, Office of Energy Technology

R. C. Clusen, Assistant Secretary for Environment

D. K. Craig, Office of Environment

G. D. Duda, Office of Environment

A. P. Duhamel, Office of Environment

C. W. Edington, Office of Environment

H. L. Hollister, Office of Environment

P. House, Office of Environment

M. L. Minthorn, Jr., Office of Environment

D. A. Smith, Office of Environment

G. Stapleton, Office of Environment

G. Weth, Office of Energy Technology

H. H. Weyzen, Office of Environment

R. W. Wood, Office of Environment

Division of Biological and Medical Research Review. Committee:

F. J. Burns, New York U. Medical Center

L. Grossman, Johns Hopkins U.

H. Koffler, U. Massachusetts

H. I. Kohn, Harvard Medical School

M. Pollard, U. Notre Dame

G. F. Whitmore, Ontario Cancer Inst., Toronto

AUA Biology Representatives and AUA Biology Committee:

W. C. Ashby, Southern Illinois U.

R. M. Bock, U. Wisconsin

R. C. Bockrath, Indiana U.

R. S. Caldecott, U. Minnesota

W. Chavin, Wayne State U.

J. Courtright, Marquette U.

W. F. Danforth, Illinois Inst. Technology

H. S. Ducoff, U. Illinois

A. Eisenstark, U. Missouri

D. Feir, St. Louis U.

R. W. Greene, U. Notre Dame

D. L. Hartl, Purdue U.

R. W. Hoshaw, U. Arizona

J. O. Hutchens, U. Chicago

B. H. Judd; (I. Texas, A.ustin

G. M. Maggiora, U. Kansas

H. J. McDonald, Loyola Medical C'enter

M. C. Miller, U. Cincinnati 
W. C. Myser, Ohio Stàte U:

R. R. Novales, Northwestern U.

J.' W. Osborne, U. Iowa

R. J. Robel, Kansas State U.

R. C. Rustad, Case Western Reserve U.

S. Silver, Washington U.

A. S. Sussman, U. Michigan

P. W. Todd, Pennsylvania State U.

M. J. Ulmer, Iowa State U.

I. Ungar, Ohio U.

J. J. Wolken, Mellon Inst.

L. Wolterink, Michigan State U.

AUA-ANL Biology Committee:

F. A. Bazzaz, U. Illinois, Urbana

W. R. Byrnes, Purduc U.

F. B. Daniel, Ohio State U. .

J. E, Miller, RER, ANL

E. D. Pentecost, EIS, ANL

W. H. Rauckhorst, CEA, ANL

J. E. Trosko, Michigan State U.

Central States Universities Inc.:

Ball State U., Chairman, Biology Dept.

Bowling Green State U., Chairman, Biology Dept.

De Paul U., Chairman, Biology Dept.

DePauw U., Chairman, Biological Sciences

Illinois State U., Chairman Biology Dept.

Kent State U., Chairman, Biological Sciences

Miami U., Chairman, Biological Sciences

Northern Illinois U., Chairman, Biological Sciences

Northern Michigan U., Chairman, Biological Sciences

Southern Illinois U., Chairman, Biological Sciençes

University of Northern Iowa, Chairman, Biology Dept.

U. Toledo, Chairman, Biology Dept.

Western Illinois U., Chairman, Biology Dept.

Western Michigan U., Chairman, Biology Dept.

Associated Colleges of the Midwest:

Beloit College, Chairman, Biology Dept.

Carleton College, Chairman, Biology Dept.

Coe College, Chairman, Biology Dept.

Colorado College, Chairman, Biology Dept.

Cornell College, Chairman, Biology Dept.

Grinnell College, Chairman, Biology Dept.

Knox College, Chairman, Biology Dept.

Lake Forest College, Chairman, Biology Dept.

Lawrence U., Chairman Biulogy Dept.

Macalester College, Chairman, Biology Dept.

Monmouth College, Chairman, Biology Dept.

Ripon College, Chairman, Biology Dept.

St. Olaf College, Chairman, Biology Dept.

V. P. Bond, Brookhaven Nat. Lab.

B. Boyle, Western Michigan U.

L. Bustad, Washington State U.

California, U. of, Library, Davis

Carleton College, Scieluce Library

N. Cohen, New York U. 
Colorado State U. Libraries

Cornell U. Library, NY State Agric. Experiment Station

Fermi National Accelerator Laboratory Library

E. Flaumenhaft, U. Akron

L. S. Gomez, Los Alamos Scientific Lab.

M. L. Griem, U. Chicago Hospitals and Clinics

Indiana U. Medical Center, Library

L. O. Jacobson, U. Chicago

H. S. Kaplan, Stanford U. School of Medicine

F. T. Kuchnir, PHY, ANL

H. Lisco, Harvard Medical School

Mann (Albert R.) Library, Ithaca

Marquette School of Medicine, Library

Mayo Clinic Library

M. L. Mendelsohn, Lawrence Livermore Lab.

Michigan Technological U., Library

Minnesota, U. of, St. Paul Campus, Library

National Library of Medicine, Bethesda

Nebraska, U. of, Libraries

N. Nelson, New York U. Medical Center, Tuxedo

New York, State U. of, at Buffalo, Health Sciences Library

W. R. Ney, Nat. Council on Radiation Protection and Measurements, Bethesda

H. M. Patt, U. California, San Francisco

Philadelphia, College of Physicians of, Library

E. L. Powers, U. Texas, Austin

S. Schofield, Orinda, Calif.

J. Schubert, Hope College

J. M. Smith, U. Utah

H. Spencer, VA Hospital, Hines

St. Louis U., Medical Center Library

R. L. Straube, National Institutes of Health

J. C. Thompson, Jr., Cornell U.

R. C. Thompson, Battelle Pacific Northwest Lab.

A. C. Upton, National Cancer Institutes

USAF Radiological Health Lab., Wright-Patterson AFB

U. S. Environmental Protection Agency Library, Washington

H. H. Vogel, Jr., U. Tennessee Center for the Health Sciences

T. White, U. Michigan

Wisconsin, Medical College of, Medical-Dental Lib., Milwaukee

Wisconsin, U. of, Milwaukee Library

M. R. Zelle, Colorado State U.

Comission Nacional de Energia Atomica, Library, Argentina

Cancer Institute, Librarian, Melbourne, Australia

CSIRO, Central Library, East Melbourne, Australia

Inst. of Medical \& Veterinary Science, Librarian, Adelaide, Australia

J. Myhill, Canberra Coll. of Advanced Education, Australia

Commission of the European Communities, Brussels, Belgium

J. M. Debois, St. Norbertus Hosp., Duffel, Belgium

A. Heyndrickx, U. of Ghent, Belgium

Ilha Universitaria, Instituto de Biofisica-UFRJ, Rio de Janeiro, Brazil

C. Pavan, U. of Sao Paulo, Brazil

G. O. Barker, Nat. Res. Council of Canada, Ottawa, Canada

N. Brearley, U. of British Columbia, Vancouver, Canada

Defense Scientific Information Service/CRAD, Ottawa, Canada

Dept. of National Health and Welfare, Ottawa, Canada 
Guelph, U. of, Library, Guelph, Ontario, Canada

Health and Welfare Canada, Radiation Protection Bu., Director, Ottawa, Canada

Toronto, U. of, Library, Canada

G. Tratt, U. of Alberta, Edmonton, Canada

C. H. Cheng, Nat. Tsing Hua U., China

Universite Lovanium, Republic of Congo

Christensen, B. Chr., Finseninstitutet, Copenhagen, Denmark

Danish AEC, Library, Ris 6 , Denmark

Faber, M., The Finsen Institute, Copenhagen, Denmark

Agricultural Res. Council, The Library, Wantage, England

J. W. Boag, Inst. of Cancer Research, Belmont, England

P. R. J. Burch, U. of Leeds, England

G. W. Dolphin, National Radiological Protection Board, Harwell, England

M. Ebert, Holt Radium Institute, Manchester, England

J. Edgington, Queen Mary College, London U., England

J. F. Fowler, Mt. Vernon Hospital, Northwood, England

A. Glucksmann, Cambridge, England

S. J. Harris, U. of Surrey, England

C. R. Hill, Inst. of Cancer Research, Beimont, England

A. Howard, Paterson Labs, Holt Radium Inst., Manchester, England

Institute of Cancer Research Library, Belmont, England

D. F. Jackson, U. Surrey, Guildford, England

L. Lajtha, Paterson Labs, Holt Radium Inst., Manchester, England

L. F. Lamerton, Inst. of Cancer Research, Belmont, England

P. Lindop, Medical Coll. of St. Bartholomew's Hosp., London, England

J. F. Loutit, MRC Radiobiology Unit, Harwell, England

W. V. Mayneord, Surrey, England

Medical Research Council, Librarian, Harwell, England

J. S. Mitchell, Addenbrook's Hospital, Cambridge, England

National Radiological Protection Board, Library, Harwell, England

R. Phillifent, H.A.S. Tech Library, Whitley Bay, England

E. E. Pochin, National Radiological Protection Board, Harwell, England

F. W. Spiers, U. of Leeds, England

L. A. Stocken, Univ. Museum, Oxford, England

J. Vaughan, Oxford, England

J. Vennart, AERE, Harwell, England

A. Bouville, Centre de Physique Nucleaire, Toulouse, France

J. Coursaget, C.E.A., Saclay, France

P. J. Fallot, Service de Biophysique, Gif-sur-Yvette, France

International Agency for Research on Cancer, Lyon, France

H. Jammet, CEA, Fontenay-aux-Roses, France

H. Franke, Radiologische Univ. Klinik, Hamburg, Germany

U. Hagen, Institut für Strahlenbiologie, Karlsruhe, Germany

A. Kaul, Klinikum Steglitz der F. Univ. Berlin, Germany

M. Keller, Kernforschungsanlage Jülich, Germany

L. Kemmerich, Ges. für Kernforschung, Karlsruhe, Germany

H. Muth, Boris Rajewsky-Inst., U. Saarlandes, Homburg, Germany

B. Rajewsky, Max Planck Inst. for Biophysics, Frankfurt, Germany

A. Schraub, Institut für Biophysik, Giessen, Germany.

A. R. Gopal-Ayengar, Bhabha Atomic Research Centre, Bombay, India

R. Hukkoo, Bhabha Atomic Research Centre, Bombay, India

M. A. Rao, All-India Inst. of Med. Sciences, New Delhi, India

Tata Inst. of Fundamental Research Library, Bombay, India

Y. Feige, Israel AEC, Yavne, Israel

Hebrew University, Librarian, Dept. of Botany, Jerusalem, Israel 
A. Benco, C.C.R. Euratom, Ispra, Italy

E. Casnati, CSN Casaccia, CNEN, Rome, Italy

G. F. Clemente, CSN Casaccia, CNEN, Rome, Italy

E. DiFerrante, C.C.R. Euratom, Ispra, Italy

Istituto Superiore di Sanita, Rome, Italy

F. Mario, Universita Degli Studi di Napoli, Italy

O. Rimondi, CNEN, Bologna, Italy

F. Salvatore, U. of Naples, Italy

K. Kariya, Inst. of Radiation Breeding, Japan

E. Matsuda, Inst. of Physical \& Chem. Res., Yamoto-machi, Japan

O. Matsuoka, Nat. Inst. of Radiological Sciences, Anagawa, Japan

Nat. Inst. of Radiological Science, Planning and Information Sec., Chiba-shi, Japan

T. Shegetoshi, Power Reactor \& Nucl. Fuel Dev. Corp. Tokai Works, Japan

Y. Ueno, Kyoto U., Japan

Korean Atomic Energy Research Inst., Library, Korea

S. S. Lee, Korean Advanced Institute of Science, Korea

M. Bogaardt, Tech, Univ. of Eindhoven, The Netherlands

M. Bogaardt, Ultra-Centrifuge Nederland, Den Haag, The Netherlands

Medical Biological Lab TNO, Director, Rijswijk, The Netherlands

O. Vos, Erasmus U., Rotterdam, The Netherlands

M. A. Chaudhri, U. of Islamabad, Rawalpindi, Pakistan

Estacao Agronomica Nacional, Biblioteca, Oeiras, Portugal

L. A. Almodovar, U. of Puerto Rico, Rio Piedras, Puerto Rico

T. O. Caspersson, Karolinska Inst., Stockholm, Sweden

K. Liden, Lunds Universitet, Sweden

A. Nilsson, Res. Inst. of Nat. Defence, Sundbyberg, Sweden

R. Walstam, Radiofysiska Inst., Stockholm, Sweden

A. Donath, Service cantonal de cont. des irradiations, Geneva, Switzerland

A. Gunther, CERN Scientific Inf. Serv., Geneva, Switzerland

W. Seelentag, World Health Organization, Geneva, Switzerland

Swiss Inst. for Nuclear Research, The Library, Villigen, Switzerland

H. Willax, Schweizerisches Inst. für Nuklearforschung, Villigen, Switzerland

I. B. Hazzaa, B. Radioisotope Ctr. for the Arab Countries, Cairo, Egypt

O. E. Chaves, Universidad de Los Andes, Merida, Venezuela

Lab. Cellular Radiobiology, Institut "Ruder Boskovic," Zagreb, Yugoslavia

Universite Nationale du.Zaire, Central Lib., Kinshasa, Zaire

A. Amsler, Milwaukee, Wis.

L. Anastasia, Institute of Gas Technology, Chicago

W. C. Bauman, Rome, N. Y.

J-C. Blais, Paris, France

A. M. Brendzel, Chicago, Ill.

E. Brooks, Searcy, Ark.

J. J. Collins, U. Illinois, Urbana

B. G. D'Arcy-Gomez, Colorado Springs, Colo.

R. N. Feinstein, Downers Grove, Ill.

J. D. Foulke, U. S. Nuclear Regulatory Commission, Washington

P. G. Freeman, Grand Forks Energy Technology Center

R. J. Michael Fry, Oak Ridge National Lab.

M. A. Gabriel, Boulder, Colo.

T. Gambill, Harrisonburg, $\mathrm{Pa}$.

G. H. Gronhovd, Grand Forks Energy Technology Center

M. P. Hagan, AFRRI-DNA, Bethesda, Md.

J. P. Hardwick, Normal, Ill.

B. S. Hass, Oak Ridge National Lab.

R. Killeen, Grayslake, Ill. 
R. L. Last, Montclair, N. J.

C. H. R. Lee, Pocono Pines, Pa.

C. K. Lee, Pocono Pines, Pa.

E. Lewandowski, Westmont, Ill.

A. Lindenbaum, New Braunfels, Tex.

M. Massey, Environmental Research and Technology, Inc., Pittsburgh, Pa.

J. Milstead, Bolingbrook, Ill.

J. R. Mitchen, Grandwood Park, Ill.

H-C. Niu, Perkin-Elmer, Pomona, Calif.

W. P. Norris, Clarendon Hills, Ill.

K. Nortridge, Freeport, 1ll:

T. Riss, Ransom, Ill.

J. G. Rose, Presque Isle, Me.

E. Saltz, Whitewater, Wis.

K. Schumann, Long Branch, N. J.

A. Simms, Medford, N. Y.

R S. Skyer, Ir., Willingboro, N. I.

D. M. Smith, Madison, Wis.

A. Solomon, University of Tennessee, Knoxville

E. M. Sorensen, Memphis State U.

F. Stellaard, Ludwig-Maximilian-Universitat, Munich, Germany

G. Svihla, Portage, Ind.

F. Swanberg, Jr., U. S. Nuclear Regulatory Commission, Washington

K-Y. Tserng, Cleveland Metropolitan General Hospital

M. A. Turner, Columbia, Mo.

R. G. Ulrich, Kalamazoo, Mich.

R. Updegrove, Bethlehem, Pa..

R. B. Uretz, U. Chicago

L. Venta, Chicago, Ill.

F. van Dorp, Inst. for Atomic Sciences in Agriculture, Wageningen, The Netherlands

W. Wallace, Morgantown Energy Technology Center

R. S. White, Rockton, Ill. 